\title{
New Zealand Aid and Dairy Development in Sri Lanka
}

\author{
Jasmine Edwards
}

\author{
A thesis \\ submitted to the Victoria University of Wellington \\ in partial fulfilment of the requirements for the degree of \\ Master of Development Studies
}

School of Geography, Environment and Earth Sciences

Victoria University of Wellington

2019 


\section{Abstract}

New Zealand's aid investment in dairy development is seen, on the one hand, as a means to improve economic, health and food security issues in developing countries. Dairy development, further, is linked to New Zealand's trade interests and supports industry expansion strategies that target the market potential in developing countries. On the other hand, it is argued that dairy consumption and production should be reduced to respond to climate change and potential negative health impacts in countries with traditionally low dairy consumption. The potential impacts of dairy development on sustainable development are complex, interconnected and contradictory. Moreover, local and gendered understandings of the impacts of dairy development are underrepresented in literature.

Drawing on a sustainable livelihood approach and gender lens as a theoretical framework, this research explores smallholder farmers' views through a case study of a New Zealand-funded aid project in Sri Lanka, the Wanni Dairy Project, which is increasing dairy production to improve rural livelihoods. In doing so, this thesis considers the multiple impacts of dairy development on sustainable livelihoods. In particular, it explores understandings of social, gender and environmental factors. Data was collected during five weeks of qualitative, case study research (using interviews, photovoice and observation methods) with female, conflict-affected farmers in Sri Lanka and stakeholders in dairy development.

This thesis contends that better understandings of the impacts of dairy development and aid can be valuably informed by local perspectives. It highlights the inherent connectivity between social, environmental and economic factors of the Wanni Dairy Project, and areas of dissonance between local understandings of the impacts of dairy development and global discourse on sustainable development. Specifically, this thesis draws attention to the diverse impacts of increasing income, health factors, and cultural and religious factors; it highlights women's independence, empowerment and agency, and ongoing inequities; and it addresses environmental impacts, climate change, and the implications of scale. This research, therefore, contributes to the information upon which development policy-makers and practitioners government, development organisations and private sector actors - can base effective and sustainable development policy and practice. 


\section{Acknowledgements}

This thesis was made possible by the support of many people and organisations to whom I am grateful. I would like to acknowledge Asia New Zealand Foundation, New Zealand Ministry of Foreign Affairs and Trade and the Ray Watters' Asia Pacific Research Award for their generous funding that enabled fieldwork in Sri Lanka. Further thanks are due to Asia New Zealand Foundation for the opportunity to present a paper as part of its 'Emerging Scholars Panel' at the NZASIA Conference. I would also like to acknowledge Graduate Women Wellington and Victoria University of Wellington for fees scholarships. This generous financial support as well as the recognition of this research encouraged me forward on this path and greatly contributed to this thesis. Thank you to Professor John Overton for his support for these funding applications, and for his encouragement to pursue my interest in aid and dairy development. Thanks also to Dr. Polly Stupples and Professor Michael Radich for providing references to support these requests.

Thank you to Kevin Riddell at Tearfund NZ, Selina Kumar at World Concern, and all the NGO field staff in Sri Lanka for being so generous with their time and knowledge, and facilitating field visits. Thanks to Lachlan McIntyre, Professor Anil Pushpakumara and Dr. Gerard Prinsen for their introductions and expertise; and to the New Zealand Aid Programme staff for welcoming this research. I would like to acknowledge my interpreter, Thurka, for her integral role in this research; and document translator, Sivagini Kumar, for providing lengthy Tamil translations.

I am immensely grateful to the five Tamil women dairy farmers who participated in this research - sharing their experiences, and contributing time, knowledge, successes and struggles. I would like to thank everyone who agreed to participate in this research, in Sri Lanka and New Zealand - their insights on dairy development and the aid context all shaped this research.

I would like to acknowledge my parents, Leone and Greg, and my New Zealand and Australian families for their support. I would also like to thank my friends, particularly those who have helped care for my children, Pratheepan and his family, and the development studies cohort for their solidarity, and passion for an equitable and sustainable future.

To my academic supervisor, Dr. Polly Stupples - I feel very privileged to have had such an excellent mentor on this learning journey. I am grateful for your knowledge, compassion and encouragement. Your support has been unwavering and taken many forms. I have especially 
valued your perspective and clarity, and your thorough, critical engagement with this topic and my writing.

To Alan - thank you for encouraging me to write this thesis, supporting my field research ambitions, and making sacrifices to give me the time and space I needed to work. Thank you for being my perpetual sounding board and helping me to clarify my thinking when I needed it. Most of all, thank you for your enduring support, guidance, patience and love.

To Lucia and Maya - you are everything a mother could hope for. Thank you for sharing in this experience. I hope that I have made you proud. Mumma did it! You are my inspiration. 


\section{Table of Contents}

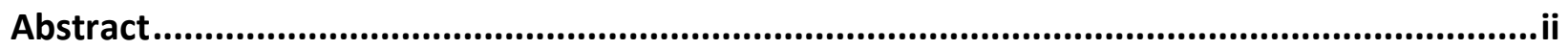

Acknowledgements ...........................................................................................................................ii

List of figures and tables .............................................................................................................. viii

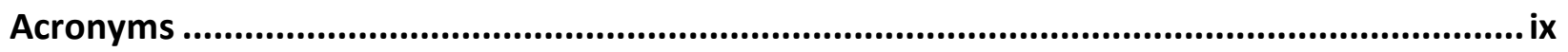

Chapter 1 : Introduction .....................................................................................................

1.1 Background and rationale ......................................................................................................

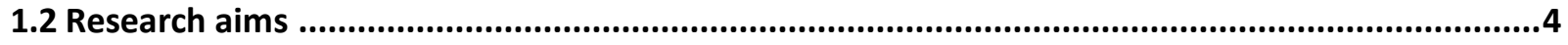

1.3 Research questions.............................................................................................................

1.4 Chapter outline .........................................................................................................................

1.5 Language ..............................................................................................................................

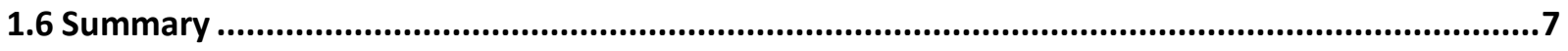

Chapter 2 : Literature review .....................................................................................................8

2.1 Introduction ........................................................................................................................................

2.2 Dairy farming and sustainable development.......................................................................

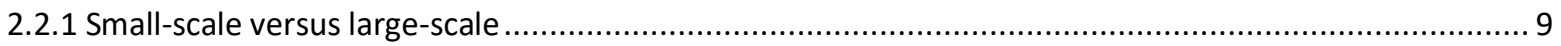

2.2.2 Dairy development and the Sustainable Development Goals .................................................... 11

2.2.3 Environmental challenges of livestock and dairy farming ............................................................. 12

2.2.4 Potential to address food security and economic opportunities ................................................ 14

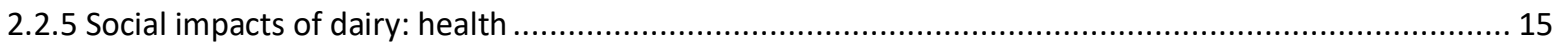

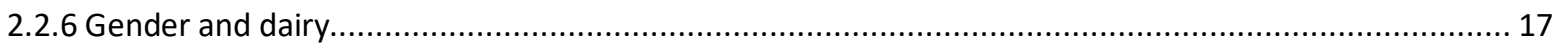

2.3 New Zealand as a major actor in global dairy development........................................................19

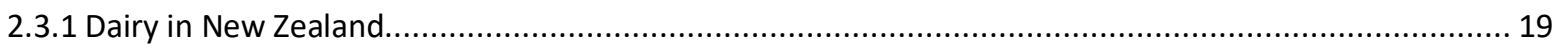

2.3.2 New Zealand commitments to sustainable dairying practice in the global context...........................21

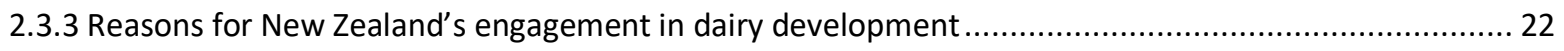

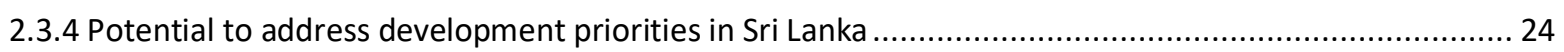

2.3.5 Partnerships and changing roles of development actors: Private sector and NGOs ...........................25

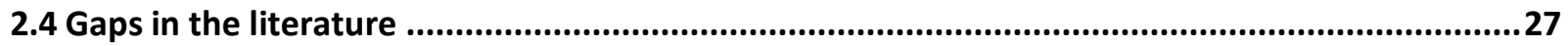

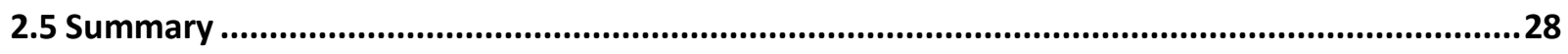

Chapter 3 : An integrated sustainable livelihoods approach .................................................30

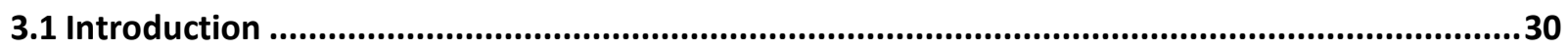

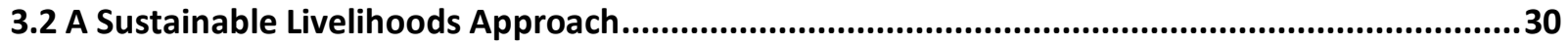

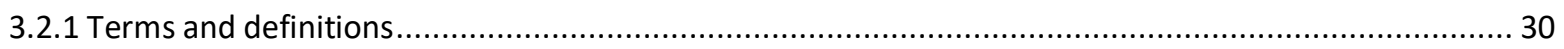

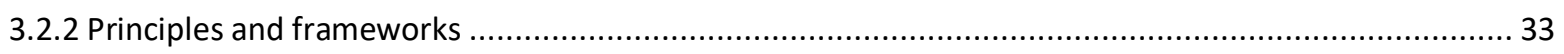

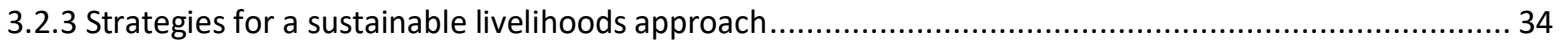


3.3 Integrating a sustainable livelihoods approach with a gender lens ...........................................37

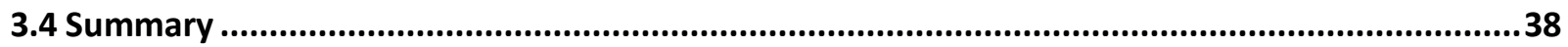

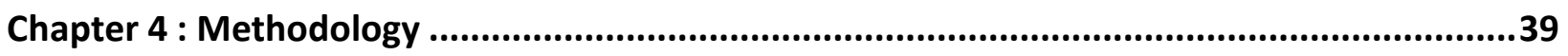

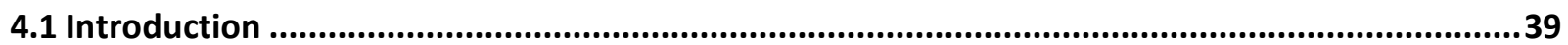

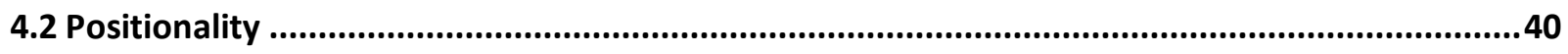

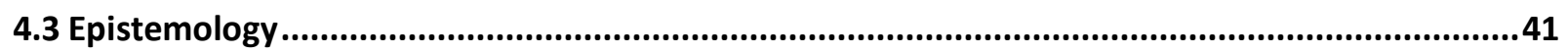

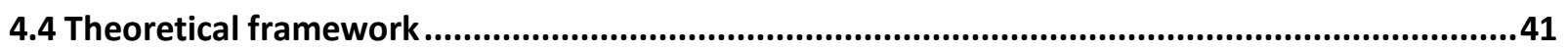

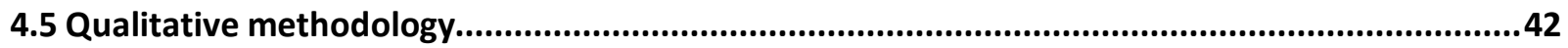

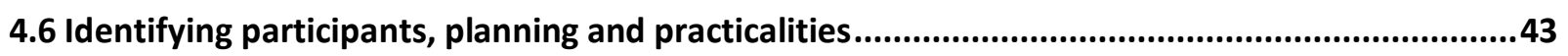

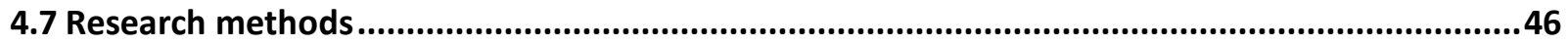

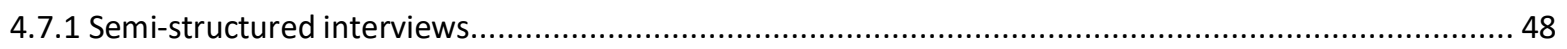

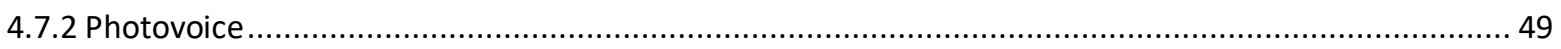

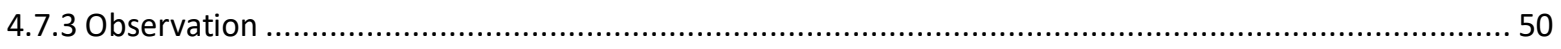

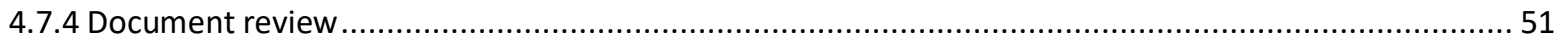

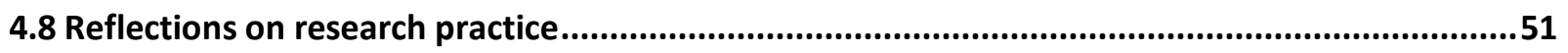

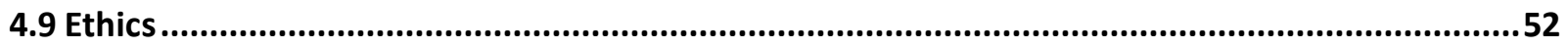

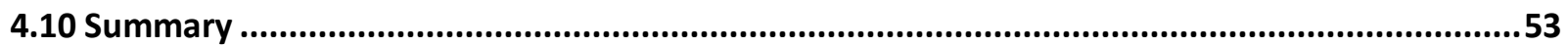

Chapter 5 : Context: Sri Lanka ............................................................................................54

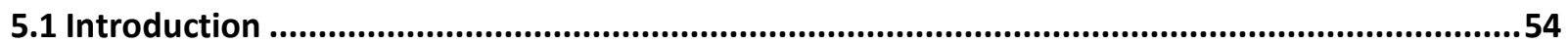

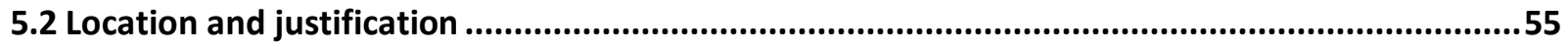

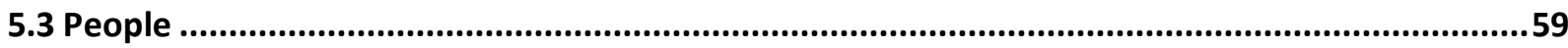

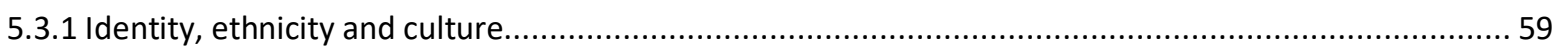

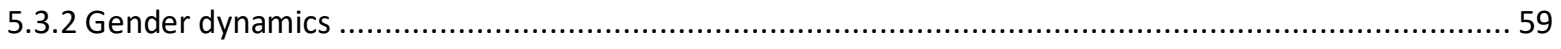

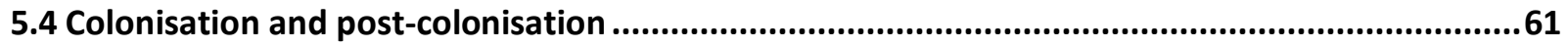

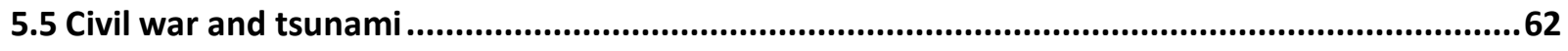

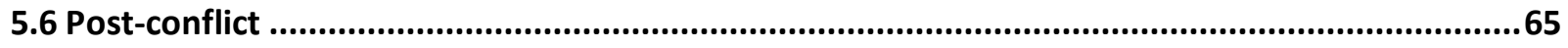

5.7 Economic and agricultural development ....................................................................................66

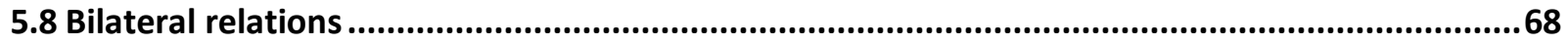

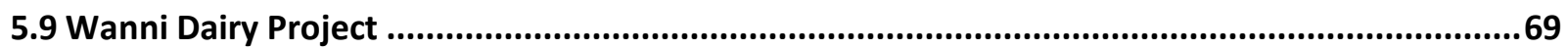

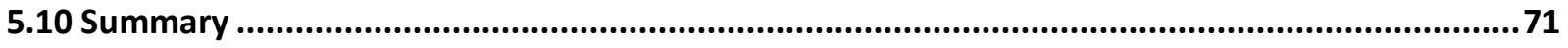

Chapter 6 : Findings and discussion: Social, gender and environmental factors .....................72

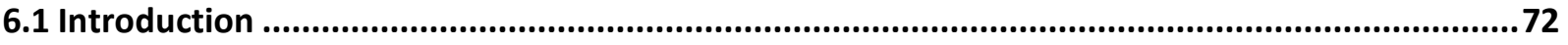

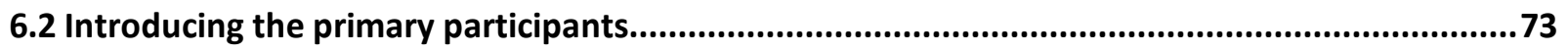




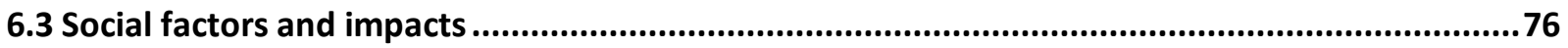

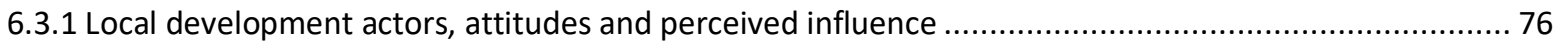

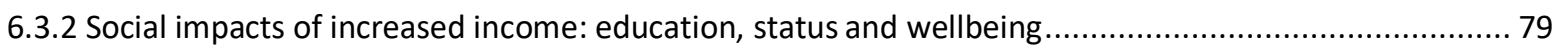

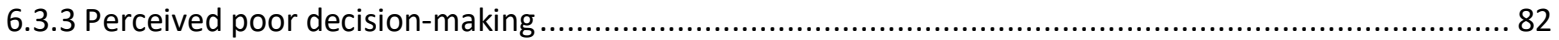

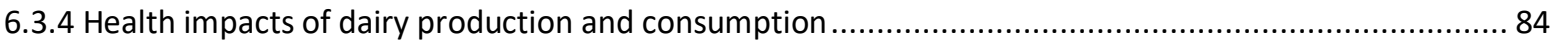

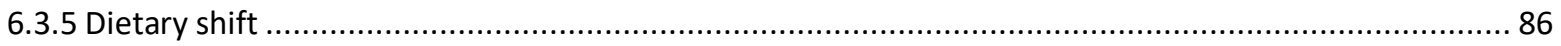

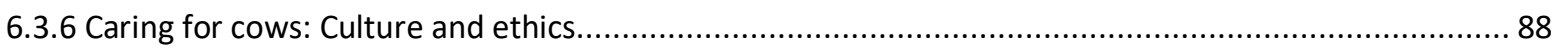

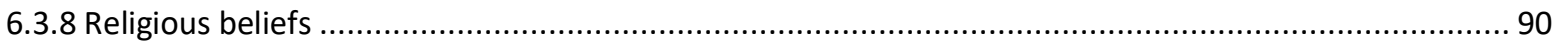

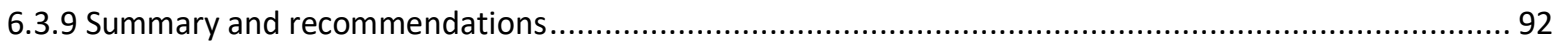

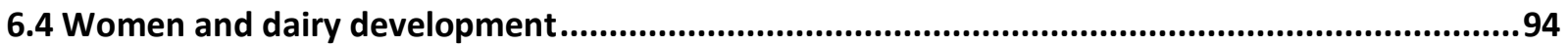

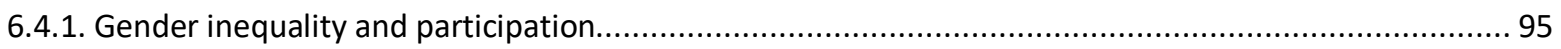

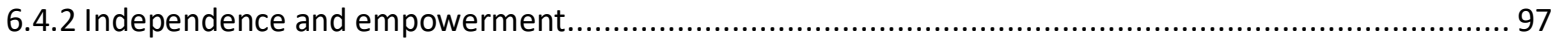

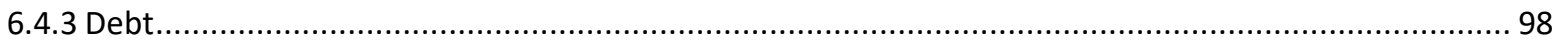

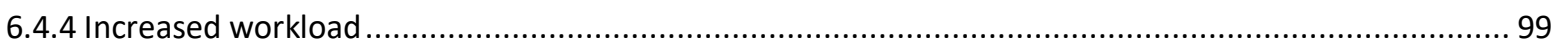

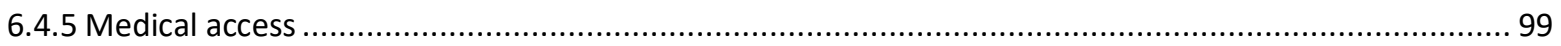

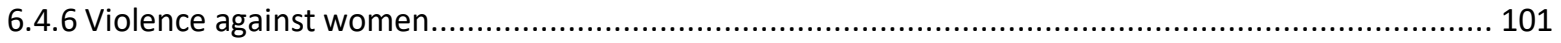

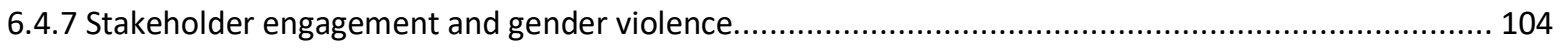

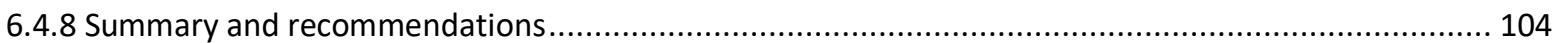

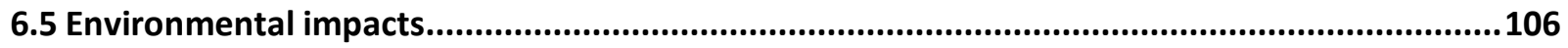

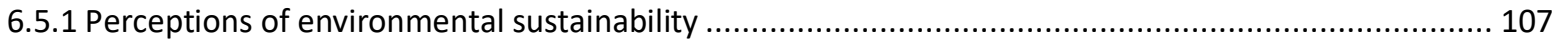

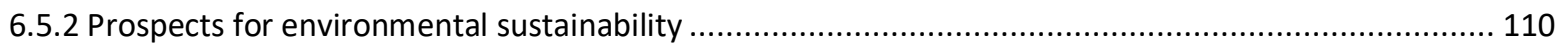

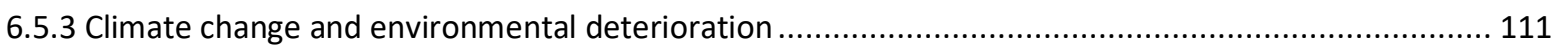

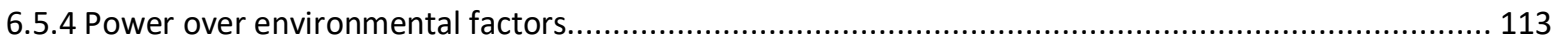

6.5.5 Farmers' priorities, the scale of dairy production and commercialisation ...................................... 115

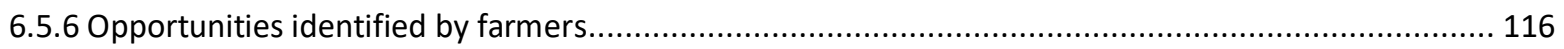

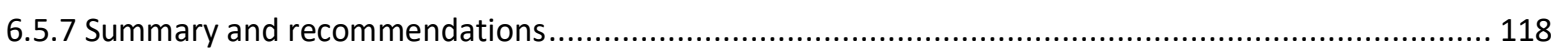

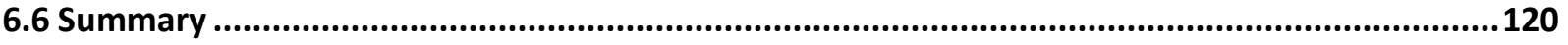

Chapter 7 : Conclusion.................................................................................................................. 124

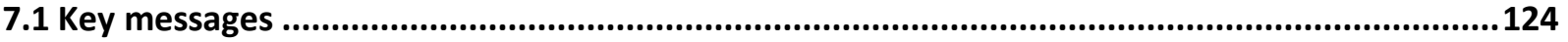

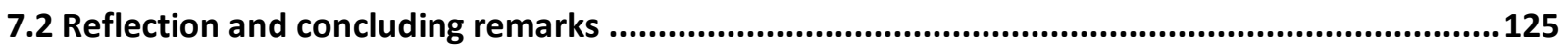

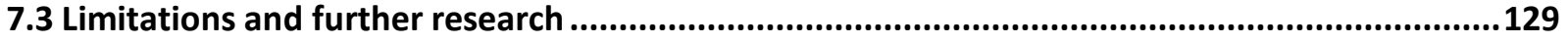

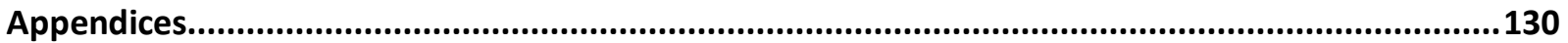

Appendix A: Support for research from project stakeholders.............................................................. 130

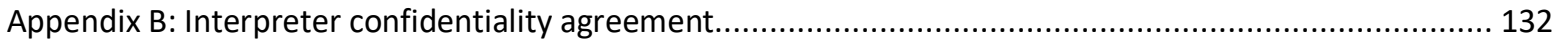

Appendix C: Participant information sheets and consent forms (English and Tamil) ................................ 133

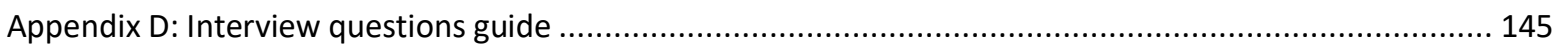

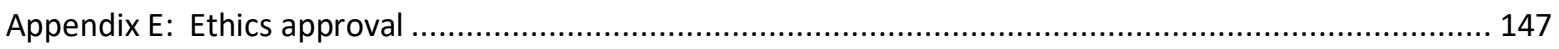

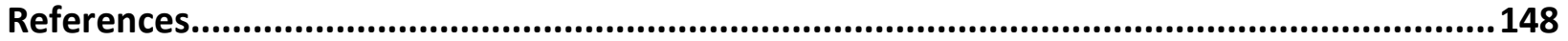




\section{List of figures and tables}

Figure 3.1. Illustrations of the factors of sustainability................................................ 31

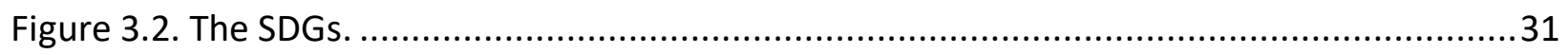

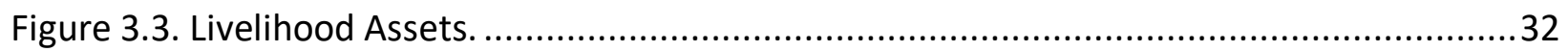

Figure 3.4. The Sustainable Livelihoods Framework. ....................................................34

Figure 3.5. Important aspects of a sustainable livelihoods framework in this research..............36

Figure 4.1. Elements of the research design...........................................................42

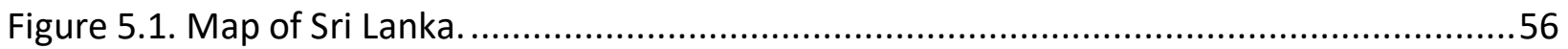

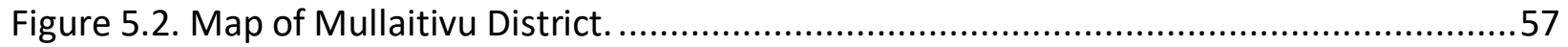

Figure 5.3. Entrance to the model farm, dairy processing plant and project offices.................57

Figure 5.4. Photos in the Northern Province......................................................................58

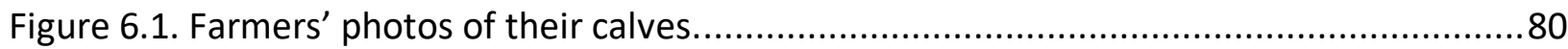

Figure 6.2. Processing plant under construction at the Wanni Dairy Project site....................85

Figure 6.3. Farmer's photo of cattle shed................................................................... 89

Figure 6.5. Farmer's photo of her Hindu shrine............................................................. 91

Figure 6.6. WCDO's overlapping and separate projects in the Mullaitivu District. ................. 101

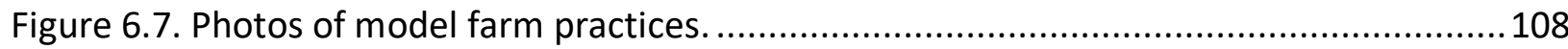

Figure 6.8. Greenhouse for planting at model farm.................................................. 109

Figure 6.9. Farmer's photo of land after heavy rain.................................................... 117

Table 4.1 Participant schedule and data collection methods ..........................................47

Table 5.1 Selected timeline 1948 - 2018: Independence to Post-conflict..............................64

Table 6.1 Five female farmers .............................................................................. 74

Table 6.2 Primary participants: female smallholder dairy farmers .....................................75

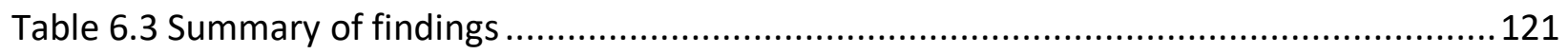




\section{Acronyms}

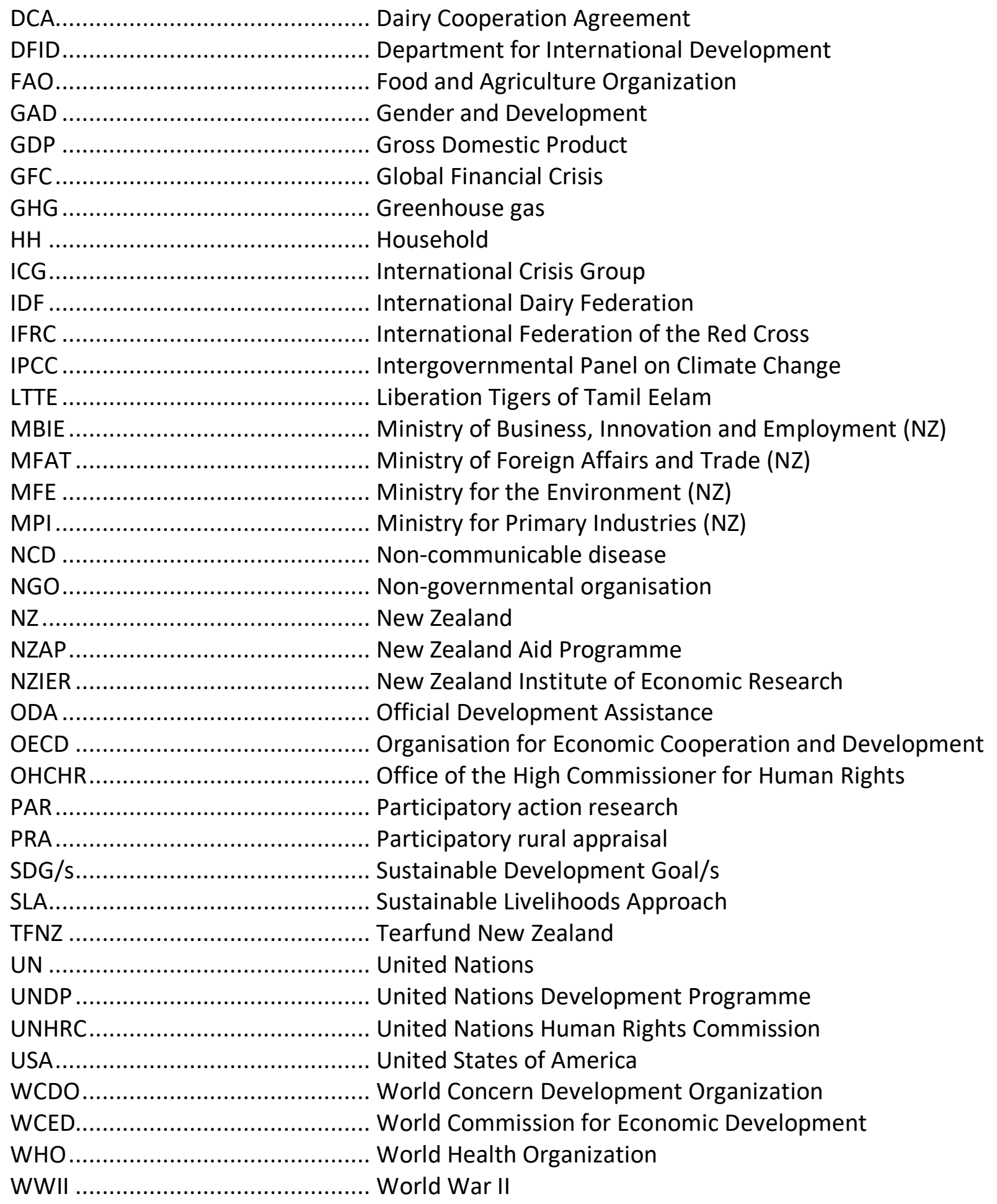




\section{Chapter 1 : Introduction}

\subsection{Background and rationale}

The pressing need to meet food demand and provide livelihood opportunities for a growing population are complex global issues and dairy development contributes to potential solutions. Dairy development initiatives, as a method of achieving sustainable economic development, aim to support farmers in developing countries to increase dairy production and improve economic livelihoods. New Zealand is a major international producer of dairy products and has funded dairy projects in 10 developing countries, including Sri Lanka, since 2012 through the New Zealand Aid Programme (NZAP) - a part of the New Zealand (NZ) Ministry of Foreign Affairs and Trade (MFAT) - and in partnership since 2014 with Fonterra, New Zealand's largest dairy company (Parliament, 2016). Although implementation is tailored to the local context, the basic premise of dairy development initiatives is to draw on New Zealand's comparative advantage in dairy production by providing expertise to increase productivity and production. While the economic objectives and impacts of dairy development projects are clear, there are other aspects of their implementation that need to be addressed, notably their environmental and social impacts.

It is widely agreed that it is necessary to adapt today's food production systems to address the environmental limitations of production and additional climate change impacts, which if unmitigated, will exacerbate the already formidable food security needs of the population on the planet (Amjath-Babu et al., 2017; Meadu et al., 2015). Effective development strategies that meet such complex issues have real potential to improve sustainable livelihoods for vulnerable communities. Dairy development initiatives, however, have the potential to produce complex and contradictory outcomes; increasing dairy production can provide inclusive economic opportunities and improve food security, but issues of environmental degradation, climate change, and health impacts in the context of increasing consumption may emerge (Braimoh et al., 2016; Gerber et al., 2013; Muehlhoff et al., 2013; Steinfield et al., 2006). It is important, therefore, for effective and sustainable development practice to be informed by an understanding of the multiple impacts of any intervention, and by the perspectives of recipient communities. 
New Zealand's involvement in dairy development initiatives in Sri Lanka was driven, at least partly, by trade tensions that emerged in 2013. These tensions, as Sri Lanka looked to decrease its reliance on foreign dairy imports and increase domestic milk supply, affected New Zealand operations in Sri Lanka. Sri Lankan authorities claimed they had detected a toxic agricultural chemical in Fonterra milk powder and imposed a two-week ban on consumer sales of Fonterra products. The ban was later overturned, however, protests over allegations that Fonterra flouted the ban and in support of local dairy producers created an unstable situation and spurred Fonterra to temporarily shut down its operations in Sri Lanka (Backhouse, 2013). These tensions were the precursor to a bilateral agreement in 2013 for New Zealand to support dairy development in Sri Lanka to build the domestic dairy industry, and thus create a more favourable trade environment between New Zealand and Sri Lanka by supporting both governments' priorities to expand the Sri Lankan dairy market (MFAT, 2013). One dairy development initiative through the NZAP Partnerships Fund, the Wanni Dairy Project, had already begun in 2012 and a further two complementary activities followed.

As I read further in this field, it became apparent that understandings of the issues (and potential issues) of dairy development are predominantly represented by agricultural actors, governments, scientists and academics; are typically focused at the macro- and meso-level; and are reliant on quantitative data. Thus, a qualitative methodology using interviews, observation and photovoice methods addresses an important gap in the literature on subjective, lived experiences of participants in dairy development projects. Moreover, understandings of dairy development (and development as a discipline) tend to be male-centric (Kishwar, 2014). In development interventions that do employ a gender approach, the approach may be only partial due to competing political pressures, as well as tensions and contradictions that can arise from such approaches (Rathgeber, 1990). It is important, therefore, that gender approaches receive attention, particularly in the vulnerability contexts of rural livelihoods, as interventions that are aimed at improving women's welfare but fail to also address broader gender issues can have unintended consequences. A focus on female farmers in this research allows for a gendered understanding, which adds depth to the knowledge produced and improves gender representation in literature. 
The acknowledgement that sustainable livelihoods are underpinned by a range of social, environmental and economic factors necessitates a holistic approach. This research, therefore, adopts a sustainable livelihoods approach (SLA) that integrates social, environmental and economic contributors to sustainable livelihoods in its investigation of locally-embedded experiences of dairy development in a case study of the Wanni Dairy Project in Sri Lanka. This qualitative approach is “inherently responsive to people's own interpretation of and priorities for their livelihoods" (Carney, 1998: 4), and it recognises the importance of micro-level research to inform deeper understandings of attitudes and perceptions, which affect behaviour and thus development outcomes (Ellis, 2000; Morse \& McNamara, 2013; Scoones, 1998). In adopting this approach, this research addresses a number of gaps in literature.

The literature on effective and sustainable development clearly has important consequences for dairy development initiatives: if global dairy expansion faces significant sustainability challenges then what long-term environmental impacts may development initiatives be exporting by increasing dairy production? How might an increasing reliance on dairy production for livelihoods in developing countries impact their governments' commitments to reducing greenhouse gas (GHG) emissions? What possible environmental impacts might smallholder dairy farmers face over time? The project descriptions for NZAP dairy development initiatives emphasise the health impacts of increased dairy production and consumption, which are assumed to be positive, yet health impacts are not targeted or measured. If successful dairy development and production expansion increases dairy consumption, what are the health implications for a population with traditionally low dairy consumption? As dairy products are not nutritionally homogeneous, the types of dairy that will be consumed must be considered.

While these broad questions are beyond what can be addressed in this master's thesis research, acknowledgement of the wider questions around dairy development provides a context for this micro-level research on the Wanni Dairy Project. Micro-level, people-centric research can address questions raised by dairy development by providing insights into the perspectives of smallholder dairy farmers, such as: How do smallholder dairy farmers perceive the relationship between environment and production? What dairy products do smallholder farmers consume, why, and what do they believe about the nutritional value of dairy? How do changes in farming practice of smallholder farmers influence their livelihoods? What is important 
to smallholder dairy farmers who are involved in development projects? How is a gendersensitive approach reflected in data on the livelihood impacts of dairy development?

This research also adds to the growing literature on integrated, multi-sectoral approaches to development aid. The global shift in the aid regime since the late 2000s has seen increasing private sector engagement and a focus on donor priorities in aid agendas. As traditional development actors have adjusted to the changing nature of aid, an emerging body of literature looks towards the ways in which partnership in development agendas affects development outcomes. It is widely accepted that the private sector is vital for development agendas, and increasing the opportunities for partnership in international development is necessary (Aggarwal \& Huelin, 2009). However, some scholars claim that the alignment of New Zealand's aid and trade priorities under the rubric of shared prosperity can be at the expense of aid recipients, whose aid dependency is increasing (Mawdsley et al., 2018; Murray \& Overton, 2016), and that the benefits of these projects for the donor, such as industry expansion, far exceed those for the recipient. This case study, then, provides an insight into the outcomes of a New Zealand-funded aid project that is based upon partnership between the government, NGO and private sectors.

\subsection{Research aims}

This research aims to enhance understandings of the impacts - particularly social and environmental - of dairy development by researching the perspectives of female dairy farmers in the Wanni Dairy Project. I also explore farmers' perceived influence over these impacts. This research also draws on interviews with other dairy development stakeholders, such as NGO staff, MFAT and academics, to add depth and context to the understandings derived from this research. It is hoped that this research will be of relevance and value to stakeholders in dairy development projects, including MFAT, NGOs, private sector agricultural actors and academic institutions, and can potentially be drawn on to shape effective development policy and practice. 


\subsection{Research questions}

The overall research question that this thesis addresses is:

What are local female farmers' perceptions of the social and environmental impacts of the Wanni Dairy Project, and how do they exercise influence over these impacts?

The research intends to portray farmers' voices and attitudes towards the project by evaluating farmers' perceptions of the project's impacts on factors of sustainable livelihoods and identifying what farmers believe about their influence over the project and its impacts. In order to answer the main research question, a number of subsequent questions guided this research:

1. What are the local attitudes towards the project?

2. What do locals believe about the impact of the project on rural livelihoods and wellbeing?

3. What do locals believe are the health impacts of the project?

4. How does culture influence the impacts of the project?

5. How has the project impacted gender issues?

6. What do locals believe are the environmental impacts of the project?

7. How do farmers influence the project and its impacts?

\subsection{Chapter outline}

This thesis comprises seven chapters. Chapter One introduces the aim of this research, the research questions, and the relevance of this research and its qualitative approach.

Chapter Two provides a literature review that addresses dairy farming and sustainable development in the context of a sustainable livelihoods approach in small-scale farming and the Sustainable Development Goals (SDGs). It then considers New Zealand's role in dairy development in the aid context, and finally, it discusses New Zealand dairy development in Sri Lanka and the potential for this research to address the issues and questions raised.

Chapters Three and Four provide the theoretical background for the thesis. Chapter Three discusses the sustainable livelihoods approach and integrates a gender lens, which provides the theoretical framework and principles that are woven throughout this research, from research design and practice to analysis. Chapter Four addresses positionality, epistemology and connects 
interpretivist-critical theoretical influences to the sustainable livelihoods approach. It then discusses the qualitative research methodology and methods, and ethical considerations.

Chapter Five describes the post-conflict development context of Sri Lanka. In doing so, it gives a brief overview of the colonial and postcolonial, political and ethnic factors that have shaped the nation since independence in 1948; discusses the impact of the civil war and the tsunami; and describes the importance of agriculture on livelihoods and the economy. The chapter then outlines Sri Lanka's bilateral relationship with New Zealand and the scope of the dairy development project that is the focus of this research.

Chapter Six presents the research findings and discussion, incorporating relevant literature, to address the research questions. The chapter first introduces the primary participants whose interviews and photographs shape the analysis. Three main sections follow, which discuss social, gender and environmental impacts and factors. Each section outlines implications and recommendations for action by development actors based on this research.

Finally, Chapter Seven provides concluding remarks on dairy development and sustainable livelihoods, addresses the limitations of this study and opportunities for further research, and concludes this thesis.

\subsection{Language}

Terms are used throughout this thesis that are ambiguous, contentious, hierarchical, binary and difficult to define, including developing countries, development, household, sustainability, private sector, NGO, women and gender. As these terms arise I suggest definitions that reflect their use in this thesis. Here I acknowledge that these definitions are imperfect, contested alternatives, but for communicative purposes, consistency and brevity are necessary.

The first of such terms, so-called developing countries, refers to what is also sometimes called the global South, the third world, low- and middle-income countries, emerging economies and majority countries. I have chosen here to use the term developing countries, despite its contested nature, because this term is commonly understood and is favoured by the NZAP in the discourse on dairy projects. 


\subsection{Summary}

This chapter introduced the research topic and the aims of this research: to understand female farmers' perceptions of the impacts of the Wanni Dairy Project on factors of sustainable livelihoods, and farmers' beliefs about their influence over these impacts. I identified the contemporary relevance of this research, particularly in addressing the pressing need for development projects to prioritise strategies that improve food security and mitigate climate change and environmental degradation to support sustainable livelihoods, as well as the contribution of this research to knowledge on integrated, multi-sectoral approaches to aid. Finally, I determined the research questions that this thesis will address and outlined the structure of this thesis to provide the reader with an expectation of the progression of chapters and their content. 


\section{Chapter 2 : Literature review}

\subsection{Introduction}

In order to understand the holistic impacts of dairy development, it is important to situate this research within the literature that addresses dairy farming and sustainable development, and the political context in which New Zealand dairy development has emerged. This chapter, therefore, begins by discussing small-scale versus large-scale dairy production, the relevance of a sustainable livelihoods approach for small-scale agriculture, and the SDGs. It discusses both the opportunities - such as improved food security and economic livelihoods - and challenges - such as environmental degradation, climate change, and implications of dietary shifts - for dairy development and sustainable livelihoods. Next, it covers New Zealand's role as a major actor in dairy development globally by addressing dairying in New Zealand, New Zealand's dairy development in the aid context, and the different stakeholders involved in it. Lastly, the chapter considers New Zealand's dairy development in Sri Lanka and the potential to address the issues raised in this chapter, in relation to health, environment, gender and community participation. ${ }^{1}$

This chapter brings into focus a more balanced understanding of sustainable dairy development by highlighting literature on social and environmental factors that, in addition to economic factors which are already well understood in the context of dairy development initiatives, contribute to sustainable livelihoods. I acknowledge that multiple other factors contribute to sustainable development, however, it is beyond the scope of this thesis to address all of these. As development partners face the challenges of meeting complex and interconnected development goals, such as improving poverty and food security alongside mitigating environmental degradation and climate change, I contend that the perspectives of people who are involved in and affected by dairy development and its impacts provide valuable insights that can inform development policy and practice, and address the gaps identified in the literature.

\footnotetext{
${ }^{1}$ This chapter addresses gender in the context of dairy development. Gender is further addressed within the sustainable livelihoods approach in Chapter Three, and gender dynamics in Sri Lanka are addressed in Chapter Five.
} 


\subsection{Dairy farming and sustainable development}

\subsubsection{Small-scale versus large-scale}

Animals have been milked for human consumption for centuries in smallholder farms around the world. Mass dairy production from specialised, intensive farming of cows, enabled by technical and scientific advances from the late $19^{\text {th }}$ century onwards, is relatively recent (Scrimgeour, 2014a; Valenze, 2011: 188). Most large-scale dairy production occurs in industrialised developed nations, yet the largest number of farms are smallholders in developing countries. Due to the perishable and voluminous nature of milk, dairy production is a highly localised industry in which smallholder farmers hold a central role (Ahuja et al., 2014: ix). ${ }^{2}$ The $20^{\text {th }}$ century was a period of exponential growth in the dairy industry as large herds and industrial processing enabled economies of scale (Scrimgeour, 2014a). Surplus production was able to be processed into dairy products for export, such as milk powder, cheese and butter (which have a longer shelf life), and the capability for long-distance distribution connected global markets (Muehlhoff et al., 2013: 28). Industry growth has continued since the turn of the century. Consolidation of farms and dairy companies - to match mass retail consolidation, mitigate seasonality of supply and increase corporate power - has enhanced dairy industry expansion in the $21^{\text {st }}$ century.

The relevance of a sustainable livelihoods approach in small-scale agriculture came to prominence in the 1980 s and 1990 s as an alternative to mainstream development practice and theory. Influential writers (Chambers, 1983; 1997; Chambers \& Conway, 1992; Escobar, 1995; Sen, 1984) critiqued the mainstream approach to development practice and suggested a collection of complementary ideas: redistribution and 'bottom-up' rather than 'trickle-down' interventions; local small-scale initiatives; an emphasis on meeting basic needs; the need for human-centred development to supplant the focus on economic factors and growth; community self-reliance; community participation as paramount; and a shift towards 'sustainable' development.

As opposed to deficit-based approaches, the sustainable livelihoods approach is a peoplecentric framework that is centred around different capitals (human, physical, natural, social and financial) - what people do have - to create livelihood strategies and affect livelihood outcomes

\footnotetext{
${ }^{2}$ Despite the considerable size of global dairy trade, $93 \%$ of production is not traded globally (Stringer et al., 2008).
} 
in a given context (Chambers \& Conway, 1992; Ellis, 2000; Scoones, 1998). A sustainable livelihoods approach acknowledges the interconnected economic, social and environmental factors upon which sustainable livelihoods depend. Chapter Three of this thesis describes the theoretical basis of the sustainable livelihoods approach and its application to this research. Here, I address the literature on sustainable livelihoods approaches in practice.

There is a wide literature on the relevance of a sustainable livelihoods approach for smallscale agriculture. The adoption of sustainable livelihoods approaches by diverse users in research and practice grew considerably in the late 1990s and 2000s, influenced in part by DFID's (Department for International Development) ${ }^{3}$ commitment to sustainable livelihoods approaches in poverty reduction programmes (Carney, 2002). The holistic approach is shown to be valuable in understanding cross-cutting issues of gender and environment, explicitly highlighting various assets, understanding the impact of policy on livelihoods, village-level livelihoods analysis, and emphasising the significance of institutional barriers to livelihoods improvement (Ibid.). For instance, case studies that employ a sustainable livelihoods approach have highlighted the role of effective communication between grassroots institutions and locals in the intensification of land use for livelihood improvement in India (Feola et al., 2015) and the empowerment of women through the adoption of women-run cooperatives to manage dairy and other agricultural production for social and economic benefits in India (Ibid.). Other studies have revealed that the mainstay of livelihoods in rural Tanzania is, in fact, dairy production, not coffee as thought, and that assets rather than livelihood activities distinguish households (Ellis, 2000); and explored the tension and trade-offs between food security and limited natural resources in the Gaza Strip, using the holistic perspective (Recanti et al,. 2017).

Despite the myriad literature on sustainable livelihoods approaches in agriculture, the multiple attributes of sustainability on dairy farms are rarely assessed (Mohanty et al., 2016). A study on small-scale dairy farming in Indonesia notes that "the expansion of animal-based production systems aimed to improve the livelihood of the rural people in the one hand, and the depletion of natural resources, on the other hand, has been becoming an important issue" (Parikesit et al., 2005: 542). However, a lack of holistic understanding is, in part, due to the

\footnotetext{
${ }^{3}$ DFID is a government department of the United Kingdom, and a global influence on development policy and practice.
} 
challenges of complex data collection, particularly in the context of smallholder dairy farmers (lbid.).

\subsubsection{Dairy development and the Sustainable Development Goals}

Future generations depend on the actions of today's people and, in the face of population growth and climate change, we need to meet increasing demand for food with less environmental impact. Sustainable development, the primary framework for today's global development policymaking, is philosophically grounded in the interdependence of economic, social and environmental values. The Bruntland Report's definition of sustainable development as "development that meets the needs of the present without compromising the ability of future generations to meet their own needs" (WCED, 1987) remains valid. Sustainable development acknowledges the realities of finite ecological resources, and the United Nations' (UN) SDGs underpin global development efforts from 2015-2030. The SDGs go further than previous development goals. Inequality is implicitly and explicitly addressed as a central issue, which in contrast to a focus on poverty, demonstrates "a concern with how society as a whole is structured, not just with the outcome for those who are worst off" (Therborn, 2001: 454). The SDGs are inclusive and universal, rather than limited to conditions in developing countries, and thus emphasise global partnership to achieve development goals. Further, there is the expectation that business, government and civil society actors are equally responsible for progressing a sustainable future (Scheyvens et al., 2016).

The linkages between the dairy sector, people and the environment are complex. The implementation of best practices, policies and investments that promote sustainable dairy development has the potential to contribute to several SDGs (IDF \& FAO, 2016a). The dairy sector directly and indirectly supports the livelihoods of 150 million farmers. Employment opportunities (SDG8) across the dairy value chain are a pathway out of poverty (SDG1) and contribute to reduced inequalities (SDG10), including gender inequality (SDG5) as women can play a key role in the dairy sector. The provision of energy, protein and nutrients in diets from dairy consumption contributes to reduced hunger (SDG2) and thus good health (SDG3). The difference between the most and least efficient producers of dairy represent an opportunity to improve responsible consumption and production (SDG12), take climate action (SDG13), restore and protect 
terrestrial ecosystems and biodiversity (SDG15) and improve management of water resources (SDG6) through the adoption of best industry practice. The dairy industry has a large and multifaceted impact on people and the planet. The negative and positive impacts are interconnected, and hence it is both a challenge and an opportunity to adapt dairy industry practice, in partnership (SDG15), so that the positive impacts of dairy development on people's economic livelihoods are situated within the context of environmental sustainability, the implications of dietary shifts, and cross-cutting gender issues.

\subsubsection{Environmental challenges of livestock and dairy farming}

In the agricultural industry, the environment is constructed as a resource for extraction and for use as a means of production rather than as an ecosystem, a home or place of livelihood (Jay, 2007). It is argued that New Zealand dairying discourses (reinforced by industry leaders and agricultural bodies) purport the commodification of land and marginalise the alternative values of the environment (Ibid.: 275). Industrialised farming - a modern method of farming that relies on technological and scientific inputs (such as synthetic fertilisers and machinery) to achieve maximum productivity at the lowest cost (i.e., economies of scale) - has created a system that increasingly influences the environment through land degradation, climate change and air pollution, water shortage, water pollution and loss of biodiversity (Steinfield et al., 2006). Despite the lower emission intensity of industrialised dairy production, because industrial methods produce higher yields per animal than traditional small-scale farming methods, natural resources have come to be used at a rate that exceeds their regenerative and absorptive capacity (Braimoh et al., 2016; Gray \& Le Heron, 2010; Steinfield et al., 2006). In other words, the production gains achieved through industrialisation are not sustainable in the long-term.

The environmental impacts of livestock are very significant. ${ }^{4}$ The pivotal publication, Livestock's Long Shadow, ${ }^{5}$ (Steinfield et al., 2006) draws attention to the magnitude of livestock's role on climate change, water quality and biodiversity. It is estimated that the livestock sector is responsible for $18 \%$ of total global GHG emissions; it uses and pollutes huge quantities of water

\footnotetext{
${ }^{4}$ Livestock is defined as farm animals that are regarded as an asset (Oxford Dictionary).

${ }^{5}$ Livestock's Long Shadow is a widely-cited report released by the FAO of the UN.
} 
as the world faces increasing scarcity and depletion; ${ }^{6}$ and is a major factor in the loss of species and ecosystem decline through its impacts on natural resources. ${ }^{7}$ Further, livestock can indirectly drive deforestation (through land conversion for livestock and crops), intensification and industrialisation (through excessive use of nitrogen fertiliser, effluent and pollutant run-off and leaching). GHG emission reduction, pressure on water resources and feed scarcity are identified as among the most serious challenges for meeting the growing demand for dairy in the Asia region (Ahuja et al., 2014: viii). Continued adaptation and innovation are required to address environmental imbalances between environmental inputs and agricultural outputs.

The livestock sector both contributes to climate change and is affected by it. Climate change and the degradation of ecosystems will have consequences for grazing systems, feed, water and energy resources whether directly through scarcity or indirectly through increased costs (Steinfield et al., 2006). Climate change will increase the probability of extreme weather events and is expected to change the occurrence of diseases and parasites in animals, which will disproportionately affect smallholder farmers in developing countries, who often have limited resources to cope with such challenges (Raney et al., 2009). Further, emissions are increasing due to population growth, increasing consumption of animal products, and higher use of nitrogen fertilisers, among other factors. ${ }^{8}$ As a result, agriculture could contribute $70 \%$ of GHG emissions by 2050 under business as usual practices (Braimoh et al., 2016). ${ }^{9}$ It is estimated that current agricultural emissions need to be cut by two thirds by 2050 to meet emission reduction targets.

\footnotetext{
${ }^{6}$ Major sources of water pollution are from animal waste, antibiotics and hormones, fertilisers and pesticides from feed crops, and sediments from eroded pastures (Steinfield et al., 2006). Agricultural demand for water may increase by $30 \%$ by 2030 , yet the $18 \%$ of the population that reside in water-stressed or water-scarce areas is likely to increase to $44 \%$ by 2050 (Braimoh et al., 2016).

${ }^{7}$ Livestock account for around $20 \%$ of all terrestrial animal biomass. Insufficient land for the recycling of waste from livestock can lead to nutrient overloads and pollution of land and water.

${ }^{8}$ Most agricultural emissions come from livestock as methane $\left(\mathrm{CH}_{4}\right)$ that is mainly created by cattle respiration (enteric fermentation) (39\%) and excretion (manure) (25\%), as well as nitrous oxide $\left(\mathrm{N}_{2} \mathrm{O}\right)(14 \%)$ that is mainly due to nitrogen fertiliser in agricultural soils (Braimoh et al., 2016: xiv). Industry use of fossil fuels in energy and transportation also contribute to carbon dioxide $\left(\mathrm{CO}_{2}\right)$ emissions. The emission intensity of milk production is generally lower in industrialised nations due to better feed and nutrition that reduce enteric and manure emissions, and produce higher yields, which indicate that the cow's metabolism is functioning well (Gerber et al., 2010).

${ }^{9}$ Livestock are a major contributor to total agricultural emissions, of which cattle (dairy and beef) are a large part.
} 
The dairy sector faces a difficult development and environmental challenge; to increase food production to meet significant demand growth while simultaneously making considerable reductions to GHG emissions to tackle global climate change (Braimoh et al., 2016). A sustained collective effort is needed to improve the environmental sustainability of dairying but mitigation strategies are not widely used, despite both environmental and economic benefits (Braimoh et al., 2016). Possible mitigation interventions are diverse and need to be tailored to local conditions and objectives. These commonly include integrating trees and shrubs in pasture, better herd management (improvements to animal breeding, health, feeding practices) and manure management. ${ }^{10}$ Further options to reduce emissions include improvements in energy efficiency across supply chains and sourcing low emission intensity inputs for feed and energy (Gerber et al., 2013). There is a tension between the pressure to scale up dairy production to improve efficiency, meet demand, and improve the cost-effectiveness of mitigation strategies, and the greater environmental impact of doing so.

\subsubsection{Potential to address food security and economic opportunities}

Global food demand is projected to increase due to population growth (projected to reach 9.5 billion people by 2050), therefore, building the resilience of food systems that provide adequate nutrition is a global priority (Alexandratos \& Bruinsma, 2012). Prospects for global growth in the dairy industry remain strong (Ahuja et al., 2014). This is due to two factors. First, developing countries are consuming more dairy as a result of population growth, per capita income growth and Westernisation (Gerosa \& Skoet, 2013: 30). Increasing income has led to the emergence of an affluent middle class in many low- and middle-income countries, which is a key market for global dairy producers. Traditional diets in many developing countries are low in dairy, thus per capita, dairy consumption is considerably lower than in developed countries. There is limited potential to grow dairy demand in developed countries, whereas developing countries are recognised for their significant growth prospects (Fonterra, n.d.; OECD, 2016; Valenze, 2011).

\footnotetext{
10 Trees and shrubs in pasture can reduce heat on animals, be used as animal feed and fencing, and, therefore, promote ecological sustainability and improve productivity; selecting more productive animals for breeding reduces the emission intensity of dairy production; increasing animal weight, reducing mortality and improving reproductive management through technology reduces emission intensity of dairy production; imbalanced feeding reduces productivity and increases emissions, thus, better feeding practices enhance animal performance; improved storage and handling of manure can prevent negative environmental impacts, and utilise nutrients and energy.
} 
Second, production is increasing but at a slower rate than consumption. Global milk production is projected to increase by 177 million tonnes by 2025 , which represents a $23 \%$ increase in total milk production (OECD, 2016). Growth in consumption is predicted to exceed growth in production (Ibid.). Milk production growth rates are unequal between developed countries. Some are increasing (due to improved productivity), while others are constant or declining. In New Zealand, for instance, growth is expected to be constrained. Therefore, the majority of this additional dairy supply (73\%) will come from developing countries where cow numbers and milk production are steadily increasing to meet the growing domestic demand (Ibid.). As domestic dairy production in developing countries is insufficient to meet growing consumer demand, developing countries, especially in Asia, are prioritised by their governments and foreign investors for their supply growth potential (and the benefits for poverty reduction) (Ahuja et al., 2014: vi; Boros \& McLeod, 2015). However, these opportunities are occurring at a time when environmental concerns (section 2.2.3) are of major importance (Ahuja et al., 2014: viii). Increasing reliance on the dairy sector for economic opportunities and food security, therefore, faces sustainability challenges.

\subsubsection{Social impacts of dairy: health}

Social impacts are 'everything that affect people' and can include changes to people's way of life; culture; community; political systems; environment; health and wellbeing; personal and property rights; and fears and aspirations (Vanclay et al., 2015). The objective of understanding the social impacts of development projects is to maximise impact and minimise harm. Health impacts are raised by MFAT as a key social impact of dairy development, which states that "agriculture is a critical issue for economic growth and public health" (MFAT, 2014: 1). The prevalence of nutrition-related narratives to promote the social impact of dairy development is seen in international dairying policies by multilateral agricultural bodies; in New Zealand's Framework for International Development in Dairy Excellence; the Dairy Cooperation Agreement (DCA) between New Zealand and Sri Lanka; agreements between New Zealand and other partners in dairy development; and in activity design documents (MFAT 2013; 2014; 2015b; 2016). Despite its dominance in surrounding discourse, however, health impacts are not directly targeted or measured in dairy development projects. 
Two rationales posit improved health as a result of dairy development. First, there is a correlation between increasing income and improved health outcomes due to greater food security (Hemme \& Otte, 2010; Muehlhoff et al., 2013: 4-5). Put simply, as incomes increase, nutrition indicators improve because people have more money to buy food. Second, increased consumption of dairy products is inherently connected to health impacts (Allen et al., 2018; MFAT, 2014; Muehlhoff et al., 2013: 6). In dairy development policy, increased dairy consumption is assumed to correlate to positive health impacts because "many of the fastest growth markets for dairy consumption and imports are developing countries where poor nutrition and calorie deficiency are ongoing problems for sizeable sections of the population" (MFAT, 2014: 2). The assumption that increased consumption creates positive health impacts has, however, been increasingly questioned in recent years (Muehlhoff et al., 2013: 6). Further, this presumes that increased production correlates to increased dairy consumption by farmer communities.

Milk is a source of protein, calcium, carbohydrate and fat, and contains many essential vitamins and minerals. It is widely accepted that dairy can be part of a healthy, balanced diet, and dairy products can alleviate some of the negative health impacts of nutrient-poor diets. Nutrients in milk, however, are often involved in more than one biological process and can produce conflicting health effects (Muehlhoff et al., 2013). Milk consumption can reduce the risk of some non-communicable diseases (NCDs) (such as osteoporosis and possibly colorectal cancer and type 2 diabetes), while its consumption is potentially associated with others (such as cardiovascular disease and prostate cancer) (Ibid.). Further, the diversity of nutritional compositions between dairy products can contribute both positively and negatively to health.

The malnourished, calorie-deficient portions of the population that characterise aid rhetoric on dairy development are not the predominantly middle-class, affluent consumers of dairy in developing countries. For example, in Myanmar where Fonterra runs an office to support the NZAP's dairy development, they have collaborated with a bakery franchise that buys three tonnes of Fonterra's dairy each month to make treats that sell for more than the average daily wage (Manch, 2018). Western-style consumption (typically with increased processing, high sugar, high fat and high animal products), that is being cultivated in target growth markets, has been associated with negative health impacts. Populations with high animal product consumption report positive health impacts when consumption is lowered (McMichael, 2007). 
Asian diets have traditionally been, and remain, relatively low in dairy, although some types of dairy have a long cultural history in South Asian diets. The prevalence of genetically-based lactose intolerance in populations with traditionally low dairy consumption affects Asian consumers (Woodford, 2008). ${ }^{11}$ Typically, populations with a long culture of dairying - Northern European and of Northern European descent - are strongly correlated with high lactase persistence, an enzyme that aids the digestion of lactose, and therefore can drink and nutritionally benefit from milk. In individuals with lactase deficiency, a high lactose diet, typical of Western countries, can cause symptoms that include abdominal pain, bloating, flatulence, and diarrhoea. In addition, a wide range of systemic problems has been associated with lactose intolerance including skin disease, rheumatological complaints, chronic fatigue, and failure to thrive in children, although further study is required (Misselwitz et al., 2013). In some Asian countries, the rate of lactase deficiency can reach almost $100 \%$ (Weaver et al., 2013). Thus, the prevalence of lactose intolerance is significantly higher than that in Caucasian populations.

Dairy companies play a strategic role in influencing attitudes (Fonterra, 2017; Woodford, 2007). Partnerships with health, education and government sectors aim to provide consistent information to consumers to enhance milk campaigns. Fonterra invests millions annually in research and marketing in their key export markets to promote awareness about the health benefits of dairy consumption (Fonterra, 2017). The promotion of some dairy products, however, is controversial. It has been argued that New Zealand exporters little consider the ethical and public health implications of the promotion of infant formula in markets with low consumer protection, for example, which undermines breastfeeding practices (Galtry, 2013). Dairy companies can be expected to promote sustainable development insofar as outcomes support economic motives, but both the positive and negative health impacts should be considered in the NZAP's dairy development to inform ethical development policy, practice and partnerships.

\subsubsection{Gender and dairy}

Aggregating social impacts is understood to be problematic because the 'community' being analysed is implicitly assumed to be a homogenous unit, but impacts are gendered. A gendered understanding of the impacts of dairying, based on a theoretically informed feminist perspective,

\footnotetext{
${ }^{11}$ Lactose intolerance is the inability to digest lactose, a sugar present in milk.
} 
is important to ensure nuanced, specific understandings; that knowledge is not based on masculine biases; and to acknowledge normative assumptions about gender roles (Lahiri-Dutt \& Ahmad, 2012: 118).

Research and practice that reflects dominant male perspectives presents an incomplete understanding; important aspects of females' experience cannot be expressed by men (Mosse, 1995: 512). It has been argued that men are universally accepted as 'good informants' because they are able to articulate knowledge that meets the expectations of the researchers. Women, however, are sometimes considered 'difficult to reach' (Ibid.). Processes understood as public and formal tend to exclude women because of the socially constructed exclusion of women from these spheres in many places. Acknowledging the experiences of women is about inclusion because women continue to be marginalised in development (Kishwar, 2014). Nevertheless, while increasing the inclusion of women may serve instrumental goals, fundamental questions of structural and personal power can remain unaddressed (Cornwall, 2003). Studies on women's livelihood strategies in Sri Lanka, for example, highlight the vulnerability of female-headed households as the victims of socio-political oppression, and, gendered norms and power relations are observed to be factors in gender disparity that persists in livelihood projects, despite the active agency of women in their own lives (Jayasinghe \& Lakshman, 2011; Vasudevan, 2013).

It is estimated that 80 million women are engaged in dairy farming to some extent globally (Boros \& McLeod, 2015). Livestock is argued to be more accessible to rural women in developing countries than other assets (Kristjanson et al., 2014; Sharma \& Vanjani, 1993). Whether or not women own dairy cows, they play a major role in dairy production as they often care for the animals - feeding, milking, cleaning - and are often responsible for composting manure, breeding animals and selling milk. Dairy production, especially in rural areas, is often a means to improve women's standing in society (Kristjanson et al., 2014; Sharma \& Vanjani, 1993). Dairy development can contribute to outcomes that support gender equality, and thus gender equality is targeted in the NZAP's dairy development.

Development initiatives, however, face the limitations of often operating within societal systems that perpetuate inequalities. Class and gender biases, and issues of patriarchal subordination, land reform and agrarian production restrict the potential for change in the status of women through dairy projects in many places (Sharma \& Vanjani, 1993). Women and children 
are also disproportionately affected by natural disasters (Gaard, 2015) and are the primary victims of environmental deterioration (Goebel, 2003), which, due to climate change, are predicted to increase and intensify. Gender and a sustainable livelihoods approach is further addressed in Chapter Three of this thesis.

\subsection{New Zealand as a major actor in global dairy development}

\subsubsection{Dairy in New Zealand}

The New Zealand dairy industry is atypical. Its domestic market is relatively small and its focus has been, and remains, beyond its borders. Dairy contributes $\$ 7.8$ billion (3.5\%) to New Zealand's GDP and remains the largest export industry (NZIER, 2017). Although the dairy industry has experienced steady growth and prospects are good, dairy trade is highly volatile. The international dairy market is one of the most heavily regulated agricultural markets. Trade barriers, milk price fluctuations, exchange rates, political measures and the performance of domestic economies have considerable impacts on trade and New Zealand has been strongly affected by these factors (Hill, 2017).

New Zealand's dairy industry is underpinned by Fonterra, the world's largest dairy exporter. Fonterra's views (voiced in media, company reports and communication with farmers, agricultural bodies and government) constitute a major element of dairy farming discourse in New Zealand. Fonterra is also "a very active shaper of the global dairy scene" (Gray \& Le Heron, 2010: 7) through their international operations, their involvement in international agriculture bodies and with trading partners (Stringer et al., 2008). There is a high public interest in dairying operations in New Zealand due to the industry's impact on the economy and environment, and farming's historical role in New Zealand nation-building. Multinational operations, industry performance and impacts of dairy production and consumption are reported on by agribusiness actors, media, government, academics and activists.

There is both support for and criticism towards the dairy industry and farming community in New Zealand. On one hand, agricultural success is argued to be the foundation of New Zealand's prosperity and a pillar of the domestic economy (Hill, 2017). Some see farming and dairy consumption as entwined with culture and identity. On the other hand, the negative impact of dairying on water, soil and air quality has incited widespread concern (Joy, 2015; MFE \& 
Statistics NZ, 2018). The increasingly urbanised population has fewer personal connections to farming than previous generations, and pressure for the industry to evolve and diversify is based on improved understandings of the positive and negative impacts of the dairy industry in a society concerned with addressing sustainability issues.

Concern is growing about the role of New Zealand's agricultural industry in reducing GHG emissions to limit the serious impacts of climate change. The application of carbon policy to the agricultural sector is controversial. Despite contributing $49 \%$ of New Zealand's overall GHG emissions in 2016 (MFE \& Statistics NZ, 2018), and public pressure for its inclusion, agriculture is not included in the Government's policy response to climate change. ${ }^{12}$ This is partly because of a lack of international agreement on appropriate responses to climate change, which affects competitivity in the global market. Further, the industry faces difficulty in identifying significant opportunities to reduce emissions without adversely impacting production (Scrimgeour, 2014b). The government response to agriculture and climate change, then, has largely been through investment in research and technology, and the regulatory framework also shapes dairying practice. $^{13}$

Other issues of dairy production are also important to consumers (Gray \& Le Heron, 2010; Guenther et al., 2015). Exposure of animal mistreatment has been condemned and more consumers are aware of ethical factors, such as the mass slaughter of male calves and animal abuse (Farmwatch, 2015; RNZ, 2018). Consumers value the health benefits of dairy consumption, however, real and perceived negative health factors, such as gastrointestinal problems, allergies and intolerances, and concerns about future health problems (discussed in section 2.2.5) are also a concern and contribute to a growing demand for dairy alternatives (Allen et al., 2018).

NZAP dairy development is, therefore, contentious. There is criticism towards aid expenditure on dairy development that prioritises national interests (Adams, 2017; Mawdsley et al., 2018). It is further argued that dairy development in the New Zealand aid agenda is not simply about aid being used in support of greater "national self-interest" (Mawdsley et al.,

\footnotetext{
${ }^{12}$ Primary policy responses are the Emissions Trading Scheme and Climate Change (Zero Carbon) Amendment Bill.

${ }^{13}$ For example, the government established the NZ Agricultural Greenhouse Gas Research Centre and is a founding member of the Global Research Alliance on Agricultural Greenhouse Gases.
}

Valentine (2015: 29-33) identifies an extensive list of regulations that cover dairying practice in New Zealand. 
2018). Rather, government support that effectively subsidises Fonterra's expansion strategy is likened to the GFC-era (Global Financial Crisis) policies of bailing out big business. The rhetoric of "inclusive", "sustainable economic growth" and "shared prosperity" is, therefore, questioned for being used to promote an aid agenda based on the same growth model that prioritised businesses at the expense of widening inequality and growing poverty. Such criticisms highlight the politicised nature of aid and the multiplicity of views towards dairy development.

\subsubsection{New Zealand commitments to sustainable dairying practice in the global context}

Issues identified in Livestock's Long Shadow (Steinfield et al., 2006) incited pressure for action to address climate change by the global dairy sector, which culminated in an official declaration in 2009: The Global Dairy Agenda for Action. The declaration, which was 'spear-headed' by Fonterra (Gray \& Le Heron, 2010: 9), acknowledges decades of improvement to emission efficiency by the dairy industry, and emphasises the need for greater cooperation between actors to take the commitment further while "providing consumers with the nutritious dairy products they want, in a way that is economically viable, environmentally sound and socially responsible" (Dairy Sustainability Initiative, 2009: 1). A subsequent sustainability declaration, the Dairy Declaration of Rotterdam, was signed in 2016 by the International Dairy Federation and Food and Agriculture Organisation as representatives of the one-billion-person global dairy community. New Zealand endorsed the declaration in 2017. This declaration recognises the UN's 2030 Agenda for Sustainable Development as the overarching framework to guide sustainability action.

Institutional and industry-led support for sustainable dairy development has grown in recent decades alongside the pressure for publicly and politically palatable industry operations. Gray and Le Heron (2010: 5) note that "both New Zealand and international dairying have evolved dramatically over the past decade. Fonterra is undergoing significant internal transformations in thinking, especially around the centrality of sustainability to its operations and future." Sustainability in dairying influences agricultural thinking in increasing and impactful ways, to target all levels of the dairy supply chain, domestically and internationally, and provide innovative solutions to improve efficiency and reduce GHG emissions through research, technology, reporting and monitoring. Views on potential solutions to the challenges of agricultural production and sustainability, however, are not homogenous - even within organisations 
(Scrimgeour, 2014a). The extent to which different actors in the dairy supply chain take actions to support sustainability commitments is influenced by perceived costs and benefits, economic viability and the regulatory context.

The first step towards the adoption of better technologies and practices that address environmental challenges (i.e., mitigation strategies) is investment in awareness-raising and extension activities, such as communication activities, demonstration farms, farmer field schools, farmer networks and training programmes (Braimoh et al., 2016). Dairy development projects in developing countries can play an important role, to facilitate the uptake of mitigation strategies, enable access and raise awareness (Gerber et al., 2013). Some dairy development projects, however, have been inhibited by instances of poor consultation, 'top-down development' and lack of understanding of local conditions and indigenous knowledge that result in ineffective development outcomes (Mekoya et al., 2008).

\subsubsection{Reasons for New Zealand's engagement in dairy development}

The 2008 Chinese milk scandal, that resulted in the death of four infants and poisoning of at least 53,000 others after milk powder was adulterated with melamine, rocked consumer confidence in infant milk powder and had substantial implications for trade (Stojkov et al., 2018). Then in 2013, Fonterra issued a global recall on baby formula that was thought to have been contaminated with a potentially fatal bacterium. Although testing confirmed that the scare was a false alarm, the severity of the issue invoked total bans on imports of certain New Zealand dairy products into Sri Lanka and other countries (Ibid.). Shortly after the 2013 incident, further contamination fears and protests over Fonterra's activities resulted in suspensions of Fonterra's trade in Sri Lanka. New Zealand's aid funding for dairy development was primarily initiated in response to the 2013 trade tensions between Sri Lanka and New Zealand and has since expanded to other developing countries (Parliament, 2016).

New Zealand recognises that cooperation in supporting domestic dairy industries in developing countries is good for smallholders, commercial producers and investors, and enables a positive trade environment (MFAT, 2013; 2014). Access to export markets is valuable, and so too is Fonterra's commercial offshore production, which generates significant economies of scale, enables year-round supply to their partners, and expands the milk-pool. A major 
component of Fonterra's global expansion strategy is focused on managing the supply chain and processing milk into powder and a range of dairy products. As a development partner, Fonterra can strengthen relationships, build supply for processing, and promote consumption in its priority markets to support its expansion strategy.

New Zealand is seen to be strongly committed to effective development cooperation; its programming is closely aligned to national priorities in its partner countries (OECD, 2015). New Zealand leverages its comparative advantage to build capacity and achieve development results, and in doing so, increasingly looks to partner with the private sector in official development assistance (ODA). The influence of the National-led government between 2008-2017 on New Zealand's aid has been instrumental in the rise of private sector engagement, the focus on national trade priorities, and development that is characterised by economic growth rather than poverty alleviation (Mawdsley et al., 2018; Zweifel \& Hill, 2015).

The elevation of sustainable economic growth as the mission of the NZAP signalled an ideological shift that prioritises New Zealand's diplomatic, security, economic and, arguably, cultural interests (Mawdsley et al., 2018). While self-interested aid is not inherently problematic, it is argued that covert interests and agendas conflict with the stated altruistic intent. The 'shared prosperity' aid regime co-opts the rhetoric and resources of aid to "stimulate and subsidise corporate capitalism" (Ibid.: 26). It is argued that "what remains unsaid, but understood, is that Fonterra's global strategy is also supported and subsidised by the country's aid programme" (Ibid.: 35).

Dairy development initiatives are distinct from trade-focused dairy development despite their alignment with New Zealand's self-interest, because aid projects have an inherent (and explicit) responsibility to 'do-no-harm' (MFAT, 2012). The primary focus of the New Zealand dairy industry (i.e., trade) is related to a business efficiency model (Jay, 2007), ${ }^{14}$ whereas good development assistance, it has been argued, should be focused on poverty alleviation, balanced across social, economic and environmental spheres and should consider cross-cutting issues of gender, human rights and environment/climate change (Mawdsley et al., 2018; Murray \& Overton, 2016; Spratt, 2018). A lack of consideration of these factors in dairy projects is considered "unsatisfactory in terms of assuring that risks associated are mitigated [and] that

\footnotetext{
${ }^{14}$ I.e., the best results for the least cost.
} 
sustainability is prioritised" (Rattray \& Thomson, 2015: 27). Influential literature critiques the mainstream focus on economic growth and prioritises holistic, human-centred development with a paramount focus on community participation to reflect relevance to local conditions, basic needs, and sustainability (Chambers, 1983; 1997; Chambers \& Conway, 1992; Pieterse, 2010).

Information on local perceptions, then, is a worthwhile data source to enhance effective and sustainable development outcomes because "only by fully understanding all the implications of our foreign investments can we ensure that New Zealand profits are not at the cost of other countries' well-being" (Chisholm, 2009: 32). Studies on local perceptions and power dynamics in Fonterra's commercial development in Latin America suggest that in developing countries especially, power imbalances can exacerbate the negative impacts on marginalised people (Ibid.); farmers can be individualistic and have low voice and governance; while influential stakeholders (Fonterra) can be perceived as a threat to farmers' livelihoods (Lumsden, 2011). Community participation can contribute to a more complete picture of the impacts of dairy development.

\subsubsection{Potential to address development priorities in Sri Lanka}

It is evident in the wide literature on the impacts of dairying on economic, social and environmental factors that dairying can be a means for improving factors of sustainable livelihoods. Dairy production has been shown to play an influential role in reducing poverty in rural communities in Sri Lanka and elsewhere (Hemme \& Otte, 2010; Prasanna \& Shiratake, 2014). It can provide economic outcomes for people in developing countries; increased dairy production can create a number of social benefits that intersect gender issues and can positively impact on health through improved nutrition (through consumption and incomes); and there is considerable variation in the environmental impacts of dairying that are influenced by scale, best practice and the willingness of dairy actors to emphasise sustainability.

Sri Lanka's dairy industry has been and continues to be defined by low domestic dairy productivity due to constraints, and high import dependence (Ibrahim et al., 1999). ${ }^{15}$ Issues faced by smallholder dairy farmers include: poor farmer knowledge and practices; limited access to markets; low productivity; low farmgate price of milk; high cost of milk production; poor extensions services for animal health; inadequate milk processing facilities; inadequate

\footnotetext{
${ }^{15}$ Many elements of this report remain relevant (Key informant, personal communication, 2018).
} 
technologies and distribution network; and lack of consumer knowledge about the role of dairy in nutrition (Ibrahim et al., 1999; Ranaweera, n.d.; Vairamuthu et al., 2010; Wijethilaka, 2018). Contextually-appropriate responses that target these issues, through NZAP dairy development initiatives in Sri Lanka, can very likely contribute to potential solutions to global development priorities identified in this chapter, such as food security and inclusive economic livelihoods.

\subsubsection{Partnerships and changing roles of development actors: Private sector and NGOs}

The roles of 'traditional' development actors such as NGOs are evolving as aid agencies recognise that collaborative approaches to development funding can maximise limited aid resources and increasingly seek the private sector as a development partner (McEwan et al., 2017). ${ }^{16}$ In part, private sector engagement is promoted by fiscal austerity measures placed on aid budgets that have an increasing emphasis on 'value for money' and 'cost-effectiveness' (Kindornay \& RileyKing, 2013). ${ }^{17}$ The Busan High Level Forum in 2011 reflected the waning interest in development with the reconstruction of 'aid' as a new era of 'development effectiveness', which can be seen as pivotal in the elevation of the private sector in aid (Mawdsley et al., 2014). ${ }^{18}$ Another reason for this shift towards private sector engagement is the changing nature of aid. The provision of technical assistance, for which private companies can possess superior expertise and resources, has increased in aid work (Doing good, doing well, 2017). Private sector engagement in development, therefore, is increasing both individually and collaboratively, and in both aid and non-aid terms.

Cowen and Shenton's (1996) influential categorisation of development as both immanent, meaning development as something that occurs as an outcome of capitalism, and intentional, meaning development that is deliberately done as a form of intervention, provides a

\footnotetext{
${ }^{16}$ Private sector is defined here as non-government, for-profit enterprises (Whitfield, 2007).

NGOs are defined here as usually non-profit, socially responsive, private enterprises. NGOs mostly provide services and rarely produce goods, although they often behave like, and are perceived as, part of the private sector. For instance, a private company, Yugashakthi, has been established by the NGOs in the Wanni Dairy Project to manage the dairy farm operations because NGOs are unable to own assets in Sri Lanka.

17 The 2008 GFC led to many donors cutting their aid budgets.

${ }^{18}$ Development effectiveness implies a less restrictive definition of ODA; development finance is conceptualised in various forms and it also recognises the broader involvement of development partners.
} 
basis for differentiating private sector engagement in aid agendas and trade activities. Here, I am considering private sector partnerships - notably Fonterra - in intentional development, the context for which is also situated within Fonterra's immanent development in Sri Lanka. Fonterra's direct (implementation) and indirect (policy influence and business activities) involvement in NZAP's development projects is consequential. Fonterra has an interest in all of New Zealand's dairy investment activities. It has been argued that the private sector - as corporate actors and especially as development partners - should consider the consequences of their activities more than they may have done previously, and implement measures to reconcile respect for the environment, social equity and financial profitability to contribute to ethical, sustainable and responsible business practices (Aggarwal \& Huelin, 2009; McEwan et al., 2017; Scheyvens et al., 2016).

There is wide recognition that private sector engagement in donor communities is vital for development agendas to strengthen economic growth and prosperity and reduce poverty (Nelson, 2011). Substantial critical commentary, however, highlights the contradictory role of private sector-led development (McEwan et al., 2017). Private sector actors played a crucial role in pushing for the shift in the aid narrative as it enables them to impose business values - such as the right to make a profit and the right to exploit land and resources - to capitalise on the real and perceived challenges and opportunities presented by growing economies in developing countries that are increasingly acting as major sources of investment, competitors for market share and important trade partners (Mawdsley et al., 2018; McEwan et al., 2017). The literature increasingly reflects concerns about the centrality of economic growth, power relations and the implications for representation and participation, as private sector becomes a central figure in development agendas (Mawdsley et al., 2018; McEwan et al., 2017; Scheyvens et al., 2016).

It is acknowledged that NGOs hold an important role in the provision of services and relief to the vulnerable and needy and that there are limitations on the abilities of corporations to adequately address implementation aspects in some contexts (such as community participation) (Desai, 2014; McEwan et al., 2017). NGOs face difficulties as the link between local and global agendas in development (Desai, 2014). Challenges in reconciling the differences between local needs and realities and the competitive, donor-driven funding environment that pressures NGOs to align strategies and policies with donor interests can result in accountability tensions (Banks 
\& Hulme, 2012). For example, the relationship between NGOs and the NZAP has been eroded since 2008 with fewer resources being allocated and a shift in the working relationship (Zweifel \& Hill, 2015). TFNZ and WCDO are funded through MFAT's Partnerships Fund and thus their activities are inherently aligned with MFAT, and thereby Fonterra's, priorities for dairy development. Despite the perception of NGOs as independent, external determination of local agendas occurs and NGO accountability is skewed towards donors rather than local communities (Ibid.). However, NGOs still have agendas and strategies that are distinct from those of partners.

\subsection{Gaps in the literature}

There are five key gaps in the literature identified in this chapter and addressed in this research.

First, participants' perspectives of the health impacts of dairy (and wider social impacts of the project) can improve our understanding of the impacts of increasing dairy production and consumption on people. It is beyond the scope of this research to determine health outcomes, but this research explores farmers' beliefs about dairy consumption - as fresh milk, in its diverse processed forms, and for its broader health repercussions on populations who traditionally consume low amounts of dairy but are experiencing a cultural dietary shift through Westernisation (and globalisation).

Second, this research explores the extent to which environmental considerations are important to local dairy farmers and if and how environmental factors are perceived to be changing due to the Wanni Dairy Project. This research explores the potential opportunities and challenges for environmental sustainability raised by farmers that affect their livelihoods. Both social and environmental aspects of sustainable livelihoods have links to economic factors, and thus construct a holistic understanding of farmers' livelihoods.

Third, this research contributes gendered knowledge on the livelihoods of women involved in the Wanni Dairy Project, which addresses the gap in gendered data on both dairy development and development more widely, and recognises the cross-cutting issue of gender equality that is targeted in the Wanni Dairy Project.

Fourth, there are few studies that employ qualitative methodologies to understand livelihood factors of dairy development. The predominance of quantitative data (with an economic focus) to assess livelihood impacts highlights the need for in-depth subjective data that 
reflects farmer perspectives. As farmers tend to have low voice and influence, qualitative data can elevate their understandings of sustainable livelihoods and the holistic impacts of dairy development initiatives. Currently, there is no micro-level, qualitative research that I am aware of on New Zealand dairy development initiatives.

Finally, this research adds to development literature on the shifting aid regime that is characterised by, among other things, increasing private sector engagement in aid. The research explores the different roles of partners in development and the links between macro- (policy and institutional) and micro- (farmer and household) levels.

\subsection{Summary}

This chapter has addressed the global context of dairying and sustainable development, and the specific factors that are relevant for New Zealand aid and dairy development in Sri Lanka in this research. The chapter first discussed the literature on dairy farming and sustainable development. In doing so, it addressed small-scale versus large-scale farming and the relevance of sustainable livelihoods approaches, and dairy development and the SDGs. It then discussed the holistic impacts of dairy development, including environmental challenges of livestock and dairy farming, the potential for dairy development to address food security and economic opportunities, health impacts, and the role of gender in dairying. Next, the chapter addressed the literature on New Zealand's role as a major actor in global dairy development. It described dairy in New Zealand and commitments to sustainable dairying practice in the global context, reasons for New Zealand's engagement in dairy development, the potential for dairy development to address development priorities in Sri Lanka, and the changing roles of private sector and NGO development actors. Finally, it identified five key gaps in the literature that this research aims to address.

The literature on the environmental challenges of dairy production highlight important questions for NZAP dairy development: What consideration is given to whether the scale of production is likely to increase as an outcome of successful dairy development, and how would the negative environmental impacts be managed of an increase in medium-scale farms? The environmental struggles of medium- and large-scale dairying, already faced in New Zealand and other countries, are likely to be harder to mitigate and regulate in dairy development contexts 
where there are governance issues, and may prove to be problematic for sustainable livelihood outcomes. By increasing reliance on dairy as a livelihood activity, what implications could there be for private sector and governments' commitments to GHG reductions and other global development goals?

Literature also identifies diverse views on the health impacts of dairy consumption. While the potentially positive impacts predominate NZAP discourse, issues that affect Sri Lanka (and elsewhere) include concerns over the negative health impacts of dietary shift on the population and the diversity of nutritional profiles of dairy products being marketed as healthy to consumers. These implications for understandings of health impacts of dairy development and the consumption it promotes raise questions: What are the potential tensions between the positive nutrition narrative and the focus on processing? In other words, how healthful are the products being produced and if steps are being taken to educate people on the health benefits of dairy, then what steps are being taken to educate people on the potential health risks, especially if 'dairy' is represented as a homogenous category? The role of dairy companies in shaping attitudes to health to promote increased consumption and therefore support expansion should also be considered in light of the alternative views towards the role of dairy in diets. To what extent is the Government of Sri Lanka representative of its people's views on a national dietary shift that some scholars argue is negatively impacting health?

In sum, dairy development initiatives aim to deliver inclusive economic outcomes that align with the SDGs and sectoral commitments, however, the implications of dairy development are complex. A review of the literature showed that while New Zealand's involvement in dairy development initiatives in Sri Lanka has the potential to contribute to a number of SDGs, effective development policy and practice that meets the needs of the community and is based on a sound understanding of multiple factors of sustainable development, including social and environmental impacts, can be enhanced by an analysis of the local perspective. Academic analysis of holistic factors of dairy development should be welcomed because a full understanding of development impacts is integral to the alignment of dairy development and sustainable development, upon which livelihoods depend. 


\section{Chapter 3 : An integrated sustainable livelihoods approach}

\subsection{Introduction}

A sustainable livelihoods approach connects the concepts of sustainability and livelihood to people in practice. The framework and principles of a sustainable livelihoods approach acknowledge the complexity of poverty and that any intervention must be based upon an appreciation of the multiple factors that underpin livelihoods, including access to natural, human, social, financial and physical assets. This chapter brings into focus the theoretical basis of a sustainable livelihoods approach, defines it in relation to this research, and introduces a sustainable livelihoods framework. It then integrates the sustainable livelihoods approach with a gender lens to recognise the importance of gender dynamics in rural livelihoods analysis.

\subsection{A Sustainable Livelihoods Approach}

\subsubsection{Terms and definitions}

In the livelihood context, sustainability means the ability to maintain and improve livelihoods while maintaining or improving assets (such as the ecological environment) and capabilities (such as skills and access), ${ }^{1}$ upon which livelihoods depend (Chambers \& Conway, 1992). Sustainability implies resilience and longevity in the complex circumstances that influence our world including economic, social and environmental factors. Diagrams (figure 3.1.) have been used to illustrate the interdependence of these factors to uphold sustainability. ${ }^{2}$ Like the different representations of sustainability in these diagrams and others, the application of sustainability in practice is subject to interpretation.

\footnotetext{
${ }^{1}$ Capabilities refers to people's ability to realise their entitlements or potential, such as being adaptable, recovering from shocks, and exploring and maximising livelihood opportunities (Chambers \& Conway, 1992; Sen, 1984).

${ }^{2}$ These diagrams depict one of the best known but also most simplistic understandings of sustainability. They have been contested and redrawn in various ways but for this research, I focus on the interrelation of these three elements.
} 

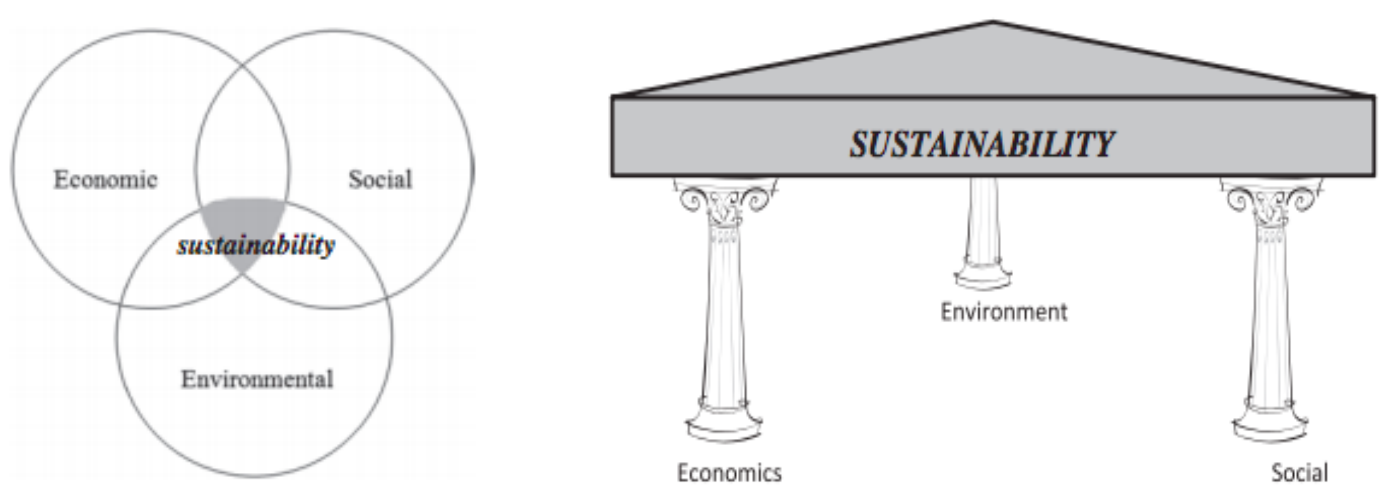

Figure 3.1. Illustrations of the factors of sustainability.

The SDGs (figure 3.2.) are the central paradigm through which sustainability is imagined at the global level, and are used to guide development strategies until 2030. They include complex, interconnected goals that emphasise poverty alleviation, climate change and disaster risk, peace and justice, economic inequality and sustainable consumption.
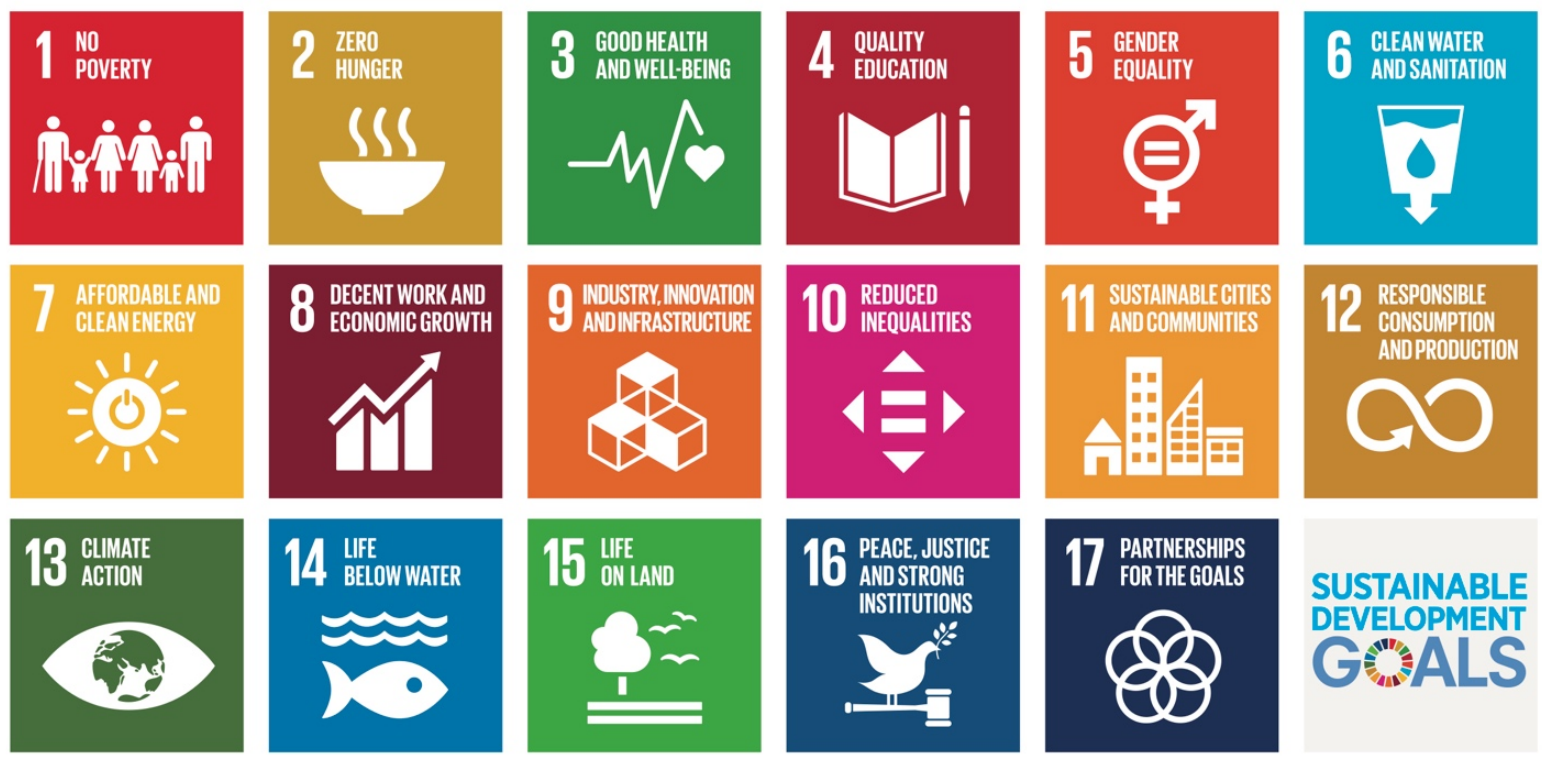

SUSTAINABLE DEVELOPMENT GALS

Figure 3.2. The SDGs.

Source: UN, 2016.

The concept of sustainable livelihoods became established in the 1980s as greater understandings emerged about the complexity of poverty. Although the term 'sustainable livelihoods' is used widely in development literature, there is variation in the meaning attributed 
to it. The most commonly adopted definition of sustainable livelihood is Scoones' (1998) modification of Chambers and Conway's (1992) definition:

A livelihood comprises the capabilities, assets (including both material and social resources) and activities required for a means of living. A livelihood is sustainable when it can cope with and recover from stresses and shocks, maintain or enhance its capabilities and assets, while not undermining the natural resource base.

This definition emphasises both the social and environmental aspects of sustainability. A livelihood is environmentally sustainable when it maintains or enhances the local or global assets, and a livelihood is socially sustainable when it can overcome stress and shocks.

Poverty can be viewed as a lack of capabilities and resources (assets and access) to acquire livelihood. Livelihoods are thus centred on the different assets, or capitals, available to individuals, households or the community. Five principal types of livelihood assets - natural, human, financial, physical and social - are depicted as a pentagon (figure 3.3.) to illustrate the dependency of livelihoods on a combination of interconnected assets (Carney, 1998). ${ }^{3}$

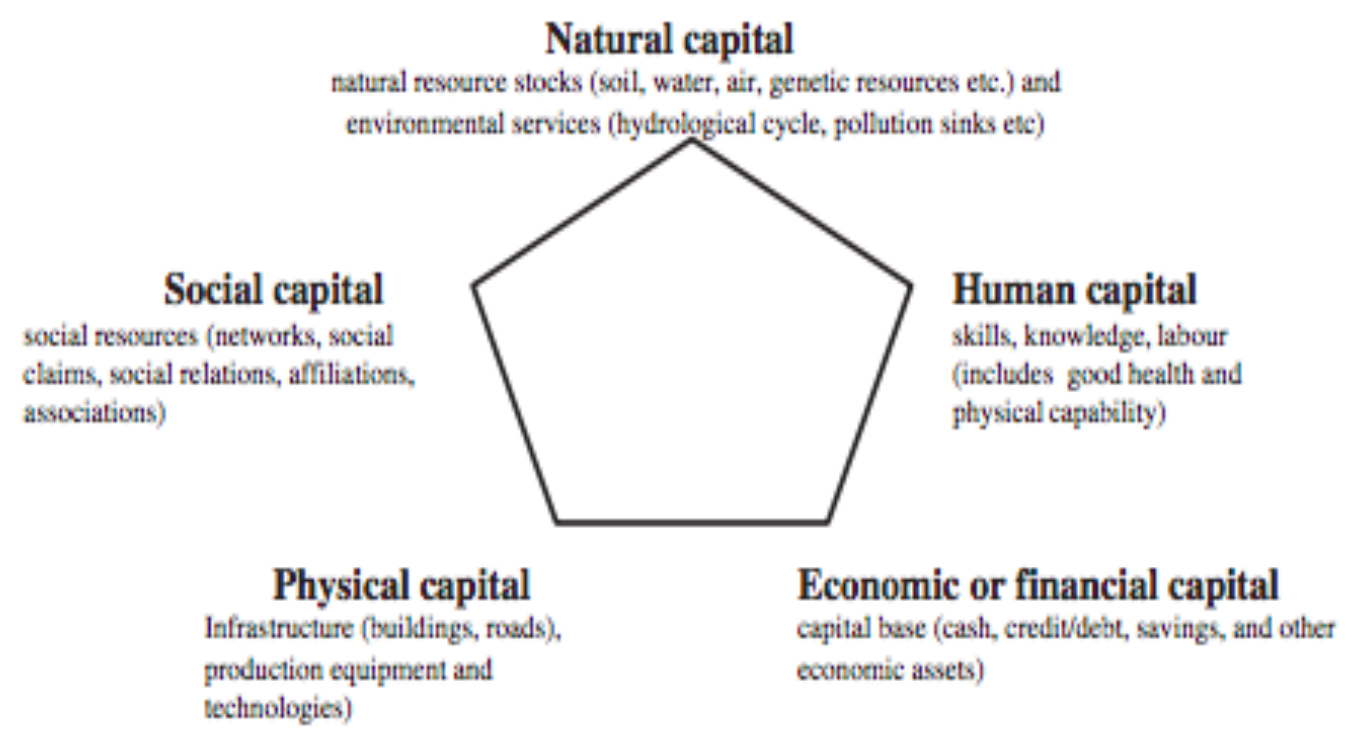

Figure 3.3. Livelihood Assets.

Source: Morse \& McNamara, 2013: 28 (adapted from Scoones, 1998).

\footnotetext{
${ }^{3}$ Assets are both tangible such as physical resources, and intangible such as access and capabilities.
} 
The opposite of poverty, or 'ill-being', is wellbeing (Chambers, 1995). Livelihood security, then, is dependent on wellbeing. Despite the influential and changing theory, rhetoric and practice that surrounds poverty and poverty alleviation, the economic view still dominates much development practice (Mawdsley et al., 2018; McEwan et al., 2017). A sustainable livelihoods approach refocuses attention on the multidimensional factors that can improve wellbeing and reduce poverty.

\subsubsection{Principles and frameworks}

The principles and frameworks of a sustainable livelihoods approach intend to not only understand the complexities of poverty but also to help guide development interventions to overcome it. Although the framework is a flexible approach that has been implemented in a number of ways, the basic principles are constant. These are:

- People-centred; people are actively involved in the analysis of their livelihoods;

- Holistic; varied actors and factors are involved in securing livelihoods;

- Dynamic; livelihoods and their influences are dynamic in nature;

- Enhances strengths; a focus on strengths supports existing livelihood strategies;

- Promotes macro-micro links; policies and institutions are informed by local insights;

- Encourages partnerships; supports public and private sectors relationships; and

- Prioritises sustainability; aims to ensure lasting poverty reduction.

(Carney, 2002: 14; Morse \& McNamara, 2013)

The implementation of these principles in practice is assisted by a sustainable livelihoods framework that acts as an analytical tool that sets out the factors of sustainable livelihoods and the relationships between these factors. A number of different frameworks exist (Morse \& McNamara, 2013: 42). This thesis refers to the framework in figure 3.4., which is specific to rural livelihoods, indicates that the components are linked both ways (linkages are depicted as twoway arrows), and emphasises both micro- and macro-levels. It is, therefore, well-suited to the aims and context of this research. 


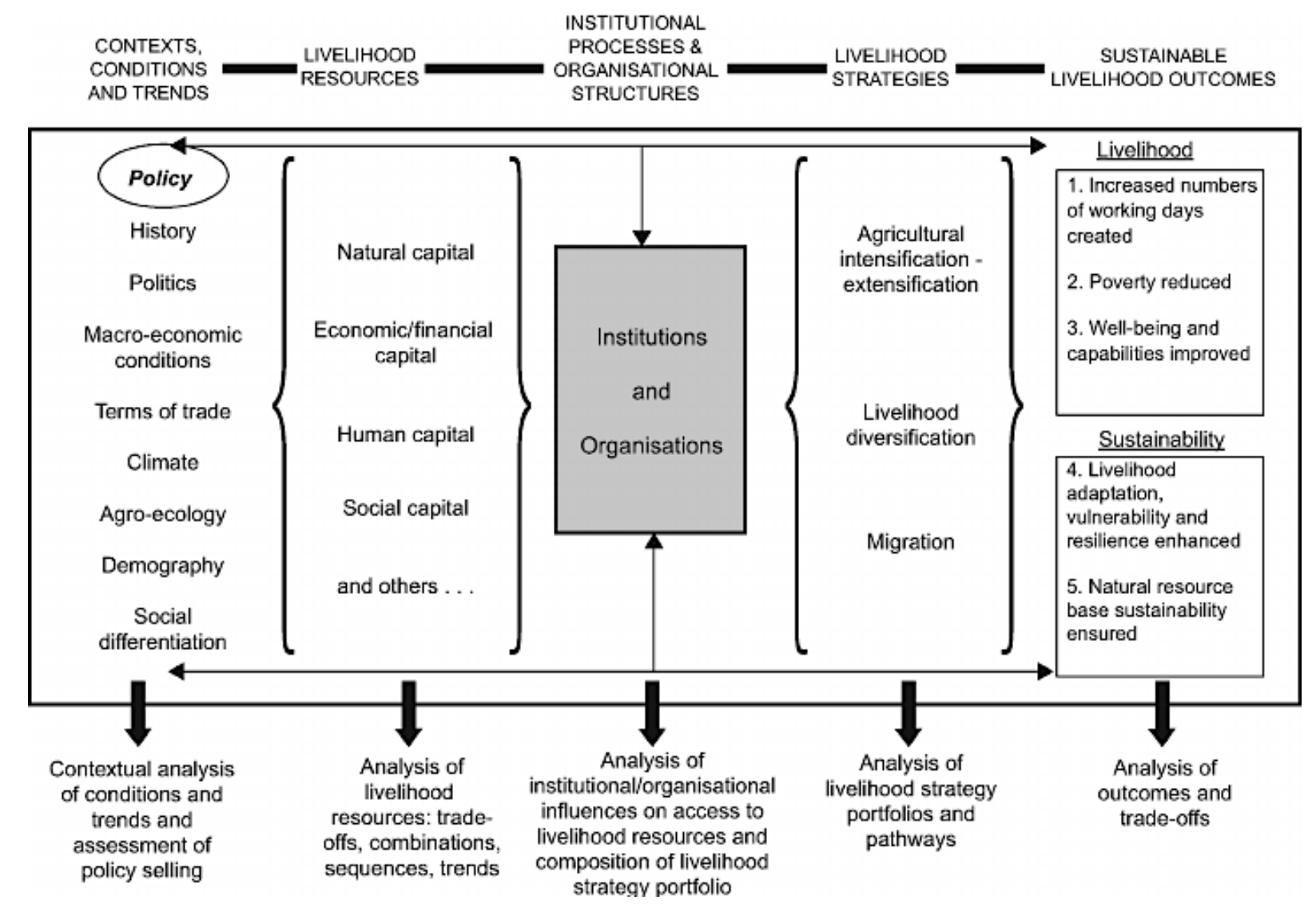

Figure 3.4. The Sustainable Livelihoods Framework.

Source: Scoones, 1998: 4.

The framework seeks to determine, based on a particular context (e.g., post-conflict rural smallholder dairying in Sri Lanka), what combination of livelihood resources (e.g., access, land, animals, etc.) result in the ability to follow what combination of livelihood strategies (e.g., agricultural intensification and extensification, livelihood diversification) with what outcomes (which can be both tangible such as money and intangible such as status) (Scoones, 1998). The framework suggests a way to organise aspects of context into manageable categories. Notwithstanding the difficulty in capturing the dynamic nature of livelihoods, the framework encourages thinking about the links between the main components (Ellis, 2000).

\subsubsection{Strategies for a sustainable livelihoods approach}

A sustainable livelihoods approach is flexible and can be used differently depending on context and expertise available for analysis (Morse \& McNamara, 2013). A sustainable livelihoods approach can be a framework for analysis, a set of principles, and a development objective and 
can be applied at the individual, household or community level (Farrington, 2001; Toner \& Franks, 2006). The specification of the application and scale is, therefore, critical. This research focuses on a sustainable livelihoods approach as a framework for analysis at the individual level.

As a framework, the sustainable livelihoods approach can be used in both research and development practice to help researchers and practitioners to understand the complexity of rural livelihoods by identifying and analysing factors involved in them (Scoones, 1998). It, therefore, can be useful for informing institutional stakeholders because it focuses on the micro-level and on understanding the interactions between the micro- and macro-level (Carney, 1998; Scoones, 1998).

Certain elements of the framework can be analysed without employing the entire framework. Indeed, a major concern is that the complexity of the framework can be difficult to implement and can ignore important issues, such as gender, culture, ethnicity and religion, among other factors (Carney, 1998; 2002; Ellis, 2000; Overton et al., 1999). Other concerns include the risk of oversimplifying complex livelihoods, the relationships between factors, and the relative importance of different contributing aspects. Nevertheless, the sustainable livelihoods approach has been widely accepted by governments and development organisations as it provides a holistic understanding that can help to understand the impacts of interventions, it is focused on people's perceptions, and it is based on participation. ${ }^{4}$

In this research, the principles of a sustainable livelihoods approach and aspects of the framework were drawn on to shape the research design and practice. My research questions were formulated to encourage responses that would provide information relevant for an analysis using the framework, and, overall the principles acted as a touchstone in the research process. I chose methods that were partially participatory, which are detailed in Chapter Four of this thesis. Rather than focusing on household assets to determine alternative livelihood strategies, this research is focused on the livelihood strategy of dairying in the category of agricultural intensification-extensification (figure 3.5.). The main focus is on constructing an understanding of the institutional/organisational influences, participants' perspectives of the influence of the

\footnotetext{
${ }^{4}$ Engaging in sustainable livelihoods research is reliant on participation, but the extent to which the research employs techniques of participatory methodologies like PAR (participatory action research) and PRA (participatory rural appraisal) varies. It is important to clearly define the application of the approach in practice.
} 
project, and their perceptions of the subsequent outcomes. Further, I attempt to alleviate some of the ignored issues identified above by incorporating a gender focus in this thesis, and by analysing cultural factors, ethnicity and religion within the discussion on social factors (which additionally are argued to be overlooked in sustainable livelihoods approaches in Sri Lanka) (Daskon \& Binns, 2009).

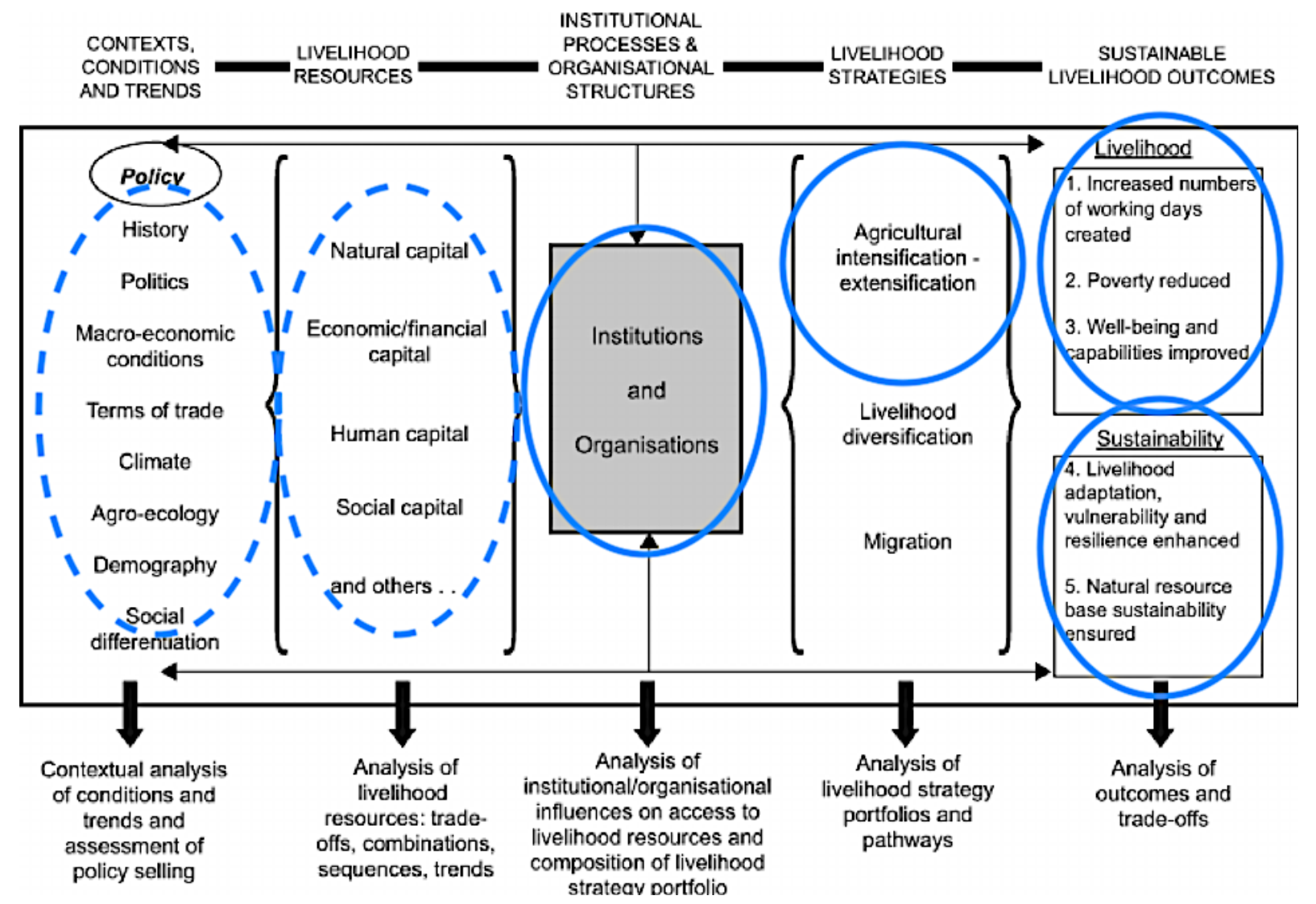

Figure 3.5. Important aspects of a sustainable livelihoods framework in this research.

Adapted by the author from Scoones, 1998.

The thick lines in figure 3.5. depict the key foci in this research, and the dotted line indicates areas that were less developed. Despite the linear depiction of the framework, these livelihood outcomes, in turn, affect the context and resources for future livelihood strategies. 


\subsection{Integrating a sustainable livelihoods approach with a gender lens}

Sustainable livelihoods frameworks and most literature on sustainable livelihoods approaches tend to neglect gender relations, ${ }^{5}$ as can be seen from the diagrams above (figure 3.4.; 3.5.), despite the integral and inseparable role of gender in rural livelihoods (Ellis, 2000). Inequalities perpetuated by socially constructed gender roles are usually characterised by unequal access to household and societal resources (Ibid.). An integrated gender and sustainable livelihoods approach in this research, therefore, recognises that development projects must be tailored to women's needs to address gender inequalities and promote sustainable livelihoods for all. Further, it intends to challenge the privilege given to knowledge and representations that suppress women's views and use men's views to generalise public knowledge.

The conceptual approach to this research, therefore, integrates the Gender and Development (GAD) approach, which emerged in the 1980s, with the sustainable livelihoods approach and framework identified in the previous section. With its theoretical roots in feminism, the GAD approach questions the social construction of gender and the assignment of specific roles and expectations for women and men (Rathgeber, 1990). The approach is holistic; links production, reproduction and all aspects of women's lives; emphasises equity; recognises the need to engage everyone in supporting gender equality; examines the underlying assumptions about economic, social and political structures; and considers the connections and tensions between gender, class, race and development. A range of terms aim to describe the issues and possibilities for change faced by women, such as empowerment, ${ }^{6}$ participation, voice, agency, and rights (Cornwall, 2003; Kabeer, 1999). Women are seen as actors of, rather than passive recipients in, development (Kabeer, 1999).

Commitment to strengthening women's rights and feminism is not always mutually agreed between 'developing' and 'developed' countries. The application of Western feminist analyses to the experiences of women is problematic; it is often top-down in practice, Eurocentric, and depicts the non-European world as politically and culturally backward (Kishwar,

\footnotetext{
${ }^{5}$ Gender relations are "the social construction of roles and relationships between men and women [...] that are usually unequal" (Ellis, 2000: 139).

${ }^{6}$ Empowerment can be seen as "the process of challenging existing power relations and of gaining greater control over the sources of power" (Batliwala, 1994: 130) but can also be seen as power within, rather than power over resources, institutions and decision-making (Kabeer, 1994).
} 
2014). However, it has been argued that gender equality cannot be achieved unless women can challenge both patriarchy and global inequality (Moser, 1993).

Women's experiences of inequality differ widely. Intersectionality, that is, "the need to account for multiple grounds of identity when considering how the social world is constructed" (Crenshaw, 1991: 1245) acknowledges that approaches that seek to represent participants' perspectives need to be sensitive to the complexity of issues of difference. It is important to recognise that "one is never just a woman, but is always a woman from somewhere who may belong to or identify with particular social, cultural, and/or political groups" (Hyndman \& de Alwis, 2004: 540). This integrated sustainable livelihoods approach recognises these important gender factors.

\subsection{Summary}

This chapter has outlined the theoretical position - which integrates a sustainable livelihoods approach with a GAD approach - upon which this research is based and indicated the extent to which it is employed in the research approach and analysis. The first part of this chapter clarified the sustainable livelihoods approach and identified the framework used in this research, which focuses on the analysis of agricultural intensification-extensification as a livelihood strategy and its connections between the organisational and institutional structures of Wanni Dairy Project and livelihood outcomes. The latter part of this chapter integrated a sustainable livelihoods approach with a GAD approach. Ultimately, through taking a people-centred, gender-sensitive, feminist theoretical approach, that is aware of intersectional nuances, this research seeks to bring to the forefront a holistic understanding of sustainable livelihoods and the integral role that gender relations play in the livelihood experiences of participants of the Wanni Dairy Project. 


\section{Chapter 4 : Methodology}

\subsection{Introduction}

Formative travel experiences catalysed my interest in inequality and development. The diverse places and people with whom I connected, as a female Pākehā New Zealander, ${ }^{1}$ impressed upon me the deep injustice of global inequalities, and at the same time, the richness in human connection. The impact of the humanity I experienced has endured. My experiences as a mother have amplified my motivation to engage in development issues. I felt that a critical understanding of the issues that contribute to inequalities was necessary to better understand privilege and to harness meaningful and intentional social impact through my choices.

The focus of this thesis on dairy development was determined by the intersection of interests in sustainability and social equality, constructions of national identity (dairying and New Zealand, for example), and the often polarised attitudes towards development interventions, national development commitments and, indeed, dairy, fostered through my postgraduate learning. I wanted to learn more about the overseas impacts of New Zealand aid.

This chapter establishes the methodology for this research and explains how the purpose of the research - to understand the local perspectives on the Wanni Dairy Project and its impacts - was implemented in practice. First, the chapter outlines positionality and a constructivist epistemology. This lays the foundation for the interpretivist-critical conceptual frame, which is congruent with the integrated sustainable livelihoods approach in the previous chapter. It then describes the methodology for a qualitative case study and identifies the methods used to collect data. The chapter recounts the logistical and practical elements of research practice and provides a brief reflection. Finally, and importantly, it summarises ethical considerations.

My aspiration is for this research to inform those with relative power, and to represent the voices of those without it. In attempting to do so, I acknowledge the ethical and political complexities and contradictions in trying to 'give voice' to others from a privileged position, my own power as an educated Western woman and note my status as an 'outsider' in the community in which my research is focused (Sultana, 2007).

\footnotetext{
${ }^{1}$ Pākehā is a Māori-language term that usually refers to fair-skinned, non-Māori New Zealanders (Lenihan, 2016).
} 


\subsection{Positionality}

Outsider status, like insider status, has strengths and weaknesses for field research. It is unhelpful to consider outsider-insider notions as static, however, as cross-cultural researchers can be both or neither in certain contexts. Positionality is temporal and dynamic (Ibid.). The binary representation of the two terms is problematic as cross-cultural researchers "may connect with something that one participant sees as a significant part of their social or cultural identity, but may not be able to connect with another aspect of a participant's identity" (Skelton, 2009: 399). Multifarious aspects of identity influence interpretations of (non-)belonging and (dis)connection.

The presence of my family in Sri Lanka while I was carrying out field research enabled a deeper construction of my personal identity, rather than one that was limited to a researcher (Scheyvens \& Storey, 2003). As a woman and a mother conducting research with other women who, too, were mothers, I perceived that this commonality created rapport with the primary participants of my research, despite the language barrier. Nevertheless, as a foreigner, particularly in a region where locals have had little exposure to foreigners, I was firmly situated as an outsider, and this, as expected, challenged my data collection at times. Some people were eager to share their experiences and knowledge, and later, ask questions about mine, while others were more reserved about sharing their viewpoints.

Issues of power and privilege create an ethical dilemma and a 'crisis of legitimacy' for Western researchers undertaking cross-cultural research (Scheyvens \& Storey, 2003; Skelton, 2009). Power dynamics are inevitable; the researcher is responsible for representing the participants and thus must produce knowledge with acute sensitivity (Scheyvens \& Storey, 2003; Skelton, 2009). The assumption that cross-cultural research is necessarily exploitative, however, implies that participants have no agency over information or their engagement with researchers. Further, an excessive focus on the potentially negative impacts of cross-cultural research impedes the value of research to enhance understandings of complex development issues.

These understandings are particularly important when the research is focused on the interactions and influences between countries because these have implications for everyone concerned (Nagar, 2002). Research that adds to the critical understanding of New Zealand as a development actor is important to understand the impact of New Zealand development policy and practice in Sri Lanka. Fear of misrepresentation and inauthenticity has led to a withdrawal of 
Western engagement in research on development issues (Ibid.). Withdrawal from such research, however, recants the responsibility of Western researchers to improve the understanding of global development issues.

\subsection{Epistemology}

Epistemological perspectives are salient in approaches to academic research because ideas about ways of knowing shape the knowledge produced. My epistemological stance is constructivist. Constructivism denotes that knowledge constitutes a subjective view of a constructed reality, contingent on human perspectives and social experiences (Gray, 2014). The constructivist view rejects the positivist argument that reality exists external to the researcher and must be discovered through a rigid process of investigation. Rather, I subscribe to the view that meaning is constructed in different ways by different people and, hence, diverse and contradictory perspectives are both possible and valid.

\subsection{Theoretical framework}

The integrated sustainable livelihoods approach described in Chapter Three of this thesis recognises the centrality of people's perceptions to knowledge creation, which reflects a constructivist and interpretivist approach; and it is aligned with critical inquiry because its intention is to uncover knowledge about perceptions and communicate these to people so that they may act upon them (Kitchin \& Tate, 2000). This approach is inductive, that is, discovery underpins the research paradigm. Although theory shapes the research, the data collected is not intended to prove or disprove theory, rather, it is through its analysis that patterns, relationships or inferences can be drawn.

Critical inquiry furthers the new understandings derived from an interpretivist approach by seeking to guide effective action. Part of the sustainable livelihoods approach and framework is concerned with people's access to resources, and the context (i.e., structural inequalities), which are considered important to critical inquiry, to unpack the complexities of development interventions and their impacts. In addition, the sustainable livelihoods approach seeks to construct a deeper understanding of the holistic factors of sustainable livelihoods and of the micro-macro links that influence them; shape the analysis through a gender-sensitive lens that 
considers broader structures and assumptions; and produce knowledge that can potentially inform development actors. An interpretivist-critical theoretical framework, therefore, is particularly appropriate to adopt with a sustainable livelihood approach.

\subsection{Qualitative methodology}

Qualitative approaches are often useful to answer the research questions posed by peoplecentred research. An appropriate qualitative strategy to address the research questions is the case study (Yin, 2003). This case study on the Wanni Dairy Project seeks 'to explore peoples' experiences and their perspectives of these experiences" (Gray, 2014: 37) and recognises that the researcher and participants can construct contextually specific knowledge to express and analyse subjective accounts (Ibid). Figure 4.1., below, depicts the way that I conceive of the theoretical and methodological elements of research practice as a foundation for this research.

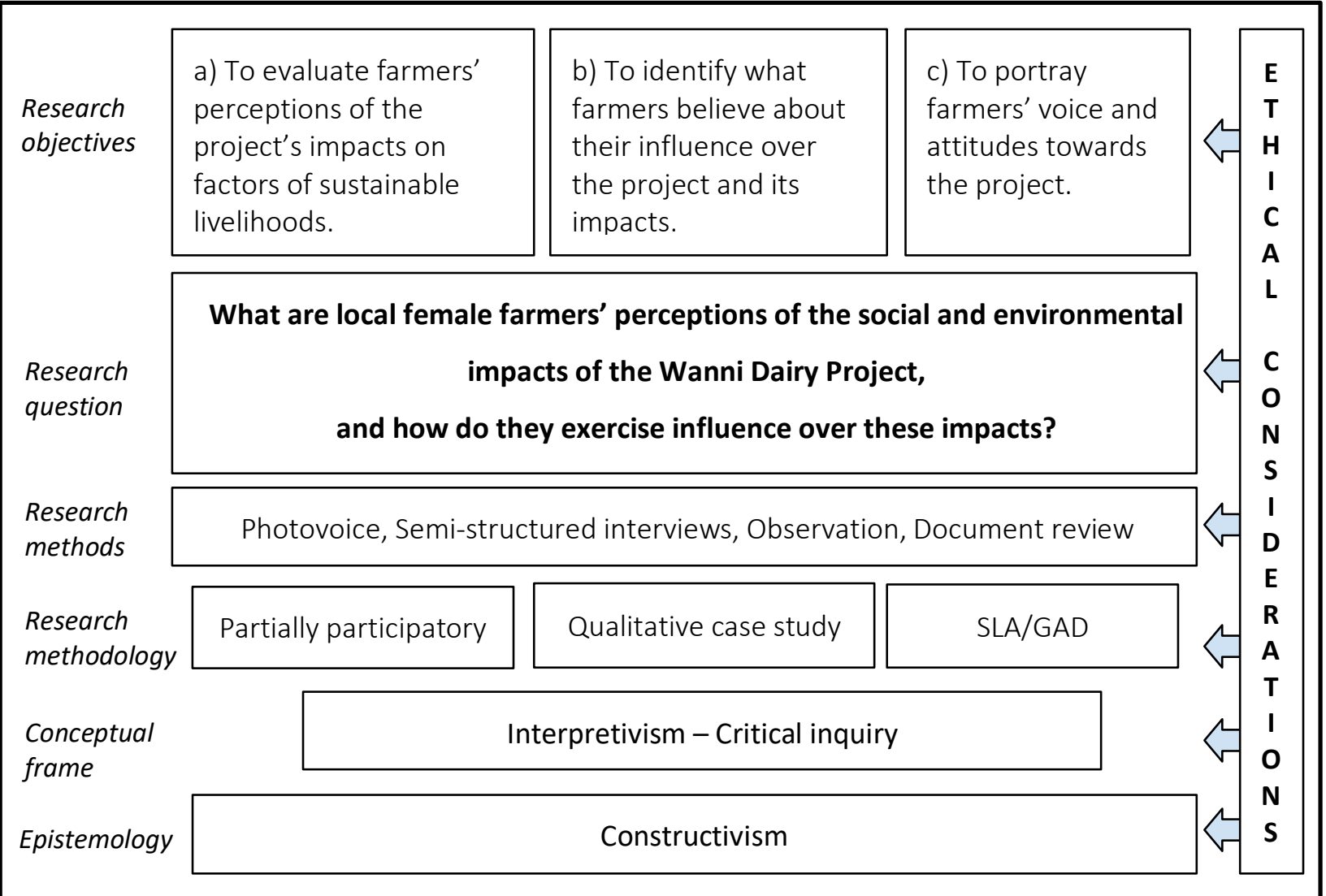

Figure 4.1. Elements of the research design.

Source: author 
The theoretical framework and qualitative approach adopted in this research involves participation. Participation is a term with many different interpretations, as the literature on typologies of participation makes clear. Mikkelson (2005: 53) defines participation as:

The fostering of dialogue between the local people and the project or programme preparation, implementation, monitoring and evaluation staff in order to obtain information on the local context and on social impacts.

Given the time constraints in this research, the participation that is possible is characterised as representative. In practice, this meant that participants understood that the views they shared in interviews would be used to shape a report on the project that would go to the NGOs and to MFAT. The purpose of representative participation is to give people a voice in determining their own development by appealing to the implementing agency to influence the shape of the project (Scheyvens \& Storey, 2003).

Participatory development is differentiated from participation in development as it is a 'ground-up' movement (Kindon, 2010). This research is partially participatory. I attempted to incorporate a participatory technique (photovoice, described in section 4.7.2) to recognise that participatory methodologies - even if only partial - can achieve valuable, 'action-oriented' research (Kesby et al., 2005). ${ }^{2}$ The methods are ethically motivated, scientifically valid, and provide a valuable source of in-depth data on perspectives and experiences, particularly on marginalised groups (Ibid.: 164). I am cautious, however, not to overstate the participatory element of this research as the majority of data collection was achieved through participation as opposed to participatory methodologies. Before progressing to the specific methods used to gather data on the research questions, the following section first turns to the planning of the research practice.

\subsection{Identifying participants, planning and practicalities}

I established support and sought feedback on my research ideas by approaching key people involved in the Wanni Dairy Project within TFNZ, WCDO, MFAT, Massey University and Peradeniya University (Sri Lanka) (see Appendix A). One of the advantages I had in order to

\footnotetext{
${ }^{2}$ Participatory methodologies are "about people's conscious efforts to seek solutions to their own problems in locally appropriate ways", which, in the context of relationships with NGOs and researchers, is closely aligned with advocacy and human rights agendas seeking social wellbeing and economic justice (Kindon, 2010: 519).
} 
successfully establish and maintain this multi-stakeholder engagement was that I received funding from MFAT to carry out this research. This appeared to validate my research objectives to other stakeholders because it indicated that I had proven the merit in this independent research and my competence to carry it out to the aid donor.

I carried out field research over a five-week period in October and November 2018. The key factor that determined my fieldwork timing was the availability of the country director of WCDO, who was the 'gatekeeper' for the participants for my research. ${ }^{3}$ I collected data from two categories of participants; female dairy farmers located in Mullaitivu District who are involved in the Wanni Dairy Project - who I refer to as the primary participants; and other informants who were involved in dairy development in Sri Lanka, including NGO, university and MFAT staff, and local dairy farmers. The country director of WCDO connected me with project staff who facilitated field visits and arranged access to primary participants. The primary participants provided in-depth data for this research and other participants were interviewed to enable a deeper contextual understanding of agricultural development and the project, to build relationships with development stakeholders and provide the opportunity for engagement, and to confirm or access further knowledge sources, such as secondary data.

When I arrived in Mullaitivu, the North-Eastern monsoon was sweeping across the East coast bringing the beginning of the rainy season. The rainy season necessitated flexibility in my research plans, but the advantage of being able to collect data about and experience the realities of monsoon that dictates the lives of farmers in Sri Lanka outweighed any logistical challenge. October is considered the 'lean season' when food security challenges are particularly acute and subsistence farming is more difficult (MFAT, 2016). I learned about the challenges farmers faced before and during the rainy season, and these were influential for farmers' experiences and livelihoods. Also, farmers could accommodate interviews better than in the lead up to rainy season where other farm work was quickly being done before the arrival of the rains.

I spent the first two days in the Mullaitivu District visiting eight farms with WCDO staff to explain my research and confirm participants. I used purposive sampling to identify the primary participants for this research, with support from WCDO. Despite the limitations of relying on WCDO to access participants, as they could then potentially direct me towards farmers of their

\footnotetext{
${ }^{3}$ Access to a community has to be negotiated through various 'gatekeepers' who can control this (Cook, 2005).
} 
choosing, I felt that WCDO was responsive to the needs I identified for selecting participants. I stressed the importance that my research considers a range of participants' experiences including those who had encountered challenges in the project and those who had achieved success.

Information sheets that had been translated into Tamil were given to potential participants and verbally explained in Tamil, giving farmers the opportunity to ask questions (Appendix C). An acquaintance who works with Tamil communities in the humanitarian sector, and a Tamil woman herself, translated the documents, using an appropriate informal language style. I confirmed with WCDO that the translations were suitable.

An interpreter was required for most interviews and all primary participant interviews. I was connected, through a research contact at Peradeniya University, with a student who became my interpreter. The main considerations in selecting an interpreter were that she was Tamil, local and female because of the cultural, political and gender sensitivity of the project. The benefit of selecting a student was that the interpreter was not known in the community but she understood the socio-political context through her own experiences living near Mullaitivu, she had strong English competency, and she had relevant knowledge and an interest in smallholder farming because of her study. I ensured that the interpreter understood the sensitive and confidential nature of my research (Appendix B), and I found her to be very respectful, patient and competent in her engagement with participants, probing further when needed and gently allowing the space for conversations to take shape. The interpreter assisted me for two weeks during the period I had arranged interviews with the primary participants.

Through the interpreter, I emphasised that participation was voluntary and that if farmers did decide to participate they could decline to answer any questions. Of the eight potential participants, I decided that I would not interview one farmer due to the risk of perceived or real harm, another farmer was not home at the time I visited, and one farmer agreed to participate and carried out the photovoice task, but was unexpectedly in hospital on the day I was supposed to interview her. Of the eight potential primary participants, five contributed to my research.

I felt that five primary participants - which was my goal - was an appropriate amount to provide some diversity of experiences, but not so many that it would be challenging to collect indepth data that relied on my capacity to recall details specific to each participant during 
interviews and differentiate between participants' experiences without relying heavily on my notes. The thirteen other informants who contributed to this research provided a suitable range of perspectives with each providing distinct expertise and experience related to the Wanni Dairy Project and dairy development in Sri Lanka.

\subsection{Research methods}

Qualitative methods allow participants to express their opinions and experiences and are effective for fostering information-sharing between researchers and participants to understand interpretations of phenomena (Creswell, 2013; Mikkelsen, 2005). The methods used to collect data for this case study were semi-structured interviews, photovoice, observation, and document review. I held seventeen semi-structured interviews, five of which involved in-depth interviews, photovoice and observation with the primary participants, and the rest of which involved semistructured interviews and observation with various project stakeholders and local dairy farmers. Using a combined approach that draws on interview and photovoice as well as personal reflection and literature enables researchers to gradually interpret the meaning of phenomenon (Creswell, 2013). Table 4.1 shows the details of the case study.

Table 4.1

Participant schedule and data collection methods

\begin{tabular}{|l|l|l|l|l|}
\hline Participants & Role & Methods & Location & Date \\
\hline Participant A & Dairy farmer & $\begin{array}{l}\text { Interview, observation, } \\
\text { photovoice }\end{array}$ & $\begin{array}{l}\text { Suthanthirapuram, } \\
\text { Mullaitivu }\end{array}$ & $\begin{array}{l}15 / 10 / 18, \\
23 / 10 / 18\end{array}$ \\
\hline Participant B & Dairy farmer & $\begin{array}{l}\text { Interview, observation, } \\
\text { photovoice }\end{array}$ & $\begin{array}{l}\text { Suthanthirapuram, } \\
\text { Mullaitivu }\end{array}$ & $\begin{array}{l}15 / 10 / 18, \\
23 / 10 / 18\end{array}$ \\
\hline Participant C & Dairy farmer & Interview, observation, \\
photovoice & Mulliavala, Mullaitivu & $\begin{array}{l}16 / 10 / 18, \\
25 / 10 / 18\end{array}$ \\
\hline Participant D & Dairy farmer & Interview observation, \\
photovoice & $\begin{array}{l}\text { Muthuvinayagapuram, } \\
\text { Mullaitivu }\end{array}$ & $\begin{array}{l}16 / 10 / 18, \\
25 / 10 / 18\end{array}$ \\
\hline Participant E & Dairy farmer & Semi-structured interview, \\
observation, photovoice & Muthuvinayagapuram, & $\begin{array}{l}\text { Mullaitivu } \\
25 / 10 / 18,\end{array}$ \\
\hline Informant 1 & Coordinator, WCDO & Interview & Mullaitivu & \\
\hline
\end{tabular}




\begin{tabular}{|l|l|l|l|l|}
\hline Informant 2 & $\begin{array}{l}\text { Dairy Extension Manager, } \\
\text { WCDO }\end{array}$ & Interview & $\begin{array}{l}\text { Mullaitivu \& } \\
\text { Trincomalee }\end{array}$ & $\begin{array}{l}16 / 10 / 18, \\
24 / 10 / 18\end{array}$ \\
\hline Informant 3 & Field officer, WCDO & Interview & Mullaitivu & $25 / 10 / 18$ \\
\hline Informant 4 & Country director, WCDO & Interview & Nilaveli & $22 / 10 / 18$ \\
\hline Informant 5 & $\begin{array}{l}\text { Academic, Peradeniya } \\
\text { University }\end{array}$ & Interview & Kandy & $5 / 10 / 18$ \\
\hline Informant 6 & Senior Grants Specialist, & Interview & Wellington & $09 / 18$, \\
\hline Informant 7 & $\begin{array}{l}\text { Development Project } \\
\text { Coordinator, NZAP MFAT }\end{array}$ & Interview & Wellington & $02 / 19$ \\
\hline Informant 8 & Development Coordinator, & Discussion, document & Wellington & $03 / 19$ \\
\hline Informant 9 & Academic & sharing & $08 / 18$ \\
\hline Model farmer & Dairy farmer & Interview & Wellington & $07 / 18$, \\
\hline Model farmer & Dairy farmer & Interview, observation & Mullaitivu & $09 / 18$ \\
\hline Farmer & Dairy farmer & Interview, observation & Mullaitivu & $24 / 10 / 18$ \\
\hline Farmer & Dairy farmer & Interview, observation & Nilavelli & $24 / 10 / 18$ \\
\hline
\end{tabular}

The involvement of two female field workers from WCDO in contacting participants was crucial in gaining the trust of participants. When I carried out the interviews, the leading NGO staff were not present, but a female community-based field worker was nearby and available to support the participants if needed. ${ }^{4}$ For instance, when a participant became upset as she shared the difficulties she faced in repaying a loan, it was valuable to seek the field worker's input to ensure that the farmer was appropriately supported and to provide some context. As participants were wary of officials and potential links to the Government of Sri Lanka, the field worker seemed to give my presence greater legitimacy, although I was aware that the peripheral presence of the field worker could influence participants' answers. Participants understood, however, that I was independent of the NGO, and appeared to feel comfortable with articulating candid views.

${ }^{4}$ The field worker would usually be talking to other women in the community who were in the area - outside the house or next door, for example. 


\subsubsection{Semi-structured interviews}

Interviews can provide powerful insights into people's experiences of the world. Semi-structured interviews are a common data collection method in qualitative research as they are both versatile and flexible. They allow for an in-depth discussion on identified important topics, and the exploration of unidentified important topics through follow-up questions based on participant's responses (Crang \& Cook, 2007). The length of interviews ranged from 15 minutes up to an hour, while some interviews were spread across multiple sessions, depending on the role of participants and the topics covered. Interviews with the primary participants took around fortyfive minutes. Appendix D outlines the interview questions.

The five primary interviews, as well as interviews with other farmers, were conducted in participants' homes or on their agricultural land. This was the most practical location, and it provided opportunities for observation and photovoice, and prompted conversation on aspects of their livelihoods. The primary participant interviews were all recorded and transcribed later, and at the end of each day I wrote up thorough notes on my recollections prompted by notes I had made throughout the day as we had travelled between places.

The language barrier was a challenge for data collection and subjected participant's experiences to another layer of interpretation. One of the major benefits of the interviews being held via an interpreter, however, was that it allowed me to formulate more thoughtful responses to questions while participants were speaking (and often participants would also add further detail after the interpreter relayed their answers). This slower rhythm enabled me to explore questions in greater depth than in interviews carried out in English that were often fast-moving.

Interviews with other participants occurred at peoples' workplaces, or public places (a hotel, for example), while some interviews were held while travelling by vehicle. Some of these interviews were able to be held in English. Roughly half were recorded and transcribed, as it was not always practical or appropriate to use the audio recorder due to heavy rain and travel noise that prevented clear recordings, or because the discussions occurred sporadically over the days I spent with the NGO staff. I took written notes during or immediately after these interviews, which were later expanded upon. These interviews, as well as many informal conversations, complemented the rich data constructed through the in-depth interviews with the primary participants involved in the Wanni Dairy Project. 


\subsubsection{Photovoice}

Photovoice is a qualitative method that asks participants to take photos that highlight their experiences to reflect research themes (Aitken \& Craine, 2005). I asked the five primary participants to take photos of things that were important to them on their farms and on a later day we discussed these photos and what they meant during a photo review that formed part of the semi-structured interviews. Thus, photos provided valuable stimuli for in-depth semistructured interviews. Narrative helped to define the imagery and add depth. For ethical and privacy reasons, participants were asked not to take identifiable photos of others. Further, the anonymity of participants' images was a priority; if images contained features that could result in the identification of the participant, I omitted those images from the thesis.

I utilised photovoice so that participants could exercise agency over visual representations of their perspectives, and in doing so, shape the data by stimulating discussion on factors they had determined important. This method intended to give more voice to the participants. I was motivated by the perceived benefit of capturing the perspectives of participants in the final product of knowledge through visual in addition to textual data, to communicate participants' portrayals to the audience, because "what we see is important" (Ibid.: 250). The centrality of imagery to the human experience means that visual data can be a valuable tool to portray particular representations, especially to audiences in Western societies that are increasingly saturated by visual images.

Through shared discussion of images, the subjective interpretation of photos is collaborative. Meaning can be derived by both participant and researcher, creator and viewer. Rose (2001: 20) suggests, however, that "rendering the world in visual terms is never innocent". Visual representations and the narratives that accompany them are inextricably bound to broader social and political structures. I, therefore, undertook the interpretative process with care, to set aside my own preconceptions and scrutinise the factors that shape visual constructions. I first viewed the images when I asked farmers to explain them during interviews (rather than before), I asked farmers to show me where the photos were taken to allow space for them to lead the discussion, and I paid particular attention to the expressions that I perceived the photos to invoke in the farmers. This enabled me to understand that a picture of a cow 
represented, for example, the financial independence of a woman to pay for her children's education, and she was proud of it.

On reflection, while photovoice was participatory, it was problematic. The geographical isolation and disconnection (technologically and socially) of the Northern Province as a result of the war meant that, especially for many women living in poverty in rural villages who faced additional barriers to access, cameras and visual imagery were somewhat unfamiliar. ${ }^{5}$ Contrary to my intention for photovoice to increase the participatory element of my research, at times I felt as though by defining the medium I was imposing my methods upon the participants. I stressed that the photo exercise was voluntary, yet all participants insisted on completing the task although some participants appeared unsure and disengaged. The photo review during the interview, however, was surprisingly more successful with all participants; not necessarily for the data, but for the pride it invoked as participants relayed the significance of their photos.

\subsubsection{Observation}

Observation entails description of and reflection on embodied, subjective experiences and interactions (Cook, 2005). Recording fieldnotes helps to understand lived experiences and often considers emotional responses, frame of mind, and striking details that assist in the construction of descriptive accounts. I kept a field diary during my five weeks in Sri Lanka to record my descriptions and perceptions of the experience; to remind me of topics to address with the participants; and to refresh my memory when I was carrying out the analysis. I found that observation and written reflection on interviews and interactions proved instrumental in shaping the overall picture and analyses because of the language limitations and the unsuitability of using an audio recorder for all interviews.

I was sensitive to the ways that notetaking may be construed during interviews with primary participants, so I wrote brief notes, phrases and words in a journal shortly after these interviews to record key events and information. I then used these notes to construct a more detailed recollection of events and interviews during my daily writing, which enabled me to deepen my understanding of the day's events (O'Leary, 2010). I maintained this daily practice,

\footnotetext{
${ }^{5}$ Northern regions were only connected to the main power grid after the war, and transportation was restricted. Limited exposure to the technological advances of the last 30 years is amplified in rural areas.
} 
even if I was not engaging in specific research activities, and this helped me to become more efficient and effective at recording observations and encouraged a reflexive and reflective mindset. Thorough documentation of conversations and observations significantly enhanced the overall data collection and partially compensated for limitations on the participatory practice I had intended but been unable to fulfil. ${ }^{6}$

\subsubsection{Document review}

I obtained policy documents from MFAT relating to the three dairy projects in Sri Lanka. These documents provided essential information about the projects; they outlined the activity design, frameworks, progress reports, and the supporting policy agreements. TFNZ also provided me with baseline data and reports on phase one of the Wanni Dairy Project. I additionally obtained a stakeholder review report and dairy extension report on the Massey/Peradeniya University veterinary project, and other relevant material pertaining to dairy development in Sri Lanka.

\subsection{Reflections on research practice}

Field research was an integral element of this thesis. The process that this entailed - including not only the time I spent 'collecting data' but also the time I spent facilitating access, building relationships, and becoming informed and prepared for the local context - provided considerable learning along the way. With each person I met, I built a deeper understanding of my research topic and became aware of what aspects of my engagement elicited responses that were useful to answer my research questions, and which were less helpful. I reflected on how beneficial it would have been if I could have returned to earlier participants to talk to them about new information I had discovered. However, experiencing the process of qualitative field research, characterised by my own limitations and the arbitrary actualisation of plans, provided substantial learning. The other major learning I valued was the practical insight I gained by engaging with development actors into the structural and political realities that influence policy and practice in the development sector.

\footnotetext{
${ }^{6}$ I needed to complete the interviews by a certain date to fit in with NGO availability, and the remote, isolated location of participants restricted interaction time. Thus, it was not possible to meet and consult with participants numerous times to enhance the elements of participatory practice as I had intended.
} 


\subsection{Ethics}

This research has been approved by the Human Ethics Committee of Victoria University of Wellington (Appendix E) and throughout the application process, I reviewed and understood all ethical requirements. Attention to ethical considerations is essential in qualitative research to provide protection for both participants and researcher (Sultana, 2007). Although methods often dominate ethical considerations, every aspect of research design should be grounded in ethics, including research goals and questions, and the critical assessment of the conceptual framework. A crucial element of ethical research in a cross-cultural context is the attention paid to positionality, reflexivity and power relations, not only in the research design phase but throughout the research process.

Important ethical considerations for this research included: full disclosure about the research purpose and participants' right to decline participation or withdraw; the anonymity of participants and their photos; the use of photovoice and the creation of reports for development actors (and acknowledgement of the limitations to participation/participatory approaches); and respectful engagement with the community through reflexive and reflective practice. I had an awareness of the potential vulnerability of participants in the Wanni Dairy Project and took care that my presence did not affect their relationships with the NGO or other farmers. I read widely to ensure I was informed about the cultural and political issues I would need to be sensitive to when visiting Sri Lanka and I consulted with New Zealand-based stakeholders who had visited the Wanni Dairy Project to better prepare for the development context.

The research topic, as well as the research context, are politically sensitive. A condition of the funding I received from MFAT was to remain cognisant of the political, trade and media issues that the research topic may raise, and proceed thoughtfully. I instigated numerous meetings with the Wellington-based MFAT staff to discuss my research plans, provided field reports and sought feedback on my findings. I also delivered an oral presentation of my research findings to MFAT and engaged with both MFAT and TFNZ to ensure that my research understandings were accurate. Notwithstanding my commitment to sensitivity, I considered it a priority to maintain an independent, academic approach to uphold the integrity of this research. 


\subsection{Summary}

This chapter described the constructivist and interpretivist-critical foundation upon which my research practice was based. The chapter addressed my positionality as a Western female researcher and outlined the theoretical, logistical and ethical elements of research design and practice. It described how the principles and framework of a sustainable livelihoods approach are an apt fit for these elements of research design and practice. It then discussed the qualitative methodology, the methods - semi-structured interviews, photovoice, observation and document review - used in this case study research, and provided a reflection on my research practice. 


\section{Chapter 5 : Context: Sri Lanka}

\subsection{Introduction}

Army checkpoints intercede long, quiet stretches of road in Northern Sri Lanka. The lush jungle gradually encroaches upon the weathered shells of abandoned homes. Their departed occupants fled or were killed in the brutal civil war that gripped the country for nearly three decades between 1983-2009. Persecuted Tamil and Muslim communities in the North - who were also worst hit by the 2004 tsunami - have suffered intense violence and loss, and efforts to address the war's legacy are needed to ensure livelihoods, wellbeing and continued peace. My friend, a Tamil refugee who has resettled in New Zealand, asked me to visit his family in Sri Lanka. His mother showed me her cows, dog-eared photos of her adult children, and her shrine, where she performed a puja; ${ }^{1}$ his sister cooked Jaffna-crab curry - the local specialty - over red-hot embers; his nieces told me about their dreams to travel; his father asked me simply if he was okay. My friend and his family, like countless others, have endured unimaginable losses and are attempting, with admirable resilience, to rebuild their lives and livelihoods.

Within this challenging post-war context, this research focuses on understanding Tamil female farmers' perspectives of livelihood impacts of dairy development, in the, predominantly Tamil, Mullaitivu District. The NZAP's dairy development is relatively new to Sri Lanka, and it has been adopted in response to the Sri Lankan government's priority to increase domestic dairy production and to improve livelihood opportunities in post-conflict communities. This chapter first justifies the research location and then describes the recent historical and contemporary context in Sri Lanka, covering colonisation, ethno-political tensions, civil war and tsunami, and the economy and agriculture. A timeline outlines key historical events in Sri Lanka that are relevant to this context. It then outlines the bilateral relations between Sri Lanka and New Zealand and describes the development activity that is the focus of this research.

\footnotetext{
${ }^{1}$ Puja is a Hindu prayer ritual.
} 


\subsection{Location and justification}

Sri Lanka is a tropical, densely populated island nation located at the bottom of the Indian subcontinent with a total area of 65,610 square kilometres. The majority of the 21 million people living in Sri Lanka eke their livelihoods from the island's natural resources through tourism, textiles and agricultural production; the environment is host to expansive tea plantations, jungle rainforests of abundant flora, fauna and wildlife, rice paddies, rubber and coconut plantations, rural subsistence farms, mangroves, picturesque coastlines and oceans. Set against the diverse natural landscape, ancient Buddhist and colourful Hindu temples, as well as mosques and churches attest to Sri Lanka's rich cultural heritage and complex history.

Sri Lanka's contemporary political situation is uncertain. The current president, Maithripala Sirisena, was elected on his ambition to implement progressive reforms, however, contradictory policy actions, political resistance and bureaucracy have hindered change (ICG, 2017a: 21). Human rights, corruption, and abuses of power continue to be pressing political issues (ICG, 2017b: 5). Nonetheless, recent years have seen remarkable progress in the wake of huge adversities. Currently, Sri Lanka is reaching an important juncture whereby its government's actions to address disparity and discontent will play an important role in defining its future path (ICG, 2017a: 28).

The dairy development project selected as a case study for this research, the Wanni Dairy Project, originated in what is known as the Wanni region, where the fighting was most intense in the last years of the war. The Wanni region (the area between the blue and purple lines on figure 5.1.) includes four of the five districts that compose the Northern Province. ${ }^{2}$ The Wanni Dairy Project continues to operate in the Mullaitivu and Kilinochchi Districts in phase two. Its recent expansion extends into the Vavuniya District and beyond the Wanni region into North, North Central and Eastern Provinces (indicated above the green line in figure 5.1.). It is thus officially renamed from 'Wanni Dairy Regeneration Activity' (phase one) to 'Dry Zone Smallholder Dairying Expansion Programme', but is still colloquially referred to as the Wanni Dairy Project.

\footnotetext{
${ }^{2}$ These are Mullaitivu, Kilinochchi, Vavuniya and Mannar. Jaffna is the fifth district, indicated above the purple line.
} 


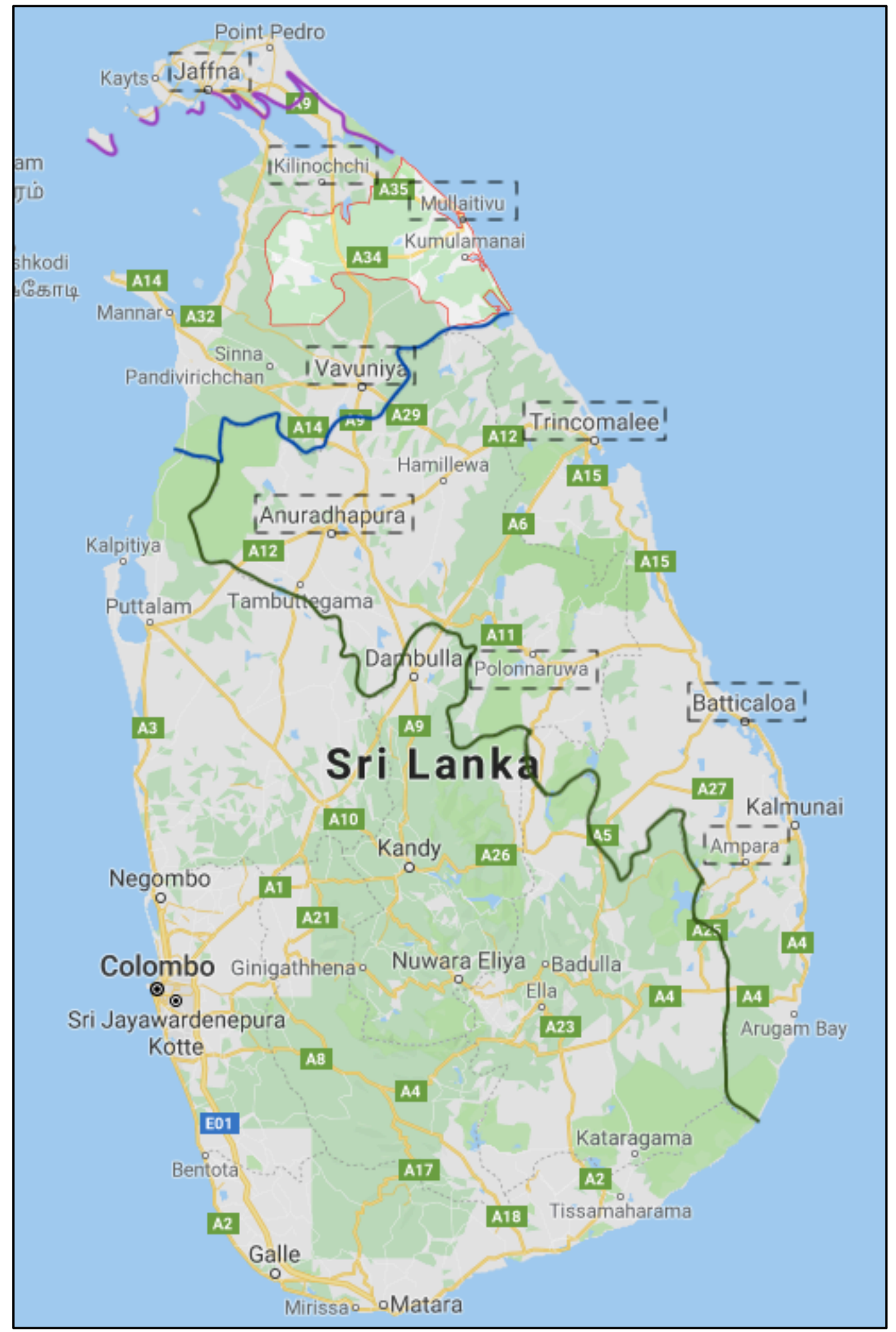

Figure 5.1. Map of Sri Lanka.

Source: Map data (C) 2019 retrieved from Google Maps (22 July 2019) (adapted by author to accentuate regions/provinces) 


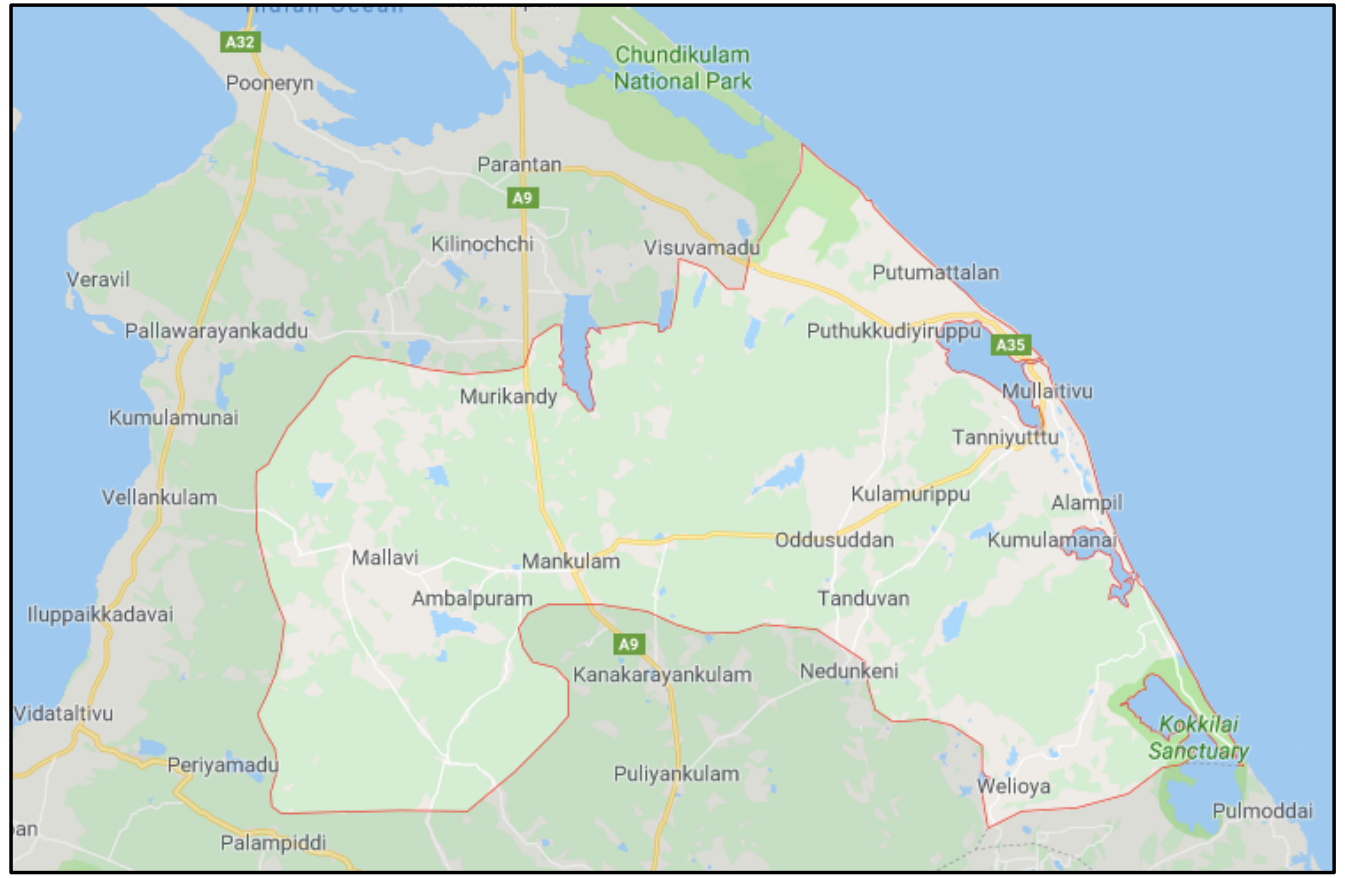

Figure 5.2. Map of Mullaitivu District.

Source: Map data (C) 2019 retrieved from Google Maps (22 July 2019)

The specific location selected for this research on the Wanni Dairy Project is the Mullaitivu District, indicated by the red border and lighter accentuation (figure 5.1.; 5.2.), which is where the project began, offices and a model farm have been established, and a dairy processing plant was under construction in late 2018 (figure 5.3.).

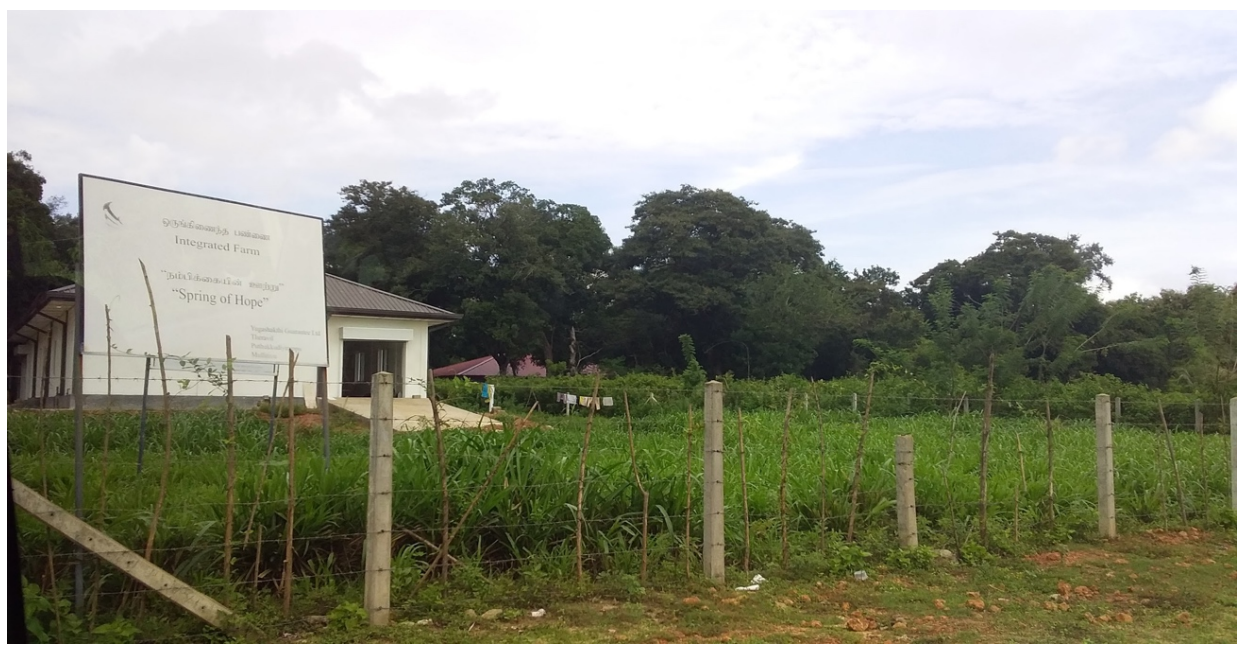

Figure 5.3. Entrance to the model farm, dairy processing plant and project offices. Source: author 
The Mullaitivu District has been intensely affected by war and tsunami. New houses are slowly being built but past violence can be seen in the crumbling, bullet-holed facades of empty homes and in the enduring roadside protests by women demanding information from the government on their missing family members (figure 5.3.). War and tsunami memorials are sombre reminders of the loss and hardship that people have faced. As one participant said, "There is not anyone here who has not experienced trauma" (Mullaitivu local, personal communication, October 2018). Access to Mullaitivu was restricted to foreigners by the Sri Lankan government until 2015, thus, scarce academic research has been done in this area.
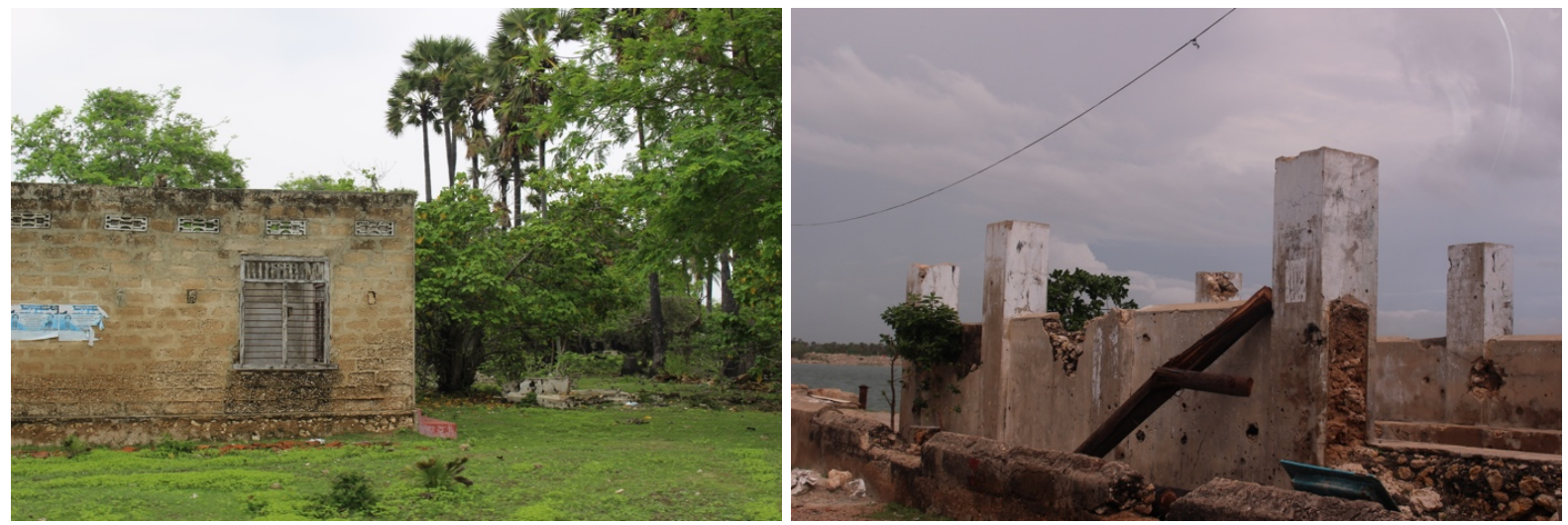

Abandoned, battered houses in the Northern Province

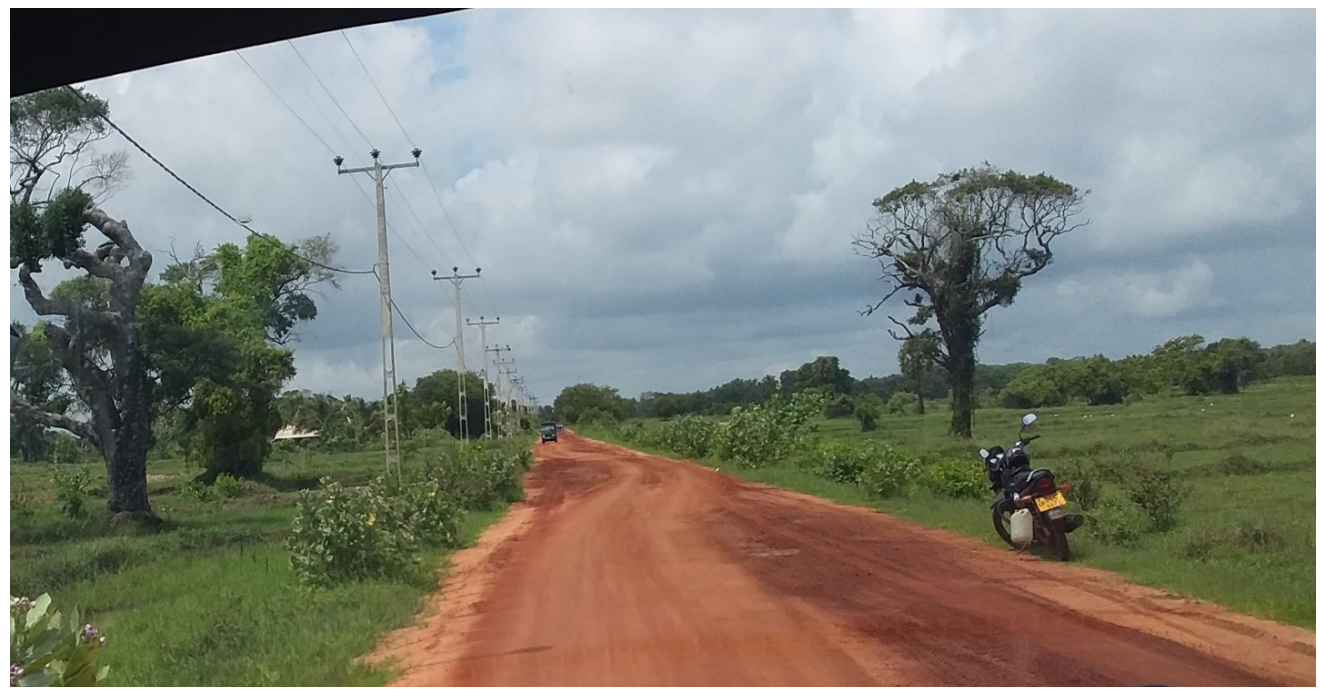

The road into the Mullaitivu District

Figure 5.4. Photos in the Northern Province.

Source: author 
Agriculture and fisheries are the main economic activities in this district. Welfare and the economy in the Mullaitivu District have improved as the country has experienced post-war domestic economic growth and overall encouraging poverty reduction, ${ }^{3}$ yet significant regional disparity persists, and low living standards and severe poverty are a concern in the region. Northern and Eastern regions experienced increases in inequality from 2009/10 to 2012/13, which indicates the disparity of welfare improvements (Newhouse et al., 2016: 21).

\subsection{People}

\subsubsection{Identity, ethnicity and culture}

Sri Lanka's multicultural population comprises three main ethnic groups - Sinhalese, Tamil and Sri Lankan Moors - who are essentially defined by their religious and linguistic distinctions. Sinhalese are mostly Therevada Buddhist, speak Sinhala, and account for around $74.9 \%$ of the population (Department of Census and Statistics, 2012). Sinhalese predominate most of the country except for Northern and Eastern Provinces. Tamil comprise two distinct groups, Sri Lankan Tamil (11.2\%) and Indian Tamil (4.2\%), the former of which are long-settled descendants from South-Eastern India while the latter group is more recent immigrants or descendants of immigrants brought to Sri Lanka under British rule. Both Tamil populations are concentrated predominantly in the North, speak Tamil, and are mostly Hindu. The Moors are Muslims, descendants of Arab traders, usually speak Tamil, and make up 9.2\% of the population. They are scattered throughout the country but have a strong presence in the ethnically mixed Eastern Provinces where there are also sizeable groups of Sinhalese and Tamil people. A small portion of the population, over the whole country and especially in coastal areas, have converted to Christianity. Less than $1 \%$ of the overall population are Burghers (mixed European descent), Parsis (West Indian immigrants) and Veddas (indigenous inhabitants) (Ibid.).

\subsubsection{Gender dynamics}

Issues of gender inequality are significant in the male-dominated context in Sri Lanka (Jayasinghe \& Lakshman, 2011). Competing nationalist discourses and the post-conflict context shape crosscutting relations of gender, ethnicity, national identity, class and geographic location. Gender

\footnotetext{
${ }^{3}$ GDP per capita grew by 5.6\% between 2002 and 2012 (Newhouse et al., 2016: 21).
} 
cannot, therefore, be considered independent from these other factors. For example, the livelihood opportunities for Muslim women in some eastern areas are different to Tamil women as they are expected to work within the confines of their homes, whereas Sinhala women of high caste experience, on average, less vulnerability and more mobility than men from a minority ethnic group (Hyndman \& de Alwis, 2004). Analyses on the role of gender in the construction of national identity highlight the constructs of women in Sri Lanka as reproducers, nurturers, guardians of tradition, culture, community and nation (de Alwis, 1994; Jayawardena, 1993). The expectation that women are primarily mothers and wives is reinforced by these perceptions, as is the regulating of women to retain such reductive identities.

The political mobilisation of women within the conflict and post-conflict contexts points to the multiplicity of identity, however. For example, the participation of Tamil women in combat shows that as well as being victims, women can be perpetrators of violence; and protests led by women - during wartime and presently - have created an important space for women's voices to counter violence and demand justice (Vasudevan, 2013). Post-war situations are a critical period in which women's ongoing (in)security status is determined and tend to show correlations with gender norms that preceded conflict (UN, 2002 cited in Vasudevan, 2013: Chapter 2, paragraph 11). Reconstruction and decision-making processes often marginalise women's needs, which is perpetuated by fewer resources and opportunities for participation, and thus inequalities continue (Jayasinghe \& Lakshman, 2011). However, post-war contexts can also open up new spaces for women to take on unconventional roles and tasks.

There are now a number of female-headed households in Sri Lanka as women, who are widowed or whose husbands are disabled, have been compelled to take on new roles and social engagements as household structures change. These household structures, however, are assumed to be relatively more vulnerable than traditional male-led household structures (Vasudevan, 2013). This sense of vulnerability is exacerbated by the severe emotional and physical trauma that these households have experienced during the war; adverse political, social and economic factors; and that single women have an added burden of responsibility to balance income-generating work and other important household work. Although a number of development interventions in Sri Lanka adopt gender-sensitive approaches, overall, socially constructed gender norms continue to marginalise women (Jayasinghe \& Lakshman, 2011). 


\subsection{Colonisation and post-colonisation}

Colonisation that spanned occupation by Portuguese (1505-1658), Dutch (1640-1796) and British (1796-1948) left its mark on the country. Sri Lanka's independence in 1948 was the straightforward culmination of peaceful resistance to British occupation, after the end of WWII initiated the decline of the British Empire and the process of de-colonisation. The colonial legacy can be seen across all sectors of society - economic, religious, political and socio-cultural - to different extents. The British left the most definitive and enduring impact not only through the democratic and constitutional principles that pervade politics, and the introduction of the modern economy (with a focus on tea, rubber and coconut plantations and a significant importreliance), but also through the rigid constructs of identity that once existed with far greater fluidity and multiplicity than they do today.

Most significantly, perhaps, are today's conceptions of ethnic polarity which have relatively recent origins in the nationalist ideology of the British colonial era. Mounting ethnopolitical tensions as the country re-established its sovereignty following 1948 have come to define Sri Lanka through violence and discrimination. Tamil and Sinhalese identities were once pliable; they coexisted alongside and overlapped with caste, religious and regional identities until nationalists politicised ethnic identity in the post-colonial era (Tambiah, 1986). The postindependence era of Sri Lanka can be seen as the continuation and evolution of the divisive, expansionary, nation-building processes initiated during British occupation (Lakshman \& Tisdell, 2000).

The decades following independence and the global emergence of 'intentional development' in the 1950s saw increasing aid dependency in Sri Lanka. ${ }^{4}$ In 1950, the Colombo Plan was formulated to represent intergovernmental cooperation to strengthen economic and social development through foreign aid. Initially between seven Commonwealth nations - Sri Lanka (then Ceylon), India, Pakistan, New Zealand, Australia, Canada and Britain - the framework now includes 27 member countries. ${ }^{5}$ Sri Lanka also signed bilateral and multilateral partnerships for aid assistance with a number of countries during this period, including Japan, USA, China,

\footnotetext{
${ }^{4}$ Intentional development is that which is focused on international aid (Cowen \& Shenton, 1996).

${ }^{5}$ The Colombo Plan was extended indefinitely in 1980.
} 
India and international financial institutions such as the World Bank and the Asian Development Bank (Wickramasinghe, 2014; Jayaweera, 1998), all of which continue to be major donors.

The colonial and post-colonial periods can be seen to have had a profound influence on Sri Lanka's social and economic development, identities, values and lifestyles, policies, and aid relationships in the three decades following independence. The challenges - especially the nationalistic, ethnic divisions - that developed during this period ostensibly formed the basis of the next three decades of civil war. The extensive impacts of civil war contribute largely to Sri Lanka's development context today.

\subsection{Civil war and tsunami}

Intensifying volatility over identity and territory between Sinhalese and Tamils erupted in civil war in 1983. The conflict devastated the people, environment and economy and finally ended in 2009. While it is important to understand this conflict because of its ongoing impacts on contemporary development in Sri Lanka, and particularly the livelihoods of those in the North who form the subject of this research, it is outside of the scope of this research to provide a lengthy and complex analysis of this 26-year long civil war and its aftermath. Others (Peebles, 2014; Seoighe, 2017; Spencer, 1990; Tambiah, 1986) have written extensively on the roots, impacts and discourse of the conflict, and provide a deeper understanding of the political and cultural complexities. The following section gives a brief and necessarily simplified overview of the key factors. A timeline (table 5.1) following this section identifies selected significant events.

The complex issues at the root of the tension are surmised as ethnic politics and discrimination, language and education, as well as employment and land issues (Spencer, 1990: 8; Tamil Guardian, 2008). Deliberately discriminatory government policies following independence exasperated hostility (see table 5.1) and resulted in the marginalisation of

minorities by limiting the rights of Tamil speakers to education, employment, citizenship and cultural and linguistic recognition. While all minorities experienced marginalisation under the Sinhalese Buddhist nationalist agenda, Tamils were the most persecuted and displayed the strongest resistance through militant violence (Seoighe, 2017: 2).

Tamil communities saw the Sinhalese administration as an extension of the colonisation of politics and land and vied for separation and self-determination for the Northern and Eastern 
Provinces through their vision for an independent state, Tamil Eelam. Various Tamil-nationalist mobilisations eventually became dominated by the Liberation Tigers of Tamil Eelam (LTTE) who fought to liberate Tamils from the Sinhalese state and, while to some they represented the Tamil population's only protection against persecution, their tactics were brutal. LTTE committed widespread violence and acts of terrorism including suicide bombings and political assassinations, and forcibly recruited soldiers including children. Many countries recognise LTTE as a terrorist organisation.

Although terrorist attacks by the LTTE occurred throughout the country, fighting was mainly confined to the Northern and Eastern Provinces where destruction and displacement have defined the population for decades. After 26 years of armed conflict, interposed with ineffective attempts at peace talks and four periods of escalating warfare - the Eelam Wars - (shown in table 5.1) and the devastating 2004 tsunami that further decimated war-torn north-eastern communities, the LTTE were finally defeated by the Sri Lankan government's aggressive military campaign in 2009 (Peebles, 2014: 17). An estimated 150,000 people were killed in the civil war, with between 40,000 and 70,000 estimated to have been killed in the final, brutal months of conflict (UNHRC, 2015 cited in ICG, 2017b: 1). Both sides are accused of atrocities including human rights abuses, large-scale civilian killings and war crimes.

The additional impact of the devastating 2004 Boxing Day tsunami along the east and south coasts affected worst those already afflicted by conflict. The disaster caused 35,322 deaths, subsequent deaths due to infectious outbreak, and displacement of 853,025 people (IFRC, 2006). The agricultural sector was seriously impacted by the loss of agricultural lands through salinization and debris. Reports claim that those in the northern regions received less aid in relief efforts than those in the south based on political allegiance rather than on the basis of need (IFRC, 2006: 37). While the tsunami seriously impacted thousands of people in Sri Lanka, people in the Northern and Eastern Provinces were among those who suffered extreme hardship, compounded by the challenges to rebuild homes and livelihoods during war-time.

Sri Lanka has had a tumultuous history since gaining independence, marred by intermittent conflict, tsunami, and political instability, but faces a hopeful road towards reconciliation and social and economic growth. Table 5.1 highlights the key events following Sri Lanka's independence that shaped social and political issues through the cycles of conflict. 
Table 5.1

Selected timeline 1948-2019: Independence to Post-conflict

\begin{tabular}{|c|c|}
\hline $\begin{array}{c}1948 \\
1952-1958\end{array}$ & $\begin{array}{l}\text { Independence. Ceylon becomes a self-governing dominion of the British Commonwealth. } \\
\text { Language policy tensions and protests. Initial support for parity of Sinhala and Tamil } \\
\text { abandoned. }\end{array}$ \\
\hline 1958 & Tamil name boards destroyed by vandals; Anti-Tamil riots. \\
\hline 1961 & Sinhala enforced as the only official language. \\
\hline $1960 \mathrm{~s}$ & Increasing dependence on foreign aid. Government favouritism of Sinhalese Buddhist. \\
\hline 1972 & Name changed from Ceylon to Republic of Sri Lanka; Tamil New Tigers party founded. \\
\hline 1976 & $\begin{array}{l}\text { Tamil New Tigers become Liberation Tigers of Tamil Eelam (LTTE); Tamils call for a separate } \\
\text { state. }\end{array}$ \\
\hline 1977 & Anti-Tamil riots. \\
\hline 1979-1982 & $\begin{array}{l}\text { Growing violence in Jaffna between Tamil extremists and police and army. Sinhala - Muslim } \\
\text { violence. }\end{array}$ \\
\hline 1983 & $\begin{array}{l}\text { Escalating violence, anti-Tamil riots spark civil war (Eelam War I begins). State of } \\
\text { Emergency declared. }\end{array}$ \\
\hline 1985-1986 & $\begin{array}{l}\text { Tamil separatists and government hold peace talks; separatists reject government } \\
\text { proposal; continued violence. }\end{array}$ \\
\hline 1987 & $\begin{array}{l}\text { Elam War I ends with India-Sri Lanka Accord. Indian Peace Keeping Force sent to } \\
\text { administer decentralisation of power to provinces but ended up at war with LTTE. }\end{array}$ \\
\hline 1990-1994 & Elam War II. Ends with the election of new President. \\
\hline 1994- 1995 & $\begin{array}{l}\text { Government launches a massive offensive against Jaffna; LTTE moves headquarters to } \\
\text { Mullaitivu. }\end{array}$ \\
\hline 1995-2002 & Eelam War III. Ends with ceasefire agreement and the election of new Prime Minister. \\
\hline 2003 & $\begin{array}{l}\text { Further attempts at peace talks; LTTE victories; LTTE withdraw from peace talks after six } \\
\text { rounds; LTTE proposes interim self-governing authority for the North and East. }\end{array}$ \\
\hline 2004 & Tsunami kills more than 35,000 people on eastern and southern coasts. \\
\hline 2006 & Eelam War IV begins. \\
\hline 2007-2008 & $\begin{array}{l}\text { Government begins an offensive in Northern Province; air raids by both sides; government } \\
\text { captures LTTE areas. }\end{array}$ \\
\hline 2009 & End of civil war. Army destroys the remainder of LTTE. 9,000 LTTE soldiers surrendered. \\
\hline 2010 & UN appoints a panel to investigate violations of international human rights. \\
\hline 2011 & $\begin{array}{l}\text { Government presents a report of the Commission of Inquiry on Lessons Learnt and } \\
\text { Reconciliation (LLRC). }\end{array}$ \\
\hline 2012 & $\begin{array}{l}\text { UN Human Relations Council passes a resolution calling for an independent investigation } \\
\text { of possible war crimes; Colombo-Jaffna railway reopens. }\end{array}$ \\
\hline 2012-2015 & Wanni Dairy Regeneration Activity (phase one). \\
\hline 2013 & Trade tensions for Fonterra in Sri Lanka; Sri Lanka and New Zealand sign DCA. \\
\hline 2014 & $\begin{array}{l}\text { New Sirisena administration appointed after a general election, rules out an international } \\
\text { investigation into war. }\end{array}$ \\
\hline 2016-2021 & Dry Zone Smallholder Dairy Expansion Programme (phase two). \\
\hline 2018 & $\begin{array}{l}\text { President Sirisena fires Prime Minister and appoints Rajapaksa. Rajapaksa steps down and } \\
\text { Prime Minister Wickremesinghe is reinstated. }\end{array}$ \\
\hline 2019 & Easter bombings target Christians and tourists, killing 259. \\
\hline
\end{tabular}

Source: Adapted from Peebles, 2015; Wickramasinghe, 2014. 


\subsection{Post-conflict}

The country has made significant progress since the armed conflict ended in 2009; economic growth mainly from tourism and exports (tea, rubber, coconut, gems, textiles and clothing) has elevated its status to a low-middle income country, the north has become accessible once again, political and social change is afoot (World Bank, 2018). Nonetheless, a long road of reconciliation lies ahead, and post-conflict Tamil communities as well as other minorities, especially those in the Northern and Eastern Provinces, continue to experience the social and economic effects of war and decades of institutionalised discrimination (ICG, 2017a). Furthermore, government promises to the international community, for example, to pass legislation to bring criminal charges against those involved in the most serious atrocities committed on both sides of the conflict, remain unfulfilled. International reports identify a closing window of opportunity to address the issues that have caused decades of political turmoil (Emmerson, 2018; ICG, 2017a).

After an unexpected election victory in 2015, the new president, Sirisena, whose policies mark a significant departure from the abuses of the previous Rajapaksa regime, united the diverse groups opposed to the previous government with his focus on reducing corruption and nepotism, and prioritising basic needs - health, education, housing, clean water and poverty alleviation - rather than large infrastructure projects. A major election promise of an amended constitution that includes the weakening of the executive presidency, a mixed electoral system, a bill of rights, and, most importantly but controversially, provincial autonomy, is largely seen as necessary for an equal and inclusive Sri Lanka (ICG, 2017a: 21).

Initially strong progress on the reform agenda, however, has slowed or ceased and there are increasing doubts over government commitment to the transitional justice process and constitutional reform (Ibid.: ii; Tamil Guardian, 2018). Building anger at unfulfilled promises and low trust in the Sirisena government among Tamils threatens to fuel underlying nationalist sentiments. The military's continued high presence and engagement in economic and civilian activities in the Northern and Eastern provinces reduces economic opportunities for struggling Tamils and provokes tension. Since 2017 there has been a wave of protests demanding the return of land still occupied by military and information on missing persons (ICG, 2017a: 70). ${ }^{6}$

\footnotetext{
${ }^{6}$ Many civilians and surrendered soldiers disappeared after being taken into state custody, and the state has a poor track record of torture, forced confessions, detention without trial, and ill-treatment.
} 
In October 2018 while I was in Sri Lanka doing field research, political crisis arose with the unexpected announcement that Sirisena had fired Prime Minister Wickremesinghe and appointed the former president, Rajapaksa, - whose government oversaw a "grave assault on the entire regime of international law" (UN, 2011: ii) - as prime minister; a move that was widely condemned as unconstitutional and undemocratic. Wickremesinghe was eventually reinstated, however, this marked the beginning of foreseeable political instability. In 2019, a series of terrorist suicide bombings killed 259 people and injured over 500 others.

Conceptions of the ethno-political conflict are bound to power and discourse. The dominant State narrative, of the victorious state, reinforces oppression through state-sponsored commemorations of the war that are contested by Tamils (Seioghe, 2017). Although the violence has ended, the pervasive stigmatisation and disenfranchisement of Tamils continue. Definitive, inclusive action is needed to protect all communities' rights. Reports warn that a failure to act will ensure an eventual return to conflict (Emmerson, 2018; UN, 2011: 28).

\subsection{Economic and agricultural development}

Sri Lanka's current economic outlook is favourable. Nonetheless, it is argued that reform progress - a new constitution that respects the rights of all; processes that address the legacy of the war, restore the rule of law and address widespread impunity; restored civilian authority in the north and east; and equitable economic restructuring - is critical for sustained growth (ICG, 2016; 2017a; World Bank, 2018). The country's economy has grown since the civil war ended in 2009, however, growth rates have been declining recently due to political uncertainty and natural disasters (floods and drought) (ICG, 2016: 5; World Bank, 2018). Climate-related risks pose a significant threat to economic and social development and are expected to intensify, with increasing frequency and duration of droughts in the dry area, and frequency and intensity of floods in the wet area. ${ }^{7}$ Climate change is expected to significantly impact agriculture, water resources, energy, environment and fisheries in Sri Lanka (World Bank, 2018).

Despite economic growth and social development, a large portion of the population lives only slightly above the extreme poverty line and there is significant regional disparity with the poor being disproportionately rural. The huge cost of the civil war and tsunami, large budgetary

\footnotetext{
${ }^{7}$ Extreme variability of rainfall from the two monsoon seasons defines the country's climate.
} 
deficits and high debt inherited from former governments, and prolonged drought has led to the Sirisena government being unable to deliver on election promises to improve living standards. A major focus continues to be export growth and attracting foreign investment to support the economy, although conflicting policy actions have undermined potential (ICG, 2017a: 6).

In this context, agriculture is a key economic activity. The majority of Sri Lanka's people are rural, poor, and depend on agriculture for subsistence and livelihoods. ${ }^{8}$ Dairy development is argued to be a clear and effective way to improve household incomes and reduce food insecurity in rural communities (Wijethilaka et al., 2018). ${ }^{9}$ The Sri Lankan Government is committed to increasing domestic dairy production to achieve sustainable and equitable benefits for livestock farmers and improve the availability and affordability of milk (Mendis \& Edirisinghe, 2014). Domestic producers met only $30 \%$ of national dairy demand in 2010 . By 2015 , nearly $50 \%$ of the domestic demand was being met by local producers, yet production was still well below targets (Wijethilaka et al., 2018).

The development needs of Sri Lanka are identified in 'Mahindra Chintana' - Vision Towards a New Sri Lanka: A Ten Year Horizon Development Framework 2006- 2016 (Rajapaksaera) (Department of National Planning \& Ministry of Finance and Planning, n.d.) and subsequently, Vision 2025 - A Country Enriched (Sirisena-era) (Government of Sri Lanka, 2017). The comprehensive frameworks set out the self-identified priorities of the Sri Lankan Government, and prioritise Transforming Agriculture for Prosperity and Agriculture and Sustainable Development, respectively. Additionally, the frameworks include strategies for development of conflict-affected areas, livelihood development, food security, health and environment, which are relevant for dairy development.

The Livestock Master Plan: A strategy for Livestock Development for Self-Sufficiency is an aspirational policy document produced by the Ministry of Livestock and Rural Community Development (2011) to reflect the sector's objectives for self-sufficiency. To support the 'Mahinda Chintana' policy document, the 'Livestock Master Plan' sets out constraints and

\footnotetext{
${ }^{8}$ Although manufacturing and service sectors (especially tourism) are significant in the increasingly urbanised economy.

$924 \%$ of the population are considered food insecure, which is primarily attributed to their nutritional status (Wijethilaka et al., 2018).
} 
strategies to develop the livestock sector's potential to contribute to economic development, social stability and nutrition status. The 'Plan' is a key reference for dairy development activities in Sri Lanka.

Several national policies and programs assist the domestic dairy industry, including policies around access to milk and the development of rural smallholder farmers' economic activity (Mendis \& Edirisinghe, 2014). Rural smallholders are supported by government price controls on fresh milk, tariffs on imported milk powder, and a range of programmes designed to make dairy farming attractive to farmers including free or subsidised vet services, trainings, development of model farms and distribution of materials, tools and equipment (MFAT, 2015b). ${ }^{10}$ Further, the government is heavily invested in the industry through farm ownership and as the largest collector and processor of fresh milk.

\subsection{Bilateral relations}

Commonwealth ties and economic and social exchanges underpin the longstanding friendly relationship between New Zealand and Sri Lanka (MFAT, 2013). New Zealand has no official aid programme with Sri Lanka, however, the New Zealand government provides ODA funding to Sri Lanka through its NGO partners and the UN (MFAT, 2018c.). New Zealand's aid activities in Sri Lanka are closely tied to its trade interests. A major contributor to growth of New Zealand exports to Sri Lanka has been the increasing demand for milk powder that places Sri Lanka as Fonterra's third largest export market. ${ }^{11}$ Fonterra's market difficulties in 2013, that included a recall on milk powder, protests and legal action over contamination concerns in Sri Lanka, resulted in the signing of the New Zealand-Sri Lanka DCA, the basis for three dairy development activities to encourage the development of Sri Lanka's domestic dairy industry. ${ }^{12}$ Both countries identify compelling reasons to undertake dairy development. It is profitable to smallholders, commercial farmers and investors alike. Strong consumer and processor demand for milk has facilitated an attractive enabling environment. The DCA aims to build cooperation on dairy matters and

\footnotetext{
10 Programmes such as the Food Production National Program and the Economic Empowerment Program.

${ }^{11}$ By 2016, exports to Sri Lanka had grown to NZ\$239 million (up from \$117 million in 2000) and imports from Sri Lanka were \$55 million (MFAT, 2018c).

12 The DCA expired in 2017, however.
} 
resolved the 2013 issues (MFAT, 2013). The three dairy activities in Sri Lanka funded through the NZAP's partnerships fund are:

- 'Transforming agriculture for economic prosperity and poverty reduction through strengthened veterinary education in Sri Lanka', a five year NZ\$2.18million extension activity with Massey University and Peradeniya University to develop vet education and thus improve animal health;

- 'Sri Lanka Dairy Excellence Training Initiative', a five year NZ\$2.75million activity to provide training to improve farmer knowledge and skills and thus dairy productivity, household incomes and standard of living; and

- 'Dry Zone Smallholder Dairy Expansion Programme' (2016-2021) that builds on the success of phase one, 'Wanni Dairy Regeneration Activity' (2012-2015), and aims to grow dairy production to improve economic and food security benefits in the northern dry zone in Sri Lanka.

The activities are complementary to each other. The lattermost activity (i.e., Wanni Dairy Project) is the focus of this research.

\subsection{Wanni Dairy Project}

The Wanni Dairy Project targets districts in Sri Lanka's northern, north-central and eastern provinces where there is a predominance of dairy farmers, tsunami and war-affected families are in recovery, and smallholder dairy farmers are vulnerable and disadvantaged. Through NGO-led workshops, model farm development, field staff support, and training, the project encourages farmers to: adopt integrated, semi-intensive farming techniques to improve fodder availability and soil fertility; improve breeding to increase productivity while maintaining resilience to local conditions; and facilitate the organisation of dairy farmer collective societies for training, milk collection and community asset management (MFAT, 2016; 2017b).

By June 2016, 2,745 farmers were participating, 1,939 of whom were registered with one of the 31 Dairy Farmer Collective Societies that had been created. ${ }^{13}$ Around $47 \%$ of registered

${ }^{13}$ Against a target of 1500. 
members are women. ${ }^{14}$ MFAT (2017b) estimates that 10,000 farming household members have been impacted through improved nutrition, and higher, more regular, monthly incomes from better milk prices and volumes collected for milk processing and other income sources generated through the programme. The project has contributed an estimated LKR291.8m (NZD2.9m) to the local economy (Ibid.). Building on the success of phase one, phase two is expected to benefit a further 7,500 smallholder dairy households and 10,000 rural youth across nine rural dry zone districts. The key issues that phase two aims to address are:

- Undersupply of local milk to the domestic market;

- Low milk quality leading to loss of potential income;

- Inadequate refrigeration/transport infrastructure and poor technology;

- Inadequate livestock and land management practices;

- Inadequate cooperation amongst farmers and with industry stakeholders;

- Weak transparency across the supply chain;

- Lack of gendered approach (MFAT, 2016: 7-10).

MFAT is the main donor for the activity, contributing NZ\$1,858,355 in phase one (a further $\$ 300,000$ was funded by partner organisations), and NZ\$3,309,463 to the total NZ\$4,964,194 in phase two. The Government of Sri Lanka and Fonterra, as stakeholders in dairy development, have an ongoing interest in the activity.

TFNZ and WCDO are the NGO partners implementing the project, providing technical support and local knowledge, respectively. TFNZ is a New Zealand-based Christian aid and development organisation that works alongside churches and other locally-based organisations to relieve poverty in vulnerable communities around the world. WCDO is an international, Christian relief and development organisation with a focus on holistic community development, with a local team based in Sri Lanka. TFNZ is contributing NZ\$1,654,731 in phase two. QPod Systems is a New Zealand company that is contracted to provide technological assistance and baseline monitoring for supply chain improvements. Yugashakthi Guarantee Ltd (Sri Lanka) is a locally-based, registered

\footnotetext{
${ }^{14}$ Gender equality is targeted by the Wanni Dairy Project (MFAT, 2014) as dairying is recognised for its potential to improve women's participation and thus contribute to lessening issues of gender equality (FAO, 2015b).
} 
company that has been established to own and manage the project's assets and support the farmers' cooperative and succession plan (MFAT, 2016).

\subsection{Summary}

Any attempt to research and understand the experiences of Sri Lankan people, particularly relating to a development intervention such as the Wanni Dairy Project, is inextricably situated within the specific post-conflict context. This chapter considered the complex economic, social and political factors and key events in Sri Lanka - contributing to both the constructs of nation and its people - that have shaped the development context for aid activities over seven decades. It outlined the longstanding bilateral cooperation between Sri Lanka and New Zealand, and then briefly outlined three NZAP dairy development initiatives, which arose from the New Zealand and Sri Lankan governments shared recognition of the importance of the dairy sector. It subsequently described the scope, objectives, progress and stakeholders of the Wanni Dairy Project, the focus of this research. 


\section{Chapter 6 : Findings and discussion: Social, gender and environmental factors}

\subsection{Introduction}

This chapter comprises the findings and discussion of this research and is structured as three main sections that consider the social (6.3), gender (6.4) and environmental (6.5) factors and impacts of the Wanni Dairy Project. Each section is shaped around qualitative data from interviews and draws on literature that highlights dairy production and consumption in the global development context. Further consideration is given to sustainable livelihoods, cross-cutting issues and development actors. The first and most expansive section, on social factors, addresses the following questions as introduced in Chapter One: What are the local attitudes towards the project? What do locals believe about the impact of the project on rural livelihoods and wellbeing? What do locals believe are the health impacts of the project? How does culture influence the impacts of the project? The section discusses local development actors, attitudes and perceived influence; social impacts of increased income: education, status and wellbeing; perceived poor decision-making; health impacts of dairy production and consumption; dietary shift; caring for cows: culture, religion, ethics; ethical learnings; and religious beliefs.

The second section on gender factors addresses another of my central research questions: How has the project impacted gender issues (and also, how have gender issues impacted the project)? It discusses gender inequality and participation; independence and empowerment; debt; increased workload; medical access; violence against women; and stakeholder engagement and gender violence.

The third section on environmental factors addresses: What do locals believe are the environmental impacts of the project? It discusses perceptions of and prospects for environmental sustainability; climate change; power over environmental factors; farmers' priorities and the scale of dairy production; and opportunities identified by farmers.

Throughout, these three sections also consider the question: How do farmers influence the project and its impacts? The chapter integrates social, gender and environmental factors as this reflects the various interconnections between factors that contribute to sustainable livelihoods, including gender issues, and it best reflects the perspectives and knowledge shared, which were 
often complex and integrated. In relation to farmers' perspectives on grazing, for example, some farmers prefer to allow their cows to graze in the jungle. Ethical, cultural and economic factors motivate this practice as farmers believe it is better practice for cows to roam freely, they produce higher yields, and they require less labour input. However, jungle roaming has environmental costs as waste is not managed and roaming cows cause damage to the jungle habitat. When practices are changed to tethered livestock and farmers must collect feed, female farmers experience a disproportionate increase in workload because other household ${ }^{1}$ roles such as caring for children and domestic responsibilities remain constant. In deciding where to situate these multi-faceted implications within this chapter, I have endeavoured to prioritise the factors most strongly emphasised by farmers. For instance, feeding practices are discussed under social factors because ethical values are an important influence on farmer practice. The gender section further reflects on the implications for female farmers' experiences of increased workloads due to feeding practices as well as other factors. Table 6.1 at the end of this chapter provides a summary of the research findings, which covers all three main sections. Before progressing with the discussion in this chapter, the next section turns to an introduction of the primary participants.

\subsection{Introducing the primary participants}

The primary participants in this research are five women who live across three different villages within the Mullaitivu District. While I acknowledge the inherent diversity of people's identities, some characteristics of the participants in this research were shared, including their Tamil ethnicity, Hindu religious identity, and their roles as mothers and wives. The participants were aged between 28 and 55 years old at the time of interviews. All of the women live in the traditional, male-led household structure. Table 5.2 provides information on the farmers I interviewed and table 5.3 outlines the households and livelihood strategies of each participant.

Primary participants have all been involved in the Wanni Dairy project since phase one and initially obtained one calf through the project. Some have previous farming experience, and others have recently diversified their livelihood strategies to include dairying. Though the women's livelihoods are all shaped by their experiences of war and all women have overcome

\footnotetext{
${ }^{1}$ Household is a cultural construct that is defined by its functions, including co-residence, economic cooperation, reproductive activities and socialisation of children. This definition is not necessarily shared by others, as in many cultural contexts (including Sri Lanka) these functions can occur across numerous residences (Varley, 2014).
} 
challenges, some participants face continued difficulties and others now feel they are achieving success. I use pseudonyms to refer to the participants to protect the anonymity of the data.

\section{Table 6.1}

Five female farmers

Shivangi is 28 years old. She lives with her husband and two children aged 9 and 6 in a modest house that was constructed by the government after the war. Three of her nine cattle are calves and she has a purebred jersey cow as well as a crossbreed. The other cows are indigenous breeds. On their three acres of land, they have paddy cultivations and a fenced area where the livestock are free-grazing. She is also a tailor and her husband is a mason.

Manishi is 52 years old. She lives with her husband and four of her six children - one adult son is studying overseas and one child died during the war. Both Manishi and her husband are dairy farmers and agricultural labourers, continuously doing something, whether it is onion and paddy cultivation, peanuts or labouring on other people's land. They own three acres of land, but their cows mostly free-graze in the jungle because they believe it is more natural.

Sarani is 39 years old and lives with her husband, two school-aged sons and her 65 year old mother. They own six acres of land. Two acres are used for paddy cultivation, and they also grow coconuts and vegetables. They have ten cows that are all indigenous breeds and free-graze. The jersey cow they got from the Wanni Dairy Project got sick and died and they are not able to get another one. The adults in the family all share responsibilities for looking after the cows, and Sarani's husband also does mason work. Sarani's young son had just been awarded a scholarship. Sarani and her husband have been dairy farming since they were children.

Naavya is 51 years old. She lives with her husband, her two adult daughters, her school-aged son and her granddaughter. She has been dairying since 2012 when she was given a calf through the Wanni Dairy Project. She now has four cows on their two acres of land, as well as a small paddy cultivation for personal use located nearby. Her husband does agricultural labour work, and her two adult daughters have recently completed their studies. Her daughter, who has graduated from university, hopes to get an office job. They cultivate chillies and some other crops on their lands and grow grasses to feed their cows.

Lavanya is 55 years old. She lives in a large, proud house that she and her husband built without any government support. She has been dairy farming since 1979 although they lost everything in the war and have slowly re-established their farming livelihoods. She has seven children. Two of her five sons are married, she has one daughter, and one child died in the tsunami. She has fifteen cows, as well as five goats, one hundred chickens, and pigeons. She has four acres of land and a nearby paddy cultivation. Her husband is a blacksmith. She takes care of all the animals herself.

The following simplified table outlines the characteristics of the participants in this research for ease-of-reference and comparative purposes. 
Table 6.2

Primary participants: female smallholder dairy farmers

\begin{tabular}{|c|c|c|c|}
\hline Age & Cows / land & HH members & HH livelihood strategies \\
\hline 28 & $9 / 3$ acres & Husband, two children $(9, \mathrm{~m}, 6, \mathrm{f})$ & $\begin{array}{c}\text { Dairy farming, tailoring, mason } \\
\text { work, rice and vegetable cultivation }\end{array}$ \\
\hline 52 & $7 / 3$ acres & Husband, four of six adult children & $\begin{array}{c}\text { Dairy farming, agricultural } \\
\text { labouring, onion, peanut and rice } \\
\text { cultivation, garment work }\end{array}$ \\
\hline 39 & $10 / 6$ acres & Husband, two children $(10,8)$ & $\begin{array}{c}\text { Dairy farming, coconut plantations, } \\
\text { vegetable and rice paddy } \\
\text { cultivation, mason work }\end{array}$ \\
\hline 51 & $4 / 2$ acres & $\begin{array}{c}\text { Husband, two adult daughters, } \\
\text { school-aged son, preschool-aged } \\
\text { granddaughter }\end{array}$ & $\begin{array}{c}\text { Dairy farming, rice paddy } \\
\text { cultivation, agricultural labouring, } \\
\text { chilli cultivation }\end{array}$ \\
\hline 55 & $15 / 4$ acres & $\begin{array}{r}\text { Husband, five adult sons, two } \\
\text { daughters-in-law, daughter. }\end{array}$ & $\begin{array}{c}\text { Dairy farming, chicken and goat } \\
\text { farming, pigeon breeding, } \\
\text { blacksmith }\end{array}$ \\
\hline
\end{tabular}




\subsection{Social factors and impacts}

The potential social impacts of dairy development projects are many and can include changes to people's way of life; their culture; their community; their political systems; their environment; their health and wellbeing; their personal and property rights; and their fears and aspirations (Vanclay et al., 2015). Chapter Two of this thesis identified tensions between the different health impacts of dairy development in developing countries' populations (Muehlhoff et al., 2013; Woodford, 2008). Positive health impacts are raised as a key social impact in the Wanni Dairy Project by macrodevelopment actors, however, this thesis explores how health impacts are perceived by people directly affected by the project. Also important to understand are cultural factors, which were found to be overlooked in the sustainable livelihoods approach in Chapter Three (Carney, 1998; 2002; Ellis, 2000; Overton et al., 1999) and in research on rural livelihoods in Sri Lanka (Daskon \& Binns, 2009). In addition to health and cultural factors, primary participants identified the significance of increased income from dairying for rural livelihoods and other social impacts associated with their aspirations, status and wellbeing. It was also reported that there are negative social impacts of increased income for some farmers. NGO actors play a key role in influencing and understanding social factors.

\subsubsection{Local development actors, attitudes and perceived influence}

WCDO engaged with the community in the Mullaitivu District for seven years prior to the Wanni Dairy Project through its work on protection of women and children. Out of this work, dairy production was identified as a method to support women's empowerment and as a response to the community's needs to rebuild livelihoods after the war. WCDO described their early engagement as the beginning of a gradual process to gain the trust of the community. Local ownership to ensure sustainability remains at the forefront for WCDO.

The project must be sustainable. It must be through the eyes of the people. I see so many projects and development organisations and they do a project and the process looks good and the indicators look good but without the ownership of the local people, it will not succeed in 10 years. We are like a crutch, we help people to walk but once they have learned to walk, then we are not needed. We step back but we are behind them so that if they need something, we are there. It needs to be what the people need and within their capabilities and the resources they have. It needs to be in their language (NGO representative, personal communication, October 2018). 
'Bottom-up' approaches recognise that solving smallholder farmers' problems requires observation, joint learning, reflection, negotiation, feedback, and subsequent modifications of innovation strategies (Kiptot \& Franzel, 2015).

NGO informants from both organisations described a particular strategy in which project staff suggest minor changes to farming norms to demonstrate tangible results and build farmers' trust in other new practices that they may like to adopt. Farmers who had attended information sessions found them relevant and useful for adapting dairying practices to increase productivity.

It's really useful. Not a time waste. The [NGO] is telling us about only what we need. We get enough information from that and we are using it (Farmer, personal communication, October 2018).

Relevant and well-communicated information supports the effectiveness of development projects (Mekoya et al., 2008). Information sessions are not only in the language of the farmers but also in language the farmers can understand. This research found that locally-based NGO staff and farmers in the Wanni Dairy Project appeared to maintain good relationships that are characterised by informality and familiarity. Regular communication with the field support staff suggests that farmer issues can be easily identified and development objectives can be more easily met.

This pragmatic approach to knowledge-sharing, in part, mitigates the unequal power dynamics that have been observed in other dairy development (Chisholm, 2009; Lumsden, 2011) and supports prospects for project effectiveness and livelihood sustainability. 'Top-down' approaches to dairy development, in which farmers' expertise is marginalised, usually fail to solve farmers' issues (Kiptot \& Franzel, 2015; MFAT, 2016). In the Wanni Dairy Project, project staff expressed admiration and respect towards farmers' capabilities, reporting that farmers often demonstrate high competency and skills and sometimes do things differently to the suggestion of the NGO but produce better results.

Some farmers, even when we are giving them the cattle shed design, they are building their own design, and it's a good one. And when we are giving calves they are doing the [artificial insemination] with other high-yield breeds and then they are getting more productive breeds. In this project, they have started using the Co3 grass, ${ }^{2}$ but now, with their knowledge of grasses, they are also buying other sorts of grasses from outside, the sugar grass, and now they are cultivating that also (NGO representative, personal communication, October 2018).

\footnotetext{
${ }^{2} \mathrm{Co} 3$ grass is a variety of fodder grass.
} 
Farmers are perceived (by NGO staff) to influence the knowledge produced and shared in the project, and model farmers are supported to share strategies directly with other farmers. Further, the creation of dairy farmer collective societies enables farmers to collectively influence negotiations with supply chain actors. This combination of subtle changes in practice and the introduction of farmer societies supports farmers to exercise agency over their dairying livelihoods and the resources that are available to support them, and thus encourages sustainability. However, it is interesting to note that farmers' perspectives differed from NGO workers'.

While this research found that farmers have overall positive attitudes towards the NGOs and the project, which reinforces the merit in WCDO's approach, farmers' perceptions of their own low influence persisted, as other studies have shown (Chisholm, 2009; Lumsden, 2011). In part, this is because the farmers I talked to felt that they have little power to address persistent issues over delayed payment by milk companies - in some cases for many months - which is identified as a significant problem because it limits farmers' ability to repay loans and meet their household needs. Farmers I spoke to also believed that as the fat content of milk is not measured individually, farmers who water down their milk benefit at the expense of others. Involvement with the dairy farmer collective societies is perceived by NGO informants to empower farmers to address issues such as this, but the farmers perceived the NGOs to hold the most influence and legitimacy in addressing these issues.

Further, there was some dissonance between farmers' and NGOs' perceptions of WCDO's views of farmers' knowledge. Some farmers perceived that their experience caring for livestock is not sufficiently valued by WCDO, despite the view of WCDO representatives that this challenge had been overcome through participatory practices such as model farmer training.

The jersey cow is dying and I asked for another one, but they didn't give. They told us that we didn't take care of that cow. I have been a dairy farmer since I was five years old and I know how to take care of it. I brought a veterinary doctor to show them, that animal got a disease, but they couldn't save that animal and now we can't get another (Farmer, personal communication, October 2018).

This farmer had little influence over the outcome determined by the NGO when she faced the loss of her cow. She was indignant at the suggestion that inadequate care contributed to the cow's death, and this view was not solely based on its economic implications, though significant; equally important was its reflection on status and ethics as an experienced, and Hindu, farmer. Cultural 
factors are an important though often overlooked aspect of sustainable livelihoods (Daskon \& Binns, 2009) and are discussed below in section 6.3.6.

Overall, the relationships between NGOs and farmers seemed to be based on respect, the importance of local knowledge, and a vision for sustainability. All farmers reported improved livelihood and wellbeing as a result of their involvement in the Wanni Dairy Project. The project is addressing their needs. Farmers appeared to influence implementation as their views are valued and approaches are tailored and flexible. Nonetheless, some farmers held perceptions of their own low influence over the Wanni Dairy Project and their livelihoods. Section 6.4 of this chapter further discusses the social and cultural context and women's sense of agency.

\subsubsection{Social impacts of increased income: education, status and wellbeing}

Farmers perceived the main benefit of the Wanni Dairy Project to be the provision of a calf, which has increased access to loans and the ability to pay them, as described by one farmer:

We got the calf. It was really an advantage. We took the loan also and we could pay it back (Farmer, personal communication, October 2018).

Accessibility to and affordability of finance has multitudinous social impacts in impoverished communities, a lack of which is identified as one of the main barriers to livelihood investment by people in developing countries (Gerber et al., 2013; Parikesit et al., 2005). Compared to developed countries where the main role of livestock is generally food production, in developing countries, livestock additionally plays other important livelihood roles, such as acting as insurance and investment (Tarawali et al., 2011). These varied roles for livestock in livelihoods are confirmed in the research findings.

The calf is an asset. Then I can get another calf from next year and we are going to get more, even more. It can be considered as a property and we are getting loans for 10 percent interest. We can get loans at any time if we need, then it's very helpful. [...] It's good for us (Farmer, personal communication, October 2018).

Improved access to finance and assets enables farmers to recover in times of need and enhances livelihood sustainability (Chambers \& Conway, 1992; Ellis, 2000).

Farmers described the positive impacts on their livelihoods and wellbeing of finance and assets, and expressed through the photovoice method the centrality of the calves provided through the Wanni Dairy Project to these improvements. 

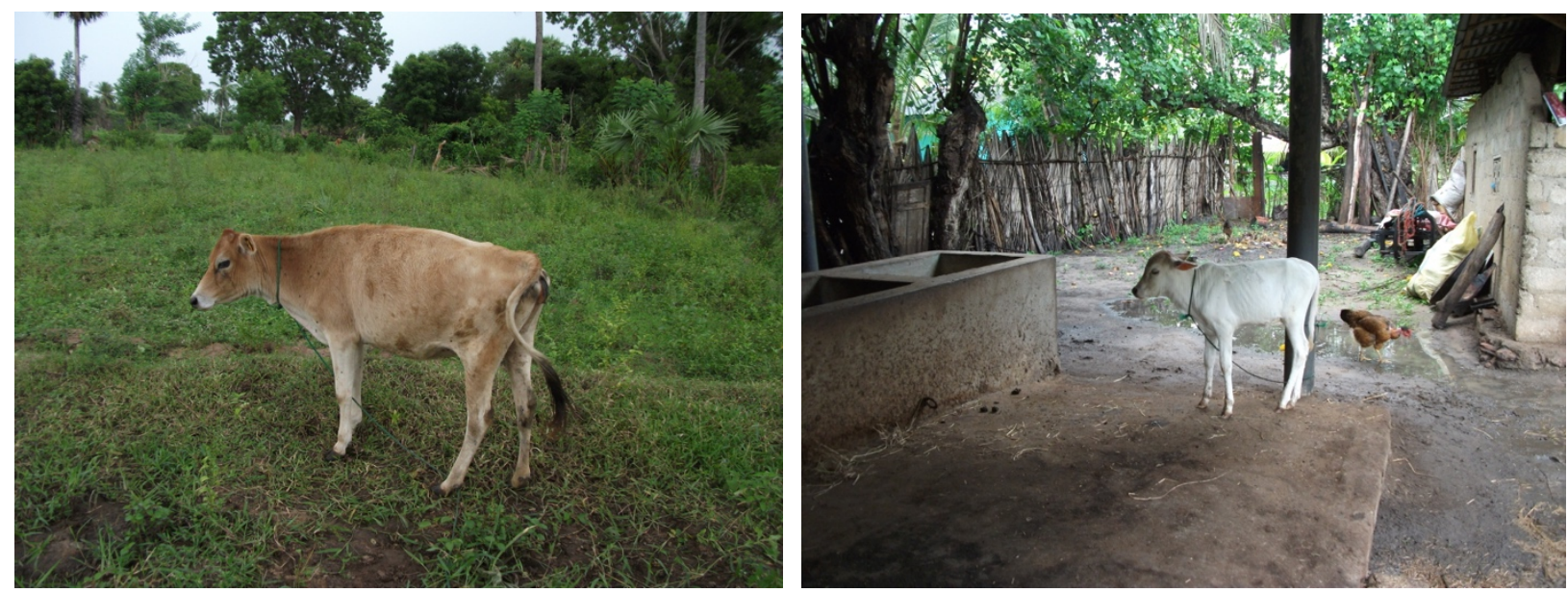

Figure 6.1. Farmers' photos of their calves.

Source: farmers (photovoice method)

All farmers captured an image of their animals and identified the independence it represented.

Then we can be independent. Then we can get satisfaction from that. Financial security. Once my son needed money immediately and we couldn't get it, it was the rainy season so we couldn't go for work from outside. Then we sold a cow and we got the money. Like that, in our emergency or urgent needs, we could use the cow (Farmer, personal communication, October 2018).

I am independent because I do not have to beg from relatives or someone else. Because they won't give. Now if I need to get money I can get a loan or, if not, I can sell a cow (Farmer, personal communication, October 2018).

We don't want to ask from others or depend on others. This project is very helpful because if we are going to get the loan from bank they won't give. And if we go for pawning also we can't get that much (Farmer, personal communication, October 2018).

The independence that farmers can achieve through financial security improved farmers' status and wellbeing. It was important to the farmers I spoke to that they were able to cope with shocks and stresses without relying on others.

The other main aspect of livestock acquisition in the Wanni Dairy Project is its ability to generate regular and reliable income from dairy production.

We are getting permanent money from this dairy project and we are saving money also, and it is key. We are giving money and saving. Then if we have more cows and can get more milk then we can fulfil all our needs and wishes (Farmer, personal communication, October 2018). 
While we are keeping the cows, we can get money and we can decrease our level of poverty (Farmer, personal communication, October 2018).

The ability to save part of their income further builds farmers' financial independence. At the time of this research, a recent drought was fresh on the minds of farmers who described the significant loss of crops and labour investment. As livestock are less susceptible to climate-related events than cultivated crops, those who had diversified or intensified towards dairying have more resilient livelihoods, could save, and thus improve their position over time.

Money from loans and income, therefore, enables farmers to fulfil both immediate and future needs. Most importantly, farmers saw dairy farming as a means to provide their children with better education and future livelihood options.

Mainly we started doing this for money because we have shortage in money and I really wanted to teach my children. I have to spend nearly $15 \ldots 20,000$ [rupees] in one month because my son is studying in India. I want money, that's why I am getting involved [...] Then we are getting benefits from that loan (Farmer, personal communication, October 2018).

Education is shown to increase livelihood diversification in post-conflict households in Sri Lanka (Munas \& Lokuge, 2016), and, livelihood diversity is strongly correlated with resilience and coping strategies for natural disasters and other stresses (Scoones, 2009). Farmers' aspirations for their children, therefore, have changed as a result of their involvement in the Wanni Dairy Project because they feel that their children will be able to achieve better education than previously imagined.

Additionally, cultural values of reciprocity and collective responsibility mean that farmers plan for and rely on this investment in their children's education to later contribute to the household income and reduce poverty.

We spend the money on education mainly, for our family. Now we have the loan and we have to live because of my children. My daughter, if she gets work - she did management in university - and if she gets work then all will be fine. So, I am looking forward now (Farmer, personal communication, October 2018).

Despite most farmers' belief that tertiary education is the best option to improve livelihoods for their children, employment opportunities in the rural, post-conflict areas in Sri Lanka are limited, particularly for farmer's commonly-held career aspirations for their children, such as doctor or 
engineer. ${ }^{3}$ Discrimination further affects job opportunities for Tamils (Emmerson, 2018; Seoighe, 2017).

At least one farmer understood the employment challenges that her children will face and expressed concern about the shift in livelihood strategies and its implications for the future of her farm. Some informants I interviewed believed that dairy farming will decline over time because knowledge is not being passed on to children. A farmer - the only one interviewed who aspires for her children to continue farming - shared this view:

My children are not ready to continue this after me [...]. I want my children to be working in this field in their future, but they are not capable of doing it (Farmer, personal communication, October 2018).

The second phase of the Wanni Dairy Project targets youth, to address the challenge to support the younger generation into dairy farming livelihoods. Other informants believed that the farmers who are doing well will expand and intensify dairy production but there will be fewer farmers and higher production in future generations. The latter scenario implies a shift from small-scale production towards medium-scale, industrialised production, the implications of which require further research in developing countries' context, particularly relating to environmental impacts (Tarawali et al., 2011). As education is perceived by farmers as the most important social impact enabled by the income from the Wanni Dairy Project, monitoring of educational outcomes of farmers' children and their influence on livelihood strategies would be beneficial to determine the extent to which livelihood strategies are shifting away from agricultural production.

\subsubsection{Perceived poor decision-making}

The social impacts of increased income from the Wanni Dairy Project are complex. While increased income reduces poverty and improves wellbeing, increased income is perceived to affect some households with what is considered poor decision-making, such as spending on what was described as 'junk' food, drug and alcohol addiction, and a desire to further increase income through child labour (NGO representative, personal communication, 2018). This subsection discusses these examples in turn.

\footnotetext{
${ }^{3}$ Agriculture and fisheries predominate livelihood strategies and post-conflict economic growth is slower in the conflict-affected areas than the rest of the country (Emmerson, 2018; Munas \& Lokuge, 2016).
} 
First, consumption of junk food can magnify negative health outcomes such as malnutrition because junk food is typically highly processed, high in fat, salt and sugar content, and often has additives and preservatives to preserve shelf-life and enhance taste, and thus has lower nutritional value than traditional healthy alternatives (Muehlhoff et al., 2013; Weerasekara et al., 2018). Dietary shifts in Sri Lanka, influenced by globalisation and Westernisation, have resulted in the decline of traditional diets and the rise of Western diets that are typified by such foods and high consumption of animal products (Weerasekara et al., 2018).

Bulloch (2014) argues that 'Western food' as a demonstration of modernity and 'moving up' can be perceived as a status symbol in developing countries. Although it is beyond the scope of this research to ascertain people's motivations for increased spending on different types of food, upon reflection on observations I recorded of the generous and warm hospitality I experienced during field visits, I would speculate that income is perhaps partly spent on what informants identified as junk food as a marker of status. Packaged sweets and chocolate tended to be offered in some of the poorer households I visited, although I was aware that these items are more costly for farmers than traditional, local produce. I reflected that some visits appeared to invoke a special effort to display farmers' achievements; young children recited English, farmers took pride in showing me recent improvements to their lands, Western foods were eaten. Conflict-affected farmers' resilience and accomplishments, and moreover, their effort to present these, was particularly evident amongst those farmers who also shared the continued challenges in their lives. On the other hand, the very successful farmers I met during this research appeared to be less concerned about instilling an impression of success.

Second, increasing prevalence of drug and alcohol addiction is attributed to the post-war context, in which men, specifically, are struggling with the emotional and psychological impacts of the conflict. The causes and effects of drug and alcohol addiction in this context were clearly articulated by the people I spoke to during this research. They indicated that the causes were a combination of factors: a lack of education about the consequences of addiction; vulnerable, traumatised people who need support; and ready access to illicit substances. The main effect they described was that women and children are exposed to increased violence. These perspectives are shared in studies that examine social factors in post-conflict communities in Sri Lanka (Guruge et al., 2017; Herath, 2018). WCDO is involved in raising drug and alcohol 
awareness with youth to address this issue and in supporting women and children affected by violence. Section 6.4 of this chapter addresses gender violence in this research.

Third, it was reported that some farmers want to maximise the newly-realised potential for dairying to increase income by keeping their children home from school in order to work. WCDO reported regular school attendance of all children through its monitoring in the villages where they are present. The farmers that I interviewed appeared to prioritise education and all of their children attended school. One farmer, however, expressed anguish that her teenage daughter needs to work in a garment factory to help repay the household debt, missing the opportunity to access higher education as her brother does. Despite farmers' value of education, farmers' financial realities inevitably influence their children's future livelihoods.

The relevance of these social factors to farmers' livelihood experiences highlights the important role of WCDO in providing education and support services. Women's self-help groups, children's clubs and NGO-monitoring of school attendance play an integral role in ensuring that increased income encourages positive outcomes and minimises negative ones in the post-conflict context. These roles appear crucial at this stage of post-conflict efforts to rebuild livelihoods and address issues, to ensure that development interventions address the holistic factors that affect livelihood outcomes and improve prospects for livelihood sustainability.

\subsubsection{Health impacts of dairy production and consumption}

Health factors are affected by rising incomes (Hemme \& Otte, 2010; Muehlhoff et al., 2013). The previous subsection addressed perceptions of potential negative health impacts and 'junk' food consumption. However, if income is spent on nutritious consumption this can improve food security and have positive health outcomes - in line with the popular development narrative (Hemme \& Otte, 2010; Muehlhoff et al., 2013). Farmers reported that their households are healthier than before, although some people, including children, continue to skip meals. Milk consumption is constant (between 0.5-1 litre per $\mathrm{HH} /$ day), regardless of changes in production or income.

I think we are getting enough nutrition. Our family's income level has gone up and so our nutrition has also improved (Farmer, personal communication, October 2018).

Perceptions of improved health of farming households in this research are, therefore, due to higher incomes rather than the nutritional benefits of dairy. Development and industry actors' 
claims that dairy development causes positive health outcomes, thereby implying (and at times explicitly stating) that dairy consumption causes positive health outcomes, would be more accurate to emphasise the correlation between increased incomes and positive health impacts (Hemme \& Otte, 2010; MFAT, 2014; Muehlhoff et al., 2013).

Nonetheless, it is argued that consumers in developing countries generally, more so than those in developed countries, highly rate the importance of the health factors of dairy foods (Guenther et al., 2015). Genetic factors, cultural factors, and communication of health and nutrition information to consumers are important factors affecting Asian dairy consumption (Ahuja et al., 2014). Dairy is perceived to be highly nutritious by farmers in this research.

I think dairy is very nutritious. Even in hospitals, they are telling us to drink milk and eat eggs. So, we are thinking it is nutritious (Farmer, personal communication, October 2018).

However, processed dairy products, some of which are not necessarily nutritious (Muehlhoff et al., 2013), are becoming more widely available because, in part, dairy development relies on growing the demand for processed dairy products to support farmers' livelihoods as they can supply milk to processing plants.

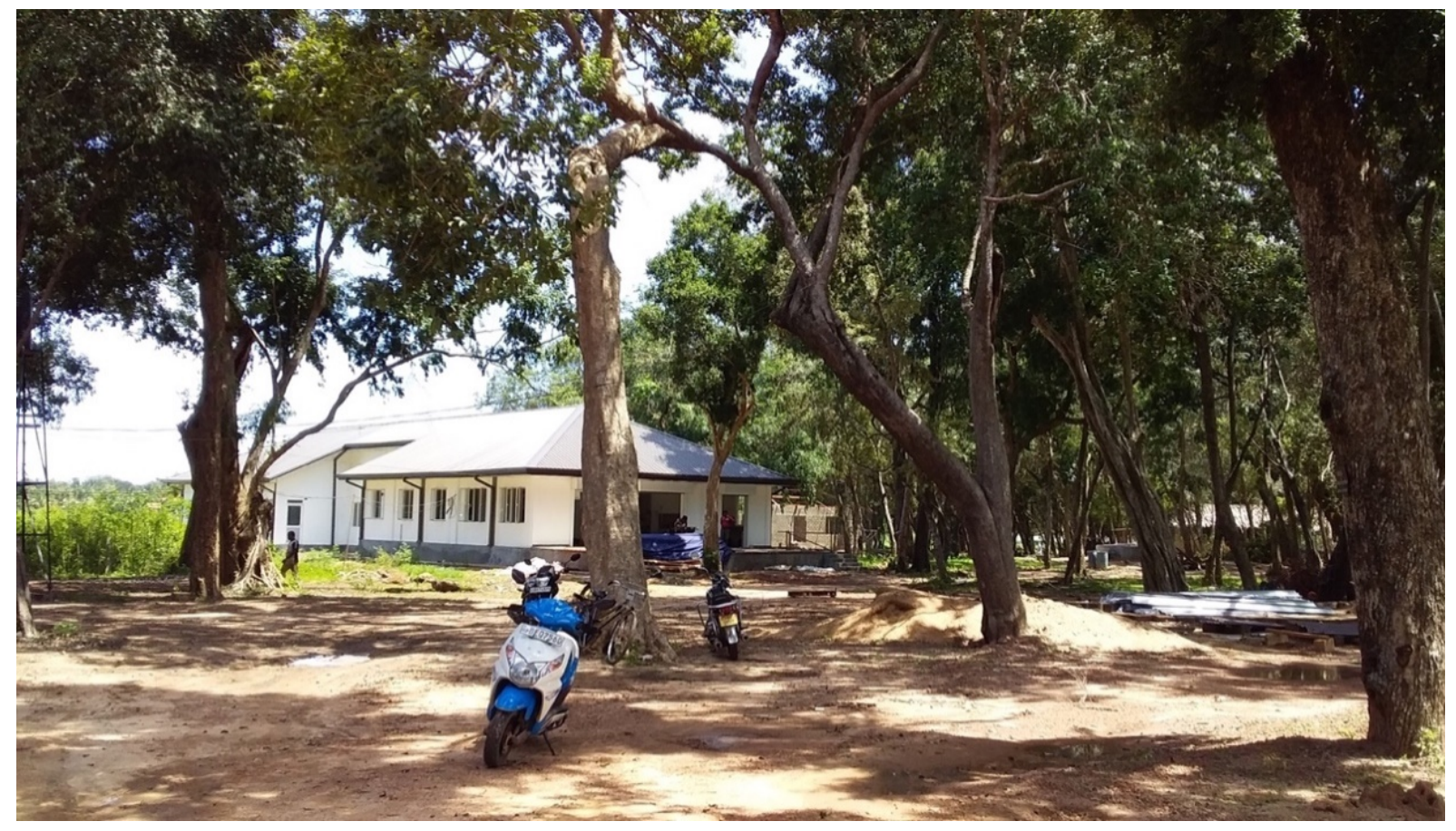

Figure 6.2. Processing plant under construction at the Wanni Dairy Project site.

Source: author 
A processing plant (figure 6.2.) to make products such as ice-cream and yoghurt was under construction at the Wanni Dairy Project site when I visited. Dairy processing forms a key aspect of the Wanni Dairy Project, and there are also plans for retail outlets to be established (MFAT, 2018b).

It seems important, therefore, that the diversity of nutritional compositions of dairy products is communicated in culturally and linguistically appropriate ways to consumers. Dairy companies have a record of unethical marketing tactics which has been highlighted in international reports (Galtry, 2013). This is especially evident in developing countries' contexts and in relation to the marketing of dairy consumption for health reasons. For instance, milk powder is promoted by Fonterra and other companies for children aged one year and over, yet, the marketing of formula milk to children under two years is internationally prohibited because it undermines breastfeeding practices (Hidayana et al., 2017).

\subsubsection{Dietary shift}

Dietary shift towards increased dairy consumption, which may contribute to increased Westernstyle consumption in general, among populations with traditionally low dairy consumption is a concern for some (Galtry, 2013; Weerasekara et al., 2018). A study in Sri Lanka highlights the role of colonisation and post-colonisation in increased food insecurity, NCDs and micro-nutrient deficiency as the globalised, Westernised food system (that is high in animal products, fat and sugar) has eroded the traditional food system (Weerasekara et al., 2018). Historically, consumption of fresh cow's milk was not common among adults in Sri Lanka as they understood that the nutrients derived from milk (protein and calcium) can also be obtained from vegetable sources (Ibid.). ${ }^{4}$ Today's Western diet is argued to have adverse effects on health, equity, and the environment in Sri Lanka, which is evident in Sri Lanka's food production and the population who consume an increasingly Western diet (Ibid.).

Farmers in this research continue to consume dairy in traditional fermented forms such as curd and many also drink fresh milk, but there is a shift occurring towards processed dairy, which can reportedly be seen across the younger generation, some of whom prefer processed products, which are increasingly available.

\footnotetext{
${ }^{4}$ Traditional South Asian forms of dairy, e.g., curd (a natural probiotic yoghurt) were consumed, however, comprised a small proportion of overall diets.
} 
I think [fresh milk] is more nutritious than milk powder so I like to consume it. But for the children, they do not like it. We are preparing milk for our home purpose: curd yoghurt and milk coffee (Farmer, personal communication, October 2018).

The first times I visited Sri Lanka around ten years ago there were hardly any dairy products. Milk powder, of course, but that was about all. Now in the supermarkets there are hundreds of processed dairy products (NGO representative, personal communication, October 2018).

Further, a number of farmers held contradictory views, contending on the one hand that dairy is nutritious, but on the other hand that dairy contributes to illness (cough and flu) and allergies. Some farmers, therefore, do not give milk to children.

We are healthy and milk is nutritious. [...] We don't give fresh milk for our children because they will get a cold easily (Farmer, personal communication, October 2018).

Farmer: In our family, also we are thinking some people will get cough from fresh milk, so some skip, and it's the remaining people who will drink one litre of milk.

Jasmine: Why do they think that the milk will give a cough?

Farmer: Fresh milk has an allergy problem. Many people believe this (Personal communication, October 2018).

These tensions between development and industry rhetoric, and local, traditional beliefs are indicative of the cultural and health complexities that appear to be overlooked by development policymakers and practitioners in dairy development initiatives and are relatively unexplored in literature on dairy development.

In commercial operations, on the other hand, private sector actors counter these widely acknowledged tensions with large investment in marketing to strategically influence beliefs about health values (Fonterra, 2018; Mawdsley et al., 2018). Stakeholders and researchers that are primarily concerned with commercial aspects of dairy production tend to focus on economic outcomes and overlook other aspects of livelihoods, including the connection between commercial processes that are occurring across the supply chain and the potential social impacts that this can have on livelihoods, including health and cultural impacts of changing diets (Snoxell, 2018). Moreover, dairy company actors, who are also involved at the macro-level because of their institutional influence, are not themselves affected by the health impacts of changing diets as a result of increasing commercialisation, whereas farmers and local consumers are affected. Health impacts and consumption trends of farmers involved in dairy development initiatives should, therefore, be an important consideration for development policymakers. 


\subsubsection{Caring for cows: Culture and ethics}

In the context of internationally influenced dairy development, especially, it is evident that cultural factors influence dairying livelihoods. For example, cows are considered sacred - and thus are not slaughtered - in the dominant local religion (Hinduism) of Tamil farmers in the Wanni Dairy Project, whereas slaughter of male calves is considered standard dairying practice in New Zealand and other countries (Braimoh et al., 2016). Non-local informants in this research considered the absence of culling practices as a barrier to efficiency because male calves consume resources that could otherwise be used for productive cows. The rhetoric around farming being more sustainable based on the compromise of ethical and cultural factors, I contend, is problematic because it reinforces the marginalisation of local, indigenous knowledge and disregards concerns about animal welfare (Daskon \& Binns, 2009; Scherer et al., 2018).

Another example of the intersection between cultural factors and dairying livelihoods can be seen in some farmers' resistance to automated milking systems suggested by the NGOs.

Milking takes a lot of time and I was told that I should get automatic milking system, but it is not good for the cows and will damage their udders. I refuse to get the automated system because I want to look after my cows and it is not ethical to use that system (Model farmer, personal communication, October 2018).

Refusal by some farmers to adopt automated milking practices, despite its productivity gains, is ethically motivated. Daskon and Binn's (2009: 494) study using a sustainable livelihood approach in Sri Lanka emphasises the significance of "understanding the interface between culture, livelihood sustainability and community." It is possible for cost-effective, sustainable small-scale dairy farming systems to prioritise ethical and cultural factors such as animal welfare over maximum economic productivity and it raises the issue of whether Western ideas about agricultural production are culturally and ethically insensitive in the Wanni Dairy Project. Ethical factors are important to New Zealand producers, ${ }^{5}$ and so too are they important to Sri Lankan producers who prioritise different, but nonetheless valid, ethical factors.

Views on ethical grazing practices also varied. Farmers believed that jungle-grazing is more

\footnotetext{
${ }^{5}$ For instance, factory farming of cows - accepted practice in many parts of the world - does not align with the values and image of New Zealand farmers.
} 
natural and ethical than tethering cows all day (fencing is not often viable for farmers). ${ }^{6}$ However, project staff encourage farmers to tether cows, practice 'cut and feed' and use cattle sheds to mitigate disease susceptibility and improve productivity, which farmers described as costly and challenging compared to the care required for indigenous breeds. Most farmers reported that they face difficulties in caring for their cows in the wet season because of inadequate cattle sheds.

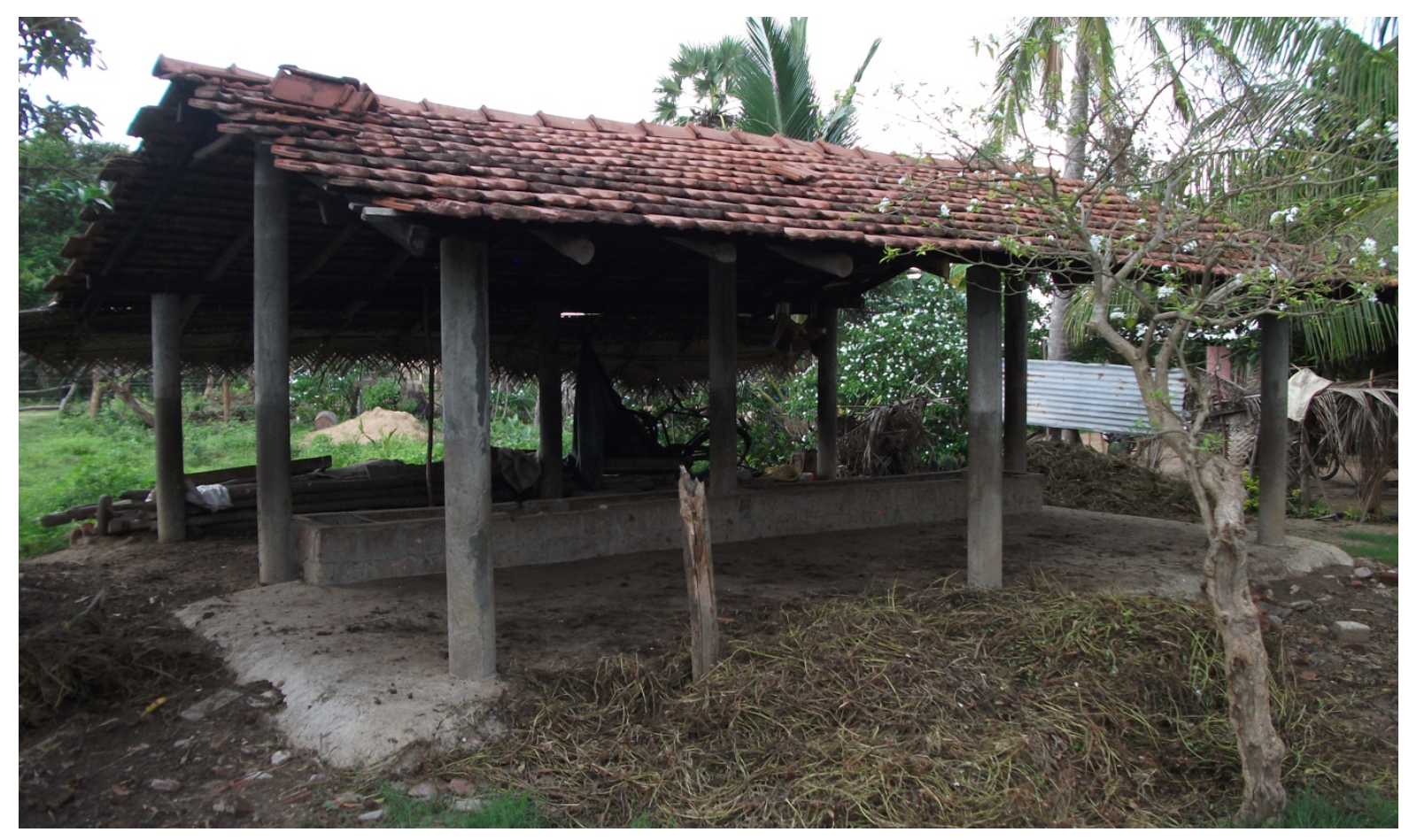

Figure 6.3. Farmer's photo of cattle shed.

Source: farmer (photovoice method)

This is our cattle shed. We built this cattle shed three years ago but only half has concrete and the other remaining part is remaining as soil. [...] Problems... for one: our cattle shed. The ground level is low. In the rainy season the rain water will go in, then we can't keep the cows there (Farmer, personal communication, October 2018).

Moreover, there is an evident contradiction between the 'ethical' pasture-based systems (i.e., untethered) that the New Zealand government promotes in dairy development initiatives (MFAT, 2018a) and the 'ethical' need to tether cows provided through the Wanni Dairy Project.

The disease and resulting death of a high-yield calf provided to a farmer through the Wanni

\footnotetext{
${ }^{6}$ Jungle-grazed livestock is more productive but the negative impact on the environment is greater.
} 
Dairy Project, despite the support and training provided, is a cautionary reminder of the risks and difficulties that farmers face in caring for these particular cow breeds that are, arguably, 'unsuitable for climatic conditions in Sri Lanka' (Knowles \& Heanue, 2019). ${ }^{7}$

The high yield is from the purebred cow, but it doesn't have a digestive system for our climate. If it gets a disease, it will be lost (Farmer, personal communication, October 2018).

Nevertheless, overall, farmers I talked to felt equipped to address the challenges of caring for highyield cows because of the training provided through the project. Farmers have a high awareness of the additional care needs and related ethical factors of farming with high-yield breeds. In their view, a productive high-yield cow is fundamental to farmers' experiences of improved wellbeing and livelihoods.

Although dairy development initiatives are premised on New Zealand sharing its dairy expertise with developing countries, I suggest that New Zealand dairy stakeholders could learn from developing countries. Learning from development contexts helps to reverse the patronising model of 'Western expertise' that has been criticised in post-development discourse (Escobar, 1995; Kothari et al., 2019). Kothari et al. (2019: xxvii) contend that a failing of the SDGs is that "culture, ethics and spirituality [are] side-lined and made subservient to economic forces". Ethical values that support non-violent animal treatment expressed in this research could shape more humane dairying practice in New Zealand (Scherer et al., 2018), which has been criticised for its violence, both that which is culturally acceptable and that which is criminal (RNZ, 2018).

\subsubsection{Religious beliefs}

The overlap between dairying and cultural factors are not just important for livelihoods, but also for wellbeing (Daskon \& Binns, 2009). Religious factors have a complex influence on beliefs, practices and relationships with animals (Ibid.). Some farmers, for example, described a spiritual connection between their livestock and their household.

Farmer: If something wrong is going to happen for the family members, it will also go with the animals. Like, they will get the disease as well.

\footnotetext{
7 Unrelated to the Wanni Dairy Project, an Australian live export company was contracted to provide cows and technical support to Sri Lankan farmers. In 2017, New Zealand exported 2000 cattle to Sri Lanka for this project. However, inadequate farmer training contributed to the deaths of hundreds of cows and was described in New Zealand parliament as "an unmitigated disaster from a human and animal welfare perspective" (Hughes, 2019).
} 
Jasmine: So not necessarily the same sickness? But more of a belief about the energy? So if the family gets sick, the animals will get sick and the other way around?

Farmer: Yes, and all the people. After that jersey cow died, my husband got a hip fracture. Within one week. Animals die because of our sickness. It's our religious belief (Personal communication, October 2018).

One farmer's photo (figure 6.5.) of a shrine she built on her farm illustrates its importance. My interpreter explained that when people and animals get sick, people visit the temple to pray. Locally-based development actors' shared understandings with farmers of this cultural context are key to the effective farmer-NGO engagement that was reported by farmers.

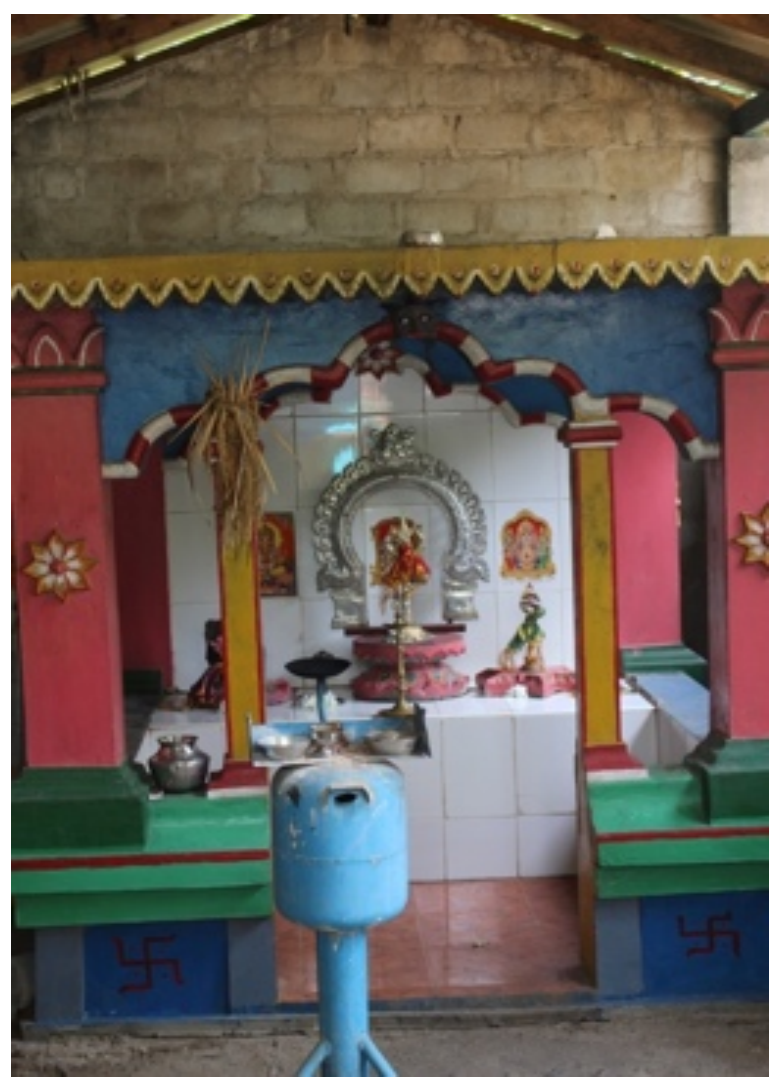

Figure 6.4. Farmer's photo of her Hindu shrine.

Source: farmer (photovoice method)

This is my personal temple (Farmer, personal communication, October 2018).

Paradoxically, the Christian missionary motive of some NGO actors suggests a potential threat to the non-Christian religious identity of farmers in the Wanni Dairy Project. $^{8}$ The 'problem of proselytizing' is argued to be central to development studies (Fountain, 2015). Fountain contends that development is proselytizing by nature, whether religious or secular, because of its moral objective of enacting transformative interventions in the lives of others, and calls for a closer discussion around ethics to broaden understandings on proselytization. All development is value-laden, and although religious proselytizing activities tend to be perceived as coercive and illegitimate (Ibid.), Christian missionary activity clearly plays an important role in many development interventions, globally and in Sri Lanka.

Informants described religious conversion as an underpinning objective of the

\footnotetext{
${ }^{8}$ Farmers are predominantly Hindu in the Northern regions, but there are also farmers from other religions in the Wanni Dairy Project.
} 
NGOs' activities in the region. Further, the succession plan for WCDO's social support activities involves eventual handover to local Christian churches. Potential social and cultural impacts of a shift in farmer's religious identity and increasing Christian church involvement in development activities appeared to be unrecognised by project stakeholders, despite the potential for missionary impact on development to be extensive (Ibid.). In India, conversion from Hinduism to Christianity, arising from missionary development interventions, is shown to affect culture (changed clothing, diet, perceptions of education, status, caste and 'progress'), and enact politicaleconomic change (Mosse, 2014). In the particular socio-political context of Mosse's study, some participants reported feelings of humiliation, guilt and betrayal when asked about religious identity, and many also experienced better opportunities and higher status. Although religious identity and the societal conditions under which development interventions come to be religious are part of the political system that frames development policy and practice, it is important that missionary elements of the Wanni Dairy Project receive attention so that unintended consequences are better understood (Fountain, 2015; Mosse, 2014).

\subsubsection{Summary and recommendations}

This section discussed social factors and impacts. The research findings indicate that, overall, the Wanni Dairy Project is perceived to effectively address the needs of the people affected by the intervention, which results in improved rural livelihoods and perceptions of wellbeing. This success is based upon participation, grassroots development and a vision for sustainability that is reflected in strong relationships between farmers and NGO actors. Farmers' perceptions of their own low influence, however, differed from NGOs' perceptions of farmers' high influence. Both farmers and NGO actors justified these positions, which highlighted the subjective nature of qualitative research and differing understandings of power dynamics.

In relation to improved livelihoods, this section discussed multiple social impacts, including improved status, education, wellbeing, independence and health; and potential negative impacts reported for some, such as unhealthy consumption, child labour and the challenge of addiction that was associated with increased wealth. This section thus highlighted the integral role of the NGOs in minimising negative outcomes and maximising positive ones in the complex post-conflict context. Perceptions of health impacts revealed that farmers consider dairy to be nutritious, yet, 
simultaneously, dairy is seen to contribute to illness and allergies. Health implications of dietary shifts and increased processing of dairy are only partially understood by some development actors.

This section identified cultural factors as being little understood by non-local development actors but highly influential in shaping farmers' practices and beliefs. In the livelihood and cultural context in Northern Sri Lanka, beliefs about cows inform attitudes and behaviours upon which ethical practice is based. This section discussed the potential for better understandings of the interdependence of culture and livelihoods by Western actors to inform ethical factors of dairying. There is a perceived burden and risk of raising high-yield calves provided by the Wanni Dairy Project because calves need considerable investment before they become productive (if they do), are more susceptible to disease (thus have higher costs of disease management), and their digestive systems are not suited to the local conditions. They, therefore, need specific care - though this does not outweigh the benefit of a productive high-yield cow. The Wanni Dairy Project has a strong focus on farmer training to equip farmers with the knowledge to care for the high-yield cows, and this is important, for farmer wellbeing and livelihoods, and animal welfare. Lastly, the section discussed the religious missionary aspect of NGO activities and the potential implications for farmers' religious identity. The recommendations based on this research are:

- NGO partners should take steps to negotiate with the milk collection companies for timely payment to farmers, or support the farmers' cooperatives to do so.

- MFAT should be cognisant of the role of dairy in dietary shifts towards Westernised consumption and the potential health impacts - negative as well as positive - and local attitudes towards such shifts, in regard to the Wanni Dairy Project's expansion of processing facilities and the types of dairy products that will be produced.

- Development stakeholders, particularly agricultural actors, should recognise the importance of cultural factors to farmers to enhance their understanding of and respect for approaches to dairy farming in Sri Lanka. Broader understandings of cultural factors may provide insights and spur reflections on ethical factors of farming in other contexts.

- MFAT should be cognisant of proselytization through the implementation of the Wanni Dairy Project, and the potential for Christian missionary objectives to have social and cultural impacts. Further steps could be taken to explore these impacts on participants. 


\subsection{Women and dairy development}

This section draws together the strands of this research that relate to the experience of being a woman and a farmer in Mullaitivu and the Wanni Dairy Project by addressing the gendered aspect of dairy development and the issues that women face in the post-conflict context. This section aims to address gaps in the discussion to complete the understanding of social impacts and set the foundation for the understanding of environmental impacts to be discussed in the next section of this chapter. This section is deliberately structured in the middle of this chapter to place gender at the centre of the discussion and to avoid construing gender as an afterthought as others have done (Ellis, 2000). Gender alone is a reductive marker of identity as one is never only a woman but also holds many other roles. Moreover, female participants may not strongly identify with their role as a woman and instead prioritise concerns that relate to other aspects of

identity (Cornwall, 2003). Nonetheless, the shared gender identity of participants in this research raises specific issues and the Wanni Dairy Project targets gender inequality. Although this thesis explores the experiences of women throughout, there is a need to address specific gender implications drawing on feminist, and gender and development literature.

The legacy of war continues to impose hardships on Tamil-speaking women in the north and east of Sri Lanka, in a highly patriarchal context that is shaped by ingrained social and cultural practices (ICG, 2017b). Women face a lack of transitional justice over experiences of rape and sexual violence, and forced disappearance, forced recruitment and deaths of family members Ibid.). Women also face economic deprivation; displacement and destruction of homes and communities; psychological trauma; and vulnerability to sexual violence, exploitation and domestic violence (Guruge et al. 2017; Herath, 2018; ICG, 2017b). Tens of thousands of widowed women have become heads of households and primary income earners (Hyndman \& de Alwis, 2004; Vasudevan, 2013). It is argued that Tamil-speaking women in the north and east have been affected by the war and its aftermath more than any other group in Sri Lanka (ICG, 2017b). Funding and support to address the severe economic and physical vulnerability of conflictaffected women in Sri Lanka is essential. 


\subsubsection{Gender inequality and participation}

Women play a key role in small-scale dairy production (Boros \& McLeod, 2015; Sharma \& Vanjani, 1993). Agricultural research often focuses on and generalises men's experiences, yet, many aspects of women's experiences are distinct (Mosse, 1995). Further, the reliance on quantitative data in research is argued to be inadequate for analysing feminist concerns (Jayasinghe \& Lakshman, 2011). Jayasinghe and Lakshamn (2011) demonstrate that qualitative understandings to explore connections between market and non-market household activities reveal the burdens and impacts of economic and social inequality for women in Sri Lanka. Another study in Sri Lanka shows that women tend to farm differently to men, using more progressive approaches, which means they often have smaller herd sizes but higher productivity (Tharsinithevy \& Sivarajah, 2011). Women, however, tend to make less profit than men for various reasons including the need for women to spend more on labour to meet the physical demands of farming, and women engaging in more non-market activities than men (Ibid.).

Women's involvement in dairy farming can nonetheless contribute to improved gender equality through improved livelihoods and social status (Boros \& McCleod, 2015; Sharma \& Vanjani, 1993). Whether or not livestock is owned by women, dairying income is mostly received and used by females in Sri Lanka (Tharsinithevy \& Sivarajah, 2011). Improved rural livelihoods as a result of dairying are usually because of increased diversification of livelihood strategies or because women who were previously not earning began dairying to support their households (Ibid.). Women in households with a higher degree of poverty often have more equal opportunity to participate in income-generating activities due to necessity (MFAT, 2016: 35).

NGO actors in the Wanni Dairy Project recognise the need and potential for development interventions to address issues and inequalities faced by women in the post-conflict context, such as economic insecurity and social stigma.

Women need to be seen for their value and their identity and to restore their dignity (NGO representative, personal communication, October 2018).

Increasing women's participation in public spheres, however, can be inhibited by gender roles that are rooted in traditional, patriarchal social and cultural norms (Guruge et al., 2017; Herath, 2018; ICG, 2017a). ${ }^{9}$ Development researchers often have observed the failure of participation to address

\footnotetext{
${ }^{9}$ Gender roles in Sri Lanka are further addressed in Chapter Five.
} 
gender inequalities due to the limited understanding and analyses of structural gender relations by project staff (Kindon, 2010; Mkenda-Mugittu, 2003; Mosse, 1994), and the limitations on meaningful change for women in the societal systems in which development interventions often operate (Sharma \& Vanjani, 1993).

In this research, project staff recognise the need to carefully manage and balance the needs of both men and women in the local context.

There need to be changes in the dairy system. But every intervention needs to be local, every single case needs to be tailored to the local needs and local situation. The people need their dignity. Everyone has value. [...] It is hard because men have ego and they are emotionally and psychologically weaker and cannot cope with the trauma as well as the women. The men feel they need to provide and there is pressure on them if they are failures. So both need to be carefully managed and balanced. [...] Achieving gender equality is about the approach because people are a product of their environment. Men must be included in a way that they can. (NGO representative, personal communication, October 2018).

In order to overcome women's low participation, project staff raise awareness of female farmers' contributions to demonstrate the potential for their involvement in dairying to improve household wellbeing.

$89 \%$ of the registered farmers were men. I asked them, "Who milks the cows? Who looks after the cows?" I spoke to them all. [...] Imagine what can be possible when women can contribute. Instead of just thinking of 'him' or 'her', I told them they should be thinking 'us'. And after changing their way of thinking about their wives and their roles, I said, "why do you not put your wife's name?" After that $49 \%$ are women. Still, more than that are women - probably $80 \%$. Then I spoke to all the women: "The man is the head of the household," I told them, "but you are the neck. And the neck tells the head which way to turn. Without the neck, the head can go nowhere!" (NGO representative, personal communication, October 2018).

By engaging with men and women on the issue of women's participation, rather than just targeting women in development projects, which could create animosity, project staff can be seen to subtly challenge gender roles "without undermining the traditional household gender structure" (NGO representative, personal communication, October 2018). In addition to acknowledging gender differences, the project aims to enforce neutrality and inclusivity towards intersectional differences such as religion, ethnicity and caste. Meeting the needs of all groups reduces divisions and potential conflict, which increases sustainability (MFAT, 2016: 36). 


\subsubsection{Independence and empowerment}

Female farmers described individual and household impacts of financial independence and security (through the acquisition of the calf as an asset and regular income from selling milk, described in the previous section of this chapter), expressing the multiplicity of their identities. Financial security, for example, enables spending on children's education, from which women derive happiness and pride, and their household derives status. Regular income from dairying is said to reduce women's financial reliance:

I am an independent woman. That's what I am proud of. [...] Due to this dairy farming I have got many benefits, like, I do not want to depend on my husband's income (Farmer, personal communication, October 2018).

It also relieves pressure on men as the sole economic provider, which is important to some women:

I can get money twice a month. I am giving milk for that Milkco company. [...] Then I can live independently. My husband is a mason. He can't get work every day so even if he missed work, I can help him, and we can save money for our children. And for their education (Farmer, personal communication, October 2018).

Participants' concerns are thus not limited to their identity as women but include their roles as mothers and wives. Cornwall (2003) contends that women's freedom to exercise agency over their concerns, arguably, can be seen to reinforce the social systems that perpetuate gender inequality when their concerns are for others in their roles as wives and mothers.

According to Kabeer (1999), empowerment is the ability to exercise choice, which relates to resources, agency and achievements. Female farmers described themselves as independent and empowered because of increased financial resources, and the resulting positive impact on their relationships, sense of personal capability and future expectations. Despite some farmers' perceptions of their own low influence over identified problems, discussed in section 6.3.1, women do exercise agency; within their households as financial contributors, and as recognised individuals in the Wanni Dairy Project who are capable of accessing information, becoming involved in dairy cooperatives and making decisions to improve their livelihoods and wellbeing. Farmers were proud of these achievements. 
I did not interview any farmers from female-headed households for this research, although I did meet some during my fieldwork. WCDO explained that the Wanni Dairy Project is advantageous to these women, who are particularly vulnerable and lack support.

Women dependent families are getting more benefits from this project. Dairy farming is very simple, they don't have to get more troubles, it's simple and they can earn money and they can be independent (NGO representative, personal communication, October 2018).

Widows often face increased economic responsibilities, social stigma, patriarchal attitudes and community break-up, which compounds their trauma (ICG, 2017b). The Wanni Dairy Project can be seen to be empowering for conflict-affected women, regardless of their household structure, by building their resources and independence in the complex social context in Sri Lanka (Herath, 2018; ICG, 2017b).

\subsubsection{Debt}

Farmers in this research described the pressure on households to repay large loans, particularly when investment in children's education enabled by expensive loans takes many years to generate a return. Livestock helps farmers to access loans, but sometimes additional income is required to repay them. One farmer described her daughter's poor working conditions at a garment factory, which helped repay the loan for her son's education.

I am feeling sad because we have to settle the loan money, so my daughter is going for garment factory work. It's very hard. That's why [I am crying]. I was thinking about my daughter. She is small, like eighteen years old. It's a really hard job to work in the garment factory. My daughter is working in the garment factory from the morning at seven until night at seven and we are getting 16,000 rupees. The whole time she's standing and working. She has to get the bus from here at five in the morning [...] because it takes two hours to travel from Vavuniya and she has to walk from here to get the bus. We don't have a bicycle or something to go on. She was working for her brother to send him money (Farmer, personal communication, October 2018).

This raised a concern that gender inequality could be potentially exasperated by farmers' debts burdens if male children's education is prioritised. According to literature, however, there is no particular gendered distribution in access to education in Sri Lanka (Jayasinghe \& Lakshman, 2011). On the contrary, there is even greater uptake of higher levels of education by females compared to males (Ibid.), and another informant in this research suggested that females were sometimes prioritised for education (Personal communication, 2018). This farmer's experience highlights the 
difficulty in making generalisations in qualitative, subjective data analysis, and the complexities and human narratives behind assertions that females have equal access to education in Sri Lanka.

\subsubsection{Increased workload}

Increased production enabled by better practices and more productive calves has led to increased time commitments for feeding and milking. Farmers described the added pressure on women to meet their other responsibilities such as caring for children and cooking. Participants all worked from around 4 am until $10 \mathrm{pm}$ and one farmer reported that at peak time she cannot complete milking in time for collection and she feels that she neglects her duties to her children.

Previously I had to milk 30 or 40 litres, and I am milking alone, so sometimes it's getting too late to take care of my children and sometimes even the milk collecting van would go. But now most cows are pregnant, and then I am getting only 10 or 12 litres of milk. Now it's not a problem, but when they are at the peak level, it's hard to milk (Farmer, personal communication, October 2018).

Other studies also show increases on work burdens for women in dairying projects and that cultural norms can inhibit women's benefit from dairying livelihoods because not all household members benefit equally from projects aimed at increasing incomes and nutritional status (Mkenda-Mugittu, 2003). 'Increased working days' as a measure of success in a sustainable livelihoods framework is gender-biased, inadequate and in conflict with social factors of livelihoods, because 'working days' disregards the huge working burden on women as the main contributors to unpaid, non-market work, which underpins the economy.

\subsubsection{Medical access}

Women in developing countries' contexts can often have poor access to medical services due to limited control over household income spending (Mkenda-Mugittu, 2003; Mupawenda et al., 2008; Shetty, 2014). Nevertheless, as women are primarily responsible for household roles and to a large extent determine the quality of life and general welfare of a household, income accrued to women is believed to have greater social welfare impact than that of men (UNDP, 2002 cited in Mupawenda et al., 2008). Access to medical services may be expected to improve, then, as female farmers' experience increased income and agency through the Wanni Dairy Project.

This research showed that only one household accesses medical services regularly, while 
others reported no access to medical services, even when needed, due to cost and distance. ${ }^{10}$ Further, increased workloads impact farmers' health. The various aspects of dairying practice, including hand-milking, collecting feed, cleaning and transporting milk, are physically demanding. Moreover, women are disproportionately affected by increasing workloads, as their household roles generally remain constant. Some farmers reported physical difficulties of increased milking, such as persistent painful conditions on their hands.

Farmer: It is difficult for milking due to this condition, these lesions on my hands. Jasmine: Do you have access to medical services? Will you get medicine to improve your hand?

Farmer: No, we have to pay to get the medicine. Not cheap. Now I am using an ointment from my friend for the condition (Personal communication, October 2018).

The basic health needs of women, particularly poor women, are 'urgent and compelling' because, in addition to adding to people's suffering if these are neglected, they can affect the health and welfare of the future generation (Shetty, 2014).

It was striking to note that all farmers reported that they had adequate access to veterinary services, and some used these for vaccinations, disease management and artificial insemination. Disease management, particularly, is a significant cost for households. A complementary NZAP dairy project in Sri Lanka aims to improve farmers' 'inadequate' access to veterinary services. The prioritisation of investment in healthy livestock over people's medical needs perhaps reflects the micro- and macro-focus on economic outcomes, as well as the local context including the cultural importance of cows, and the marginalisation of women's health. For instance, automated milking would ease the physical demands on farmers but some farmers are concerned about cows' suffering from such practices. There is potential to explore alternative, culturally-acceptable, economically-viable solutions to the physical challenges of milking. A gendered understanding of the Wanni Dairy Project's impacts on farmers' needs for and access to medical services would be beneficial to identify opportunities to reduce barriers as well as minimise work-related medical conditions (Mkenda-Mugittu, 2003).

\footnotetext{
${ }^{10}$ Despite the reported lack of medical access, it appeared that some farmers do access hospitals in times of urgent need. One potential participant was unexpectedly in hospital on the day I visited. Another participant said she did not access medical services, but mentioned that a visit to the hospital shaped her perceptions about healthy food.
} 


\subsubsection{Violence against women}

Gender-based violence occurs throughout Sri Lanka but has grown significantly and is reportedly very high in the north and east since the end of the conflict (ICG, 2017a). ${ }^{11}$ Addressing the economic, social, psychological and security needs and rights of women affected by conflict in the target area of the Wanni Dairy Project is essential to reduce inequalities and ongoing trauma. WCDO informants described the essential work to empower and protect women and children, both that which is done through the Wanni Dairy Project and that which is run alongside but separately funded, including women's self-help groups, children's clubs, sexual abuse reporting lines, caring for orphaned children, enabling the conviction of domestic abusers, and early interventions in schools around drug awareness. There are farmers involved in both the Wanni Dairy Project and women's self-help groups, but there are also people who are only involved in one aspect of WCDO's work, as depicted in figure 6.6.

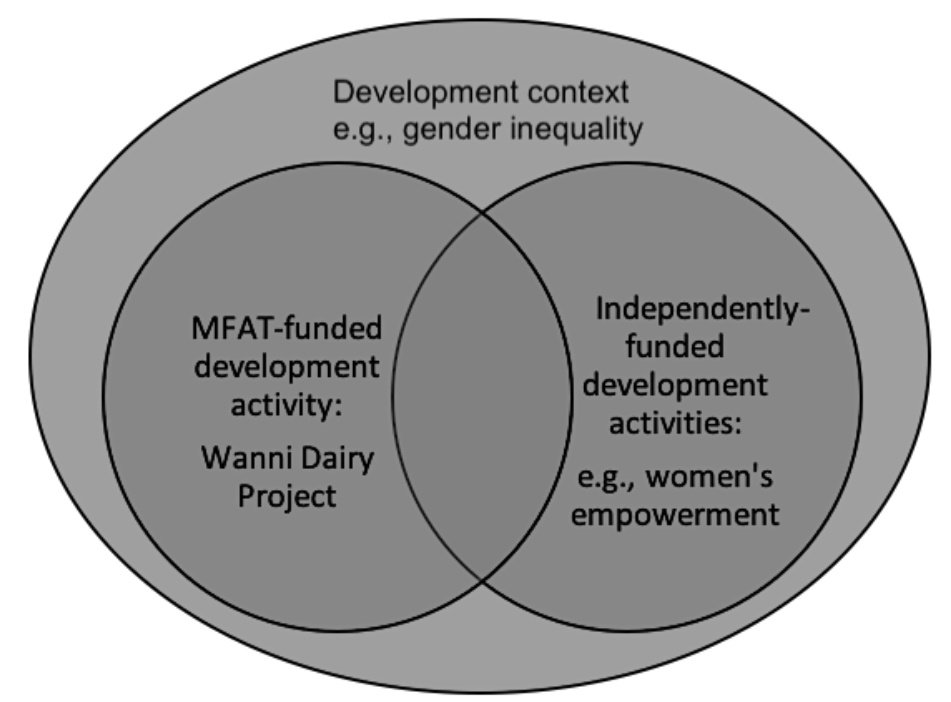

Figure 6.5. WCDO's overlapping and separate projects in the Mullaitivu District.

Source: author

The section where the activities overlap represents people (both staff and participants) who are involved in both aspects of WCDO's development activities. Broadly, the diagram also depicts the interconnectivity between the two spheres of activity within the development context.

\footnotetext{
${ }^{11}$ Gender-based violence (also referred to as violence against women) refers to violence and exploitation directed against a person on the basis of gender, limited here to women, which includes acts that cause or threaten to cause physical, mental or sexual harm, non-sexual physical assault, domestic violence and economic deprivation.
} 
Farmers tend to perceive the various aspects of WCDO's activities as connected, and I also understood, through interviews and observations, the links between the NGO's activities in the region due to the vulnerability context in which they operate. The local connections upon which the Wanni Dairy Project has achieved success were enabled by WCDO's post-conflict community engagement, and the Wanni Dairy Project has, in turn, enabled the continuation of much of WCDO's other work in the community. MFAT (2016: 14) notes:

This activity will complement WCDO's social development programmes funded through other sources, including those that [...] assist families to avoid social ills such as increased alcoholism and domestic violence that can occur with increased incomes and intra-family tensions as women take on leadership roles. Womens' groups that form part of WCDO's child protection programme will act as a forum to monitor and respond to such issues.

When the Wanni Dairy Project began in 2012, the NZAP was focused on funding economic development priorities and, therefore, the WCDO's gender-focused activities in the region, which also support the project, were not funded by MFAT. This subsection relates to findings of this research that bear relevance to but are not direct impacts of the Wanni Dairy Project. I have included this data from my fieldwork in the discussion because it is relevant to the dairy development context and provides important depth on the gender issues in the local area.

Informant interviews revealed cases of domestic violence and even homicide of women involved in WCDO activities in Mullaitivu.

Two of the farmers we work with have been murdered by their husbands. Burned. [We] took the other women to the police station - 17 women - and they all spoke. [...] This was significant for them (NGO representative, personal communication, October 2018).

Today I just heard that a woman - one of our farmers - was found hanged. They are saying suicide, but I think it could be another murder (NGO representative, personal communication, October 2018).

While the victims were not participants in the Wanni Dairy Project, and the circumstances surrounding these incidences are complex, the occurrence of gender-based violence within the communities in this region and some of the potential contributing factors raise the question of the extent to which female farmers involved in the Wanni Dairy Project may be at risk of genderbased violence. Key informants suggested that increased income of women is one factor, amongst others, that have purportedly caused domestic abuse and homicide of female farmers 
in the Mullaitivu District, as a result of women's resistance to their husbands spending income on drug and alcohol addictions, and the challenge to normative gender roles and men's status in the post-war context. This simplified explanation is consistent with other research that identifies multiple factors that contribute to increasing gender violence, prevalent in the north and east, in Sri Lanka since the end of the war (Guruge et al., 2017; Herath, 2018; ICG, 2017a). ${ }^{12}$

As I continued to engage with stakeholders after I completed field research in Sri Lanka, I learned of WCDO's earlier than anticipated withdrawal from the region in June 2019. This accelerated aspects of the succession plan for the Wanni Dairy Project, which involves handover of local operations to Yugashakthi (with continued support from TFNZ), the private company established by the NGOs. This handover bodes well for the sustainability of the project. However, the early withdrawal of WCDO threatens the continuation of the independently-funded activities that support the gender equality focus of the Wanni Dairy Project, and certainly have implications for gender equality more broadly in the post-conflict Mullaitivu region. The findings of this research, in which informants highlight the need for the activities that support women and children, therefore, support the continuation of activities that address the complex gender issues in the region, and encourage policymakers to further prioritise gender in the Wanni Dairy Project.

There is insufficient data to draw conclusions on gender violence, particularly in regard to the Wanni Dairy Project, but this research indicates that there is a real need for development projects in this region to consider risks around gender violence and take steps to minimise potential for harm to conflict-affected women, who face ongoing trauma, hardship and high vulnerability. A gender strategy that is formalised within the Wanni Dairy Project would allow for greater insights into gendered issues (Mkenda-Mugittu, 2003) and demonstrate development that puts people's needs at the forefront (Mawdsley et al., 2018).

\footnotetext{
12 Factors that contribute to gender-based violence include:

- Patriarchal cultural, religious and societal attitudes about gender roles; abuser attempts to assert power.

- $\quad$ Exposure to armed violence; childhood experiences of violence.

- Community breakup: cultural and structural transformation due to sudden social disruptions associated with the end of the conflict; marital instability; stigma that inhibits remarriage of widows and abandoned women; young age; low socio-economic status; low educational attainment.

- The end of LTTE rule which strictly enforced prohibitions against sexual abuse; a culture of sexual exploitation, harassment and intimidation; ongoing militarisation; high alcohol consumption; drug use.
} 


\subsubsection{Stakeholder engagement and gender violence}

One of the intended outcomes of this research, by employing representative participation in my methodology, was to communicate the data I collected to enhance macro- and micro-links and information-sharing between development actors. I wrote a research report for the NGOs, a policy brief for MFAT, held follow-up meetings with key project staff and presented my preliminary research findings at the MFAT offices in Wellington to NZAP staff involved in the Wanni Dairy Project and the agricultural portfolio. This enabled constructive discussion and raised awareness around some of the issues and understandings from my research. Reports of gender violence clearly raise concerns for MFAT, which has a do-no-harm policy that states:

To manage environmental and social risks or impacts, the New Zealand Aid Programme will not fund Activities that: lead to social harm, including [...] increased crime including violence against women (MFAT, 2012).

I understand that MFAT is in the process of refocusing its approach to NZAP development activities to integrate holistic factors including gender alongside the economic focus that has dominated development policy over the last decade. Based on this research, I expect that the refocused, holistic approach by MFAT would be advantageous for gender issues (and the region) and would be welcomed by NGO partners in the Wanni Dairy Project. Even when development interventions are successful at improving women's livelihoods and gender equality, it is argued that it is still necessary to address the broader gender dynamics and social structures that often perpetuate gender inequalities, despite the challenges in doing so (Kabeer, 1994).

\subsubsection{Summary and recommendations}

This section discussed gender factors. It discussed gender inequality and participation, which occurs in the context of conflict-affected female farmers in a patriarchal society, who face high economic and physical vulnerability. The research findings showed that female farmers have experienced empowerment, financial independence and improved wellbeing as a result of extra income earned by increasing dairy production. These factors contribute to reducing the significant economic vulnerability and deprivation experienced by conflict-affected women. Consistent with other dairy development projects, the increase in workloads to enable this improvement disproportionately affects the work burden of women, who still fulfil most other household and reproductive roles (Mkenda-Mugittu, 2003; Mupawaenda, 2008). Households' 
access to medical services remains low, which also disproportionately affects women, especially as the physical demands of women's workloads can heighten the need for medical services.

Cases of gender-based violence in rural communities in the post-conflict Mullaitivu region provided compelling evidence to support a focus on gender issues and holistic approaches to development in the Wanni Dairy Project. The discussion highlighted that while the Wanni Dairy Project targets gender inequality as a cross-cutting issue, acquiring sufficient donor-support for the necessary gender activities remains a challenge. Local partners provide the necessary understanding of the complex social issues faced by communities in order to facilitate women's protection activities, and therefore, I contended that funding for such activities should be prioritised by MFAT in the Wanni Dairy Project. The recommendations based on the findings of this research are:

- Drawing on the strengths of WCDO's complementary, independently-funded gender activities, MFAT should consider a gender-integrated development strategy that prioritises gender equality, empowerment and protection throughout implementation of the Wanni Dairy Project.

- MFAT and NGOs should consider options to improve farmer's access to medical services to address health issues that arise from increasing workloads due to increasing dairy production. While there is a focus on access to veterinary services for animals, a focus on medical services for people would improve labour conditions and social outcomes.

- NGOs should explore possible culturally and economically viable solutions to the challenges of increased milking.

- MFAT should ensure that the NGO partners are adequately supported to carry out activities to protect women and children from violence, and explore further potential options to address structural gender inequality.

- NGO partners should prioritise the development of model farmers who are women to provide relevant and appropriate support for other women farmers, who experience gender-specific implications of intensified dairy production; and to encourage women to exercise influence to improve structural gender inequality. 


\subsection{Environmental impacts}

Environmental issues receive relatively significant attention in New Zealand and many other developed countries (nevertheless, actions to address environmental concerns can be inhibited by competing priorities and contested solutions). It is argued that this attention towards environmental issues is because social, equity and livelihood issues are 'addressed' in these countries, whereas countries with predominant social and livelihood issues tend to have consequently limited consideration of environmental issues (McDermott et al., 2010; Tarawali et al., 2011). ${ }^{13}$ While this generalisation overlooks contextual complexities, it draws attention to the differing priorities of stakeholders in dairy development and sustainable development and how these priorities are enacted in different contexts. For example, considerable concerns over environmental issues of dairying in New Zealand, discussed in Chapter Two of this thesis, include water and soil quality, and climate change. Dairy expansion in the north and east of Sri Lanka, however, is primarily seen by the governments of New Zealand and Sri Lanka as an effective way to achieve economic growth and address poverty. There is relatively limited consideration of environmental impacts of dairying in this context, despite the role of dairy development initiatives in increasing the number of and reliance on livestock for livelihoods, which is inherently connected to natural resource use.

There is consensus that today's global sustainable development efforts transpire within a diminishing window of time in which drastic changes to global production and consumption must occur to limit negative impacts to people and the environment (IPCC, 2019). Concerns about water and soil degradation of dairying is for the most part considered an issue for countries with intensive and large-scale dairy industries but this section contends that these are also important in dairy development projects such as the Wanni Dairy Project. Moreover, climate change is a pertinent, intersecting global and local development concern (Steinfield et al., 2006). Calls to reduce livestock and dairy consumption to combat GHG emissions contradict dairy industry expansion. This research, therefore, discusses local perceptions of the environmental sustainability of dairying in relation to global environmental implications and livelihood factors.

\footnotetext{
${ }^{13}$ I acknowledge increasing income and wealth inequality (and other inequalities), food and housing insecurity, and poverty that affects many people in New Zealand and challenges the claim that social, equity and livelihood issues are addressed in New Zealand.
} 


\subsubsection{Perceptions of environmental sustainability}

The New Zealand Government has repeatedly described dairy development initiatives as a 'triple win': they produce food, reduce emissions and build resilience to climate change (MFAT, 2018a). The Wanni Dairy Project focuses on improved farming practices as the catalyst for sustainable economic livelihoods, in line with the known opportunities to improve dairy production efficiency in developing countries (Gerber et al., 2013; Parikesit et al., 2005). In addition to economic viability, these opportunities often improve environmental factors (Gerber et al., 2013; Braimoh et al., 2016). In the Wanni Dairy Project these include: introducing high-yield breeds; educating farmers on practices that increase milk yields such as better feed varieties and utilising cattle shelters; promotion of an integrated farming system (combining crop production and animals) to enhance soil and biodiversity; and utilising existing farm resources such as manure and composting systems to reduce reliance on industrial chemical fertilisers, among other strategies. ${ }^{14}$ The images in figure 6.7., which shows some of these practices, were taken on the Wanni Dairy Project model farm.

Observation and informant interviews during fieldwork demonstrated how these strategies are implemented in practice and that consideration of environmental sustainability shapes the NGO's promotion of these practices. Farmers' dairying success enables them to strengthen and diversify their livelihood strategies through investment in such practices; by planting diverse crops if they have suitable land, improving cattle sheds, constructing fencing, buying more cows, and growing more cow feed, for example, most of which have both economic and environmental benefits. The Wanni Dairy Project also enables more working days for farmers, and, as the rice and dairy peak seasons alternate, it was reported that there is a limited opportunity cost of labour although there are gendered implications of this assumption, which were discussed in the previous section.

\footnotetext{
14 These strategies are employed in the Wanni Dairy Project, however, the extent to which other NZAP dairy development initiatives include these strategies differs.

WCDO identified communicative challenges with farmers around the importance of reducing dependence on external outputs. The economic result of environmental factors is key, and the Government subsidises industriallyproduced fertiliser, for example, so farmers still want to use it to maximise crop yields.
} 


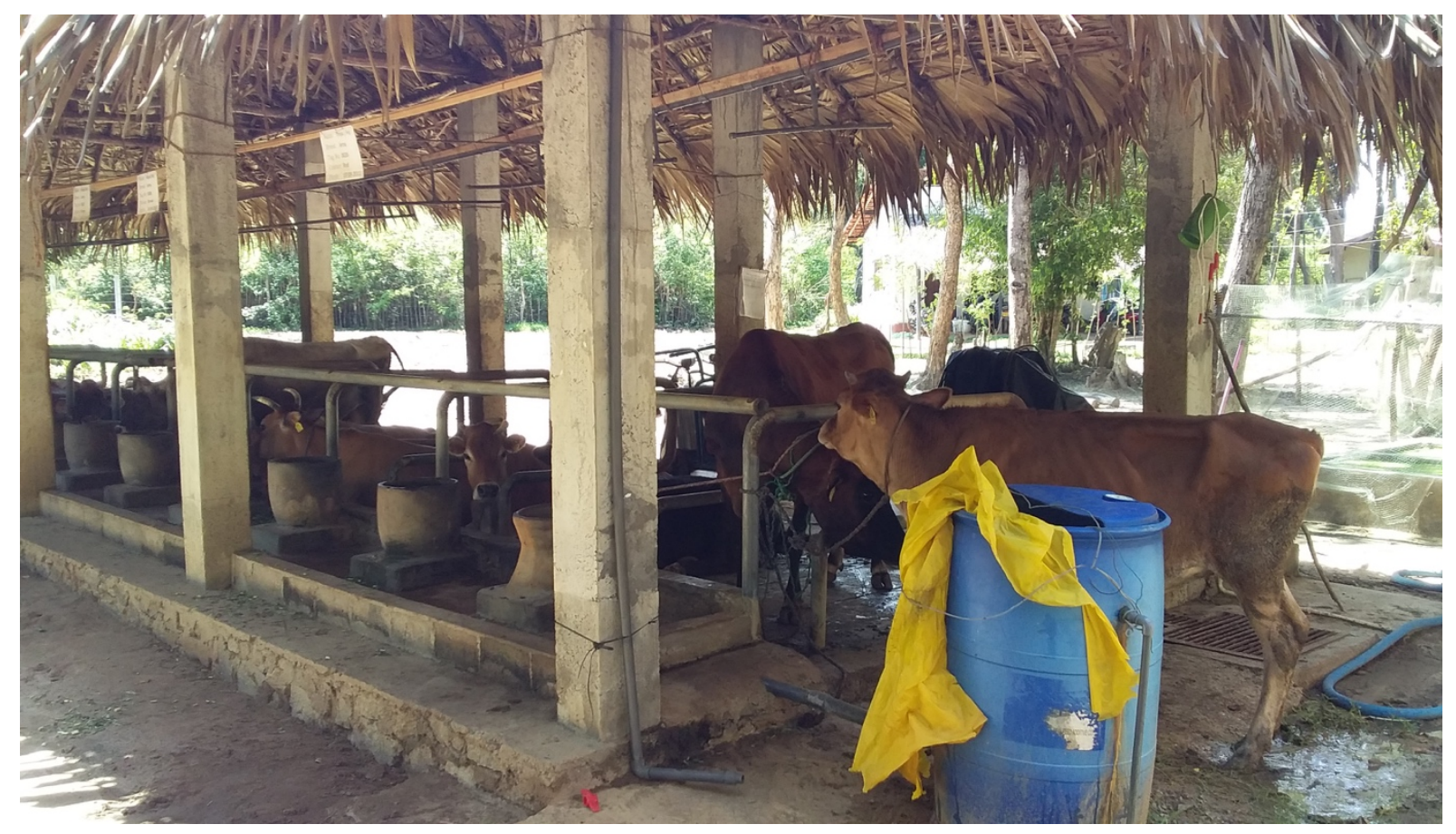

Cattle shelters in use and jersey (high-yield) cows

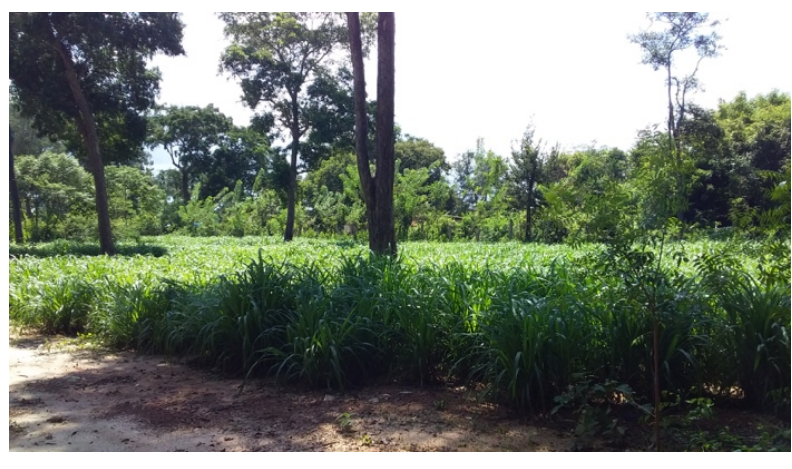

Co3 grasses growing at the model farm

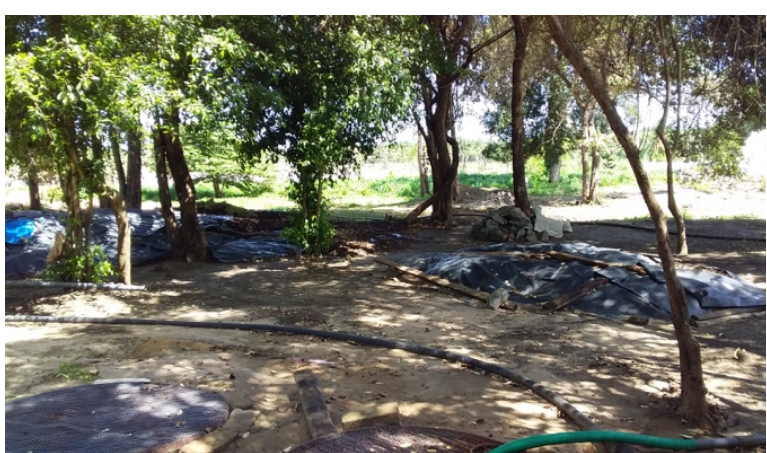

Compost piles

Figure 6.6. Photos of model farm practices.

Source: author

The Wanni Dairy Project is thus perceived to have positive environmental impacts by farmers and project staff.

We have Co3 grass also. We are giving calcium supplements and cattle feed. We buy it from outside. It's an integrated system. Cows have a positive impact on the land. We are also using manure as fertiliser. There is no negative impact on the land. I am happy (Farmer, personal communication, October 2018).

The main practice that contributes to positive perceptions is the use of manure to improve soil fertility, which reduces reliance on industrial fertilisers. Fertile soil supports highly diversified 


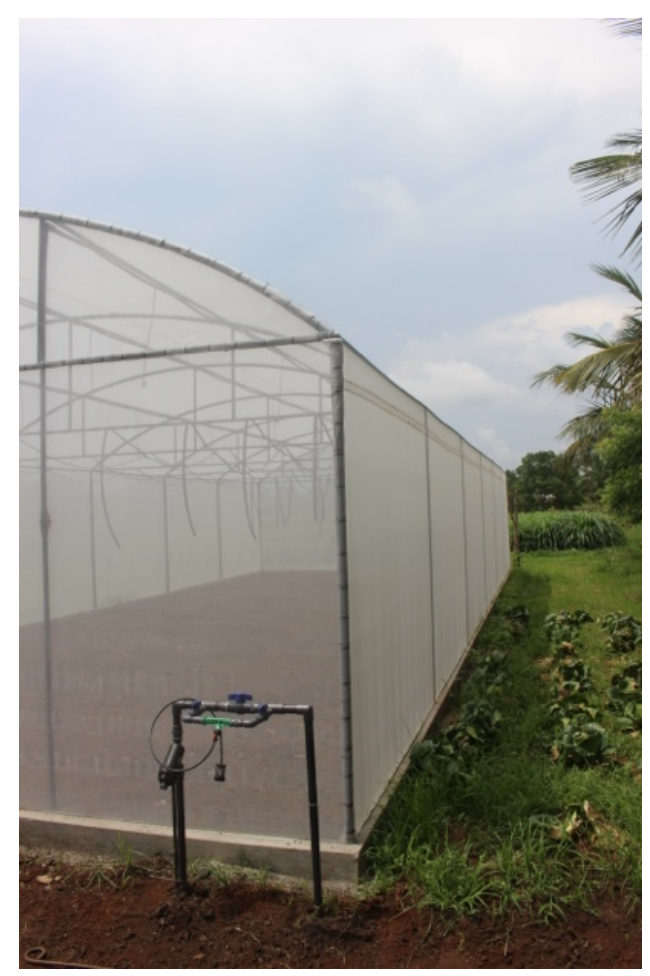

Figure 6.7. Greenhouse for planting at model farm.

Source: author

cultivation, which is both good for the ecosystem and economically viable, even though it is not as financially profitable as commercial farming (de Alwis, 2018). A model farmer had built a greenhouse (figure 6.8.), for planting new varieties of organic vegetables, with income from dairying. The Wanni Dairy Project can be seen to successfully strengthen the integrated aspects of farming in the ways described above.

Although there was a clear plan for intensifying production and diversifying livelihood strategies to increase resilience (Scoones, 2009), many of the farmers I interviewed said their land is unsuitable for diverse crops because it has poor drainage. Cultivation is therefore limited to very few vegetable or legume crops, rice (usually for home consumption), and grasses for animal feed. Some farmers must forage for animal feed. Further, because the unpredictable climate and rainy season, and prolonged droughts come at a significant cost to crops and livelihoods, farmers' focus is on increasing their livestock and dairy production for income rather than strengthening an integrated farming system per se.

Intensifying dairy production in Sri Lanka has economic potential for farmers but the environmental impacts, especially in the long-term, are less clear-cut. Non-commercial aspects of land use have long been valued in Sri Lanka for the benefits over time to soil conservation, soil moisture improvement, microclimate and wildlife protection (Galhena, 2012 cited in de Alwis, 2018). The integrated nature of farmers' livelihood strategies is central to maintaining an environment in which resources are in balance as production increases - as has been the case for over a thousand years of dairying in Sri Lanka - but this appears to be in potential conflict with farmers' priority to intensify livestock farming (de Alwis, 2018). 


\subsubsection{Prospects for environmental sustainability}

Expansion and intensification of dairy production may replace other less profitable livelihood strategies - prompting transition, rather than diversification, in the long-term - thus increasing reliance on dairying for livelihoods, which raises potential economic and environmental vulnerabilities (Tarawali et al., 2011). Authors have noted that the displacement of traditional values, which include the interdependence between livelihoods, agriculture and the environment, has occurred in Sri Lanka as farmers increasingly look to the economic benefits of commercialising farming systems (de Alwis, 2018; Tarawali et al., 2011). A study on a NZAP dairy project in Myanmar suggested economic gains in commercialisation (Snoxell, 2018). Donaghy (2015 cited in MFAT, 2016: 15) notes that "Government and milk processors appear in agreement that upscaling smaller farms is the solution to meeting the demand for milk" and MFAT (2016: 18) states that "farmers will be encouraged to undertake operational expansion". Industry stakeholders are working together to promote this expansion in the Wanni Dairy Project. ${ }^{15}$

The impacts of dairy farming on environmental factors appear to be only partially understood by farmers and project staff in this research. Potential adverse environmental impacts of dairy development in Sri Lanka are identified as: declining soil and water quality and biodiversity due to intensification, increasing farm size and establishment of new farms; pollution of waterways; loss of forest and habitat due to land conversion; and increased pollution from processing plants (MFAT, 2015b: 48). Farmers and local project staff in this research described only positive environmental impacts and did not identify any risks. Cross-cutting environment and climate change impacts of the Wanni Dairy Project at the end of phase one are evaluated as 'good'. However, phase one did not target the mitigation of environmental impacts (MFAT, 2017b: 28). Phase two activity design documents for the Wanni Dairy Project note that, "there is insufficient weather, soil and water data and benchmarking. This has resulted in a lack of knowledge of land use optimisation, disaster risk reduction, water management, environmentally-friendly land management, and climate change adaptation" (MFAT, 2016: 8).

In this research, I observed what appears to be a disconnect between the planned

\footnotetext{
15 Partners are actively involved with industry stakeholders and contribute to their planning and marketing (e.g., regular exchanges with Fonterra) (MFAT, 2016: 18). The Wanni Dairy Project assumes that market demand and processing capacity will keep ahead of growth in milk production (Ibid.). TFNZ and WCDO support Yugashakthi plans to roll out a nation-wide dairy cooperative in its 10-year strategy.
} 
expansion of smallholder dairying and its inherent environmental impacts because they are considered relatively small. Integrated, smallholder farming systems in Sri Lanka are considered to be "generally benign" for the environment and so it is claimed that "the contribution of smallholder dairying to climate change in Sri Lanka is insignificant" (MFAT, 2015b: 48, 49). This is despite acknowledgement of the inherent environmental impacts of dairy production, processing and distribution and that those in poverty depend most on the ecosystem (MFAT, 2016: 36). Contradictions such as activities to change cultural norms on slaughter practices, which are justified by the potential to significantly lower GHG emissions by culling unproductive cows (MFAT, 2016: 8), also weaken the claim that environmental impacts are insignificant.

One review of an NZAP dairy development initiative in the Philippines noted, "the physical environment is not insensitive to dairy farming and processing, even at the small scale [...]. Effluent management, soil and water management generally and the management of chemicals and fertilisers used are all areas of environmental concern for the sector [...] Baselines have not been established, for example, to measure nitrate or phosphate run-off" (Rattray \& Thomson, 2015: 22-23). The report continues, "It is easy to understand how the project can consider environmental risks to most probably be minimal but the milking parlours and holding paddocks of even these small farms are, to the layman's eye, fairly unsightly. In the very least for NZ MFAT, there is a reputational risk to be managed." This infers that, contrary to the "insignificant environmental impact' narrative, the environmental sustainability of dairy development initiatives requires close attention, particularly if projects are successful in attracting more farmers to the industry and long-term environmental impacts are intensified.

\subsubsection{Climate change and environmental deterioration}

Climate change is at the forefront of global environmental concerns, the impacts of which affect social, equity and livelihood factors (Braimoh et al., 2016; Steinfield et al., 2006). Impacts of climate change, such as rising sea levels, temperatures, and the intensity and frequency of weather events, are already being experienced around the world but exceedingly greater challenges are anticipated (Braimoh et al., 2016; IPCC, 2019; Steinfield et al., 2006). Sri Lanka and New Zealand, as island nations and as largely reliant on agricultural production, are particularly vulnerable to climate change impacts. Farmers' livelihoods will be disproportionately affected in 
the coming decades, increasingly so in developing countries with additional vulnerability factors (Raney et al., 2009). Women (and children), moreover, bear the burden of environmental deterioration (Goebel, 2003) and natural disasters (Gaard, 2015) as they have fewer resources as a result of inequities. ${ }^{16}$

The sustainable livelihoods approach has been criticised for conceptualising livelihood sustainability in terms of its ability to recover from shocks and stresses when long-term impacts of climate change will also affect livelihood capabilities (Scoones, 2009). Here, I consider the links between the Wanni Dairy Project, livelihoods and climate change to understand the ways in which development projects can shape present and future livelihoods.

This research suggests that farmers have a low understanding of climate change. Climate change is understood by farmers to refer to weather changes that are experienced in the local context, rather than global processes that relate to rising global temperature. Farmers recognised that extreme and unpredictable weather events are becoming more regular and affecting their livelihoods, particularly through crop losses, and anticipate that these are going to continue and worsen, but did not discuss these in relation to climate change. Agricultural production is seen to be affected by impacts of climate change (even though climate change is not attributed as the cause), for which livestock increases farmers' resilience, but livestock's role in contributing to climate change is not considered.

The disconnection between livestock and climate change is hardly a surprise. Even in New Zealand where climate change is a prominent agricultural issue and farmers have access to information and support, only $63 \%$ of dairy farmers believe that human activity contributes to climate change (The Neilson Company, 2019). Although information has become more accessible to people in northern Sri Lanka since the war ended in 2009, conflict-affected areas remain relatively isolated in terms of technology, information and infrastructure. Low levels of literacy also restricts farmers' access to information about climate change, despite a wealth of expertise

\footnotetext{
${ }^{16}$ Marriage institutions, socially constructed responsibilities, and patriarchal ideologies of domination, colonialism and exploitation limit women's access to natural resources, mobility, participation in decision-making, and knowledge and power (Gaard, 2015). Women in developing countries may often be the ones who face more work to collect water, fuel and fodder; are majority of the world's hungry; and may experience additional workloads due to male urbanisation (when environmental deterioration limits rural work). Women are far more likely to die in natural disasters than men due to a lack of warning, being confined to homes and trying to protect children. If women survive, they face increased likelihood of sexual assault, and if they die, the loss of mothers leads to increased infant mortality, early marriage of girls, neglect of girls' education, sexual assaults, trafficking and child prostitution.
} 
about agricultural production and the interdependence between people and the environment.

The New Zealand Government's claims that dairy development will reduce emissions are largely based on the assumption that, because high-yield breeds and better practices improve dairy production efficiency, farmers can produce the same amount of milk as they are currently producing with lower emissions by using high-yield breeds and adopting better practices. This is true to an extent. However, neither dairy development initiatives nor the New Zealand or Sri Lankan governments intend to maintain current production levels. Dairy development initiatives are explicitly aligned with goals to increase production. This research, moreover, identifies farmers' intentions to increase livestock numbers in order to further increase production, which will increase emissions. If farmers do indeed shift away from integrated farming systems, which often complement jungle production (foraging), the loss of carbon sequestration is a further potential negative environmental impact (Geiger, 2014 cited in de Alwis, 2018). ${ }^{17}$ Despite the production efficiency gains that are possible, it appears unlikely that the Wanni Dairy Project will contribute to emission reductions over the medium- to long-term.

\subsubsection{Power over environmental factors}

The dominance of Western dairying knowledge and norms that are perpetuated by dairy development through expansion of production and consumption can be analysed with postdevelopment and postcolonial critiques. Even after independence, power imbalances between nations can still be seen to influence the use of natural resources in a way that displaces traditional knowledge and values. Conceptions of sustainable livelihoods in Sri Lanka have traditionally been situated within the environment rather than the economy (de Alwis, 2018). People in Sri Lanka have generally appreciated the interdependence between the environment and the community, weather, physical and natural resources (Ibid.). It is argued that the 'utmost care' in which the environment in Sri Lanka was traditionally utilised is in 'complete contrast' to New Zealand where the dairy (and meat) industry's focus on profit has resulted in environmental destruction (Ibid.). It can be seen as ironic, then, that powerful New Zealand development actors are in a position of expertise on environmental factors of dairy farming, when New Zealand's farming has been to the considerable detriment of the environment (MFE \& Statistics NZ, 2018).

\footnotetext{
17 The expansion of larger, intensified farms contributes to deforestation of jungle that reduces carbon.
} 
There are clear economic and social benefits that dairy development has achieved for people in developing countries, however, dairy development can also be understood to disproportionately benefit developed countries' interests (Mawdsley et al., 2018). Dairy expansion by major Western dairy producers and governments has exhausted environmental resources in many developed countries. Dairy development in developing countries - both in aid and trade contexts - utilises developing countries' resources to continue global dairy industry expansion (de Alwis, 2018). In the Wanni Dairy Project, this is seen by growing the role of dairy production, processing and consumption in a previously isolated region that, notwithstanding the current prevalence of poverty, represents more broadly the market potential in Sri Lanka's growing economy. Investment in dairy development, even in impoverished regions, can influence longerterm shifts that support global dairy expansion.

As one possible response to such postcolonial critiques, McKinnon (2005) identifies the agency of locally-based development professionals who may choose to prioritise local knowledge and locally-defined needs above the 'expertise' of development professionals. The Wanni Dairy Project staff enact this form of agency: they effectively elevate local perspectives through participatory approaches. This enables local actors to draw attention to environmental aspects of farming practices in the Wanni Dairy Project, which is done so in the ways described at the beginning of this section. However, the extent to which their approach addresses environmental issues and power dynamics is also limited by local knowledge and institutional priorities. For example, despite the environmental concerns of dairy development and the potential for farmers and project staff to positively influence some environmental factors in the Wanni Dairy Project, key environmental considerations such as the impact of increasing scale and livestock numbers on climate change and water resources, are not addressed. These concerns are not prioritised at the institutional level, and, because dairy farming is seen by farmers and project staff to have a positive impact on the environment at the small scale, there is also limited consideration at the local level.

Paradoxically, Western development actors could use the power and information (or 'expertise') available to them, such as knowledge about climate change and water quality impacts in relation to increasing scale of dairy production, to positively affect environmental issues. Donors, governments and industry actors have a responsibility to ensure that objectives of development 
projects adequately address environmental factors to ensure the sustainability of livelihoods and to support global climate efforts and the SDGs. As dairy development projects can be an important first step towards mitigating the negative environmental impacts of dairying (Parikesit et al., 2005), there is an opportunity for the Wanni Dairy Project to provide better support and information about environmental issues of dairying to farmers.

\subsubsection{Farmers' priorities, the scale of dairy production and commercialisation}

One of the most important environmental questions that this research on the Wanni Dairy Project raises is the extent to which dairy development will increase the scale of dairying and overall livestock numbers. The acquisition of the high-yield cow is the key factor affecting practice and livelihoods. As farmers are focused on maximising their livelihoods, all farmers in this research planned to acquire more high-yield cows and they continued to keep indigenous breeds in addition. Some farmers reported that they have changed their practices to care for the high-yield cow but not adopted these changes for indigenous breeds because of the high labour demands. Other farmers could see the value in changing practices to maximise dairy production. Farmers I spoke to believed that they have a shortage of land for the number of cows being farmed, in order to achieve optimal farm sustainability. Paradoxically perhaps, all farmers that I spoke to expressed ambitions to increase the number of cows on their farms, but only one wanted to acquire more land.

I have a shortage of land. If I have five cows then I need five acres of land. Then I can plant the grasses and everything and I can keep it in a good position. My aim is to buy land and do farming very well before I die. It's my dream. I want to make it real (Farmer, personal communication, October 2018).

If I have more money, then I can buy more cows. I want to increase the number of cows (Farmer, personal communication, October 2018).

It is clear that economic and environmental bottom lines are often in direct competition with each other, as they often are in Western contexts. The environmental impacts of herd growth and intensification are often not well understood in developing countries, however, as dairying knowledge is typically situated within small-scale production (Tarawali et al., 2011).

It was unclear in this research how farmers planned to adapt to increasing labour demands that came with larger herds, but investment - for example, in milking automation or hired labour to collect feed - would be necessary to enable feasible scale increases. It seems 
plausible then, that farmers may increasingly look to commercialise aspects of dairy production, despite both the cultural concerns identified earlier in this chapter, and a key informant's view that commercial scale of dairy production is not possible in Sri Lanka because "water is poor and the risk is too large for one farmer to have so many cows" (NGO representative, personal communication, October 2018). Informant views on the future scale of dairy farming in Sri Lanka were split, however, with some experts believing that there would be an increase in mediumscale farms and commercial processes, and others believing that commercial dairying would be no more viable than the current system. It is, therefore, important that baseline monitoring occurs in the Wanni Dairy Project to measure environmental impacts over time. Policy documents for phase two indicate that this is an area that should be developed, and an informant indicated there were plans to establish soil baselines (MFAT, 2016).

Commercialisation of dairy production - far from a clear trajectory for the Wanni Dairy Project, but a possibility - involves private sector actors, who provide technology, infrastructure, training and access to market activities. Fonterra, as a private sector stakeholder in NZAP dairy development initiatives, has a vested interest in the Wanni Dairy Project. ${ }^{18}$ Fonterra staff had visited the Wanni Dairy Project model dairy farm, processing plant and offices the week prior to my field research and regular communication and exchange of ideas occurs between Fonterra and development actors with the view to potentially working together in future. I was unable to interview any Fonterra staff in this research to explore the connections further, and the key informants I interviewed did not elaborate on their engagement with Fonterra. Therefore, it was difficult to ascertain the extent to which New Zealand actors, i.e. Fonterra, may be involved in potential commercialisation.

\subsubsection{Opportunities identified by farmers}

Conducting research during the beginning of the rainy season allowed me to appreciate some of the challenges that people face in regions where the seasonal monsoons dictate production. After months of drought that had affected farmers, the rain was welcome but brought new problems to farmers who had not managed to complete important agricultural works in time. One farmer looked at the image captured below (figure 6.9.) and despaired over the wasted

\footnotetext{
${ }^{18}$ Fonterra also runs their own model farms in Sri Lanka, and Sri Lanka is a major trade market for dairy products.
} 
money they had spent preparing the land, as they had been unable to complete planting.

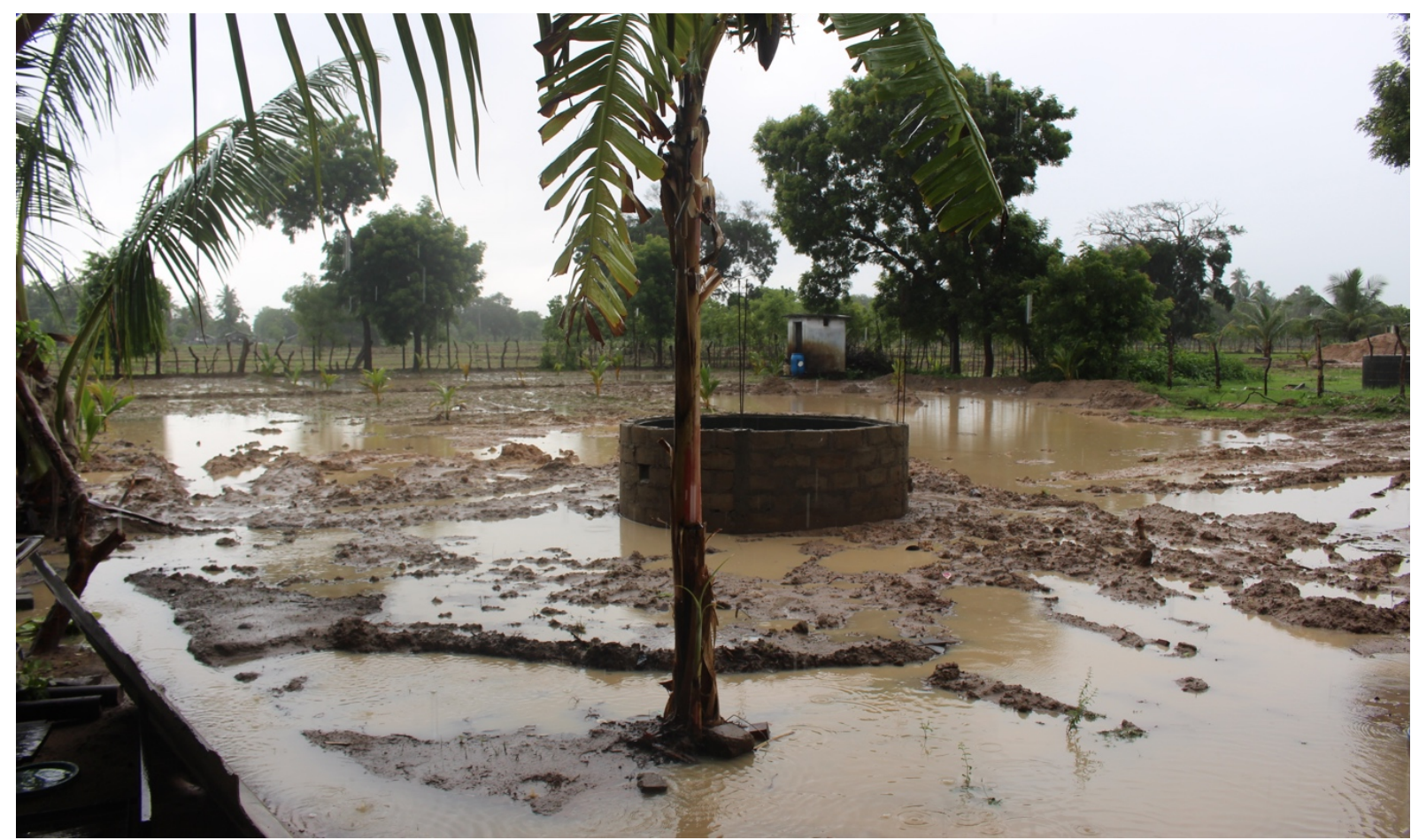

Figure 6.8. Farmer's photo of land after heavy rain.

Source: farmer (photovoice method)

Many of the challenges faced by farmers do not have easy solutions. Vulnerability, poverty and little access to support limits farmers' ability to mitigate challenges even when potential opportunities are identified. Reduced vulnerability factors and poverty, and improved access to support through the Wanni Dairy Project, therefore, helps farmers to overcome challenges that influence livelihoods. Some farmers identified further opportunities for improvement.

Farmers would like support to create plans and access information for new livelihood investments. One key opportunity identified by some farmers to improve environmental sustainability and economic impacts is biogas production, a process that turns manure into energy, which can be used for household cooking. Biogas production is already an established practice in Sri Lanka that forms part of a highly-efficient, traditional, sustainable waste management system (de Alwis, 2018). The by-product of biogas production is still used for fertiliser and compost.

Jasmine: What is the impact on the land of dairy farming? 
Farmer: It has a positive impact. We are using manure fertiliser and if I have enough money I can produce biogas and use for our home purposes. So then it doesn't have any negative effect. I think if I have money enough money we can invest. If I have money I can build it. Jasmine: How do you produce the biogas? How much money will you need?

Farmer: I wish to do it but I do not know the planning and what I need.

Although farmers already believe that dairy farming has positive impacts on the environment, this does not preclude ambitions to further improve environmental sustainability.

\subsubsection{Summary and recommendations}

This section discussed local perceptions of local environmental factors and impacts of the Wanni Dairy Project. The Wanni Dairy Project is widely perceived to have positive environmental impacts due to strategies that produce both economic and environmental gains. Integrated farming methods, in particular, are identified as contributing to positive environmental outcomes, although the extent to which farmers have the ability to utilise integrated farming methods differs.

This section discussed how, on one hand, there are limited understandings of climate change and livestock's contribution to GHG emissions, and on the other hand, that dairy development is seen to increase farmer's resilience to the impacts of climate change. Yet, the implications of increased and intensified dairy farming on climate change are little considered in the Wanni Dairy Project despite a large literature on the negative environmental impacts of dairying and an ongoing focus on global commitments to sustainable development.

It next discussed the dominance of Western knowledge and the shift away from traditional conceptions of interdependence between the environment and livelihoods in Sri Lanka as economic priorities grow. The environmental destruction caused by Western dairy production for economic gain and the findings of this research, which indicated farmers' desires to expand dairy production and livestock numbers, thus raise the issue of increasing scale and expansion of dairy farming. The role of the private sector actors, and commercialisation processes, which play a key role in global dairy development, may increase in the Wanni Dairy Project as they increasingly support opportunities to expand dairy production in developing countries.

However, farmers highly value environmental factors and identify opportunities for the Wanni Dairy Project to provide support for further strategies to improve environmental management. I contended that consideration of the full environmental impacts of dairy development initiatives is a fundamental responsibility of macro-level development actors who are 
supporting livelihood changes. It is critical that the impact of dairy development projects in developing countries on environmental factors - both local and global - receives adequate attention to ensure that short- to medium-term development outcomes are not at the expense of the environment and long-term livelihoods. The recommendations based on the findings of this research are:

- NGOs should investigate solutions to limitations on the use of land reported by farmers.

- MFAT and NGOs should investigate potential environmental impacts of increasing scale of dairy production and number of cows by establishing baselines for soil composition and factoring climate change advice into policy.

- MFAT should initiate climate change education as a policy priority to build awareness and resilience that can be implemented by NGOs.

- NGOs and MFAT should investigate the feasibility of biogas production and take steps to support farmers to explore this opportunity. 


\subsection{Summary}

This chapter discussed the findings and implications of this research - structured in three sections on social, gender and environmental factors of and impacts on sustainable livelihoods in the Wanni Dairy Project - which were identified through qualitative field research and analysed through a sustainable livelihoods approach and a gender lens. Interconnections between these factors reflected the depth of perspectives and knowledge shared, and the interdependence between factors of sustainability in a sustainable livelihoods approach. In other words, the research findings and discussion demonstrated the well-understood but often overlooked interdependence between social, environmental and livelihood factors, which people rely on to achieve livelihoods and wellbeing, and the gendered aspects of these factors. Each section provided a summary and recommendations based on this research. The summary of findings (table 6.3), below, surmises the key findings in relation to the research questions addressed throughout the chapter. The table follows the same structure as this chapter, addressing sequentially social, gender and environmental factors, and connects the findings to the relevant research questions.

Table 6.3

\section{Summary of findings}

\begin{tabular}{|l|l|l|}
\hline Findings & Implications & $\begin{array}{l}\text { Research } \\
\text { question* }\end{array}$ \\
\hline $\begin{array}{l}\text { Positive NGO - farmer } \\
\text { relationships characterised by } \\
\text { a focus on participatory } \\
\text { approaches, local knowledge } \\
\text { and sustainability. }\end{array}$ & $\begin{array}{l}\text { Strong prospects for livelihood sustainability. } \\
\text { Farmers can influence the project and tailor practices to } \\
\text { suit local conditions. However, farmers perceptions of } \\
\text { low influence persist at times. }\end{array}$ & 1,7 \\
\hline $\begin{array}{l}\text { High-yield calf considered the } \\
\text { main factor for improved } \\
\text { livelihoods and wellbeing. }\end{array}$ & $\begin{array}{l}\text { Farmers want to increase livestock numbers to further } \\
\text { increase income and assets to improve financial } \\
\text { independence and resilience. }\end{array}$ & 2 \\
\hline $\begin{array}{l}\text { Education for children is the } \\
\text { primary motivation to improve } \\
\text { livelihoods. }\end{array}$ & $\begin{array}{l}\text { Livelihood strategies may shift as farming knowledge is not } \\
\text { passed on. } \\
\text { Those who have prioritised higher education over } \\
\text { expertise for farming livelihoods may experience limited } \\
\text { employment prospects. } \\
\text { Next generation of dairy farmers may decline; Wanni Dairy } \\
\text { Project targets youth to increase dairy farmers. }\end{array}$ & 2 \\
\hline
\end{tabular}




\begin{tabular}{|c|c|c|}
\hline Findings & Implications & $\begin{array}{l}\text { Research } \\
\text { question* }\end{array}$ \\
\hline $\begin{array}{l}\text { Some farmers are affected by } \\
\text { negative factors of increased } \\
\text { income including junk food } \\
\text { consumption, addiction, child } \\
\text { labour. }\end{array}$ & $\begin{array}{l}\text { NGO interventions are key to address contributing factors } \\
\text { and minimise negative impacts. } \\
\text { External factors are influential, e.g., Westernisation, } \\
\text { globalisation, and vulnerability context. }\end{array}$ & $2,3,4$ \\
\hline $\begin{array}{l}\text { Farmers believe household } \\
\text { nutrition has improved due to } \\
\text { increased income but dairy } \\
\text { consumption is unchanged. }\end{array}$ & $\begin{array}{l}\text { There is tension between narratives that promote } \\
\text { nutritional outcomes of dairy development initiatives due } \\
\text { to dairy consumption and local views and } \\
\text { cultural/genetic/health factors. }\end{array}$ & 3,4 \\
\hline $\begin{array}{l}\text { Farmers' consumption of } \\
\text { processed dairy foods is likely } \\
\text { to increase. }\end{array}$ & $\begin{array}{l}\text { Dietary shifts are occurring as preference for and access to } \\
\text { processed dairy increases. Dairy development supports } \\
\text { increased dairy processing to maximise livelihoods. } \\
\text { There is tension between health/cultural factors and } \\
\text { dietary shifts. Ethical communication of diverse health } \\
\text { factors is important. }\end{array}$ & 3,4 \\
\hline $\begin{array}{l}\text { Contradictory views about the } \\
\text { health value of dairy, with } \\
\text { some thinking it is nutritious } \\
\text { and also thinking it causes } \\
\text { illness and allergies. }\end{array}$ & $\begin{array}{l}\text { Cultural factors and beliefs influence attitudes and } \\
\text { behaviours around dairy consumption. } \\
\text { Contentious role of commercialisation and private sector } \\
\text { in marketing to influence health attitudes. }\end{array}$ & 3,4 \\
\hline $\begin{array}{l}\text { The high value of } \\
\text { cultural/ethical factors by } \\
\text { farmers is often perceived as a } \\
\text { limitation on dairy } \\
\text { development. }\end{array}$ & $\begin{array}{l}\text { Economic/environmental factors compete with ethical } \\
\text { factors regarding farming practices. Lack of understanding } \\
\text { by non-local actors. Potential learnings by Western actors } \\
\text { to improve animal welfare values. }\end{array}$ & 4,7 \\
\hline 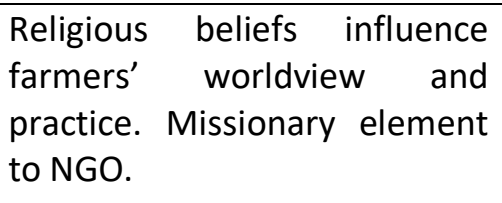 & $\begin{array}{l}\text { Cultural complexities that impact dairy development but } \\
\text { are little understood by non-local actors. } \\
\text { A risk to the religious identity of farmers. }\end{array}$ & 4,7 \\
\hline $\begin{array}{l}\text { Women experience increased } \\
\text { financial independence and } \\
\text { empowerment. }\end{array}$ & $\begin{array}{l}\text { Able to help husbands and children by increasing family } \\
\text { income. Pride in children's education. There is tension } \\
\text { between feminist goals and women's concerns for others. }\end{array}$ & 5 \\
\hline $\begin{array}{l}\text { Dairying helps farmers to } \\
\text { access and repay loans but the } \\
\text { debt burden is large. }\end{array}$ & $\begin{array}{l}\text { Farmers have subjective experiences of financial struggle } \\
\text { and loans. }\end{array}$ & 5,2 \\
\hline
\end{tabular}




\begin{tabular}{|c|c|c|}
\hline Findings & Implications & $\begin{array}{l}\text { Research } \\
\text { question* }\end{array}$ \\
\hline $\begin{array}{l}\text { Increased workload for women } \\
\text { farmers due to constant } \\
\text { household roles. }\end{array}$ & $\begin{array}{l}\text { Not all household members benefit equally from dairy } \\
\text { development. Increasing working days doesn't regard } \\
\text { non-market activity. Health impacts of increased } \\
\text { workload. }\end{array}$ & 5 \\
\hline Medical access low. & $\begin{array}{l}\text { Physical demands increase the need for women's access } \\
\text { to medical services. Medical access is a feminist issue. } \\
\text { Animal health prioritised over women's health. }\end{array}$ & 5,3 \\
\hline $\begin{array}{l}\text { Violence against women } \\
\text { occurs in the region. }\end{array}$ & $\begin{array}{l}\text { Women who are participating in the project are } \\
\text { considered vulnerable. } \\
\text { Importance of gender approach and complementary NGO } \\
\text { activities to address holistic/gender factors. }\end{array}$ & 5 \\
\hline $\begin{array}{l}\text { Early withdrawal of WCDO } \\
\text { leaves potential gaps in } \\
\text { services to address gender } \\
\text { concerns. }\end{array}$ & $\begin{array}{l}\text { MFAT should look to meet this need in line with do-no- } \\
\text { harm policy. }\end{array}$ & 5 \\
\hline $\begin{array}{lr}\text { Environmental focus on } \\
\text { integrated farming practices } \\
\text { through } \\
\text { implementation. }\end{array}$ & $\begin{array}{l}\text { Farmers can invest in livelihood options that benefit } \\
\text { environmental factors. Importance of economic result of } \\
\text { environmental factors. Not all farmers have suitable land. }\end{array}$ & 6 \\
\hline $\begin{array}{l}\text { Farmers perceive positive } \\
\text { environmental impacts of the } \\
\text { Wanni Dairy Project. }\end{array}$ & $\begin{array}{l}\text { Manure recycling increases soil fertility and reduces } \\
\text { reliance on external inputs. Environmental impact of plans } \\
\text { to increase dairying not considered. }\end{array}$ & 6 \\
\hline $\begin{array}{l}\text { Low understanding of climate } \\
\text { change by farmers. }\end{array}$ & $\begin{array}{l}\text { Livestock is seen for its role in increasing resilience to } \\
\text { climate change but not in contributing to climate change. } \\
\text { Emission reduction seems unlikely. Contradictory goals by } \\
\text { macro-stakeholders to increase production and reduce } \\
\text { emissions. Risk of increased reliance on dairy industry for } \\
\text { livelihoods in tension with global goals. Potential for } \\
\text { project to educate about climate change. }\end{array}$ & 6 \\
\hline $\begin{array}{l}\text { Farmers desire to increase cow } \\
\text { numbers but questions over } \\
\text { land size. }\end{array}$ & $\begin{array}{l}\text { Unclear how the scale of farming might change and how } \\
\text { farmers will respond to changing practices at a larger } \\
\text { scale. }\end{array}$ & 6,7 \\
\hline $\begin{array}{l}\text { Desire to improve } \\
\text { environmental sustainability. } \\
\text { Opportunity for biogas } \\
\text { production. }\end{array}$ & $\begin{array}{l}\text { Farmers desire planning support and information to } \\
\text { elevate environmental sustainability. }\end{array}$ & 6,7 \\
\hline
\end{tabular}




\section{* Research questions}

What are the local attitudes towards the project?

What do locals believe about the impact of the project on rural livelihoods and wellbeing?

What do locals believe are the health impacts of the project?

How does culture influence the impacts of the project?

How has the project impacted gender issues? (and how have gender issues impacted the project?)

What do locals believe are the environmental impacts of the project?

How do farmers influence the project and its impacts?

Overall, the findings and discussion indicated that there is potential for development actors to build on the achievements of the Wanni Dairy Project that support conflict-affected farmers' livelihoods by increasing the holistic focus of the Wanni Dairy Project activities and engagement with farmers. WCDO exemplifies agency through a strong, local, participatory focus in its activities in the Mullaitivu region to promote the multiple factors of sustainable livelihoods, and, in turn, good communication and farmer influence further affects livelihood achievement. However, I contended that donor funding and policy alignment that elevates holistic factors would further improve development outcomes by responding to local peoples' needs and opportunities identified in this research. In particular, female farmers' perspectives and other local knowledge collected in informant interviews identified the significance of cultural factors in livelihoods; the complexities of perceptions and potential impacts of health factors; the importance of NGO support to minimise the negative social impacts of increased income and maximise positive ones; the need for activities to support multiple aspects of gender inequalities as a goal in itself; and the potential for greater consideration of environmental factors to enhance sustainability prospects.

In sum, actions that address the social, gender and environmental concerns identified in this research would enhance the sustainability of the positive economic, social and potentially environmental outcomes achieved by the Wanni Dairy Project, and would acknowledge development actors' awareness around the complexity of dairy development impacts on sustainable livelihoods, particularly in the sensitive context of dairy development. These actions would demonstrate the New Zealand government's and NGO partners' commitment to effective development practice and the SDGs, and demonstrate responsive action to community perspectives. 


\section{Chapter 7 : Conclusion}

\subsection{Key messages}

In exploring perceptions of livelihood impacts - particularly social and environmental - through a qualitative case study of female farmers who are participating in the Wanni Dairy Project in Sri Lanka, this research has shaped understandings of New Zealand aid and dairy development in a number of ways. The knowledge produced through this research has enabled a consideration of micro-level, local understandings of dairy development in the post-conflict context in Sri Lanka, social factors of sustainable livelihoods, and cross-cutting issues such as gender equality and the environment. Key informants who work in the development and agricultural sectors also shaped this research with contextual data based on their insights and expertise. These nuanced, local perspectives, which have been largely absent from the discourse on dairy development and aid, offer a valuable lens through which to consider New Zealand's development impact in Sri Lanka as an aid donor for the Wanni Dairy Project.

First, by offering an insight into the lived experiences of female farmers, this research contributes to the representation of local development stakeholders and a foundation of robust information upon which development policy and practice can be based. It is hoped that this research can enhance the links between micro- and macro-levels in the Wanni Dairy Project by communicating findings with development actors such as MFAT, TFNZ and WCDO. Indeed, it appears that this research has already had some impact within MFAT and TFNZ. Stakeholders have invited me to share my research and, based on concerns I identified, MFAT and TFNZ initiated an investigation into potential negative impacts on women of the Wanni Dairy Project. The role of this research in drawing attention to the importance of gender issues, in particular, has also contributed to the way that gender issues have been approached in other NZAP dairy development projects and in strengthening the communication between MFAT and NGO partners (MFAT representative, personal communication, 2019).

Second, this research allows us to critically consider how local perspectives on development and livelihoods intersect with global development concerns. It is vital that local experiences are understood by global development actors, such as donors and private sector actors, but also that local development practice is rooted in an awareness of global issues of 
sustainable development. Evidence of farmers' low understandings of climate change, for example, demonstrated the tensions between local and global knowledge and priorities, which may become increasingly problematic as the Wanni Dairy Project expands and increases reliance on dairy production for livelihoods. Dairy development, and indeed sustainable development, is laden with tensions and trade-offs. This research suggested that the potential implications of such trade-offs for holistic sustainable livelihoods require further attention.

Third, analysis of the local-global relations in dairy development draws attention to the roles of different actors in both dairy development and the development sector more broadly. Power relations, aid modalities and the aid paradigms within which these operate have an inherent impact on the way that development policy and practice shapes livelihoods. For example, the Wanni Dairy Project emerged during an era that is characterised by the alignment of New Zealand's aid policy with its trade priorities and the shifting nature of aid, including changing donor relationships with NGOs. This thesis confirmed what are, arguably, the implications of this era in New Zealand's development policy, in that social, gender and environmental concerns require closer attention than they have previously received as part of a holistic approach to development to ensure effective outcomes.

\subsection{Reflection and concluding remarks}

The central question addressed in this thesis - what are local female farmers' perceptions of the social and environmental impacts of the Wanni Dairy Project, and how do they exercise influence over these impacts? ${ }^{1}$ - is situated within the need to address the tensions between dairy development and sustainable global development, which the literature underscored in Chapter Two. Dairy development in Asia is seen, on the one hand, as a means to improve economic, health and food security issues, and New Zealand's aid investment in dairy development in Asia is linked to trade interests and supports market growth. On the other hand, it is argued that dairy consumption and production should be reduced to respond to global climate change and

\footnotetext{
${ }^{1}$ The sub-questions that follow this are: What are the local attitudes towards the project? What do locals believe about the impact of the project on rural livelihoods and wellbeing? What do locals believe are the health impacts of the project? How does culture influence the impacts of the project? How has the project impacted gender issues? What do locals believe are the environmental impacts of the project? How do farmers influence the project and its impacts?
} 
potential negative health impacts in countries with traditionally low dairy consumption.

In order to elevate and integrate these multiple factors that contribute to livelihoods, this research drew on a sustainable livelihoods approach and a gender lens, outlined in Chapter Three. These principles and framework guided the research design, practice and analysis as this research explored the perceptions and implications of a New Zealand-funded aid project in Sri Lanka, the Wanni Dairy Project. This research adopted a qualitative methodology, described in detail in Chapter Four, to collect data during five weeks of case study research with female, conflict-affected farmers in Sri Lanka.

An overview of the historical and post-conflict development context in Sri Lanka, in Chapter Five, provided the necessary foundation upon which we could base our understanding of the inequalities and issues faced in conflict-affected communities in Sri Lanka. Farmers' perspectives and experiences as well as efforts to improve livelihoods and wellbeing, such as dairy development projects, are embedded in this specific context. The chapter then elaborated on the nature and scope of the case study selected for this research.

After first introducing the primary participants in this research, the findings and discussion in Chapter Six emphasised the complex nature of the impacts of the Wanni Dairy Project and argued that better understandings of the impacts of dairy development should be informed by local perspectives. Despite the popularity of bottom-up, participatory approaches to development, development actors with relative power often influence development projects with top-down approaches due to donor priorities and power dynamics. The people who are affected by development interventions are typically underrepresented in decision-making processes about their own development (Gaard, 2015). The local perspectives explored in this research revealed a number of insightful, informative considerations for the Wanni Dairy Project, and, perhaps, more broadly, dairy development and aid in the context of sustainable development. The chapter discussed these across three main sections - social, gender and environmental factors and impacts -, which wove together analyses of subjective local knowledge, researcher observations, and consideration of the global and bilateral policy influences on sustainable development.

In sum, there are inherent challenges of balancing economic, social and environmental factors of sustainable development in dairy development projects. These challenges are not only present between the multiple factors of sustainable livelihoods, but also within them. The 
discussion of social factors and impacts of the Wanni Dairy Project highlighted such intratensions: differing views of farmers and NGOs in relation to farmer influence and knowledge; positive and potentially negative impacts of increased income; contradictory local perceptions of health impacts of dairy as both nutritious and associated with health problems (reflective of the diverse views in literature that are represented by different actors in different ways); and cultural, ethical and religious factors that, again, are viewed by some as constraints on dairying potential and others as influential, valued aspects of identity and wellbeing.

The subjective and culturally specific ethical factors of dairy production are an apt example of the competing ideas about what 'should' be done in development. Culturally appropriate responses to local issues are important, but these are often at odds with economic priorities of donors. There may be promise emerging for the elevation of holistic sustainable livelihoods in development projects, as the refocused, holistic objectives of the NZAP bring to bear greater consideration of social and environmental factors. Dairying, however, remains very much tied to New Zealand's economic priorities, which will, perhaps, inhibit the elevation of other factors in such projects. I found it particularly striking that the increasing global focus on environmental factors in dairying is employed as justification for the marginalisation of cultural factors (e.g., cultural norms around animal slaughter of male calves), when, in fact, this is because economic factors (i.e., increasing production) continue to be accepted as the primary goal. Further, ongoing marginalisation of cultural values is supported by international processes of globalisation, industrialisation and Westernisation.

These global trends similarly raise concerns for the marginalisation of information on diverse, contextual health factors of dairy consumption and dietary shifts as dairying expansion appears to take priority. Emerging international trends in which people are increasingly looking towards the health, environmental and ethical benefits of plant-based diets will have interesting implications for continued dairy expansion through aid (Allen et al., 2018). Questions that emerge from this research include whether the NZAP, with its increasing attention towards understanding holistic impacts, will step back from dairy development initiatives as the complexities of a holistic understandings become clearer, or, whether dairy development will be increasingly seen as a way for aid to support the New Zealand dairy industry as political pressures, consumer shifts and industry challenges mount. 
If the NZAP continue its commitment to dairy development initiatives, what appears clear, based on this research, is that gender needs to be further mainstreamed into its approach and implementation of projects. The discussion of gender and dairy in Chapter Six highlighted the importance of a gendered approach, because women continue to face the inequities of deeprooted structural systems that perpetuate inequality, which can have serious consequences. Gender inequality, as a cross-cutting issue in the Wanni Dairy Project, is concerned with dairying as a means to improve women's situations. Successes for women's representation, participation, independence and empowerment are all related to the economic focus of the project. However, this research broadened the scope to consider social and environmental factors, in addition. The discussion contended that "gender has to be mainstreamed in all project activities and not treated in isolation" (Mkenda-Mugittu, 2003: 470), which may help to address important social impacts identified in this research such as disproportionately increased workloads, low medical access, and violence against women, all of which significantly affect women's livelihoods and experiences of wellbeing. Moreover, the discussion of environmental impacts in Chapter Six highlighted the disproportionate burden on women of environmental challenges, due to inequities and fewer resources. A question that emerges, therefore, is how will development projects adopt a meaningful gender focus that addresses the pertinent, evolving needs of women, because increasing environmental deterioration as a result of climate change will be overly experienced by women, especially in aid contexts.

Additionally, the discussion of environmental factors and impacts in Chapter Six contended that there is a compelling need for development actors to devote greater attention to the possible environmental implications of dairy development in the Wanni Dairy Project. The disconnect between the Project's planned expansion and identified risks highlighted what are, perhaps, the inherent limitations of short- to medium-term development projects, as environmental impacts that take time to be fully realised may be beyond the consideration and accountability of projects. It is difficult to predict which form/s of expansion (commercialisation, scale increases, number of farmers) will eventuate in the Wanni Dairy Project. However, the environmental risks that have been identified and would require much greater efforts to address than current mitigation activities, appear to be in conflict with goals to expand Wanni Dairy Project, and the Sri Lankan dairy industry, more broadly. These tensions may grow, as 
international support for urgent climate action intensifies, and the Wanni Dairy Project becomes further established as a means of market growth, and as a solution to development needs.

\subsection{Limitations and further research}

The research findings are context-specific, subjective accounts of perceived realities. They cannot be generalised; instead they provide an insight into the experiences of a purposive sample of female farmers in the Wanni Dairy Project, which could provide a basis for future comparison. There remain significant challenges in the realities and the narratives that reinforce inequalities for ethnic minorities in Sri Lanka. The findings capture some of the issues faced by some farmers, and self-identified opportunities that can be explored and may be relevant more broadly.

Further research is warranted to draw broad conclusions and investigate the gaps that remain in knowledge on cross-cutting gender and environmental impacts, and health and cultural impacts of dairy development projects to identify appropriate ways to address these issues. Given that gender equality is targeted by the Project, further research on the Wanni Dairy Project - or other similar projects - could explore the structural inequalities that challenge gender outcomes. High participation rates of women are not comprehensive indicators of the impacts that women experience, and additional research would inform more effective interventions to address ongoing gender inequalities. Research on the localised environmental factors faced by farmers could improve approaches to increase positive environmental impacts and minimise negative ones. Health impacts and perceptions should be considered more closely as health impacts underscore discourse on MFAT's dairy development in Sri Lanka but there are challenges in measuring these, and locals can hold contradictory views about the health impacts of dairy.

There is also a need for current research on the issues and opportunities of dairy farming in Sri Lanka, particularly in relation to the interconnected goals for sustainable development. Ideally, understandings of the multiple factors of sustainable livelihoods should extend beyond dairy development project timeframes and industry prerogatives, and such research may further explore interconnections between the roles of different actors and holistic impacts. Finally, I encourage future researchers to consider the value that qualitative, local research adds to development understandings and the potential for its constructive use by development actors to inform and influence development practice. 


\title{
Appendices
}

\section{Appendix A: Support for research from project stakeholders}

\author{
OFFICE OF THE DEAN \\ FACULTY OF VETERINARY MEDICINE \& ANIMAL SCIENCE \\ UNIVERSITY OF PERADENIYA, \\ PERADENIYA, SRI LANKA
}

Faculty of Vterinary Medicine and Animal Science,

University of Peradeniya

Peradeniya, 20400,

Sri Lanka

24 July 2018

To whom it may concern;

Re: Invitation to Jasmine Edwards for agricultural research in Sri Lanka

This letter confirms that Faculty of Veterinary Medicine and Animal Science, University of Peradeniya wishes to extend our support to Jasmine Edwards, student from Victoria University, Wellington New Zealand, to conduct research towards her Master's thesis on the Wanni dairy development activity.

Veterinary Faculty staff from the University of Peradeniya are happy to meet and discuss the dairy extension work. Ms Edwards does not require any financial support from the university.

Regards,

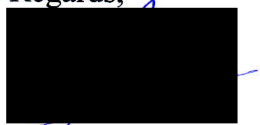

Dear

faculty of Voterinany Medich

Animal Science

Professor H.B.S. Ariyaratne

Dean / Faculty of Veterinary Medicine and Animal Science.

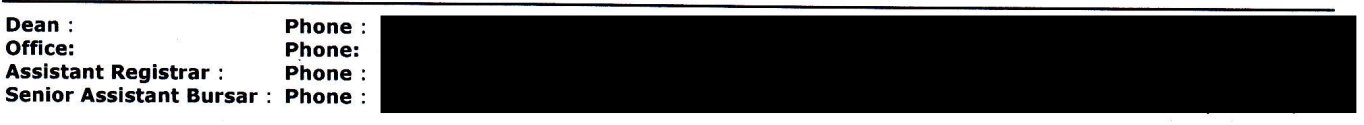




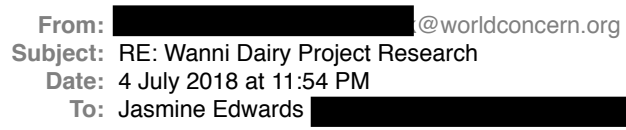

Dear Jasmine,

Greetings from Sri Lanka.

Glad to hear that you are interested to interview our farmers and we will arrange 5 farmers. Our total number of registered farmers are 1912 and among them $49 \%$ are female farmers. Our total base is approx. over 2500 farmers. We are happy to hep as your education will help many more in the world.

Thank you for your appreciation. I am just a woman, trying to do what I am called to do. It will be a privilege to meet you in person.

I travel frequently to Nepal and out of the country. It is good if we can coordinate your travel to SL. I will be in SL until the 20th of August I will be back in early October and will stay in SL until end of November.

Hope this is helpful. Take care.

Best Regards,

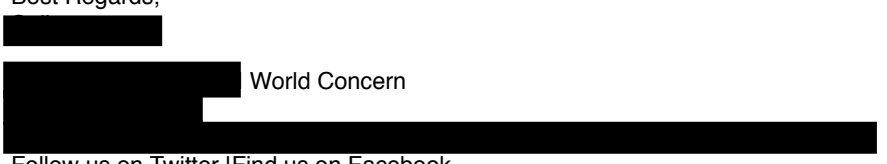

Follow us on Twitter IFind us on Facebook

-----Original Message-----

From: Jasmine Edwards

Sent: Wednesday, July 4, 2018 7:59 AM

To: $@$ worldconcern.org>

Subject: Wanni Dairy Project Research

Dear

My name is Jasmine and I am a Master's student in Development Studies from Victoria University in Wellington, New Zealand. You may have seen my emails with - I am planning to visit Sri Lanka this year for qualitative research on the Wanni Dairy Project and its livelihood, environment and social impacts. I hope to interview around 5 farmers, and I would really like to hear from women especially. I hope that my research can help to inform the NZ community and government about the project's impacts.

First, I must say that from what I have read and heard about you that I deeply admire what you have done to rebuild your community. You are inspirational. It would be a privilege to meet you when I visit. I would really appreciate your contribution and guidance.

I mentioned to that in the next six weeks I would be grateful for feedback and discussions about what sort of research would be useful to you and the community, and I hope that I can make my project relevant for you as well. Let me know what you think and if you have any questions or would like to talk further. I hope to meet you soon.

Kind regards,

Jasmine 
Appendix B: Interpreter confidentiality agreement

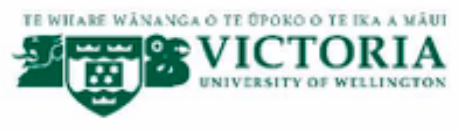

\section{Interpreting Confidentiality Agreement}

Project Title: A Sustainable Livelihood Approach to New Zealand aid and dairy development in Sri Lanka

Principal Investigator: Jasmine Edwards

I, , agree to ensure that the responses and identities of participants will remain confidential to Jasmine Edwards and myself.

I agree to take the following precautions:

1. I will not discuss any aspect of the interviews with anyone except Jasmine Edwards.

Signature:

Date: 


\section{Appendix C: Participant information sheets and consent forms (English and Tamil)}

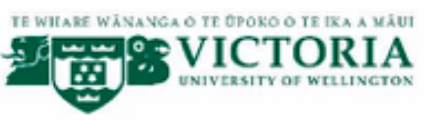

\section{A Sustainable Livelihood Approach to New Zealand aid and dairy development In Sri Lanka}

\section{INFORMATION SHEET FOR PARTICIPANTS (1)}

You are invited to take part in this research. Please read this information before deciding whether or not to take part. If you decide to participate, thank you. If you decide not to participate, thank you for considering this request.

\section{Who am I?}

My name is Jasmine Edwards and I am interested in the impacts of dairy development on people's lives. This research project is work towards my Master's thesis in Development Studies at Victoria University of Wellington, New Zealand.

\section{What is the aim of the project?}

This project aims to understand local female farmers' views of the impacts of the Wanni Dairy Regeneration Activity. This research has been approved by the Victoria University of Wellington Human Ethics Committee (\#25982).

\section{How can you help?}

You have been invited to participate because you are a female dairy farmer participating in the Wanni Dairy Regeneration Activity. If you agree to take part, I will ask you to take photos (a camera will be provided) and I will interview you at your place of work or a nearby venue. I will provide instructions for the photos to take and ask you questions about the photos and dairy farming. The interview will take one hour. An interpreter will also be present, unless you wish to do the interview in English. I will audio record the interview with your permission and write it up later. You can choose to not answer any question or stop the interview at any time, without giving a reason. I will also write up notes on my observations relating to dairy development during my field research. You can withdraw from the study by contacting me at any time before 30 October 2018. If you withdraw, the information you provided will be destroyed or returned to you.

\section{What will happen to the information you give?}

This research is confidential. This means that the researchers named below will be aware of your identity but the research data will be combined and your identity will not be revealed in any reports, presentations, or public documentation. However, you should be aware that in small projects your identity might be obvious to others in your community. I am not part of the New Zealand government, TEAR Fund, World Concern, Massey University or any stakeholder in 
Wanni Dairy Regeneration Project. This project is receiving funding from the New Zealand government and support from TEAR Fund and World Concern, who are interested in receiving feedback on the effectiveness of the dairy programme. I will share a report with the New Zealand Ministry of Foreign Affairs and Trade, TEAR Fund, World Concern and Massey University to share the knowledge from this research but your identity will not be revealed. Declining to participate will NOT affect your involvement in the development programme in any way.

Only my supervisors, the interpreter and the transcriber (who will both be required to sign a confidentiality agreement), and I will read the notes or transcript of the interview. The interview transcripts, summaries and any recordings will be kept securely and destroyed on 1 December 2019.

\section{What will the project produce?}

The information from my research will be used in my Master's thesis, a policy brief to the New Zealand Ministry of Foreign Affairs and Trade, a research report to the project's stakeholders and/or academic publications and conferences. Photos may be published.

\section{If you accept this invitation, what are your rights as a research participant?}

You do not have to accept this invitation if you do not want to. If you do decide to participate, you have the right to:

- choose not to answer any question;

- ask for the recorder to be turned off at any time during the interview;

- withdraw from the study before 30 October 2018;

- ask any questions about the study at any time;

- receive a copy of your interview recording;

- be able to read any reports of this research by emailing the researcher to request a copy.

If you have any questions or problems, who can you contact?

If you have any questions, either now or in the future, please feel free to contact me or my supervisor:

\section{Student:}

Name: Jasmine Edwards

jasmine.edwards@vuw.ac.nz

\section{Supervisor:}

Name: Dr Polly Stupples

Role: Lecturer

School: Geography, Environment and Earth Sciences

\section{Human Ethics Committee information}

If you have any concerns about the ethical conduct of the research you may contact the Victoria University HEC Convenor: Dr Judith Loveridge. Email 


\section{0.}

\section{நியுசிலாந்து உதவி திட்டத்திற்க்கும் ஸீ லங்காவில் பால்பண்ணை அபிவிருத்திக்கும் நிலையான வாழ்வாதார அணுகுமுறை}

\section{பங்கு பற்றுபவரின் தகவல் தாள் (1)}

இந்த ஆராய்ச்சியில் பங்கு பற்றுவதற்க்கு நீங்கள் அழைக்கப்படுகிறீர்கள. நீங்கள் பங்கு பற்றுவீர்களா இல்லையா என்று முடிவு செய்யு முன் இந்த விபரத்தாளை வாசிக்கவும். பங்கு பற்றுவதானால் நன்றி. புங்கு பற்றவில்லை என்றால் இதை கருத்தில் கொண்டதற்கு நன்றி.

நான் யார்?

என் பெயர் யஸ்மின் எட்வேட்ஸ் (Jasmine Edwards). நான் பால்பண்ணை அபிவிருத்தி மக்களின் வாழ்வில் என்ன தாக்கத்தை உண்டாக்கும் என்பதை அறிய ஆர்வமாக உள்ளேன்.

இந்த ஆராய்ச்சி

விக்டோரியா பல்கலைக் கழகம் வெலிங்டனில் நான் பங்கு பற்றும் எனது முதுகலை ஆய்வறிக்கைக்கு பயன் படும்.

\section{இத்திட்டத்தின் குறிக்கோள் என்ன?}

இந்த ஆய்வுத்திட்டத்தின் நோக்கம் வன்னி பால்பண்ணை மீளுருவாக்கச் செயற்பாடு பற்றி உள்ளூர விவசாயிகளின் கருத்தையும் விளைவுகளையும் பற்றி புரிந்து கொள்வதே. இந்த ஆராய்ச்சியை விக்டோரியா பல்கலைக் கழகத்தின் மனித நெறிமுறை குழு அநநுமதித்துள்ளது. (\#25982)

\section{நீங்கள் இதற்க்கு எப்படி உதவலாம்?}

நீங்கள் ஒரு பெண் பால்பண்ணை விவசாயியென்பதால் இந்த ஆய்விற்க்கு அழைக்கப்பட்டுள்ளீர்கள். பங்கு பெற இணங்கினால் நீங்கள் புகைப்படங்கள் எடுக்கும்படி கேட்கப்படுவீர்கள் (கேமரா கொடுக்கப்படும்). அத்துடன் உங்களை உங்கள் வேலையிடத்திலோ அல்லது அதற்க்கு அருகிலோ சந்தித்து பேட்டி எடுப்பேன். புகைப்படம் எடுப்பதற்கான முறையை உங்களுக்கு சொல்லித்தருவேன். அத்துடன் நீங்கள் எடுத்த புகைப்படங்கள் பற்றியும் பால்பண்ணை தொழில் பற்றியும் கேள்விகள் கேட்பேன். இந்த பேட்டி 1 மணி நேரம் எடுக்கும். ஒரு மொழிபெயர்ப்பாளர் இருப்பார்

பேடடியை உங்கள் அநுமதியுடன் ஒலிப்பதிவு செய்து பின் அதை எழுத்தாக்கம் செய்வேன். ஏதாவது கேள்விக்கு உங்களுக்கு பதில் சொல்ல விருப்பமில்லாவிட்டால் நீங்கள் மறுக்கலாம் அல்லது பேட்டியை எந்நேரத்திலாவது நிறுத்தலாம். காரணம் சொல்ல தேவையில்லை. நான் கள ஆராய்ச்சியின் போது பால்பண்ணை சம்பந்தமாக அவதானங்களை குறிப்பெடுப்பேன். ஐப்பசி 2018 க்கு முன்பாக நீங்கள் என்னைத் தொடர்பு கொண்ட பின் இந்த ஆய்வில் இருந்து விலகலாம். நீங்கள் விலக முடிவெடுத்தால் நீங்கள் கொடுத்த விபரங்கள் உங்களிடம் திருப்பிக் கொடுக்கப்படும் அல்லது அழிக்கப்படும்.

\section{நீங்கள் கொடுத்த விபரங்களுக்கு என்ன நடக்கும்?}

இந்த ஆராய்ச்சி இரகசியமானது. அதாவது ஆராய்ச்சியாளருக்கு உங்களை யாரென்று தெரியும். ஆனால் முழு ஆராய்ச்சித் தகவல்களெல்லாம் ஒருங்கிணைக்கப் பட்டு உங்கள் அடையாளம் அறிக்கையிலோ, விபரம் வழங்கலிலோ அல்லது பொது ஆவணங்களிலோ குறிப்பிட மாட்டாது. ஆனால் சிறிய ஆராய்ச்சி திட்டங்களில் உங்கள் அடையாளம் உங்கள் சமூகத்தில் உள்ளவர்களுக்கு வெளிப்படையாக தெரியலாம். நான் நியுசிலாந்து அரசாங்கத்திலோ, Tear fund, World concern, Massey University அல்லது வன்னி பால்பண்ணை மீளுருவாக்கத் திட்டதத்தின் பங்குதாரரோ அல்ல. நான் இந்த அறிக்கையை நியுசிலாந்து வெளிநாட்டு விவகாரம் மற்றும் வர்த்தக அமைச்சுடன் மற்றும் Tear fund, World concern, Massey University உடன் பகிர்ந்து கொள்வேன். அனால் உங்கள் அடையாளம் வெளியிடப்பட மாட்டாது. என்னுடைய மேற்பார்வையாளரும், மொழிபெயர்ப்பாளரும், எழுத்து 
வடிவமாக்குபவரும் (இவர்கள் இருவரும் இரகசிய உடன்படிக்கையில் கையெழுத்திட்டிருப்பார்கள்) நானும் மட்டுமே குறிப்புகளையும் எழுத்தாக்கத்தையும் படிப்போம். பேட்டியின் பதிவுகள் எழுத்தாக்கம் சுருக்கங்கள் மற்றும் பதிவுகள் 1 மார்கழி 2019 அன்று அழிக்கப்படும். ஆராய்ச்சி நியூசிலாந்து அரசாங்கத்திடமிருந்து நிதி பெறும். இந்த ஆராய்ச்சியில் பங்கேற்கவில்லை என்றால், எந்த விளைவும் இல்லை.

\section{இந்த திட்டம் எதற்க்கு பாவிக்கப்படும்?}

இத் திட்ட விபரங்கள் என் முதுகலை ஆய்வறிக்கைக்குப் பாவிக்கப்படும். அத்துடன் நியுசிலாந்து வெளிநாட்டு விவகாரம் மற்றும் வர்த்தக அமைச்சின் கொள்கைச் சுருக்கத்துக்கு பாவிக்கப் படுவதுடன் ஆராய்ச்சி அறிக்கை பங்குதாரருக்கு கொடுக்கப்படும். அத்துடன் கல்வி வெளியீடுகளுக்கோ மாநாடுகளுக்கோ பயன் படலாம்.

இந்த அழைப்பை நீங்கள் ஏற்றுக் கொண்டால் இந்த ஆய்வின் பங்குதாரராக உங்கள் உரிமைகள் என்ன?

இந்த அழைப்பை விருப்பமில்லாவிடில் ஏற்க தேவையில்லை. பங்கு பெற விரும்பின் உங்கள் உரிமைகள் பின்வருமாறு:

• எந்தக் கேள்விக்காவது விருப்பமில்லாவிடில் பதில் சொல்ல தேவையில்லை

- ஒலிப்பதிவுக்கருவியை எந்நிலையிலும் அணைக்கும் படி கேட்கலாம்

- இ இந்த ஆய்விலிருந்து 3 ஐப்பசி 2018க்கு முன் விலகலாம்

• ஆய்வைப் பற்றி எந்நிலையிலும் கேள்விகள் கேட்கலாம்

• உங்கள் பேட்டியின் ஒலிப்பதிவின் பிரதியை பெறலாம்

• இந்த ஆய்வின் எந்த அறிக்கை பிரதியையாவது ஆராச்சியாளருக்கு மின்னஞ்சல் அனுப்பி கேட்கலாம்

உங்களுக்கு ஏதாவது கேள்விகள் அல்லது பிரச்சினைகள் இருந்தால் யாரைத் தொடர்பு கொள்வது?

உங்களுக்கு ஏதாவது கேள்விகள் இப்போதோ அல்லது பிற்காலத்திலோ இருந்தால் என்னையோ என் மேற்பார்வையாளரையோ தயவு செய்து தொடர்பு கொள்ளவும்

மாணவி:

பெயர்: யஸ்மின் எட்வேட்ஸ் (Jasmine Edwards)

jasmine.edwards@vuw.ac.nz
மேற்பார்வையாளர்:

பெயர்: டாக்டர் பொலி ஸ்டப்பிள்ஸ் (Dr Polly Stupples)

நிலை: விரிவுரையாளர்

கல்லுாரி: நிலவியல், சூழல் மற்றும் புவி அறிவியல் பகுதி

தொலைபேசி:

மனித நெறிமுறைக்குழு விபரம்

உங்களுக்கு நெறிமுறை நடவடிக்கை சம்பந்தமாக ஏதாவது கேள்விகள் இருந்தால் விக்டோரியா பல்கலைக் கழக HE நடத்துனர்: இணை பேராசிரியர் சூசன் கோபேட் Judith Loveridge ஐத் தொடர்பு கொள்ளலாம். மின்னஞ்சல்:

தொலைபேசி: 


\section{A Sustainable Livelihood Approach to New Zealand aid and dairy development in Sri Lanka}

\section{CONSENT TO INTERVIEW (1)}

This consent form will be held for 5 years.

Researcher: Jasmine Edwards, School of Geography, Environment and Earth Sciences, Victoria University of Wellington.

- I have read the Information Sheet and the project has been explained to me. My questions have been answered to my satisfaction. I understand that I can ask further questions at any time.

- I agree to take part in an audio recorded interview and take photos.

I understand that:

- I may withdraw from this study at any point before 30 October 2018, and any information that I have provided will be returned to me or destroyed.

- The identifiable information I have provided will be destroyed on 1 February 2019.

- Any information I provide will be kept confidential to the researcher and the supervisor and the interpreter and the transcriber.

- Photos taken may be published but the identity of the photographer will be kept confidential.

- I understand that the results will be used for a a Master's thesis, a policy brief to the New Zealand Ministry of Foreign Affairs and Trade, and/or academic publications and conferences.

- My name will not be used in reports, nor will any information that would identify me.

- I would like a copy of the recording of my interview: Yes No

- I would like to receive a copy of the final report and have Yes No added my email address below:

Signature of participant:

Name of participant:

Date:

Contact details: 


\section{நியுசிலாந்து உதவி திட்டத்திற்க்கும் ஸீ லங்காவில் பால்பண்ணை அபிவிருக்திக்கும் நிலையான வாம்வாதார அணுகுமுறை}

\section{பேட்டிக்கான ஓப்புதல் (1)}

இந்த ஒப்புதல் படிவம் 1 வருடத்திற்க்கு வைத்திருக்கப் படும்

ஆராச்சியாளர்: யஸ்மின் எட்வேட்ஸ் (Jasmine Edwards), நிலவியல், சூழல் மற்றும் புவி அறிவியல் பகுதி, விக்டோரியா பல்கலைக் கழகம் வெலிங்டன் (School of Geography, Environment and Earth Sciences, Victoria University of Wellington)

- நான் தகவல் தாளை வாசித்ததுடன் இத்திட்டம் எனக்கு விளக்கப்பட்டது. எனது கேள்விகளுக்கு திருப்திகரமான பதில்கள் அளிக்கப்பட்டன. நான் எந்நேரமாயினும் மேலதிக கேள்விகள் கேட்கலாம் என அறிகிறேன்

• நான் ஒ ஒலிப்பதிவு பேட்டிக்கும் புகைப்படம் எடுப்பதற்கும் உடன் படுகிறேன்

நான் பரிந்து கொள்வதாவது:

- நான் இந்த ஆய்விலிருந்நு எந்த நிலையிலும் 14 ஐப்பசி 2018க்கு முன் விலக முடியும்

- அத்துடன் நான் கொடுத்த விபரங்கள் எனக்கு திருப்பிக் கொடுக்கப்படும் அல்லது அழிக்கப்படும்

- ந நான் கொடுத்த என்னை அடையாளம் கண்டு பிடிக்கக் கூடிய விபரங்கள் 1 மாசி 2019 அன்று அழிக்கப்படும்

• நான் கொடுத்த விபரங்கள் ஆராச்சியாளரையும், மேற்பார்வையாளரையும், மொழிபெயர்ப்பாளரையும், எழுத்து வடிவமாக்குபவரையும் தவிர மற்றவருக்கு கொடுக்கப்படாமல் இரகசியமாக வைத்திருக்கப்படும்

• ுகைப்படம் வெளியிடப்படலாம் ஆனால் புகைப்படம் எடுத்தவரின் அடையாளம் இரகசியமாக வைத்திருக்கப்படும்

- இந்த ஆராய்ச்சியின் முடிவுகள் முதுகலை ஆய்வறிக்கைக்கும், நியுசிலாந்து வெளிநாட்டு விவகாரம் மற்றும் வர்த்தக அமைச்சிற்கும், கல்வி வெளியீடுகளுக்கும், மாநாடுகளுக்கும் பயன் படுத்தப்படும்

• என் பெயர் அறிக்கைகளிலோ அல்லது என் அடையாளம் எந்த விபரங்களிலோ இடம் பெறாது

• என் பேட்டிப் பதிவின் நகலை பெற விரும்புகிறேன்

ஆம் இல்லை

• என் பேட்டியின் தமிழாக்கத்தின் நகலை பெற விரும்புகிறேன்

ஆம் இல்லை

• என் பேட்டியின் சுருக்கத்தின் நகலை பெற விரும்புகிறேன்

ஆம் இல்லை

- இறுதி அறிக்கையின் நகலை நகலை பெற விரும்புகிறேன் அத்துடன் என் மின்னஞ்சல் முகவரியை இணைத்துள்ளேன்

ஆம் இல்லை

பங்கு பெற்றவரின் கையொப்பம்:

பங்கு பெற்றவரின் பெயர்:

தேதி:

தொடர்பு விபரம்: 


\section{A Sustainable Livelihood Approach to New Zealand aid and dairy development In Sri Lanka}

\section{INFORMATION SHEET FOR PARTICIPANTS (2)}

You are invited to take part in this research. Please read this information before deciding whether or not to take part. If you decide to participate, thank you. If you decide not to participate, thank you for considering this request.

\section{Who am I?}

My name is Jasmine Edwards and I am interested in the impacts of dairy development on people's lives. This research project is work towards my Master's thesis in Development Studies at Victoria University of Wellington, New Zealand.

\section{What is the aim of the project?}

This project aims to understand local female farmers' views of the impacts of the Wanni Dairy Regeneration Activity. This research has been approved by the Victoria University of Wellington Human Ethics Committee (\#25982).

\section{How can you help?}

You have been invited to participate because you are involved with some aspect of agricultural development. Your views would be valuable to inform this research. If you agree to take part, I will interview you at your place of work or a nearby venue. I will ask you questions about your role and/or knowledge of dairy farming. The interview will take around half an hour. An interpreter will also be present, unless you wish to do the interview in English. I will audio record the interview with your permission and write it up later. You can choose to not answer any question or stop the interview at any time, without giving a reason. I will also write up notes on my observations relating to dairy development during my field research. You can withdraw from the study by contacting me at any time before 30 October 2018. If you withdraw, the information you provided will be destroyed or returned to you.

\section{What will happen to the information you give?}

This research is confidential. This means that the researchers named below will be aware of your identity but the research data will be combined and your identity will not be revealed in any reports, presentations, or public documentation. However, you should be aware that in small projects your identity might be obvious to others in your community. I am not part of the New Zealand government, TEAR Fund, World Concern, Massey University or any stakeholder in Wanni Dairy Regeneration Project. This project is receiving funding from the New Zealand 
government and support from TEAR Fund and World Concern, who are interested in receiving feedback on the effectiveness of the dairy programme. I will share a report with the New Zealand Ministry of Foreign Affairs and Trade, TEAR Fund, World Concern and Massey University to share the knowledge from this research but your identity will not be revealed. Declining to participate will NOT affect your involvement in the development programme in any way.

Only my supervisors, the interpreter and the transcriber (who will both be required to sign a confidentiality agreement), and I will read the notes or transcript of the interview. The interview transcripts, summaries and any recordings will be kept securely and destroyed on 1 December 2019.

What will the project produce?

The information from my research will be used in my Master's thesis, a policy brief to the New Zealand Ministry of Foreign Affairs and Trade, a research report to the project's stakeholders and/or academic publications and conferences.

\section{If you accept this invitation, what are your rights as a research participant?}

You do not have to accept this invitation if you do not want to. If you do decide to participate, you have the right to:

- choose not to answer any question;

- ask for the recorder to be turned off at any time during the interview;

- withdraw from the study before 30 October 2018;

- ask any questions about the study at any time;

- receive a copy of your interview recording;

- be able to read any reports of this research by emailing the researcher to request a copy.

If you have any questions or problems, who can you contact?

If you have any questions, either now or in the future, please feel free to contact me or my supervisor:

Student:

Name: Jasmine Edwards jasmine.edwards@vuw.ac.nz

\section{Supervisor:}

Name: Dr Polly Stupples

Role: Lecturer

School: Geography, Environment and Earth Sciences

\section{Human Ethics Committee information}

If you have any concerns about the ethical conduct of the research you may contact the Victoria University HEC Convenor: Dr Judith Loveridge. Email 


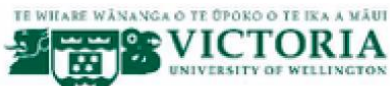

\section{நியுசிலாந்து உதவி திட்டத்திற்க்கும் யீ லங்காவில் பால்பண்ணை அபிவிருக்திக்கும் நிலையான வாழ்வாதார அணுகுமுறை}

\section{பங்கு பற்ஷுபவரின் தகவல் தாள் (2)}

இந்த ஆராய்ச்சியில் பங்கு பற்றுவதற்க்கு நீங்கள் அழைக்கப்படுகிறீர்கள. நீங்கள் பங்கு பற்றுவீரகளா இல்லையா என்று முடிவு செய்யு முன் இந்த விபரத்தாளை வாசிக்கவும். பங்கு பற்றுவதானால் நன்றி. புங்கு பற்றவில்லை என்றால் இதை கருத்தில் கொண்டதற்கு நன்றி.

நான் யார்?

என் பெயர் யஸ்மின் எட்வேட்ஸ் (Jasmine Edwards). நான் பால்பண்ணை அபிவிருத்தி மக்களின் வாழ்வில் என்ன தாக்கத்தை உண்டாக்கும் என்பதை அறிய அர்வமாக உள்ளேன்.

விக்டோரியா பல்கலைக் கழகம் வெலிங்டனில் நான் பங்கு பற்றும் எனது முதுகலை ஆய்வறிக்கைக்கு பயன் படும்.

\section{இத்திட்டத்தின் குறிக்கோள் என்ன?}

இந்த ஆய்வுத்திட்டத்தின் நோக்கம் வன்னி பால்பண்ணை மீளுருவாக்கச் செயற்பாடு பற்றி உள்ளூர் விவசாயிகளின் கருத்தையும் விளைவுகளையும் பற்றி புரிந்து கொள்வதே. இந்் ஆராய்ச்சியை விக்டோரியா பல்கலைக் கழகத்தின் மனித நெறிமுறை குழு அநுமதித்துள்ளது. (\#25982)

\section{நீங்கள் இதற்க்கு எப்படி உதவலாம்?}

நீங்கள் வேளாண்மை அபிவிருத்தியின் ஏதாவது பகுதியில் சம்பந்தப்பட்டுள்ளதால் இந்் ஆய்வில் பங்கு பற்ற அழைக்கப்பட்டுள்ளீர்கள். உங்கள் கருத்துக்கள் இந்த ஆய்வில் மிக மதிப்புள்ளவையாக கருதப்படுகிறது. இந்த ஆய்வில் பங்கு பெற இணங்கினால் உங்களை உங்கள் வேலையிடத்திலோ அல்லது அதற்க்கு அருகிலோ சந்தித்து பேட்டி எடுப்பேன். உங்களை உங்கள் பதவி மற்றும் பால்பண்ணை விவசாயம் பற்றிய அறிவைப்பற்றி கேள்விகள் கேட்பேன். இந்த பேட்டி அரை மணி நேரம் மட்டில் எடுக்கும். பேடிியை உங்கள் அநுமதியுடன் ஒலிப்பதிவு செய்து பின் அதை எழுத்தாக்கம் செய்வேன். ஏதாவது கேள்விக்கு உங்களுக்கு பதில் சொல்ல விருப்பமில்லாவிட்டால் நீங்கள் மறுக்கலாம் அல்லது பேட்டியை எந்நேரத்திலாவது நிறுத்தலாம். காரணம் சொல்ல தேவையில்லை. நான் கள ஆராய்ச்சியின் போது பால்பண்ணை சம்பந்தமாக அவதானங்களை குறிப்பெடுப்பேன். ஐப்பசி 302018 க்கு முன்பாக நீங்கள் என்னைத் தொடர்பு கொண்ட பின் இந்த ஆய்வில் இருந்து விலகலாம். நீங்கள் விலக முடிவெடுத்தால் நீங்கள் கொடுத்த விபரங்கள் உங்களிடம் திருப்பிக் கொடுக்கப்படும் அல்லது அழிக்கப்படும். ஒரு மொழிபெயர்ப்பாளர் இருப்பார்.

\section{நீங்கள் கொடுத்த விபரங்களுக்கு என்ன நடக்கும்?}

இந்த ஆராய்ச்சி இரகசியமானது. அதாவது ஆராய்ச்சியாளருக்கு உங்களை யாரென்று தெரியும். ஆனால் முழு ஆராய்ச்சித் தகவல்களெல்லாம் ஒருங்கிணைக்கப் பட்டு உங்கள் அடையாளம் அறிக்கையிலோ, விபரம் வழங்கலிலோ அல்லது பொது ஆவணங்களிலோ குறிப்பிட மாட்டாது. ஆனால் சிறிய ஆராய்ச்சி திட்டங்களில் உங்கள் அடையாளம் உங்கள் சமூகத்தில் உள்ளவர்களுக்கு வெளிப்படையாக தெரியலாம். நான் நியுசிலாந்து அரசாங்கத்திலோ, Tear fund, World concern, Massey University அல்லது வன்னி பால்பண்ணை மீளுருவாக்கத் திட்டதத்தின் பங்குதாரரோ அல்ல. நான் இந்த அறிக்கையை நியுசிலாந்து வெளிநாட்டு விவகாரம் மற்றும் வர்த்தக அமைச்சுடன் மற்றும் Tear fund, World concern, Massey University உடன் பகிர்ந்து கொள்வேன். ஆனால் உங்கள் அடையாளம் வெளியிடப்பட மாட்டாது. என்னுடைய மேற்பார்வையாளரும், மொழிபெயர்ப்பாளரும், எழுத்து வடிவமாக்குபவரும் (இவர்கள் இருவரும் இரகசிய உடன்படிக்கையில் கையெழுத்திட்டிருப்பார்கள்) நானும் 
மட்டுமே குறிப்புகளையும் எழுத்தாக்கத்தையும் படிப்போம். பேட்டியின் பதிவுகள் எழுத்தாக்கம் சுருக்கங்கள் மற்றும் பதிவுகள் 1 மார்கழ 2019 அன்று அழிக்கப்படும். ஆராய்ச்சி நியூசிலாந்து அரசாங்கத்திடமிருந்து நிதி பெறும். இந்த ஆராய்ச்சியில் பங்கேற்கவில்லை என்றால், எந்த விளைவும் இல்லை.

\section{இந்த திட்டம் எதற்க்கு பாவிக்கப்படும்?}

இத் திட்ட விபரங்கள் என் முதுகலை ஆய்வறிக்கைக்குப் பாவிக்கப்படும். அத்துடன் நியுசிலாந்து வெளிநாட்டு விவகாரம் மற்்றும் வர்த்தக அமைச்சின் கொள்கைச் சுருக்கத்துக்கு பாவிக்கப் படுவதுடன் ஆராய்ச்சி அறிக்கை பங்குதாரருக்கு கொடுக்கப்படும். அத்துடன் கல்வி வெளியீடுகளுக்கோ மாநாடுகளுக்கோ பயன் படலாம்.

இந்த அழைப்பை நீங்கள் ஏற்ஷுக் கொண்டால் இந்த ஆய்வின் பங்குதாரராக உங்கள் உரிமைகள் என்ன?

இந்த அழைப்பை விருப்பமில்லாவிடில் ஏற்க தேவையில்லை. பங்கு பெற விரும்பின் உங்கள் உரிமைகள் பின்வருமாறு:

• எந்தக் கேள்விக்காவது விருப்பமில்லாவிடில் பதில் சொல்ல தேவையில்லை

- ஒலிப்பதிவுக்கருவியை எந்நிலையிலும் அணைக்கும் படி கேட்கலாம்

- இ இந்த ஆய்விலிருந்து 3 ஐப்பசி 2018க்கு முன் விலகலாம்

- ஆய்வைப் பற்றி எந்நிலையிலும் கேள்விகள் கேட்கலாம்

• உங்கள் பேட்டியின் ஒலிப்பதிவின் பிரதியை பெறலாம்

- இந்த அய்வின் எந்த அறிக்கை பிரதியையாவது ஆராச்சியாளருக்க மின்னஞ்சல் அனுப்பி கேட்கலாம்

உங்களுக்கு ஏதாவது கேள்விகள் அல்லது பிரச்சினைகள் இருந்தால் யாரைத் தொடர்பு கொள்வது?

உங்களுக்கு ஏதாவது கேள்விகள் இப்போதோ அல்லது பிற்காலத்திலோ இருந்தால் என்னையோ என் மேற்பார்வையாளரையோ தயவு செய்து தொடர்பு கொள்ளவும்

மாணவி:

பெயர்: யஸ்மின் எட்வேட்ஸ் (Jasmine Edwards)

jasmine.edwards@vuw.ac.nz

\section{மேற்பார்வையாளர்:}

பெயர்: டாக்டர் பொலி ஸ்டப்பிள்ஸ் (Dr Polly Stupples)

நிலை: விரிவுரையாளர்

கல்லுரி: நிலவியல், சூழல் மற்றும் புவி அறிவியல் பகுதி

மனித நெறிமுறைக்குழு விபரம்

உங்களுக்கு நெறிமுறை நடவடிக்கை சம்பந்தமாக ஏதாவது கேள்விகள் இருந்தால் விக்டோரியா பல்கலைக் கழக HE நடத்துனர்: இணை பேராசிரியர் சூசன் கோபேட் Judith Loveridge ஐ ஐத் தொர்பு கொள்ளலாம். மின்னஞ்சல்: 


\section{A Sustainable Livelihood Approach to New Zealand aid and dairy development In Sri Lanka}

\section{CONSENT TO INTERVIEW (2)}

This consent form will be held for 5 years.

Researcher: Jasmine Edwards, School of Geography, Environment and Earth Sciences, Victoria University of Wellington.

- I have read the Information Sheet and the project has been explained to me. My questions have been answered to my satisfaction. I understand that I can ask further questions at any time.

- I agree to take part in an audio recorded interview.

I understand that:

- I may withdraw from this study at any point before 30 October 2018 , and any information that I have provided will be returned to me or destroyed.

- The identifiable information I have provided will be destroyed on 1 February 2018.

- Any information I provide will be kept confidential to the researcher and the supervisor and the interpreter and the transcriber.

- I understand that the results will be used for a Master's thesis, a policy brief to the New

Zealand Ministry of Foreign Affairs and Trade, and/or academic publications and conferences.

- My name will not be used in reports, nor will any information that would identify me.

- I would like a copy of the recording of my interview: Yes No

- I would like for my job title and employer to remain Yes No confidential:

- I would like to receive a copy of the final report and have Yes No added my email address below:

Signature of participant:

Name of participant:

Date:

Contact details: 


\section{நியுசிலாந்து உதவி திட்டத்திற்க்கும் மீீ லங்காவில் பால்பண்ணை அபிவிருத்திக்கும் நிலையான வாழ்வாதார அணுகுமுறை}

\section{பேட்டிக்கான ஒப்புதல் (2)}

இந்த ஒப்புதல் படிவம் 1 வருடத்திற்க்கு வைத்திருக்கப் படும்

ஆராச்சியாளர்: யஸ்மின் எட்வேட்ஸ் (Jasmine Edwards), நிலவியல், சூழல் மற்றும் புவி அறிவியல் பகுதி, விக்டோரியா பல்கலைக் கழகம் வெலிங்டன் (School of Geography, Environment and Earth Sciences, Victoria University of Wellington)

- நான் தகவல் தாளை வாசித்ததுடன் இத்திட்டம் எனக்கு விளக்கப்பட்டது. எனது கேள்விகளுக்கு திருப்திகரமான பதில்கள் அளிக்கப்பட்டன. நான் எந்நேரமாயினும் மேலதிக கேள்விகள் கேட்கலாம் என அறிகிறேன்

• நான் ஒலிப்பதிவு பேட்டிக்கு உடன் படுகிறேன்

நான் பரிந்து கொள்வதாவது:

• நான் இந்த ஆய்விலிருந்நு எந்த நிலையிலும் 14 ஐப்பசி 2018க்கு முன் விலக முடியும். அத்துடன் நான் கொடுத்த விபரங்கள் எனக்கு திருப்பிக் கொடுக்கப்படும் அல்லது அழிக்கப்படும்

- நான் கொடுத்த என்னை அடையாளம் கண்டு பிடிக்கக் கூடிய விபரங்கள் 1 மாசி 2019 அன்று அழிக்கப்படும்

• நான் கொடுத்த விபரங்கள் ஆராச்சியாளரையும், மேற்பார்வையாளரையும், மொழிபெயர்ப்பாளரையும், எழுத்து வடிவமாக்குபவரையும் தவிர மற்றவருக்கு கொடுக்கப்படாமல் இ இரகசியமாக வைத்திருக்கப்படும்

- இந்த ஆராய்ச்சியின் முடிவுகள் முதுகலை ஆய்வறிக்கைக்கும், நியுசிலாந்து வெளிநாட்டு விவகாரம் மற்றும் வர்த்தக அமைச்சிற்கும், கல்வி வெளியீடுகளுக்கும், மாநாடுகளுக்கும் பயன் படுத்தப்படும்

- என் பெயர் அறிக்கைகளிலோ அல்லது என் அடையாளம் எந்த விபரங்களிலோ இடம் பெறாது

- நான் பிரதிநியாக இருக்கும் நிறுவனம் மற்றும் அந்நிறுவனத்தில் என் பதவி பற்றிய விபரம் நான் கொடுத்த விபரம் சம்பந்தமாக குறிப்பிடப்படலாம்

• என் பேட்டிப் பதிவின் நகலை பெற விரும்புகிறேன்

ஆம் இல்லை
ஆம் இல்லை
ஆம் இல்லை
ஆம் இல்லை

- இறுதி அறிக்கையின் நகலை நகலை பெற விரும்புகிறேன் அத்துடன் என் மின்னஞ்சல் முகவரியை இணைத்துள்ளேன்

ஆம் இல்லை

பங்கு பெற்றவரின் கையொப்பம்:

பங்கு பெற்றவரின் பெயர்:

தேதி:

தொடர்பு விபரம்: 


\section{Appendix D: Interview questions guide}

\section{Main participant interview guide}

\section{Rapport building/basic info:}

- Tell me about yourself and your family.

- How long have you been a dairy farmer?

- What made you become a dairy farmer? Family history?

- Who else lives in your household?

- Are they also working on the dairy farm? What are their roles?

- Tell me about your land and animals (do you own the land, how much land, how many animals, how long has this land been farmed)

- Tell me about your usual day from the start to the end.

- Is dairy farming your main income? If not, what else do you do for income?

\section{Photo prompt questions:}

- Tell me about some of the photos you have taken and why:

(What are you proud of?)

(What is important to you on the dairy farm?)

(What are the difficulties and risks of dairy farming?)

How do you overcome/manage these difficulties?

(Show natural resources on the dairy farm)

How has environmental/resource management changed since you have been involved in the dairy project?

(Show change in the dairy farm since the dairy project)

What is the difference in your standard of living compared to before the dairy project and now?

Do you think that the dairy farm is sustainable for the next generation? Why?

Why not?

(What does dairy look like in your home?)

How much dairy does your household consume? What products?

What do you believe about the role of dairy for health?

Does your household consume more or less dairy than your parents did?

\section{Project questions}

- How did you become involved in the dairy project?

- Why? What does the dairy project do for you? 
- How much income do you earn from dairy farming? How has this changed since you have been involved in the dairy project?

- What does the community think of the dairy project?

- What do you think?

- What does the dairy project do very well?

- What can the dairy project improve on? Are there any things that could be done better?

- Can you/do you share your local knowledge and expertise with the dairy project team? How do you influence the dairy project?

\section{Further questions}

- Do you think that farmer training will be effective for sharing the dairy project with other farmers? Why? Why not?

- What are the attitudes of dairy farmers who are not involved in the dairy project towards farmers who are?

- If you were training dairy farmers to improve their farms, what are the most important messages that they need to understand?

- What are women's roles in dairy farming?

- Have women's roles in dairy farming changed since the dairy project? How?

- Does culture/religion affect farming practice? (ie, culling of calves, diet)

- Any other comments?

\section{Other participant interview guide}

- What do you do in your role in agricultural/dairy development? (Background)

- How long have you been in this role?

- Are you aware of the dairy project? (offer explanation if not)

- What is your understanding of the dairy project? (or dairy development projects generally)

- In your view, are aid projects with foreign governments effective for agricultural development? Why? Why not?

- What do you think could be better about dairy development projects?

- What do dairy development projects do well?

- In your view, what are the impacts of dairy development projects on the community?

- Resource management? Livelihoods? Animal treatment? Status of women? Health in the community? Dairy consumption?

- Who benefits from dairy development?

- Do you think dairy farming is sustainable for the future generation? Why? Why not?

- What do you think about farmer's influence in dairy projects? Is it strong/weak? In what ways?

- What kind of aid project do you think would have the most benefit for the rural livelihoods? (is dairy development where money is most needed?) 


\begin{tabular}{l|l}
\hline TO & Jasmine Edwards \\
\hline FROM & Dr Judith Loveridge, Convenor, Human Ethics Committee \\
\hline DATE & 31 August 2018 \\
\hline PAGES & 1 \\
\hline \multicolumn{2}{|l|}{$\begin{array}{l}\text { Ethics Approval: 25982 } \\
\text { A Sustainable Livelihood Approach to New Zealand aid and dairy } \\
\text { development in Sri Lanka }\end{array}$} \\
\hline
\end{tabular}

Thank you for your application for ethical approval, which has now been considered by the Human Ethics Committee.

Your application has been approved from the above date and this approval is valid for three years. If your data collection is not completed by this date you should apply to the Human Ethics Committee for an extension to this approval.

Best wishes with the research.

Kind regards

Judith Loveridge

Convenor, Victoria University Human Ethics Committee 


\section{References}

Adams, P. (2017, May 5). McCully's Record on Aid Needs Questioning. The Dominion Post. https://www.stuff.co.nz/dominion-post/comment/92215305/peter-adams-mccullysrecord-on-aid-needs-questioning

Aggarwal, R., \& Huelin, A. (2009). The Private Sector: Important Partners in Aid for Trade. International Trade Forum, (4), 34-35.

Ahuja, V., Otte, J., \& Makkar, H. (2014). Dairy Asia: Towards Sustainability. Elements of a Regional Strategy for Sustainable Dairy Development in Asia. Bangkok: FAO.

Aitken, S. C., \& Craine, J. (2005). Visual Methodologies: What you See is not Always What you Get. In R. Flowerdew \& D. Martin (eds.), Methods in Human Geography (pp. 250-269). Essex: Pearson Education.

Alexandratos, N., \& Bruinsma, J. (2012). World Agriculture Towards 2030/2050. [ESA Working Paper No. 12-03]. Rome: FAO.

Allen, S., Goddard, E., \& Farmer, A. (2018). How Knowledge, Attitudes, and Beliefs Impact Dairy Anti-Consumption. British Food Journal, 120(10), 2304-2316.

Amjath-Babu, T., Aggarwal, P., \& Vermeulen, S. (2018). Climate Action for Food Security in South Asia? Analyzing the Role of Agriculture in Nationally Determined Contributions to the Paris Agreement. Climate Policy, 1-16.

Backhouse, M. (2013, September 1). Fonterra Seeks to Ease Tension in Sri Lanka. NZ Herald. https://www.nzherald.co.nz/dairy-industry/news/article.cfm?c_id=\&objectid=11117840

Banks, N., \& Hulme, D,. (2012). The Role of NGOs and Civil Society in Development and Poverty Reduction. [Brooks World Poverty Institute Working Paper No. 171]. http://dx.doi.org/10.2139/ssrn.2072157

Batliwala, S. (1994). The Meanings of Women's Empowerment: New Concepts for Action. In G. Sen, A. Germain \& L.C. Chen (eds.), Population Policies Reconsidered: Health Empowerment and Rights (pp. 130-131). Cambridge: Harvard University Press.

Boros, R., \& McCleod, A. (2015). Empowering Women in Afghanistan: Reducing Gender Gaps Through Integrated Dairy Schemes. Rome: FAO.

Braimoh, A., Hou, X., Heumesser, C., \& Zhao, Y. (2016). Greenhouse Gas Mitigation Opportunities in Agricultural Landscapes: A Practitioner's Guide to Agricultural and Land Resources Management. World Bank. 
Brower, A., Sprague, R., Vernotte, M., \& McNair, H. (2018). Agricultural Intensification, Ownership, and Landscape Change in the Mackenzie Basin. Journal of New Zealand Grasslands, 80, 47-54.

Bulloch, H. (2014). Contending Developments: Local Notions of Development on Siquijor Island, Philippines. Journal of International Development, 26(2), 177-186.

Carney, D. (1998). Implementing the Sustainable Rural Livelihoods Approach. In D. Carney (ed.), Sustainable Rural Livelihoods: What Contribution can we Make? London: DFID.

Carney, D. (2002). Sustainable Livelihoods Approaches: Progress and Possibilities for Change. London: DFID.

Chambers R. (1983). Rural Development: Putting the Last First. Essex, England: Longmans Scientific and Technical Publishers; New York: John Wiley.

Chambers, R. (1995). Poverty and Livelihoods: Whose Reality Counts? Environment and Urbanization, 7(1), 173-204.

Chambers R. (1997). Whose Reality Counts: Putting the First Last. London: Intermediate Technology Publications.

Chambers, R., \& Conway, G. (1992). Sustainable Rural Livelihoods: Practical Concepts for the 21st Century. IDS Discussion Paper No. 296 (pp. 7-8). Brighton: IDS.

Chisholm, E. (2009). Fonterra in Latin America: A Case Study of a New Zealand Company Abroad. Political Science, (61)1, 19-32.

Cook, I. (2005). Participant Observation. In R. Flowerdew \& D. Martin (eds.), Methods in Human Geography (3 ${ }^{\text {rd }}$ ed.) (pp. 167-188). Essex: Pearson Education.

Cornwall, A. (2003). Whose Voices? Whose Choices? Reflections on Gender and Participatory Development. World Development, 31(8), 1325-1342.

Cowen, M., \& Shenton, R. (1996). Doctrines of Development. London; New York: Routledge.

Crang, M., \& Cook, I. (2007). Doing Ethnographies. London: Sage.

Crenshaw, K. (1991). Mapping the Margins: Intersectionality, Identity Politics and Violence Against Women of Color. Stanford Law Review, 43(6), 1241-1299.

Creswell, J. W. (2013). Qualitative Inquiry \& Research Design: Choosing Among Five Approaches ( $3^{\text {rd }}$ ed.). Thousand Oaks, CA: Sage. 
Dairy Asia. (2017). Dairy Asia: Towards Sustainability. http://dairyasia.org/file/Dairy_Asia_Brochure_April17.pdf

Dairy Sustainability Initiative. (2009). A Global Dairy Agenda for Action. https://dairysustainabilityframework.org/wp-content/uploads/2014/08/Declaration_FinalText_English-18-June-2009.pdf

Dalton, J. (2019, 26 January). Western Corporations Funding Huge Expansion of Eco-Damaging Dairy Factory Farms in Sri Lanka, Study Finds. The Independent. https://www.independent. co.uk/news/world/asia/sri-lanka-dairy-industry-cows-farm-us-nestle-australia-newzealand-animal-welfare-a8748186.html?fbclid=IwAR3MZxa109VQpy KYmzoQ5HdAB_2VddUme0gTtwuMI8xMNVFeY97ZNpM3B8

Daskon, C., \& Binns, T. (2009). Culture, Tradition and Sustainable Rural Livelihoods: Exploring the Culture-Development Interface in Kandy, Sri Lanka. Community Development Journal, 45(4), 494-517.

de Alwis, C. (2018). Right Effort for Right Livelihood: Historical Model of Sustainable Development from Sri Lanka. In K. Prasad (ed.), Communication, Culture and Ecology. Communication, Culture and Change in Asia. Vol. 6. Singapore: Springer.

de Alwis, M. (1994). Towards a Feminist Historiography: Reading Gender in the Text of the Nation. In R. Coomaraswamy \& N. Wickremasinghe (eds.), Introduction to Social Theory (pp. 86-107). New Delhi: Konark.

Department of Census and Statistics. (2012). Sri Lanka Census of Population and Housing, 2011. http://www.statistics.gov.Ik/PopHouSat/CPH2011/index.php?fileName=pop42\&gp=Activiti es\&tpl=3

Department of National Planning \& Ministry of Finance and Planning. (n.d.). Mahinda Chintana: Vision for a New Sri Lanka: A Ten Year Horizon Development Framework 2006-2016 Discussion Paper. https://www.thegef.org/sites/default/files/ncsa-documents/Mahinda ChintanaTenYearDevelopmentPlan.pdf

Desai, V., \& Potter, R. (2006). Doing Development Research. London: Sage.

Desai, V. (2014). The Role of Non-Governmental Organizations (NGOs). In V. Desai \& R. Potter (eds.), The Companion to Development Studies (pp. 568-572). Routledge.

Doing Good, Doing Well; Aid and the Private Sector. (2017). The Economist, 423(9039), 56. http://link.galegroup.com.helicon.vuw.ac.nz/apps/doc/A491106378/AONE?u=vuw\&sid=AO NE\&xid=32609965

Ellis, F. (2000). Mixing It: Rural Livelihoods and Diversity in Developing Countries. Oxford: Oxford University Press. 
Emmerson, B. (2018, July 23). UN special report: Report of the Special Rapporteur on the Promotion and Protection of Human Rights While Countering Terrorism: Mission to Sri Lanka. Tamil Guardian. https://www.tamilguardian.com/sites/default/files/File/OHCHR/ UN\%20SR\%20Ben\%20Emmerson\%20July\%202018.pdf

Escobar, A. (1995). Encountering Development: the Making and Unmaking of the Third World. Princeton, N.J.: Princeton University Press.

Farmwatch. (2015). Born to Die: The Dark Side of the New Zealand Dairy Industry. [Video file]. https://vimeo.com/146749967

Farrington, J. (2001). Sustainable Livelihoods, Rights and the New Architecture of Aid. Natural Resource Perspectives, 69. London: The Overseas Development Institute. https://www.odi.org/sites/odi.org.uk/files/odi-assets/publications-opinion-files/2823.pdf

Feola, G., Lerner, A. M., Jain, M., Montefrio, M. J. F., \& Nicholas, K. A. (2015). Researching Farmer Behaviour in Climate Change Adaptation and Sustainable Agriculture: Lessons Learned from Five Case Studies. Journal of Rural Studies, 39(C), 74-84.

Fonterra. (2017). Investor Day Presentation. https://www.fonterra.com/content/dam/fonterra public-website/pdf/Fonterra_Investor_Day_presentation_dec17_NZX.pdf

Fonterra. (2018). Dairy Development (Sri Lanka). https://www.fonterra.com/lk/en/dairy_development.html

Fonterra. (n.d.). Fonterra and MFAT Partner to Advance Dairy in Developing Countries. https://www.fonterra.com/nz/en/our-stories/media/fonterra_and_mfat_partner_to_ advance_dairy_in_developing_countries.html

Fountain, P. (2015). Proselytizing Development. In E. Tomalin (ed.), The Routledge Handbook of Religions and Global Development (pp. 80-97). London; New York: Routledge.

Gaard, G. (2015). Ecofeminism and Climate Change. Women's Studies International Forum, 49, 20-33.

Galtry, J. (2013). Improving the New Zealand Dairy Industry's Contribution to Local and Global Wellbeing: The Case of Infant Formula Exports. New Zealand Medical Journal (Online), 126(1386), 82-89.

Gerber, P., Steinfeld, H., Henderson, B., Mottet, A., Opio, C., Dijkman, J., Falcucci, A., \& Tempio, G. (2013). Tackling Climate Change Through Livestock- A Global Assessment of Emissions and Mitigation Opportunities. Rome: FAO. http://www.fao.org/3/a-i3437e.pdf

Gerber, P., Vellinga, T., Opio, C., Henderso, B., \& Steinfeld, H. (2010). Greenhouse Gas Emissions from the Dairy Sector, A Life Cycle Assessment. Rome: FAO. 
Gerosa, S., \& Skoet, J. (2013). Milk Availability: Current Production and Demand and MediumTerm Outlook. In E. Muehlhoff, A. Bennet \& D. McMahon (eds.), Milk and Dairy Products in Human Nutrition (pp. 11-37). Rome: FAO.

Goebel, A. (2003). Women and Sustainability: What Kind of Theory do we Need? Canadian Woman Studies, 23(1), 77-84.

Government of Sri Lanka. (2017). Vision 2025. Office of the Prime Minister of Sri Lanka. http://www.pmoffice.gov.lk/download/press/D00000000061_EN.pdf

Gray, D. (2014). Doing Research in the Real World (3 ${ }^{\text {rd }}$ ed.). London: Sage.

Gray, S., \& Le Heron, R. (2010). Globalising New Zealand: Fonterra Co-operative Group, and Shaping the Future. New Zealand Geographer, 66(1), 1-13.

Guenther, M., Saunders, C., Dalziel, P., Rutherford, P., \& Driver, T. (2015). Maximising Export Returns: Consumer Attitudes Towards Attributes of Food and Beverages in Export Markets Relevant to New Zealand. [AERU Research Report No. 336]. Lincoln: Lincoln University, Agribusiness and Economics Research Unit.

Guruge, S., Ford-Gilboe, M., Varcoe, C., Jayasuriya-Illesinghe, V., Ganesan, M., Sivayogan, S., et al. (2017). Intimate Partner Violence in the Postwar Context: Women's Experiences and Community Leaders' Perceptions in the Eastern Province of Sri Lanka. PloS ONE, 12(3), E0174801.

Hemme, T., \& Otte, J. (2010). Status and Prospects for Smallholder Milk Production: A Global Perspective. Rome: FAO.

Herath, D. (2018). Breakup of Community Social Structures in the War-Affected Northern and Eastern Sri Lanka. Background Paper No 3. In World Bank, Socio-Economic Assessment of the Conflict Affected Northern and Eastern Provinces. Kandy: International Centre for Ethnic Studies.

Hidayana, I., Februhartanty, J., \& Parady, V. A. (2017). Violations of the International Code of Marketing of Breast-Milk Substitutes: Indonesia Context. Public Health Nutrition, 20(1), 165-173.

Hill, J. (2017). Assessing the Overall Impact of the Dairy Sector. In N. van Belzen (ed.), Achieving Sustainable Production of Milk - Vol. 2: Safety, Quality and Sustainability. Oxford: Burleigh Dodds Science Publishing.

Hughes, G. (2019, April 9). Oral Questions: Questions to Ministers - Agriculture. New Zealand Parliament. 
Hyndman, J., \& de Alwis, M. (2004). Bodies, Shrines, and Roads: Violence, (Im)mobility and Displacement in Sri Lanka. Gender, Place \& Culture, 11(4), 535-557.

Ibrahim, M. N. M., Staal S. J., Daniel, S. L. A., \& Thorpe W. (1999). Appraisal of the Sri Lanka Dairy Sector. Volume 1. Main Report. Department of Animal Science, University of Peradeniya; International Livestock Research Institute; Ministry of Livestock Development and Estate Infrastructure.

Intergovernmental Panel on Climate Change (IPCC). (2019). Climate Change and Land. [Draft report]. https://www.ipcc.ch/report/srccl/

International Crisis Group (ICG). (2016, May 18). Sri Lanka: Jumpstarting the Reform Process. [Asia Report No. 278]. Brussels, Belgium.

ICG. (2017a, May 16). Sri Lanka's Transition to Nowhere. [Asia Report No. 286]. Brussels, Belgium.

ICG. (2017b, 28 July). Sri Lanka's Conflict-Affected Women: Dealing with the Legacy of War. [Asia Report No. 289]. Brussels, Belgium.

International Dairy Federation (IDF) \& Food and Agriculture Organization (FAO). (2016a). The Global Dairy Sector: Facts. http://www.dairydeclaration.org/Portals/153/FAO-GlobalFacts.pdf?v=1

IDF \& FAO. (2016b). The Dairy Declaration of Rotterdam. http://www.dairydeclaration.org/Portals/153/Dairy\%20Declaration.pdf?v=1

International Federation of Red Cross. (2006). Legal issues from the International Response to the Tsunami in Sri Lanka. [Report]. IRFC: Author.

Jay, M. (2003). Production, Environment and Biodiversity: Conflicting Dairy Discourses? Proceedings of the 22nd New Zealand Geographical Society Conference, 289-293. Christchurch: New Zealand Geographical Society.

Jay, M. (2007). Political Economy of a Productivist Agriculture: New Zealand Dairy Discourses. Food policy, 32, 266-279.

Jayasinghe, M., \& Lakshman, R. (2011). Gendered Impact of Rural Livelihood Development Interventions - a Case Study from Sri Lanka through a Longitudinal Lens. Sri Lanka Economic Journal, 12, 82-116.

Jayawardena, K. (1993). Some Aspects of Religious and Cultural Identity and the Construction of Sinhala Buddhist Womanhood. In D. Allen (ed.), Religion and Political Conflict in South Asia (pp. 161-180). Delhi: Oxford University Press. 
Jayaweera, S. (1998). Fifty Years of Sri Lanka's Independence, A Socio-Economic Review. Colombo: Sri Lanka Institute of Social and Economic Studies.

Joy, M. (2015). Polluted Inheritance: New Zealand's Freshwater Crisis. Wellington: BWB Texts.

Kabeer, N. (1994). Reversed Realities: Gender Hierarchies in Development Thought. London; New York: Verso.

Kabeer, N. (1999). Resources, Agency, Achievements: Reflections on the Measurement of Women's Empowerment. Development and Change, 30. Oxford, UK: Institute of Social Studies.

Kesby, M., Kindon, S., \& Pain, R. (2005). 'Participatory' Approaches and Diagramming Techniques. In R. Flowerdew \& D. Martin (eds.), Methods in Human Geography (2 ${ }^{\text {nd }}$ ed.) (pp. 144-166). Essex: Pearson Education.

Kindon, S. (2010). Participation. In S. J. Smith, R. Pain \& S. A. Marston (eds.), The Sage Handbook of Social Geographies (pp. 516-545). London: Sage.

Kindornay, S., \& Reilly-King, F. (2013). Promotion and Partnership: Bilateral Donor Approaches to the Private Sector. Canadian Journal of Development Studies / Revue Canadienne D'études Du Développement, 34(4), 533-552.

Kiptot, E., \& Franzel, S. (2014). Voluntarism as an Investment in Human, Social and Financial Capital: Evidence from a Farmer-to-farmer Extension Program in Kenya. Agriculture and Human Values 31(2), 231-243.

Kishwar, M. P. (2014). Feminism and Feminist Issues in the South: A Critique of the "Development" Paradigm. In V. Desai \& R. Potter (eds.), The Companion to Development Studies ( $3^{\text {rd }}$ ed.) (p. 402). Routledge.

Kitchin, R., \& Tate, N. (2000). Conducting Research in Human Geography: Theory, Methodology and Practice. Harlow: Prentice Hall.

Knowles, L., \& Heanue, S. (2019, April 4). Australian Cattle Exported to Sri Lanka Dying and Malnourished, Local Farmers Left Suicidal. ABC News. https://www.abc.net.au/news/201904-04/australian-dairy-cattle-sent-to-sri-lanka-dying-malnourished/10936258

Kothari, A., Salleh, A., Escobar, A., Demaria, F., \& Acosta, A. (2019). Pluriverse: A PostDevelopment Dictionary. New Delhi: Tulika Books.

Kristjanson, P., Waters-Bayer, A., Johnson, N., Tipilda, A., Njuki, J., Baltenweck, I., Grace, D., \& MacMillan, S. (2014). Livestock and Women's Livelihoods. In A. Quisumbing, R. MeinzenDick, T. Raney, A. Croppenstedt, J. Behrman \& A. Peterman (eds.), Gender in Agriculture. Dordrecht: Springer. 
Lahiri-Dutt, K., \& Ahmad, N. (2012). Considering Gender in Social Impact Assessment. In F. Vanclay \& A. M. Esteves (eds.), New Directions in Social Impact Assessment: Conceptual and Methodological Advances (pp. 117-137). Cheltenham, UK: Edward Elgar.

Lakshman, W. D., \& Tisdell, C. A. (2000). Sri Lanka's Development Since Independence: SocioEconomic Perspectives and Analyses. UK: Nova Publishers.

Lenihan, R. (ed.). (2016). Pakeha. Dictionary Plus Society and Culture. Oxford: Oxford University Press.

Lumsden, J. (2011). Fonterra in Latin America: Relationships, Responsibility and the Future. Otago Management Graduate Review (Online), 71-91.

Manch, T. (2018). New Zealand Dairy Aid in Myanmar Hoping to Foster a Love of Milk. Stuff NZ. https://www.stuff.co.nz/business/farming/100148335/new-zealand-dairy-aid-in-myanmarhoping-to-foster-a-love-for-milk

Mawdsley, E., Murray, W., Overton, J., Scheyvens, R., \& Banks, G. (2018). Exporting Stimulus and "Shared Prosperity": Reinventing Foreign Aid for a Retroliberal Era. Development Policy Review, 36(S1), 025-043.

Mawdsley, E., Savage, L., \& Kim, S. (2014). A 'Post-Aid World'? Paradigm Shift in Foreign Aid and Development Cooperation at the 2011 Busan High Level Forum. Geographical Journal, 180(1), 27-38.

McDermott, J. J., Staal, S. J., Freeman, H. A., Herrero, M., \& Van de Steeg, J. A. (2010) Sustaining Intensification of Smallholder Livestock Systems in the Tropics. Livestock Science, 130(1), 95-109.

McEwan, C., Mawdsley, E., Banks, G., \& Scheyvens, R. (2017). Enrolling the Private Sector in Community Development: Magic Bullet or Sleight of Hand? Development and Change, 48(1), 28-53.

McKinnon, K. (2005). Politics and Professionalism in Community Development Examining Intervention in the Highlands of Northern Thailand. [CIGAD Working Paper Series 9/2005]. Palmerston North, NZ: Massey University; Centre for Indigenous Governance and Development.

McMichael, A. J., Powles, J., Butler, C., \& Uauy, R. (2007). Food, Livestock Production, Energy, Climate Change, and Health. The Lancet, 370(9594), 1253-1263.

Meadu, V., Coche, I., Vermeulen, S., \& Engelund Friis, A. (2015). Info Note: The Paris Climate Agreement: What it Means for Food and Farming. [Information sheet]. CCAFS. https://cgspace.cgiar.org/bitstream/handle/10568/69225/CCAFS\%20info\%20note\%20AgCo p21.pdf?sequence=1\&isAllowed=y 
Mekoya, A., Oosting, S., Fernandez-Rivera, S., \& Van der Zijpp, A. (2008). Multipurpose Fodder Trees in the Ethiopian highlands: Farmers' Preference and Relationship of Indigenous Knowledge of Feed Value with Laboratory Indicators. Agricultural Systems, 96(1), 184-194.

Mendis, S. S., \& Edirisinghe, J. C. (2014). Milk Powder Imports and Government Policy: The Case of Sri Lanka. Sri Lanka: Department of Agribusiness Management, Faculty of Agriculture and Plantation Management, Wayamba University of Sri Lanka.

Mikkelsen, B. (2005). Methods for Development Work and Research (2 ${ }^{\text {nd }}$ ed.). New Delhi: Sage.

Ministry for the Environment (MFE) \& Statistics NZ. (2018). New Zealand's Environmental Reporting Series: Our land 2018. [Report]. https://www.mfe.govt.nz

Ministry of Foreign Affairs and Trade (MFAT). (2012). Environmental and Social Impacts: Operational Policy. [Policy document]. https://www.mfat.govt.nz/assets/Aid-Progdocs/Tools-and-guides/Environmental-and-Social-Impacts-Operational-Policy_0.pdf

MFAT. (2013). Arrangement on Dairy Cooperation between the Government of New Zealand and the Government of the Democratic Socialist Republic of Sri Lanka (2013). [Bilateral arrangement document]. Wellington, New Zealand: Author.

MFAT. (2014). Framework for International Development in Dairy Excellence between Fonterra and the Ministry of Foreign Affairs and Trade. [Memorandum of Understanding document]. Wellington, New Zealand: Author.

MFAT. (2015a). New Zealand Aid Programme Investment Priorities 2015-19. https://www.mfat. govt.nz/assets/Aid-Prog-docs/Policy/NZ-Aid-Investment-Priorities-2016-19.pdf

MFAT. (2015b). Activity Design Document: Sri Lanka Dairy Excellence Training Initiative. [Activity design document]. Wellington, New Zealand: Author.

MFAT. (2016). New Zealand Partnerships for International Development Fund: Activity Design Document PF 7-519: Dry Zone Smallholder Dairying Expansion Programme (Sri Lanka). [Activity design document]. Wellington, New Zealand: Author.

MFAT. (2017a). Partnerships Fund - Activity Progress Report Year 3 PF3-402. [Activity progress report]. Wellington, New Zealand: Author.

MFAT. (2017b). Sustainable Development Fund Activity Completion Report: Wanni Dairy Regeneration Programme (March 2012 - June 2016). [Activity completion report]. Wellington, New Zealand: Author.

MFAT. (2018a). COP24: Act!on Agriculture: It's Time for More Act!on. Proceedings from Katowice Climate Change Conference, Katowice, Poland, 10-12 December, 2018. 
MFAT. (2018b). Partnerships Fund - Activity Progress Report PF7-519. [Activity progress report]. Wellington, New Zealand: Author.

MFAT. (2018c). Sri Lanka: Our Relationship with Sri Lanka. https://www.mfat.govt.nz/en/countries-and-regions/south-asia/sri-lanka/

Ministry of Livestock \& Rural Community Development. (2011). Livestock Master Plan: A Strategy for Livestock Development for Self-Sufficiency. [Policy document]. Colombo, Sri Lanka: Ministry of Livestock \& Rural Community Development.

Ministry of Livestock \& Development and Estate Infrastructure. (2000). Policy Strategy for Dairy Industry. Colombo, Sri Lanka: Ministry of Livestock \& Development and Estate Infrastructure.

Misselwitz, B., Pohl, D., Frühauf, H., Fried, M., Vavricka, S., \& Fox, M. (2013). Lactose Malabsorption and Intolerance: Pathogenesis, Diagnosis and Treatment. United European gastroenterology journal, 1(3), 151-159.

Mkenda-Mugittu, V. (2003). Measuring the Invisibles: Gender Mainstreaming and Monitoring Experience from a Dairy Development Project in Tanzania. Development in Practice, 13(5), 459-473.

Mohanty, S., Mohanty, R., Mandal, K., Ghosh, S., Rautaray, S., \& Kumar, A. (2016). Impact of Water Resources Development and Technology Introductions on Livelihood of Farmers in Eastern India: A Case Study. Irrigation and Drainage, 65(5), 724-733.

Morse, S., \& McNamara, N. (2013). Sustainable Livelihood Approach a Critique of Theory and Practice. Dordrecht: Springer Netherlands.

Moser, C. (1993). Gender Planning and Development: Theory, Practice, and Training. London; New York: Routledge.

Mosse, D. (1995). Authority, Gender and Knowledge: Theoretical Reflections on Participatory Rural Appraisal. Economic and Political Weekly, 30(11), 569-578.

Mosse, D. (2014). Caste and the Conundrum of Religion and Development in India. In E. Tomalin (ed.), The Routledge Handbook on Religions and Global Development (pp. 200-214). London; New York: Routledge.

Muehlhoff, E., Bennet, A. \& McMahon, D. (2013). Milk and Dairy Products in Human Nutrition. Rome: FAO. http://www.fao.org/3/i3396e/i3396e.pdf

Munas, M., \& Lokuge, G. (2016). Shocks and Coping Strategies of Coastal Communities in War Conflict-Affected Areas of the North and East of Sri Lanka. Regional environmental change, 16(2), 289-299. 
Mupawaenda, A., Chawatama, C., \& Muvavarirwa, S. (2009). Gender Issues in Livestock Production: A Case Study of Zimbabwe. Tropical Animal Health and Production, 41(7), 1017-1021.

Murray, W., \& Overton, J. (2016). Retroliberalism and the New Aid Regime of the 2010s. Progress in Development Studies, 16(3), 244-260.

Nagar, R. (2002). Footloose researchers, 'Traveling' Theories, and the Politics of Transnational Feminist Praxis. Gender, Place and Culture, 9(2), 179-186.

Nelson, J. (2011). The Private Sector and Aid Effectiveness: Toward New Models of Engagement. In K. Makino, W. Jung \& H. Kharas (eds.), Catalyzing Development: A New Vision for Aid (pp. 83-111). Washington, DC: Brookings Institution Press.

New Zealand Institute of Economic Research (NZIER). (2017). Dairy Trade's Economic Contribution to New Zealand. https://nzier.org.nz/static/media/filer_public/29/33/ 29336237-3350-40ce-9933-a5a59d25bd31/dairy_economic_contribution_update _final_21_february_2017.pdf

Newhouse, D. L., Suarez Becerra, P., \& Doan, D. (2016). Sri Lanka Poverty and Welfare: Recent Progress and Remaining Challenges. Washington, DC: World Bank.

https://openknowledge.worldbank.org/handle/10986/23794

O’Leary, Z. (2010). The Essential Guide to Doing Your Research Project. London: Sage.

OECD. (2015). OECD Development Co-operation Peer Reviews: New Zealand 2015. Paris: OECD Publishing. http://dx.doi.org/10.1787/9789264235588-en

OECD. (2016). Dairy and Dairy Products. OECD-FAO Agricultural Outlook 2016-2025. Paris: OECD Publishing. http://dx.doi.org/10.1787/agr_outlook-2016-11-en

Overton, J., Scheyvens, R., \& Purdie, N. (1999). Conclusions: Achieving Sustainable Development. In J. Overton and R. Scheyvens (eds.), Strategies for Sustainable Development. Experiences from the Pacific (pp. 254-267). London: Zed Books.

Parikesit, P., Takeuchi, K., Tsunekawa, A., \& Abdoellah, O. (2005). Resource Analysis of SmallScale Dairy Production System in an Indonesian village- a case study. Agriculture, Ecosystems and Environment, 105(3), 541-554.

Parliament, New Zealand. (2016). Foreign Affairs, Defence and Trade Committee Supplementary Questions FY2015/16: Appendix B, 9. https://www.parliament.nz/resource/en-nz/51SCFDT _EVI_00DBSCH_EST_63067_1_A436301/c027cb0b728e1450c8b50a7c0f49a8d271a76668

Peebles, P. (2015). Historical Dictionary of Sri Lanka. Rowman \& Littlefield. 
Pieterse, J. N. (2010). My Paradigm or Yours? Variations on Alternative Development. In J. N. Pieterse (ed.), Development Theory Deconstructions/reconstructions. London: Sage.

Prasanna, R., \& Shiratake, Y. (2014). Sustainability of Resources: Dairy Sector Dual Circulation System Under Market Liberalization - A Case Study of the Dairy Sector in the Kurunegala District, Sri Lanka. Agroecology and Sustainable Food Systems, 38(1), 109-133.

Radio NZ (RNZ). (2018, June 28). 'Heartbreaking' Footage of Cow Beating Released by Animal Rights Group. RNZ. https://www.radionz.co.nz/news/national/360630/heartbreakingfootage-of-cow-beating-released-by-animal-rights-group

Rajak, D. (2010). In Good Company: An Anatomy of Corporate Social Responsibility. Stanford, CA: Stanford University Press.

Ranaweera, N. F. C. (n.d.). Sri Lanka: Opportunities for Dairy Sector Growth. FAO. http://www.fao.org/docrep/011/i0588e/i0588e08.htm

Raney, T., Gerosa, S., Khwaja, Y., Skoet, J., Steinfield, H., McLeod, A., Opio, C., \& Cluff, M. (2009). The State of Food and Agriculture 2009: Livestock in the Balance. Rome: FAO. http://www.fao.org/docrep/012/i0680e/i0680e00.htm

Rathgeber, E. (1990). WID, WAD, GAD: Trends in Research and Practice. The Journal of Developing Areas, 24(4), 489-502.

Rattray, E., \& Thomson, W. (2015). Philippines-New Zealand Dairy Project: Mid-Term Review Report. Dairy Link Ltd. https://www.mfat.govt.nz/assets/Aid-Progdocs/Evaluations/2016/June-2016/PNZDP-Mid-Term-Review-Report-FINAL.pdf

Recanati, F., Castelletti, A., Dotelli, G., \& Melià, P. (2017). Trading off Natural Resources and Rural Livelihoods. A Framework for Sustainability Assessment of Small-Scale Food Production in Water-Limited Regions. Advances in Water Resources, 110, 484.

Rose, G. (2001). Visual Methodologies: An Introduction to the Interpretation of Visual Materials. London: Sage.

Scherer, L., Tomasik, B., Rueda, O., \& Pfister, S. (2018). Framework for Integrating Animal Welfare into Life Cycle Sustainability Assessment. The International Journal of Life Cycle Assessment, 23(7), 1476-1490.

Scheyvens, R., \& Storey, D. (2003). Introduction. In R. Scheyvens \& D. Storey (eds.), Development Fieldwork (pp. 2-13). London: Sage.

Scheyvens, R., Banks, G., \& Hughes, E. (2016). The Private Sector and the SDGs: The Need to Move Beyond 'Business as Usual'. Sustainable Development, 24(6), 371-382. 
Scoones, I. (1998). Sustainable Rural Livelihoods: A Framework for Analysis. [IDS Working Paper No. 72]. Brighton: IDS.

Scoones, I. (2009). Livelihoods Perspectives and Rural Development. The Journal of Peasant Studies, 36(1), 171-196.

Scrimgeour, F. (2014a). The Dairy Industry. In F. Scrimgeour, A. Emerson \& J. S. Rowarth (eds.), New Zealand Agriculture: An Economic Perspective (pp. 69-80). Wellington: NZX Limited.

Scrimgeour, F. (2014b). Carbon and the Emissions Trading Scheme. In F. Scrimgeour, A. Emerson \& J. S. Rowarth (eds.), New Zealand Agriculture: An Economic Perspective (pp. 167-174). Wellington: NZX Limited.

Sen, A. (1984). Resources, Values and Development. Oxford: Blackwell.

Seoighe, R. (2017). War, Denial and Nation-Building in Sri Lanka: After the End. Cham: Springer International Publishing.

Sharma, M., \& Vanjani, U. (1993). When More Means Less: Assessing the Impact of Dairy 'Development' on the Lives and Health of Women in Rural Rajasthan (India). Social Science \& Medicine, 37(11), 1377-89.

Shetty, P. (2014). Nutritional Problems, Policies and Intervention Strategies in Developing Economies. In V. Desai \& R. Potter (eds.), The Companion to Development Studies (pp. 441445). London; New York: Routledge.

Skelton, T. (2009). Cross-Cultural Research. In R. Kitchin and N. Thrift (eds.), International Encyclopedia of Human Geography (pp. 398-403). Oxford: Elsevier.

Snoxell, S. (2018). Rural Livelihoods and Constraints to Commercial Farming in Tanintharyi Region, Myanmar. [Master's thesis]. Christchurch: Lincoln University.

Spencer, J. (1990). Sri Lanka: History and the Roots of Conflict. London; New York: Routledge.

Spratt, J. (2018). Donor Policy Domains in Official Development Assistance: Ideas, Actors and Rules in and Beyond Asia. Asia Pacific Journal of Public Administration, 40(2), 83-97.

Steinfeld, H., Gerber, P., Wassenaar, T., Castel, V., Rosales, M., \& de Haan, C. (2006). Livestock's Long Shadow: Environmental Issues and Options. Rome: FAO.

Stojkov, K., Noy, I., \& Sağlam, Y. (2018). The Trade Impacts of a Food Scare: The Fonterra Contamination Incident. Journal of Agricultural \& Food Industrial Organization, 16(2).

Stringer, C., Tamásy, C., Le Heron, R., \& Gray, S. (2008). Growing a Global Resource-Based Company from New Zealand: The Case of Dairy Giant, Fonterra. Aldershot, UK: Ashgate. 
Sultana, F. (2007). Reflexivity, Positionality and Participatory Ethics: Negotiating Fieldwork Dilemmas in International Research. ACME: An International Journal for Critical Geographies, 6(3), 374-385.

Tambiah, S. J. (1986). Sri Lanka: Ethnic Fratricide and the Dismantling of Democracy. Chicago, IL: University of Chicago Press.

Tamil Guardian. (2008, 19 February). Root Causes of the Ethnic Conflict in Sri Lanka. Tamil Guardian. https://www.tamilguardian.com/content/root-causes-ethnic-conflict-sri-lanka

Tamil Guardian. (2018, 24 July). Tamils 'Disenfranchised' and Reform at a 'Virtual Halt' in Sri Lanka, says Scathing UN report. Tamil Guardian. https://www.tamilguardian.com/content /tamils -\%E2\%80\%98disenfranchised\%E2\%80\%99-and-reform-\%E2\%80\%98virtual-halt\% E2\%80\%99-sri-lanka-says-scathing-un-report

Tarawali, S., Herrero, M., Descheemaeker, K., Grings, E., \& Blümmel, M. (2011). Pathways for Sustainable Development of Mixed Crop Livestock Systems: Taking a Livestock and ProPoor Approach. Livestock Science 139(1), 11-21.

Tharsinithevy, K., \& Sivarajah, P. (2011). Gender Aspects of Dairying in Eastern Province, Sri Lanka. International Conference on Building Resilience, Kandalama, Sri Lanka, 19-21 July, 2011.

The Nielson Company. (2019). Climate Issues Facing Farmers: Sustainable Land Management and Climate Change Research Programme. [Report]. Ministry for Primary Industries. https://www.mpi.govt.nz/dmsdocument/33747/send

Therborn, G. (2006). Inequalities of the World. London: Verso.

Toner, A., \& Franks, T. (2006). Putting Livelihoods Thinking into Practice: Implications for Development Management. Public Administration and Development, 26, 81-92.

United Nations (UN). (2011, March 31). Report of the Secretary-General's Panel of Experts on Accountability in Sri Lanka. http://www.un.org/News/dh/infocus/Sri_Lanka/POE_ Report_Full.pdf

UN. (2016). Sustainable Development Goals. www.un.org/sustainabledevelopment/sustainabledevelopment-goals

Valentine, B. H. (2015). New Zealand Farmers and Environmental Legislation. [Master's thesis]. Palmerston North: Massey University.

Valenze, D. (2011). Milk: a Local and Global History. London: Yale. 
Vanclay, F., Esteves, A. M., Aucamp, I., \& Franks, D. (2015). Social Impact Assessment: Guidance for Assessing and Managing the Social Impacts of Projects. Fargo ND: International Association for Impact Assessment.

Varley, A. (2014). Gender, Families and Households. In V. Desai and R. Potter (eds.), The Companion to Development Studies (pp. 397-402). London; New York: Routledge.

Vasudevan, R. (2013). Everyday Resistance: Female Headed Households in Northern Sri Lanka. Geneva: Graduate Institute Publications.

Weaver, C., Wijesinha-Bettoni, R., McMahon, D., \& Spence, L. (2013). Milk and Dairy Products as Part of the Diet. In E. Muehlhoff, A. Bennet \& D. McMahon (eds.), Milk and Dairy Products in Human Nutrition (pp. 103-182). Rome: FAO. http://www.fao.org/3/i3396e/i3396e.pdf

Weerasekara, P. C., Withanachchi, C. R., Ginigaddara, G. A. S., \& Ploeger, A. (2018). Nutrition Transition and Traditional Food Cultural Changes in Sri Lanka during Colonization and PostColonization. Foods 2018, 7(1).

Whitfield, L. (2007). Identity Construction in Development Practices: The Government of Ghana, Civil Society, Private Sector and Development Partners. In S. Ardener \& F. Moore (eds.), Professional Identities: Policy and Practice in Business and Bureaucracy (Vol. 3) (pp. 143159). Berghahn Books.

Wickramasinghe, N. (2014). Sri Lanka in the Modern Age: A History. Oxford University Press.

Wijethilaka, D., De Silva, S., Deshapriya, R., \& Gunaratne, L. (2018). Factors Affecting Sustainable Dairy Production: A Case Study from Uva Province of Sri Lanka. IOP Conference Series: Earth and Environmental Science, 157(1).

Woodford, K. (2007). Devil in the Milk: Illness, Health and Politics: A1 and A2 Milk. Nelson, New Zealand: Craig Potton.

World Bank. (2018). Sri Lanka: Overview. http://www.worldbank.org/en/country/srilanka/overview

World Commission on Environment and Development (WCED). (1987). Our Common Future. Oxford; New York: Oxford University Press.

Yin, R. (2003). Case Study Research: Design and Methods ( $3^{\text {rd }}$ ed.). Thousand Oaks, CA: Sage.

Zweifel, E., \& Hill, D. (2015). Still a Good Neighbour? Implications of Changing Priorities in New Zealand Aotearoa's Aid Sector. New Zealand Geographer, 71(2), 67-80. 